Universidad Politécnica de Madrid

Escuela Técnica Superior de Arquitectura

\title{
El pliegue en la arquitectura
}

\section{The Fold in Architecture}

\section{Tesis Doctoral}

Pablo Miguel De Souza Sánchez

Máster en teoría, historia y crítica de la arquitectura.

Arquitecto.

Licenciado en Bellas Artes.

Madrid.

Junio de 2017 
Departamento de Composición Arquitectónica

Escuela Técnica Superior de Arquitectura

\section{El pliegue en la arquitectura \\ The Fold in Architecture}

Pablo Miguel De Souza Sánchez

Máster en teoría, historia y crítica de la arquitectura.

Arquitecto.

Licenciado en Bellas Artes.

DIRECTORES.

D. Rafael García García. Doctor Arquitecto

D. Juan Bordes Caballero. Doctor Arquitecto

Madrid.

Junio de 2017 

Tribunal nombrado por el Magfco. y Excmo. Sr. Rector de la Universidad Politécnica de Madrid, el día de de 20 .

Presidente:

Vocal:

Vocal:

Vocal:

Secretario:

Suplente:

Suplente:

Realizado el acto de defensa y lectura de la Tesis el día de 20 , en la Escuela Técnica Superior de Arquitectura de Madrid.

Calificación:

EI PRESIDENTE 



\section{Agradecimientos.}

A mis directores Juan Bordes Caballero y Rafael García García, sus respectivas investigaciones me han abierto caminos y ayudado a dar respuesta a muchas de las incógnitas que quedaban sin resolver en mi investigación. La publicación de Juan Bordes "La infancia de las vanguardias" y los artículos de Rafael García "Estructuras laminares de hormigón en Holanda y Láminas plegadas de hormigón armado. Realizaciones en España" y el acceso al artículo "La structura come forma" de Luigi Moretti aportado por Rafael, han sido esenciales a la hora de completar el documento aquí presentado, sin esta información no habría sido posible concluir con éxito y enlazar los diferentes capítulos desarrollados en la investigación.

A los tutores de las cuatro prácticas de investigación realizadas durante el periodo de formación en las que pude dar forma desde diferentes puntos de vista a esta investigación: José Manuel Barbeito y Manuel De Prada tutores de la asignatura "Sobre la separación de las artes", Miguel Ángel Baldellou y Ana Estéban Maluenda: "Arquitectura y arquitectos españoles contemporáneos, historia y crítica", Rafael García: "Documentación y análisis de la arquitectura" y $\mathrm{M}^{\mathrm{a}}$ Teresa Valcárce y Roberto Osuna tutores de la asignatura "Las publicaciones periódicas de arquitectura desde 1930 como fuente documental".

A Sophia Vyzoviti, mi supervisora de la estancia de investigación y docencia en la

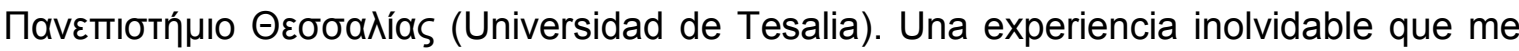
abrió las puertas a un mundo nuevo de posibilidades formales y práctica docente.

A mis compañeros de doctorado y máster, en especial a Francisco Casas por aportar sus ideas y conocimientos y haber iniciado esta ruta conmigo.

A Ricardo Antón, que sembraste la semilla de la arquitectura en mí.

A José Luis Esteban Penelas, mi mentor, me diste el impulso suficiente para acabar mi etapa de formación y la inspiración necesaria para comenzar con esta investigación.

A Beatriz, María, Román y Pedro, por su apoyo y ayuda.

A mis padres Fernando y Sofía, vuestro amor es mi mejor tesoro. A mis hermanos, Javier, que siempre estará con nosotros e Inés que ha crecido conmigo, vió comenzar este camino compartiendo libros, juegos y música nocturna, y ahora lo acaba haciéndolo suyo.

A mi querida esposa Elena, ejemplo de tesón, esfuerzo y comprensión, sin ti no hubiera sido posible completar esta tesis.

A todos, Gracias. 



\section{Resumen.}

En el último cuarto del siglo XX reconocidos arquitectos y teóricos de la arquitectura como Greg Lynn, José Morales, Manuel Gausa, Juan Carlos Sancho y Sol Madridejos, así como filósofos como Félix Guattari y Guilles Deleuze han encontrado múltiples vínculos entre el concepto de pliegue, su exploración formal y definición topológica y la creación arquitectónica.

término pliegue abarca una gran variedad de definiciones y aplicaciones en la arquitectura, desde la descripción y utilización estructural de Fred Angerer y Heino Engel y la exploración formal de Farshid Moussavi, hasta la lectura más conceptual y teórica de Peter Eisenman, Greg Lynn y Deleuze. En palabras de Manuel Gausa "hablamos de pliegues, despliegues y repliegues como posibles trayectorias dinámicas. Trayectorias aescalares entre estructuras y organizaciones, entre dispositivos y ciudades, entre escenarios y proyectos, referidas a geometrías evolutivas (formaciones rizomáticas -en forma de raíz-, despuntes y estirones, arracimamientos -en forma de racimo-, entramados y enrroscamientos, fluctuaciones, reversas y quiebros)".

La finalización en el año 2002 de las obras de la terminal internacional del puerto de Yokohama en Japón, dirigidas por Alejandro Zaera y Farshid Moussavi -FOA-, y la construcción de la Capilla de Valleacerón de los arquitectos Sol Madridejos y Juan Carlos Sancho Osinaga realizada en el año 2000 en Almadenejos, Castilla-La Mancha, trajeron a escena una práctica común entre los arquitectos y estudiantes durante el siglo XX, la utilización arquitectónica de pliegues de elementos superficiales planos inspirados en los patrones desarrollables del origami, el arte japonés de la papiroflexia.

¿Qué obras de arquitectura se han visto inspiradas en sus composiciones formales por el arte del origami japonés? ¿Cómo y cuándo la arquitectura integró los patrones geométricos de la papiroflexia? ¿Cuáles son los diferentes mensajes que evoca el pliegue arquitectónico?

El presente trabajo trata de entender y explorar el origen de los recursos y mecanismos de formalización arquitectónica inspirados en el origami. Busca recapitular el conocimiento adquirido en las diferentes experiencias arquitectónicas para analizar y sintetizar tanto sus configuraciones morfológicas como su contenido semántico, destacando las relaciones conceptuales y formales entre el origami y la arquitectura.

En conclusión, este documento se constituye como un estudio de metodología histórica, de caso y experimental, de las variables semánticas, sintácticas y morfológicas, derivadas del uso de patrones de superficies plegadas en la arquitectura contemporánea, desde estructuras estáticas de superficies plegadas hasta arquitecturas cinéticas e interactivas de diseño paramétrico.

\section{Palabras clave:}

origami, papiroflexia, pliegue, origami y arquitectura, pliegue arquitectónico, papiroflexia abstracta, arquitecturas plegadas, la levedad del pliegue, estructuras laminares plegadas, láminas plegadas de hormigón armado, morfologías estereométricas facetadas, configuraciones morfológicas plegadas, arquitecturas paramétricas, geometrías dinámicas, estructura como forma. 



\section{Abstract.}

In the last quarter of the 20th century, renowned architects and architecture theorists such as Greg Lynn, José Morales, Manuel Gausa, Juan Carlos Sancho and Sol Madridejos, as well as philosophers like Felix Guattari and Guilles Deleuze have found multiple links between the concept of folding, its formal exploration and the topological definition and architectural creation.

The term "fold" covers a wide variety of definitions and applications in architecture, from the structural description and use of Fred Angerer and Heino Engel and the formal exploration of Farshid Moussavi, to the more conceptual and theoretical reading of Peter Eisenman, Greg Lynn and Deleuze. In the words of Manuel Gausa "we speak of crease, deployments and folds as possible dynamic trajectories. A-scalar trajectories between structures and organizations, between devices and cities, between scenarios and projects, referring to evolutionary geometries (rhizomatic formations, shoots and spurs, clusters, trusses and twists, fluctuations, revesas and squares).

The completion in 2002 of the building of the Yokohama international port terminal in Japan, led by Alejandro Zaera and Farshid Moussavi -FOA-, and the construction of the Chapel of Valleacerón by the architects Sol Madridejos and Juan Carlos Sancho Osinaga in the year 2000 in Almadenejos, Castilla-La Mancha, brought to the scene a common practice between architects and students during the twentieth century, the architectural use of folds of flat surface elements inspired by the crease patterns of origami, the Japanese art of paperfolding.

What works of architecture have been inspired in their formal compositions by the art of origami? How and when did architecture integrate the geometric patterns of origami? What are the different messages that evokes the architectural fold?

The present work tries to understand and to explore the origin of the resources and mechanisms of architectonic morphogenesis inspired by origami. It seeks to recapitulate the knowledge acquired in the different architectural experiences to analyze and synthesize both its morphological configurations and its semantic content, highlighting the conceptual and formal relations between origami and architecture.

In conclusion, this document constituted an historical, case study and experimental research methodology of the semantic, syntactic and morphological variables of the use of folded patterns derived from origami in contemporary architecture, from folded plate static structures, to kinetic and interactive architectures of parametric design.

\section{Keywords:}

Origami, origami and folding, origami and architecture, architectural folding, abstract origami, folded architectures, the lightness of fold, folded laminated structures, reinforced concrete folded sheets, faceted stereometric morphologies, folded morphological configurations, dynamic geometries, Shape 



\section{ÍNDICE}

\section{INTRODUCCIÓN}

APROXIMACIÓN CONCEPTUAL

METODOLOGÍA HISTÓRICA, DE CASO Y EXPERIMENTAL 16

\section{HISTORIA Y CONCEPTO DEL PLIEGUE}

1.1. DEL ORIKATA AL ORIGAMI 29

De los pliegues ceremoniales al arte lúdico del origami japonés. 30

El pliegue de papel en China. $\quad 39$

La tradición de plegado en Europa. 42

1.2. EL ORIGAMI ABSTRACTO

1.2.1. La papiroflexia didáctica: Friedrich Fröebel 51

1.2.2. Patrones de pliegue estructurales: La Bauhaus 58

1.2.3. Los juegos de construcción en papel y cartón 68

The toy. El juego de arquitectura de los Eames. 68

Las esculturas-juego de Bruno Munari. $\quad 71$

Polypops. Los juguetes de cartón de Roger Limbrick.

El Flexagón, los Calidociclos y los Kinetogamis $\quad 77$

1.2.4. Las esculturas de papel plegado: Folded paper sculptures 85

$\begin{array}{ll}\text { 1.2.5. El origami arquitectónico } & 87\end{array}$

El "rigid origami"

Curved Folding o pliegue curvo 98

El Origami Modular 105

Las "Origami Tessellations" 108

1.3. EL PLIEGUE EN LAS PUBLICACIONES DEL S. XX Y XXI 119

Las primeras reseñas históricas. $\quad 121$

1.3.1. Modelos y casos en las publicaciones periódicas de arquitectura 122

Yoshimuras y pleats regulares para luminarias. 1950

El patrón de plegado espina de pez. 1952

La interesección entre dos láminas plegadas. $1954 \quad 127$

Primera cúpula de patrón de pliegue yoshimura polar. 1956

Variantes del yoshimura cilíndrico y polar. $1956 \quad 133$

Estructuras Plegadas. 1961

Arquitecturas fantásticas, visionarias y prototipos. 1962

1.3.2. El pliegue moderno y su divulgación en textos didácticos. 140 
Construcción Laminar. Fred Angerer. 1960

Sistema de estructuras. Heino Engel. 1964

Why Buildings stand up. Mario Salvadori. 1980

Folding Architecture; Spatial, Structural and Organizational Diagrams. 2003146

The Function of Form and Ornament. Farshid Moussavi. 2009

1.4. EL PLIEGUE Y SUS SIGNIFICADOS 149

Hacia una semántica del pliegue. 149

1.4.1. Vivir en lo oblícuo 150

1.4.2. El pliegue y el barroco. Hacia la autonomía del espacio interior.

1.4.3. La levedad del pliegue, estructuras difusas. 157

La inspiración natural, morfologías, algoritmos y fractales. $\quad 160$

La geometría de la naturaleza.

La deriva infográfica. $\quad 163$

1.4.4. Curvilinealidad arquitectónica: lo plegado, lo flexible y lo elástico. 164

1.4.5. Pliegues, repliegues, despliegues. 166

\section{PLIEGUES CONSTRUIDOS}

$\begin{array}{lr}\text { 2.1. LAS FORMAS FACETADAS } & 168\end{array}$

$\begin{array}{ll}\text { 2.1.1. Encuentro entre Oriente y Occidente. } & 169\end{array}$

2.1.2. Las nuevas formas de los movimientos de vanguardia. 173

El Futurismo italiano.

El Cubismo checo. 174

El Expresionismo Alemán. 182

$\begin{array}{lr}\text { 2.2. EL PLIEGUE LIBRE } & 191\end{array}$

2.2.1. La inspiración oriental. Frank Lloyd Wright 204

J. Lyman Silsbee, el viaje iniciático y la biblioteca personal de Wright. 204

Friedrich Fröebel y las primeras nociones espaciales. 207

El pliegue de la pequeña escala. 209

Proyectar con geometrías plegadas y en base hexagonal. 212

2.2.2. De lo leve y lo pesado. Marcel Breuer. 217

La experiencia en la Bauhaus. $\quad 221$

Las casas "mariposa” y la monumentalidad multifacética 223

2.3. EL PLIEGUE CONFORMADOR Y ESTRUCTURAL 227

2.3.1. Plegaduras laminares de hormigón armado 228

2.3.2. Láminas plegadas de madera, metal, cristal, polipropileno... 246 
Buckminster Fuller.

2.4. EL PLIEGUE CON MALLAS ESPACIALES

2.4.1. Mallas estáticas

251

2.4.2. Mallas dinámicas. Emilio Pérez Piñero

256

2.5. SUPERFICIES PLEGADAS, CINÉTICAS E INTERACTIVAS

\section{CONCLUSIONES}

3.1. UN NUEVO MATERIAL DOCENTE

282

3.2. MAPA HISTÓRICO-MORFOLÓGICO

BIBLIOGRAFIA

RELACIÓN DE IMÁGENES

ANEXOS. PUBLICACIONES DESTACADAS

Origami folding patterns in the work of F. LI. Wright.

308

Mirador.

309

Crumbled umbrella.

310

Origami tessellations in continuum:

311

Poster: Exploring the Performativity of Origami Tessellations.

312 

INTRODUCCION

APROXIMACIÓN CONCEPTUAL

METODOLOGÍA HISTÓRICA, DE CASO Y EXPERIMENTAL 16
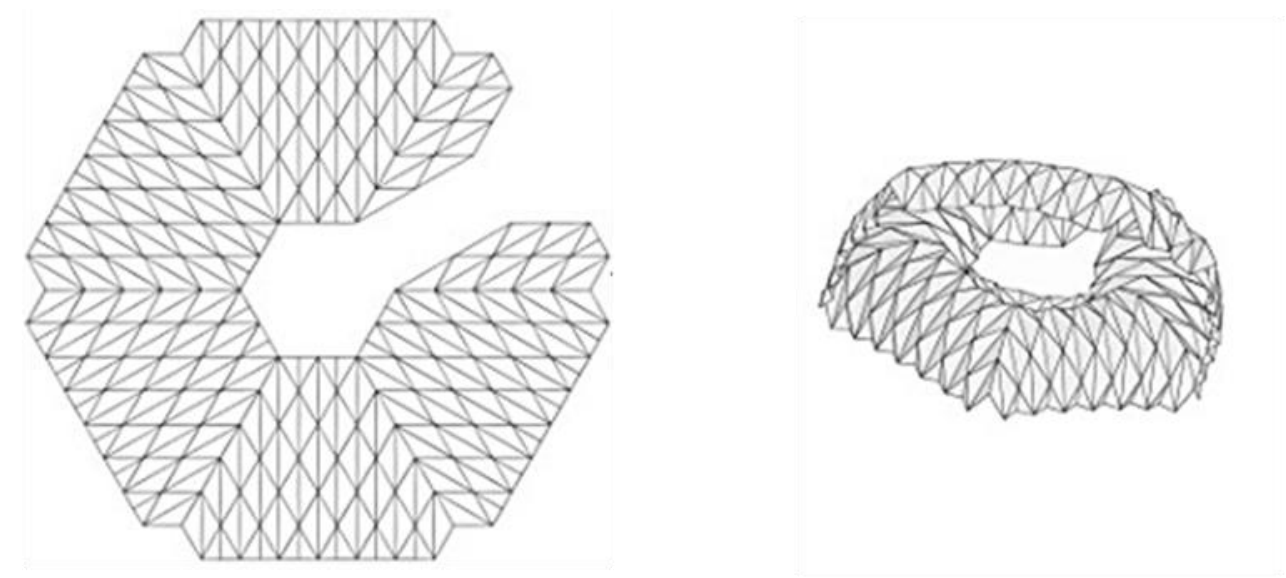


\section{INTRODUCCIÓN}

"Supongamos por un momento que la arquitectura pueda ser conceptualizada como una banda de Moebius, con una continuidad ininterrumpida entre el interior y el exterior. (...) Gilles Deleuze ha propuesto exactamente ese tipo de continuidad posible con su idea del pliegue. Para Deleuze, el espacio plegado articula una nueva relación entre vertical y horizontal, figura y fondo, dentro y afuera - todas las estructuras articuladas por la visión tradicional. De modo distinto al espacio de la visión clásica, la idea del espacio plegado niega el encuadre en favor de una modulación temporal. El pliegue ya no privilegia la proyección simétricamente, en su lugar hay una curvatura variable." 1

Peter Eisenman.

${ }^{1}$ Eisenman, Peter (enero 1992) Visions Unfolding: Architecture in the Age of Electronic Media. Domus No. 734: 17-21 


\section{APROXIMACIÓN CONCEPTUAL}

En el último cuarto del siglo $\mathrm{XX}$ reconocidos arquitectos y teóricos de la arquitectura como Greg Lynn ${ }^{2}$, José Morales y Manuel Gausa ${ }^{3}$, Juan Carlos Sancho y Sol Madridejos ${ }^{4}$, así como filósofos como Félix Guattari y Guilles Deleuze ${ }^{5}$ han encontrado múltiples vínculos entre el concepto de pliegue, su exploración formal y definición topológica y la creación arquitectónica.

El Diccionario de la Real Academia Española de la Lengua define pliegue como doblez, especie de surco o desigualdad, doblez hecho artificialmente en cualquier cosa flexible. Plegar es doblar, ceder, someter... doblar es torcer algo encorvándolo, volver una cosa sobre otra.

El término pliegue abarca una gran variedad de definiciones y aplicaciones en la arquitectura, desde la descripción y utilización estructural de Fred Angerer ${ }^{6}$ y Heino Engel ${ }^{7}$ y la exploración formal de Farshid Moussavi ${ }^{8}$, hasta la lectura más conceptual y teórica de Peter Eisenman ${ }^{9}$, Greg Lynn y Deleuze. En el Diccionario Metápolis de Arquitectura Avanzada se nos muestran múltiples entradas de conceptos afines: enrollamientos, enroscamientos, bucles, contorsionismos, dobleces, nudos, manipulación... En palabras de Manuel Gausa "hablamos de pliegues, despliegues y repliegues como posibles trayectorias dinámicas. Trayectorias a-escalares entre estructuras y organizaciones, entre dispositivos y ciudades, entre escenarios y proyectos, referidas a geometrías evolutivas (formaciones rizomáticas, despuntes y estirones, arracimamientos, entramados y enroscamientos, fluctuaciones, revesas y quiebros)" ${ }^{10}$.

La finalización en el año 2002 de las obras de la terminal internacional del puerto de Yokohama en Japón, dirigidas por Alejandro Zaera y Farshid Moussavi -FOA-, en base a la idea ganadora del primer premio del concurso internacional convocado en 1995, y la construcción de la Capilla de Valleacerón de los arquitectos Sol Madridejos y Juan Carlos Sancho Osinaga realizada en el año 2000 en Almadenejos, Castilla-La Mancha, trajeron a escena una práctica común entre los arquitectos y estudiantes durante el siglo XX, la utilización arquitectónica de pliegues de elementos superficiales planos inspirados en los patrones desarrollables del origami, el arte japonés e internacional ${ }^{11}$ de la papiroflexia.

\footnotetext{
${ }^{2}$ Lynn, Greg. (1993) Folding in Architecture. Números 1 a 4, Volúmen 63 de la revista Architectural Design.

Academy Editions. Wiley-VCH Publishers. Londres.

${ }^{3}$ Gausa, Manuel. Guallart, Vicente. Müller, Willy et all. (2008, $1^{\text {a }}$ ed. 2001) Diccionario Metápolis de Arquitectura Avanzada. Actar Editorial, Barcelona., ISBN: 978-84-95273-93-2

${ }^{4}$ Sancho, J. Carlos et Madridejos, Sol (2001) Sancho / Madridejos, Suite en 3 movimientos. Editorial Rueda, Madrid.

${ }^{5}$ Deleuze, Gilles (1989) El pliegue. Leibniz y el Barroco. Edit. Paidós Básica, España.

${ }^{6}$ Angerer, Fred (1972). Construcción laminar. Elementos y estructuración. 51, Gustavo Gili, Barcelona. (Bauten mit tragenden flächen konstruktion und gestaltung, 1960). SURFACE STRUCTURES IN BUILDING: structure and form

${ }^{7}$ Engel, Heino (1970). Tragsysteme, Structure Systems. (Sistemas de estructuras) Trad. Fernando de Aguirre e Yraola, Juan Batanero García/Geraldo. Edit. Blume, 1970. Madrid, España. pp 214 capítulo Superficies Activas

${ }^{8}$ Moussavi, Farshid. (2009) The Function of Form ACTAR, Harvard Graduate School of Design. ISBN-10: 8496954730 ISBN-13: 9788496954731

${ }^{9}$ Eisenman, Peter (Enero 1992) "Visions Unfolding: Architecture in the Age of Electronic Media". Domus No. 734.

${ }^{10}$ Manuel Gausa, Vicente Guallart, Willy Müller et all. (2002) Diccionario Metápolis de Arquitectura Avanzada. Actar Editorial, Barcelona., ISBN: 8495273934. pp 472

${ }^{11}$ Koshiro Hatori concluye en su artículo sobre la historia del origami que éste no se puede considerar un arte japonés puesto que se desarrolló en paralelo y con característimas muy diferenciadas tanto en occidente como en oriente.

Hatori, Koshiro (21-06-2011) History of Origami in the East and the West before Interfusion. Origami 5: Fifth International Meeting of Origami Science, Mathematics, and Education. A. K. Peters/CRC Press; ISBN-10: 1568817142.
} 
Alejandro Zaera describe de este modo las relaciones entre el origami y el proyecto de la terminal internacional del puerto de Yokohama: "La estructura que propusimos en el concurso se basaba en una pieza de acero plegada, en un intento de hacer que la estructura fuera coherente con la idea general del proyecto como una organización plegada. Esta propuesta también tenía sus ventajas en términos de resistencia a las tensiones sísmicas y afinidad con las técnicas de la industria naval, con la que el edificio mantiene un evidente vínculo. Esta estructura parecida a la del cartón celular surgió de lo que originalmente era una referencia a la tradición local de construcción de origami. Estas referencias a los sistemas de construcción locales -mediados tanto literal como culturalmente- constituían un intento de contextualizar la propuesta sin tener que recurrir a la imitación de la construcción local." 12

¿Qué obras de arquitectura se han visto inspiradas en sus composiciones formales por el arte del origami? ¿Cómo y cuándo la arquitectura integró los patrones geométricos de la papiroflexia? ¿Cuáles son los diferentes mensajes que evoca el pliegue arquitectónico?

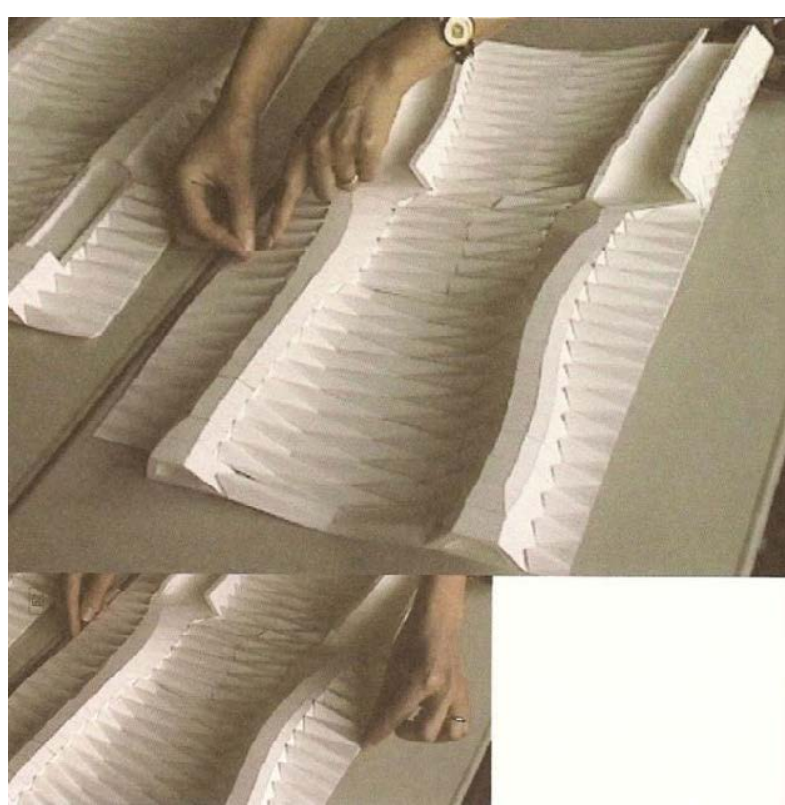

Si entendemos el arte como una expresión de la actividad humana que busca representar y transmitir sensaciones y significados, la arquitectura, como arte, podríamos definirla como una expresión de la actividad humana que busca dar respuesta formal y constructiva a un programa de necesidades espaciales evocando, transmitiendo y representando, sensaciones, emociones, sentimientos y significados.

1. Maqueta de trabajo para la terminal de pasajeros del puerto de Yokohama.

Alejandro Zaera y Farshid Moussavi. Foreign Office Architects, FOA.

Fuente: Verb ACTAR, "Architecture Booganzine". Roca i Batlle 2, Barcelona, octubre 2001.

En los libros La Función de la Forma y La Función del Ornamento ${ }^{13}$, la arquitecta Farshid Moussavi, resalta la función sensorial y significante de la forma y el ornamento arquitectónico, apostando por las amplias posibilidades significantes de la forma arquitectónica. Estudiar la forma como elemento transmisor del mensaje y el fondo como concepto esencial para la comunicación, es clave para conocer y entender la experiencia arquitectónica en su conjunto.

El presente trabajo trata de explorar y entender el origen de los recursos y mecanismos de formalización arquitectónica inspirados en el pliegue. Busca recapitular el conocimiento adquirido en las diferentes experiencias arquitectónicas para analizar y sintetizar tanto sus configuraciones morfológicas como su contenido semántico, destacando las relaciones conceptuales y formales entre el origami y la arquitectura.

\footnotetext{
${ }^{12}$ Verb ACTAR (octubre 2001) Architecture Booganzine. Edit. Actar. Roca i Batlle 2, Barcelona. pp.17-18

${ }^{13}$ Moussavi, Farshid et Kubo, Michael (2008) La función del ornamento. Ed. Actar. Barcelona.
} 


\section{El concepto de pliegue.}

El concepto de pliegue tiene un extenso y diverso margen de definiciones. Acotar las distintas acepciones lingüísticas que sobre el pliegue se han dado en la historia arquitectónica contemporánea, desde la visión geométrica, estructural y CATASTROPHE MANIFOLDS
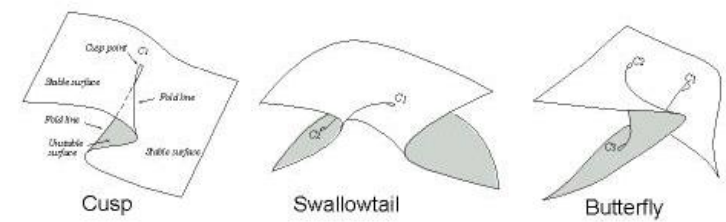
matemática, hasta la filosófica y poética ha sido tarea necesaria e inicial para abordar el presente estudio. Se ha impuesto así una revisión panorámica que contextualice determinados términos y defina el enfoque prioritario de esta investigación.

2. Catastrophe Theory and origami Folds. Leong Cheng Chit. Diciembre 2008 www. paperfolding.com/chengchit/3d.php

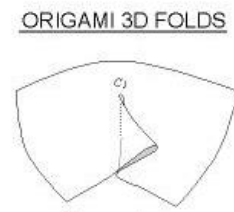

Cusp crimp ORIGAMI FLAT FOLDS

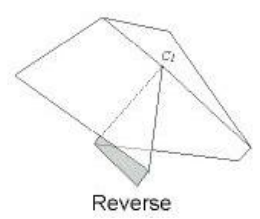

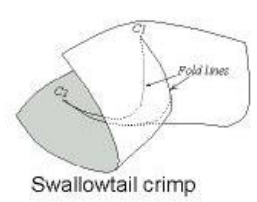

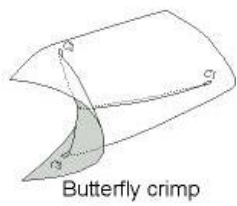

Butterfly crimp

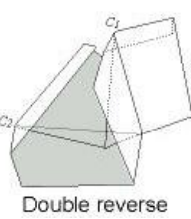

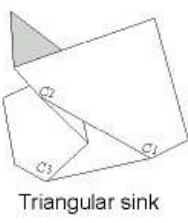

J. C. Sancho y Sol Madridejos ${ }^{14}$ citando a Deleuze ${ }^{15}$ distinguen entre el pliegue inorgánico, simple y directo, y el pliegue orgánico, compuesto, cruzado e indirecto. Y van más allá en su definición cuando se refieren al pliegue orgánico como el pliegue de la cultura occidental, heredado de las manifestaciones artísticas de la escultura helénica, en lo que se ha dado a conocer como la técnica de los "paños mojados". Mientras que el pliegue inorgánico representa el pliegue de superficies planas facetadas que derivan del arte del origami japonés.

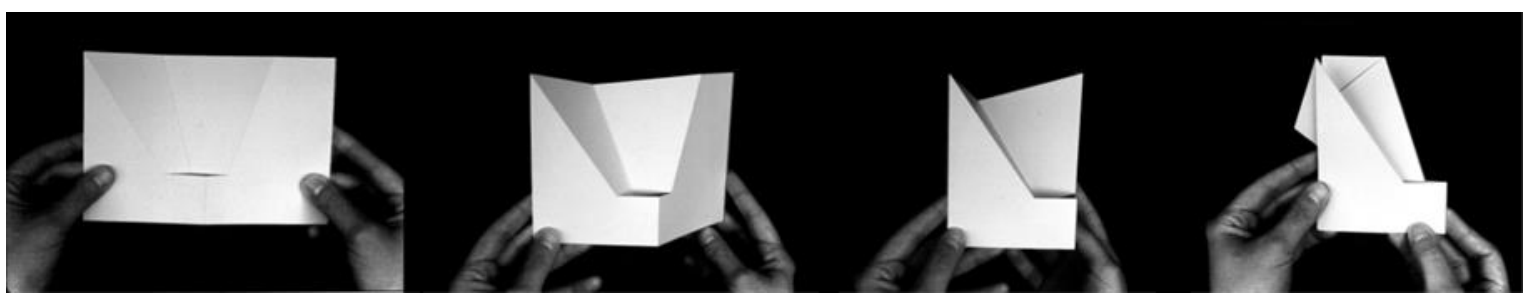

3. Maqueta de trabajo para la capilla Valleacerón. Sol Madridejos y J. C. Sancho Osinaga

Fuente: "Suite en 3 movimientos", Editorial Rueda, Madrid, 2001.

Estas dos grandes acepciones requieren de una necesaria y más profunda reflexión desarrollada en su capítulo específico. Esta investigación también se ha destinado a exponer y esclarecer el contexto conceptual en el que se enmarcan las múltiples definiciones de pliegue y destacar las aportaciones simbólicas y/o metafóricas que ofrecen a la creación arquitectónica.

\footnotetext{
${ }^{14}$ Sancho, J. Carlos et Madridejos, Sol (2001) Sancho / Madridejos, Suite en 3 movimientos. Ed. Rueda, Madrid: 118-119

${ }^{15}$ Deleuze, Gilles (1989) El pliegue. Leibniz y el Barroco. Edit. Paidós Básica, España.
} 


\section{Los inicios del siglo XX. El Origami arquitectónico.}

El origami arquitectónico ${ }^{16}$ fue enunciado inicialmente por el doctor arquitecto Tomohiro Tachi en una clase magistral ofrecida en el año 2010 en el Massachusetts Institute of Technology (MIT) donde expondría diferentes sistemas de diseño de formas arquitectónicas generadas en origami computacional. En ese curso Tachi mostraría los tres software específicos diseñados por él: el Rigid Origami Simulator ${ }^{17}$, el Free Form Origami ${ }^{18}$ y el Origamizer ${ }^{19}$, programas que calculan y realizan una simulación en 3D de procesos de plegado de superficies planas.

Durante la primera parte del siglo XX, para los arquitectos y artistas de las vanguardias, expresionistas, cubistas y constructivistas, el trabajo en papel sirvió para la experimentación formal y la exploración y representación de nuevos espacios arquitectónicos de gran valor expresivo, espacios complejos y agresivos, cargados de ritmos, quiebros y singularidades. Donde mejores ejemplos encontramos de estas experiencias es en los cursos preliminares obligatorios para todos los alumnos de la Bauhaus. En los Vorkurse, en su denominación alemana, los profesores Laszlo MoholyNagy y Josef Albers, hicieron del papel uno de sus principales materiales de trabajo, usándolo como un buen método de introducir a los estudiantes en las posibilidades de explorar el espacio y la forma directamente con el manejo del material. Estos cursos servían para inculcar a los alumnos una inusual libertad expresiva y formal.

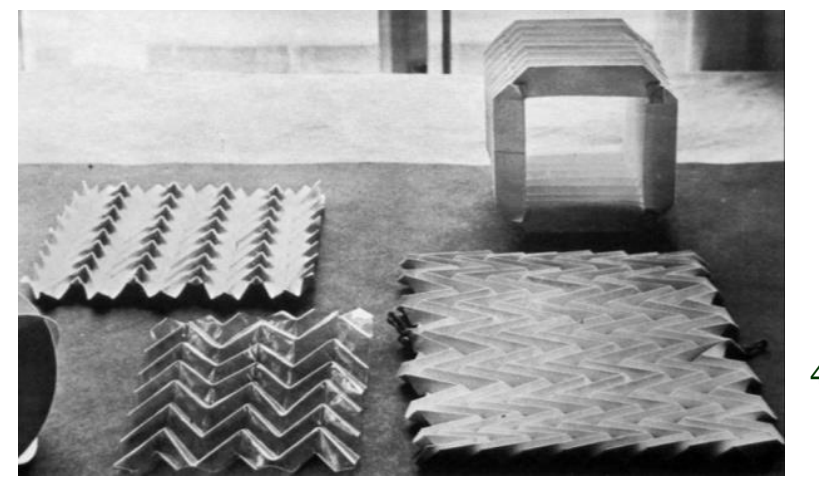

4. Trabajos de los alumnos de la Bauhaus. (1920-30) Fuente: Wingler, Hans M. et Wingler, Hedwig (1991, $1^{\text {a }}$ ed. 1969) Bauhaus: Weimar, Dessau, Berlin, Chicago. Edit. MIT Press. ISBN-13: 978-0262730471

A esta etapa la consideramos los inicios del origami abstracto, la corriente artística de finales de siglo $X X$ que se desprende de los referentes figurativos del origami tradicional que trata de representar objetos de la vida cotidiana y figuras de animales. El origami abstracto utiliza las técnicas y procedimientos básicos de pliegue o "bases" de las figuras tradicionales generando una serie de patrones modulares de pliegue de superficies de múltiples variantes geométricas.

\footnotetext{
${ }^{16}$ Tachi, T. (2010) Architectural Origami: Architectural Form Design Systems Based on Computational Origami. Lecture Notes for MIT Course 6.849, Cambridge, MA.

${ }^{17}$ Tachi, T. (2009) Simulation of Rigid Origami. In Origami4: The Fourth International Conference on Origami in Science, Mathematics and Education, edited by Robert Lang, pp. 175-187. A K Peters. http://www.tsg.ne.jp/TT/software/

${ }^{18} \mathrm{~T}$. Tachi, Freeform Origami, www.tsg.ne.jp/TT/software/

${ }^{19}$ Tachi, T. (2010) Origamizing polyhedral surfaces. IEEE Transactions on Visualization and Computer Graphics, vol. 16, no. 2.
} 


\section{Las formas facetadas: relaciones entre lo plegado, lo prismático y lo cristalino.}

Es pertinente aquí reconsiderar la relación entre lo plegado, lo prismático y lo cristalino. Podemos considerar que algo es o ha sido plegado cuando viene de otro origen superficial no transformado. Entendiendo que las formas facetadas prismáticas que se generan a partir de la extrusión de una generatriz se pueden realizar mediante el pliegue de láminas delgadas, es evidente que estas formas poliédricas, que generalmente fueron realizadas con procedimientos de corte y pliegue de papel en las escuelas, son mucho más representativas del trabajo del arquitecto que piensa en espacios, frente a las formas cristalinas macizas y en general convexas, exentas de huecos y espacios internos significativos y que se forman por procedimientos de pulido y talla. Fred Angerer distinguía entre construcciones macizas, de entramado y laminares ${ }^{20}$. Destacando que, al contrario de las construcciones macizas donde no existe relación entre el aspecto exterior y el espacio interior, las construcciones laminares expresan en su espacio interior el orden exterior que las conforma. Por lo que esta investigación también ha considerado representativas todas aquellas figuras poliédricas y morfologías arquitectónicas generadas mediante superficies facetadas no desarrollables, pero sí continuas y, por lo tanto, factibles de ser realizadas mediante las técnicas del plegado.

Llamativos son los casos del cubismo checo o del expresionismo alemán, que se agruparian en lo que hemos llamado formas poliédricas y que en su naturaleza facetada recuerdan también formas cristalográficas. Las referencias a lo cristalino y lo mineral relacionadas con las obras de los componentes de La Cadena de Cristal -Die Gläserne Kette en alemán- parecen invocar la búsqueda de la transparencia en arquitectura, pero también los múltiples reflejos lumínicos que producen las piezas de cristal y diamante pulidos.

Buenos ejemplos a analizar los constituyen los proyectos de Bruno Taut y los hermanos Luckhardt. No parece pues que los espacios interiores de estos proyectos estén inspirados en las sólidas y macizas piedras minerales y sí en las construcciones con delgadas superficies plegadas propias del origami modular.

¿Qué querían representar las formas facetadas del cubismo checo o las del expresionismo alemán? Con independencia de cómo fueran construidas, algunas de estas manifestaciones formales arquitectónicas beben de conceptos profundos del arte Japonés del origami en la fascinación por las posibilidades formales y expresivas de una lámina continua flexible, ligera y débil que, como una hoja de papel, aumenta su resistencia mediante el pliegue, pero también en su contenido simbólico, abstracto, etéreo, traslúcido y efímero impregnado de las esencias del Ukiyo-e, estilo artístico japonés de principios del siglo $X X{ }^{21}$ que se introdujo y popularizó en la sociedad europea y americana a raíz de las primeras exposiciones universales.

\footnotetext{
${ }^{20}$ Angerer, Fred (1972). Construcción laminar. Elementos y estructuración. 51, Gustavo Gili, Barcelona. (Bauten mit tragenden flächen konstruktion und gestaltung, 1960). SURFACE STRUCTURES IN BUILDING: structure and form

${ }_{21}$ Lister, David (20 de Marzo de 2005) History of Origami: outline suggestions for a basic, essential history. Fuente: British Origami Societ; http://www.britishorigami.info/

El Ukiyo-e fue un estilo artístico de finales del S. XIX y principios del S. XX que se caracterizó por la representación con las técnicas del xilograbado y la estampación de motivos y escenas tradicionales delicadas, efímeras y sutiles.
} 


\section{Los años 50. Las láminas plegadas de hormigón armado.}

Gracias a la potencia creadora de múltiples e innumerables formas y espacios de los trabajos con superficies plegadas, los movimientos arquitectónicos de principios de siglo se convirtieron en un buen campo de experimentación simbólica y formal previo al uso decididamente conformador y estructural del pliegue de los años 50. Concebida como una superficie plana continua y extensa que ha sido plegada conceptualmente y construida con materiales de comportamiento mecánico isotrópico, la lámina plegada de hormigón armado se convirtió no solo en configurador de la forma exterior sino también en un delimitador del espacio interior.

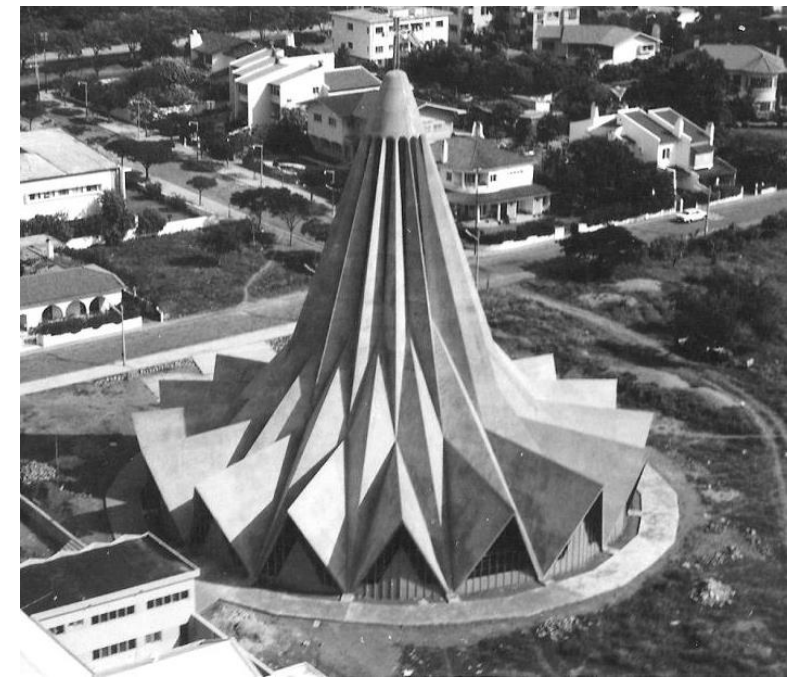

5. Iglesia de San Antonio da Polana. Maputo, Mozambique. 1962

Arquitecto Nuno Craveiro Lopes. Foto de Daniel Clements.

Patrón de pliegue yoshimura polar

Fuente: www.delagoabayworld.wordpress.com Último acceso: 27/08/2015

Como explica Rafael García ${ }^{22}$, los grandes ejemplos de láminas plegadas de hormigón armado de las décadas de los 50 y 60 constituyeron un conjunto a estudiar que marcó un hito en la creación arquitectónica contemporánea gracias a su potencial arquitectónico y constructivo. En estos años las plegaduras de hormigón se beneficiaron de las técnicas del pre y postesado, ganándose en esbelteces y luces alcanzadas. Durante la segunda parte del siglo XX, tanto holandeses y alemanes como también españoles como Félix Candela, Eduardo Torroja, José Ramón Azpiazu, junto con Iberoamericanos como Alejandro Pietri y Carlos Raúl Villanueva exploraron las posibilidades de estas láminas en su vertiente configuradora y estructural con gran éxito.

Estructuralmente es importante distinguir entre superficies plegadas desarrollables, que requieren de un necesario refuerzo constructivo en el material de la arista para aumentar su rigidez, y superficies -también plegadas- que generan formas prismáticas ${ }^{23}$ que cumplen por sí mismas los necesarios criterios de estabilidad y no requieren de un complemento externo ya que su superficie facetada y continua es autoportante, capaz de asimilar sus propios esfuerzos de forma homogénea, sin deformaciones significativas, sin abrirse y/o desplegarse.

\footnotetext{
22 García, García. Rafael. (enero-marzo 2013) Dos décadas de estructuras plegadas de hormigón. Inicio y ocaso de un movimiento. Informes de la Construcción, Vol. 65, 529, 27-39, ISSN: 0020-0883. elSSN: 1988-3234. doi: 10.3989/ic.11.083. ${ }^{23}$ Fred Angerer calificará a estas construcciones como plegaduras prismáticas y semiprismáticas. $(1974,50)$
} 

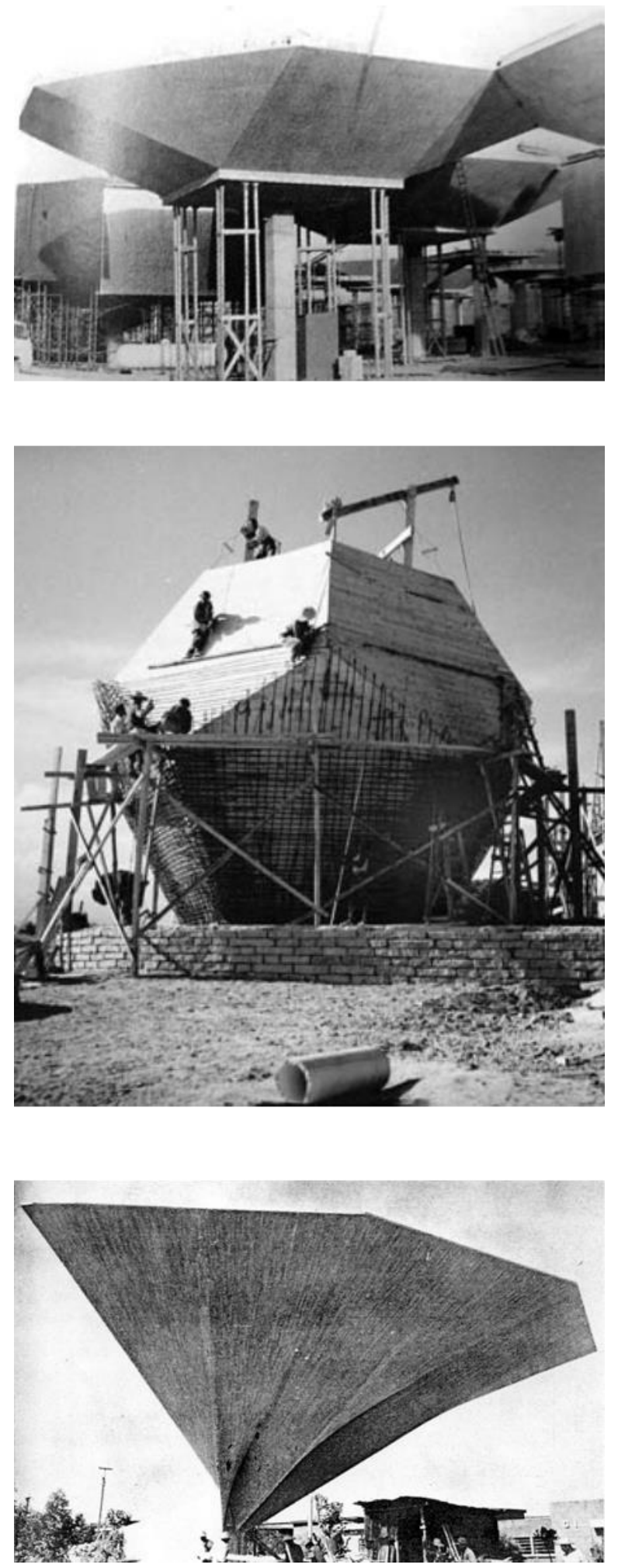

6. Fábrica Olivetti-Underwood en Harrisburg (1966-70) Fuente: Usos sutiles de la construcción laminar.

Ejemplos en los maestros de la arquitectura moderna. Rafael García García. 201124

Las superficies desarrollables y desplegables son importadas por la arquitectura como un mecanismo abstracto de control, creación y exploración formal. En el arte del Origami, el papel es el material prioritario en el que se aplican todas las transformaciones de plegado. En la arquitectura en muy pocos casos se da el hecho de plegar directamente el material final por problemas obvios de escala, resistencia del material y continuidad estructural. La mayoría de los casos estudiados de superficies desarrollables han sido realizados en hormigón armado, casos en los cuales, aun logrando una percepción visual de doblez, ésta no existe, aunque el resultado final sea similar al obtenido en el papel.

7. Depósito de carbón Instituto de Ciencias de la Construcción Eduardo Torroja (IETcc)

Fuente: Archivo Documental ITCCET

Sin entrar en el mundo de las membranas y las dobleces, mundo en el que se dan situaciones mixtas de transformaciones complejas del material, también podrían considerarse muchas otras alternativas en que las superficies no son planas, superficies curvas, regladas y alabeadas, algunas de estas últimas tienen su origen en el mecanismo conceptual de plegado en el que se forman aristas, como se puede ver claramente en la marquesina para músicos en Santa Fé y en la entrada a los laboratorios Lederle, ambas cubiertas construidas en Méjico en los años 50 por Félix Candela.

8. Marquesina para músicos. Santa fe, México. 1953-57 Aldo Pani (Arq.) y Félix Candela (Diseño y Construcción). Fuente: Faber, Colin. "Candela: The Shell Builder". New York Reinhold Publishing Corporation, 1963.

\footnotetext{
${ }^{24}$ García, García. Rafael. (2011) Usos sutiles de la construcción laminar. Ejemplos en los maestros de la arquitectura moderna. Actas del Séptimo Congreso Nacional de Historia de la Construcción, Santiago 26-29 octubre 2011, eds. S. Huerta, I. Gil Crespo, S. García, M. Taín. Madrid: Instituto Juan de Herrera, 2011 pp 496
} 
Finales del Siglo XX. Las mallas tridimensionales plegables.

Desde un punto de vista estructural, la rigidez que adquiere una simple hoja de papel al ser doblada se ha tenido en consideración en la arquitectura, al trasladar los procesos de plegado hacia la consecución de una múltiple malla tridimensional de vectores de fuerza que, al ser plegada, aumenta su canto y gracias a su distribución en el espacio, mejoran las posibilidades de la forma arquitectónica.

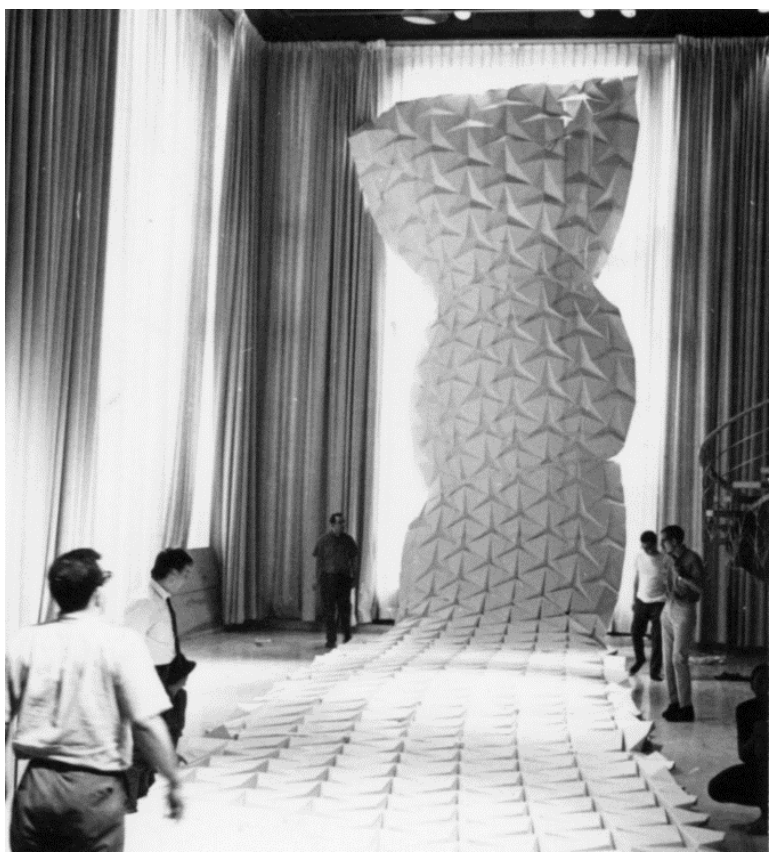

Esta malla tridimensional se puede realizar con estructuras de barras metálicas o de madera cubiertas por una superficie plegable textil o una superficie rígida facetada adaptada y a veces plegable de cristal, metal, madera, cartón y plástico.

Mallas reticuladas, móviles, plegables o fijas, las exploraciones espaciales y arquitectónicas realizadas en los años 60 por Ronald Dale Resch ${ }^{25}$ y Emilio Pérez Piñero derivadas de las "origami tessellations" son un buen ejemplo de ello.

9. Modelo en papel del patrón Ron Resch. 1960 Fuente: http://www.ronresch.org/ronresch/

Ya entrada la década de los 90 será la cubierta para la piscina olímpica municipal de San Pablo en Sevilla de Félix Escrig ${ }^{26}$, con 30 metros de luz y 11000 m3 de volumen total, la más importante construcción realizada hasta la fecha mediante mallas espaciales estructurales desplegables.

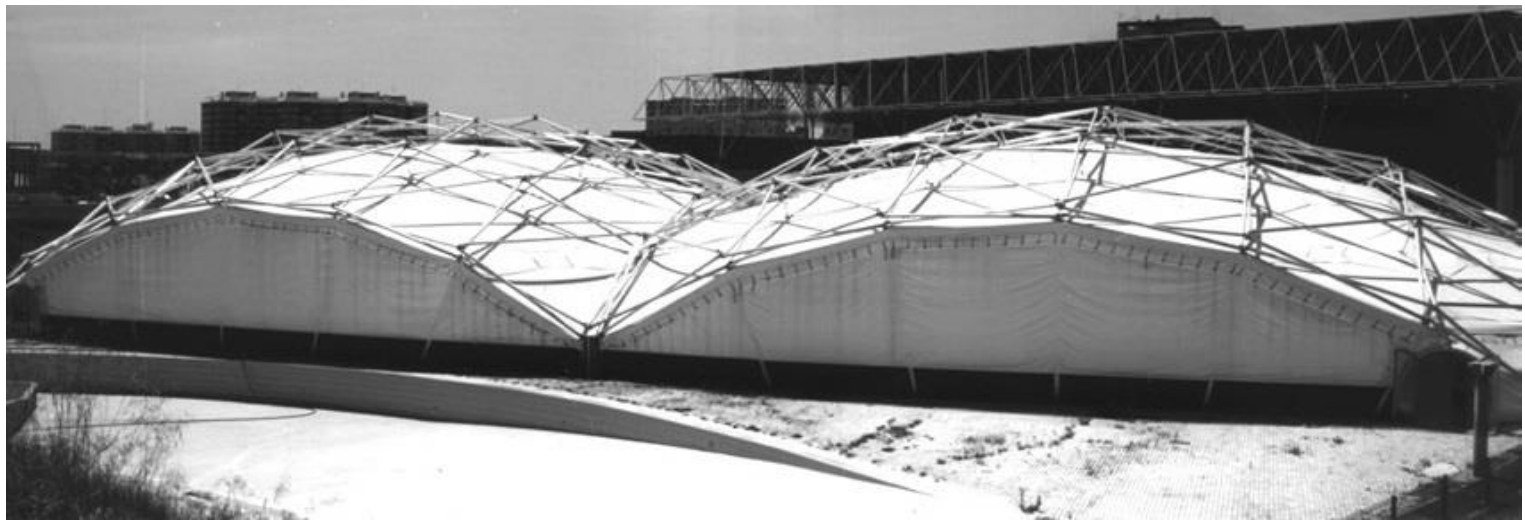

10. Piscina olímpica municipal de San Pablo en Sevilla de Félix Escrig y José Sánchez Fuente: Escrig, Félix. Sanchez, José. (2002) Mobile and rapidly assembled architecture. Arquitectura móvil y de rápido montaje. Star Structural Architecture 1. Editorial Starbooks. Página 42

\footnotetext{
${ }^{25}$ Ron Resch (Ronald Dale Resch) fue un artista, pionero en el desarrollo de representaciones virtuales 3D por medios informáticos. Es conocido sobre todo por sus trabajos de Origami abstracto y modular: http://www.ronresch.org/ronresch/ ${ }^{26}$ Escrig, Félix et Sanchez, José (2002) Mobile and rapidly assembled architecture. Arquitectura móvil y de rápido montaje. Star Structural Architecture 1. Editorial Starbooks. ISSN: 1137-201 X
} 


\section{Siglo XXI. Los nuevos patrones y las estructuras cinéticas e interactivas.}

Los patrones Yoshimura (llamado así por el astrofísico japonés Koryo Miura ${ }^{27}$ en honor a su maestro y también conocido como pliegue en diamante o triángulo turco), Miura (llamado así en honor a K. Miura al diseñar en 1970 con este patrón un modelo de despliegue de grandes formaciones de paneles solares de satélites espaciales), Fishbone (espina de pez) y Pleats (plisado o acordeón) junto con sus transformaciones circulares, diagonales y escalares entre otras, son un ejemplo de la importancia práctica del origami rígido y forman un amplio mundo de variantes que se han aplicado y se siguen utilizando en el diseño arquitectónico actual. $Y$ su estudio nos abre nuevas puertas a la experimentación con superficies plegadas combinadas, uso de nuevos materiales como maderas contrachapadas, fibrocemento, plásticos reforzados con fibras de vidrio, carbono $\mathrm{u}$ otros, dobles pieles colaborativas estructurales, etc.

La exploración de las nuevas mallas geométricas que resultan de la combinación de los cuatro patrones básicos de plegado y la comprensión y control del comportamiento dinámico y las formas intermedias y finales de su proceso de plegado nos abren un nuevo abanico de posibilidades cinéticas e interactivas para la utilización de estos patrones de plegado en la arquitectura y el diseño.

Cursos experimentales como los "Folding Architecture Course"28 que tuve la oportunidad de codirigir junto con la profesora Sophia Vyzoviti en el Departamento de Arquitectura de la Universidad de Tesalia en Grecia en los cursos 2012-13 y 2013-14 y los Talleres Verticales que he realizado junto con los profesores Rubén Servando, Fernando Martín Menis y Daniel Díez en los cursos 2014-15 y 2016-17 en la Escuela de Arquitectura de la Universidad Europea de Canarias, están profundizando asimismo en la creación de nuevos patrones de plegado que, al transformarse y construirse con materiales ligeros, posibiliten la creación de arquitecturas cinéticas e interactivas.
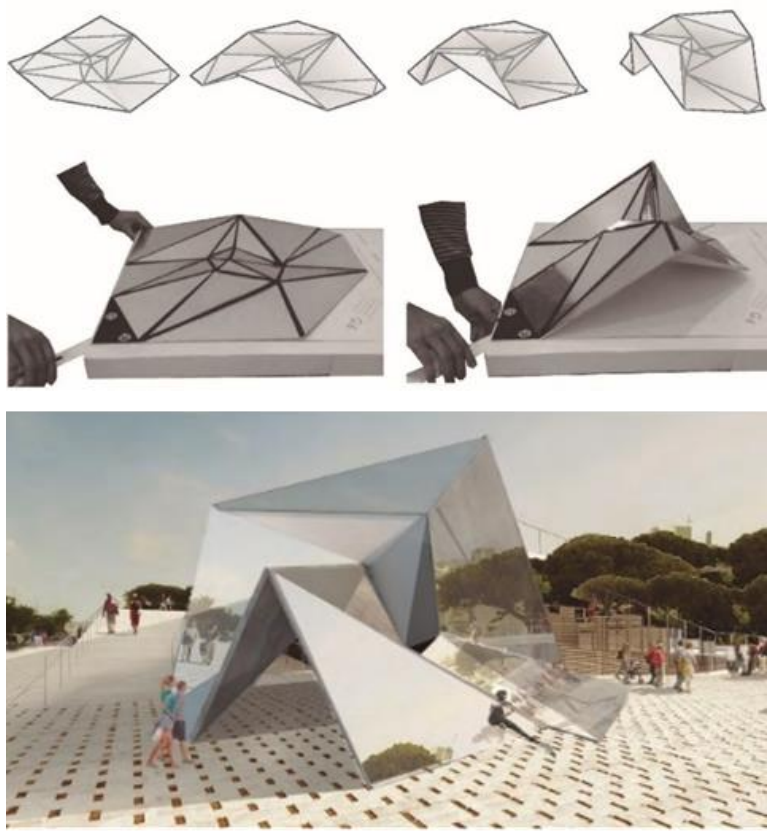

11. Proyecto FusionArch. 2015. FNJACPS

Fuente: Póster: Arte y Arquitectura cinética e interactiva en la formación técnica y artística. (junio 2015) IV Feria de Jóvenes Investigadores. La Laguna. Canarias.

\footnotetext{
${ }^{27}$ Miura K. (1985) Method of packaging and deployment of large membranes in space. Inst. Space Asronaut. Sci. 618, 1-9. ${ }^{28}$ Vyzoviti S. et De Souza P. (2012) Origami Tessellations in a Continuum. Integrating design and fabrication in architectural education. pag 165-175. Transactions on Architectural Education №59. European Association for Architectural Education. EAAE. Münster.
} 


\section{METODOLOGÍA HISTÓRICA, DE CASO Y EXPERIMENTAL}

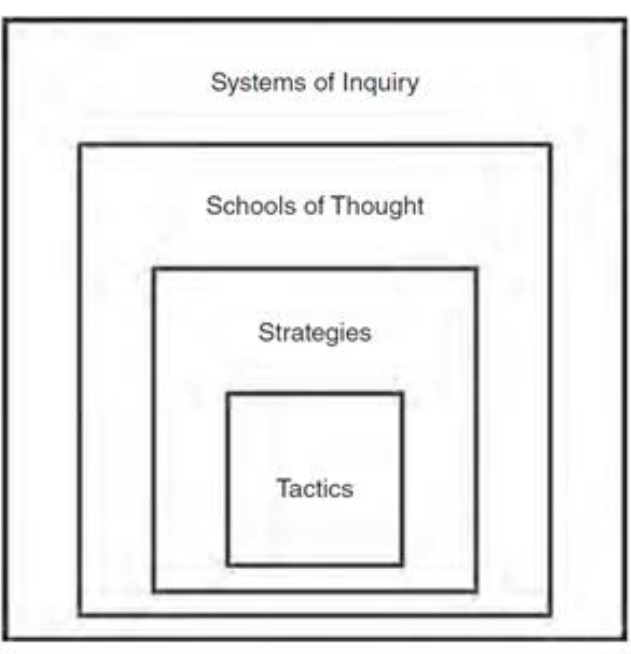

Para explicar la metodología de investigación seguida en la presente tesis tomo de referencia la clasificación que hacen Linda Groat y David Wang en su publicación Architectural Research Methods 29. La ilustración adyacente representa la escala de definición de una investigación: Las técnicas de investigación, también llamadas tácticas, están enmarcadas por las prácticas metodológicas o estrategias que a su vez están enmarcadas en sistemas más amplios de investigación, las escuelas de pensamiento y los sistemas de indagación, de observación de la realidad, de posicionarse frente al mundo.

12. Marcos de pensamiento y reflexión de una investigación

Fuente: Groat, Linda; Wang, David (2013)

Architectural Research Methods. John Wiley \& Sons, Inc., Hoboken, New Jersey. pp 10

\section{Systems of Inquiry: Metodología de indagación flaneuriana}

Nuestro acercamiento a un problema producirá distintos resultados dependiendo de nuestro punto de vista, es decir, de nuestra actitud y expectativas acerca de ese fenómeno, éstas expectativas vienen determinadas en gran medida por la disciplina científica en la que se enmarca nuestra investigación. Por lo que se hace necesario definir previamente desde qué posición estamos realizando la observación y desde qué presupuestos.

Carole Gray y Julian Malins ${ }^{30}$ en su publicación sobre los procedimientos de investigación para artistas y diseñadores definen la investigación como una indagación inteligible y sistemática, una indagación abierta, fácil de entender y transparente, que además tenga un procedimiento ordenado y riguroso. Gray y Malins resumen los procesos involucrados en la indagación e investigación en: (1) una pregunta, problema o necesidad que abre a la indagación; (2) un enfoque deliberado / procedimental; (3) una transformación / síntesis / o producción de un nuevo "conocimiento"; (4) unos resultados públicos y su comunicación.

Pero incluso para Gray y Malins las Bellas Artes por su propia naturaleza son "anti método" 31. Casualidad, caos, aleatoriedad, anarquía, etc. son parte de un proceso de trabajo creativo en el que, por muy caótico o anárquico que pueda parecer, la noción de tener un procedimiento es una parte esencial para la producción artística.

\footnotetext{
${ }^{29}$ Groat, Linda; Wang, David (2013) Architectural Research Methods. John Wiley \& Sons, Inc., Hoboken, New Jersey. ISBN-13: 978-0750658515

30 Gray, Carole et Malins, Julian (1993, trad. 2013) Procedimientos / Metodología de Investigación para Artistas y Diseñadores. The Centre for Research in Art \& Design. Gray's School of Art, Faculty of Design, The Robert Gordon University, Aberdeen, Scotland, UK. pp. 2-3

${ }^{31}$ Gray, Carole et Malins, Julian (1993, trad. 2013) Procedimientos / Metodología de Investigación para Artistas y Diseñadores. The Centre for Research in Art \& Design. Gray's School of Art, Faculty of Design, The Robert Gordon University, Aberdeen, Scotland, UK. pp. 6
} 
La creación artística y arquitectónica tiene algo de indagación sistemática y analítica, pero mucho más de indagación anárquica, libre y variable, como encuentros y descubrimientos aparentemente fortuitos provocados por un deliberado devaneo, una búsqueda perimetral por áreas aparentemente inconexas, lo que en el siglo XIX se vino a llamar "flaneurismo" un errar sin rumbo fijo por la urbe y la sociedad. El artista flâneur es un paseante urbano aparentemente ocioso e intelectualmente activo que mira analíticamente a la ciudad y a la ciudadanía, clasificando, encontrando vínculos entre los elementos urbanos y los acontecimientos callejeros.

Como nos explica Dorde Cuvardic ${ }^{32}$ en su libro El flâneur en las prácticas culturales, el costumbrismo y el modernismo", el flâneur nace a comienzos del siglo XIX con una mirada panorámica elevada, vertical y estática común al Romanticismo, de carácter a menudo alegórico y místico. Y evoluciona hacia una visión horizontal a ras de suelo, móvil, fragmentada, de apariencia más literal y referencial. Mediante su mirada, el flaneur es capaz de apoderarse del espacio público y convertir las inhóspitas calles en un acogedor paisaje interior, les inyecta nuevas perspectivas, insuflándoles una mirada poética que descompone y resintetiza los elementos del entorno urbano en nuevas configuraciones para convertirlos en parte de un mobiliario común, con una nueva narración compartida.

Para Juan Carlos Gea el flaneur empezó siendo un botánico del paisaje urbano y un "explorador del capitalismo en el reino del mercado" ${ }^{33}$, la evolución de las ciudades y el crecimiento exponencial de sus imposiciones sobre quienes las habitamos, permite acuñar un nuevo tipo de flaneurismo más activo, en el que, paradójicamente, el flaneur adquiere objetivos y convierte el flaneurismo en un método de indagación.

Así pues, el inicio de esta indagación de medotología "flaneuriana" en la que unas referencias nos llevaban a otras y éstas nos hacen descubrir nuevas relaciones y significados, se puede situar en el mes de abril del año 2003, un deslumbramiento casual atrajo mi atención durante un viaje de estudios a Finlandia, era un pequeño prototipo de luminaria realizado en papel plegado que se encontraba sobre uno de los pianos de la casa estudio de Alvar Aalto.

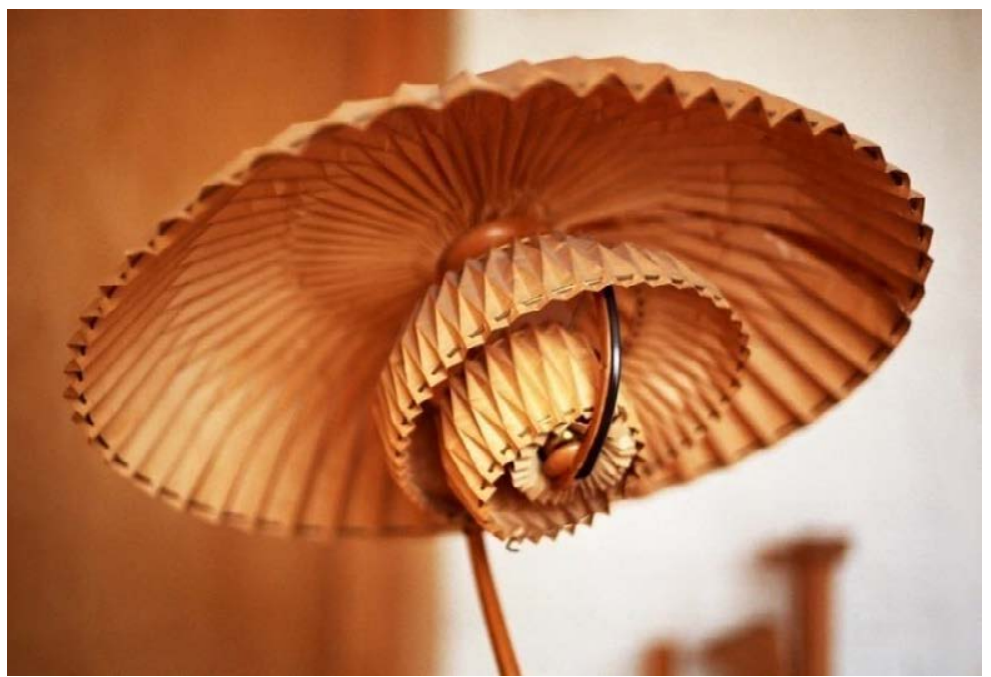

13. Maqueta para una lámpara de sobremesa.

Casa-estudio de A. Aalto.

Patrón geométrico: Yoshimura extendido circular (extended polar yoshimura). Fotografía: Pablo De Souza. Abril del 2003.

\footnotetext{
32 Cuvardic García, Dorde (2012) El flâneur en las prácticas culturales, el costumbrismo y el modernismo. Éditions Publibook. 14, rue des Volontaires 75015 PARIS - France pp17-18

${ }^{33}$ Gea, Juan Carlos (2006) Flaneur con causa o Tokyo refundado. Catálogo de exposición de fotografía de Ken-ichiro Suzuki: Nowhere in Tokyo. Fuente: http://www.enfocarte.com/6.29/suzuki/suzuki2.html 2016/12/05
} 
En esos años a Finlandia se la calificaba como el Japón de Europa, no solo por lo avanzado y exitoso de su tecnología de telecomunicaciones, sino también por una cierta dosis de relación entre el arte y arquitectura nórdicos y japoneses, donde colores suaves y grises de tonos naturales aplicados con transparencias y veladuras, que caracterizaban las acuarelas de pintores nórdicos reconocidos como Peter Zörn, eran utilizados en diseños de mobiliario, de moda y de objetos tecnológicos, con materiales naturales, satinados y traslúcidos.

Hasta entonces yo había utilizado para los proyectos de arquitectura del primer curso, el plegado de papel con patrones básicos como el plisado (también llamado en acordeón o pleat) y las cintas continuas de triángulos equiláteros. Así que la maqueta de Alvar Aalto abría un nuevo mundo de posibilidades formales.

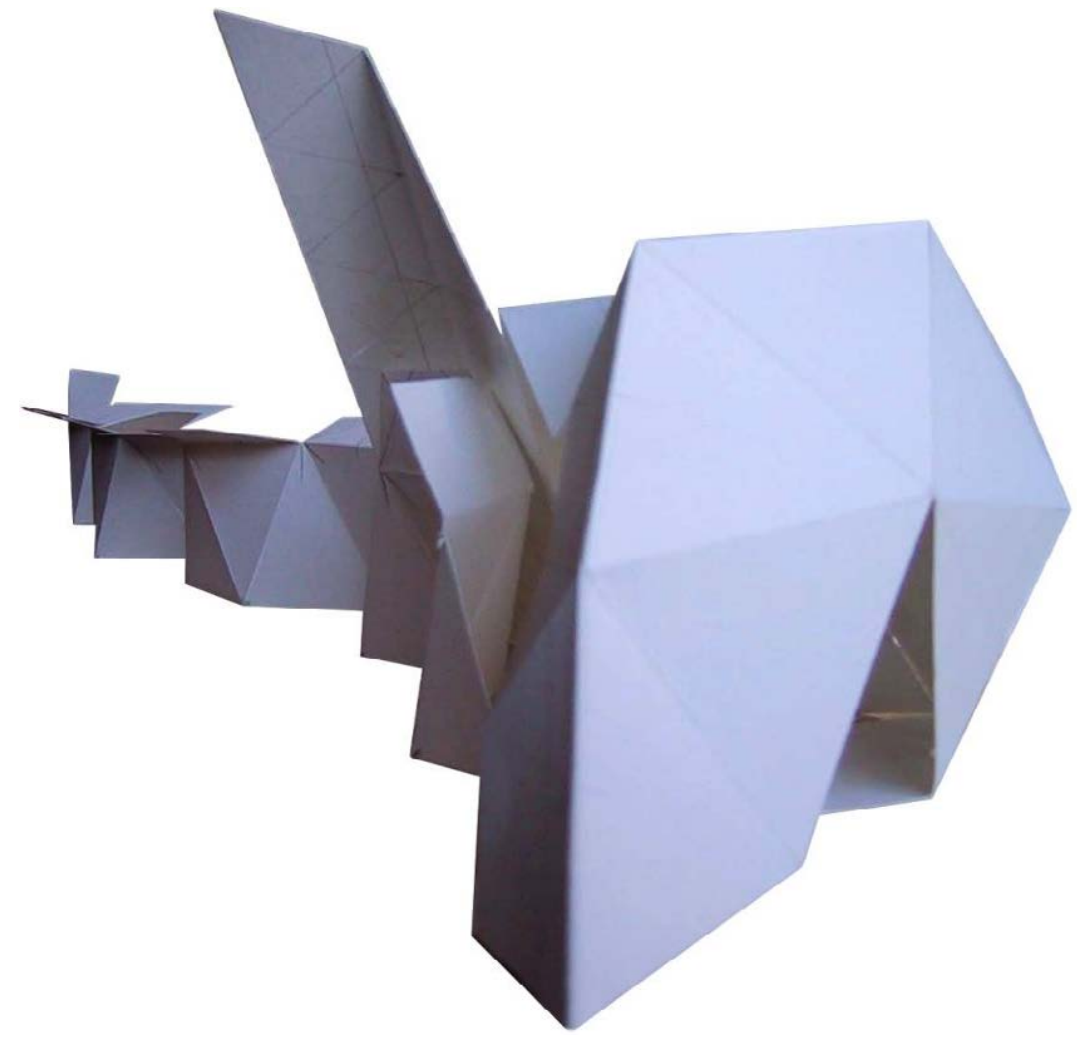

14. Maqueta de Pabellón Expositivo.

Realizada en cartulina blanca.

Patrón geométrico de triángulos equiláteros.

Pablo De Souza. Noviembre 2001.

A medida que avanzaba en mi formación académica fueron apareciendo ante mí referencias a estos patrones de plegado en publicaciones especializadas como los libros de Heino Engel: "Sistemas de estructuras" ${ }^{34}$ y de Mario Salvadori: "Why buildings stand up: the strength of architecture" ${ }^{35}$, que en una de sus páginas mostraba el desarrollo del plegado en diamante o Yoshimura de una forma sencilla y su posible uso como cubierta abovedada.

\footnotetext{
${ }^{34}$ Engel, Heino. (1970). Tragsysteme, Structure Systems. (Sistemas de estructuras) Trad. Fernando de Aguirre e Yraola, Juan Batanero García/Geraldo. Edit. Blume, 1970. Madrid, España.

${ }^{35}$ Salvadori, Mario. et al (1980) Why buildings stand up: the strength of architecture. W. W. Norton. New York.
} 
En viajes sucesivos a centro-europa iría encontrando objetos arquitectónicos con estructuras plegadas con patrones triangulares muchas veces anónimos que, como pequeños huesos que un arqueólogo va catalogando y uniendo para tratar de reconstruir un esqueleto, me mostraban múltiples y variadas formas de usar los patrones de pliegue en la arquitectura.
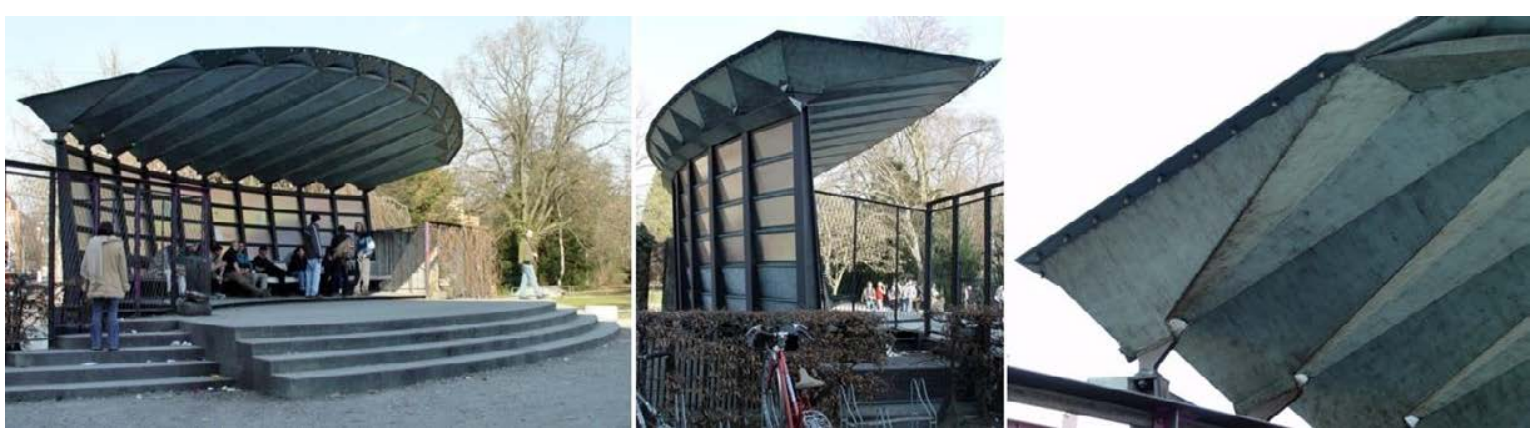

15. Marquesina para conciertos.

Acero laminado con pátina antioxido y cristal.

Patrón geométrico: Semiyoshimura circular con cartelas triangulares posteriores de refuerzo.

Stadtgarten (Parque Central), Winthertur, Suiza.

Fotografía: Pablo De Souza. (2005-05-17)

\section{Schools of Thought: Disciplinas de conocimiento artística y arquitectónica}

En las disciplinas científicas y de las ciencias sociales las metodologías de investigación llevan desarrollándose durante siglos, con lo que se ha conseguido establecer unos procedimientos y técnicas que ofrecen garantías a los investigadores (véase por ejemplo a Montero y León ${ }^{36}$ ).

En cambio, la investigación en las disciplinas artísticas, del diseño y de la arquitectura ha carecido de unos procedimientos definidos hasta bien entrado el siglo $\mathrm{XX}{ }^{37}$, pues los ámbitos de investigación en estas disciplinas son extremadamente diversos y la creación y desarrollo de estas disciplinas se ha generado mediante la acción y reflexión a menudo vinculadas al proceso creativo individual y no establecidas como base para la construcción de un discurso y narración analítica y sintética de estas disciplinas.

\footnotetext{
${ }^{36}$ Montero, Ignacio; León, Orfelio G. (febrero-marzo, 2002) Clasificación y descripción de las metodologías de investigación en Psicología. International Journal of Clinical and Health Psychology, vol. 2, núm. 3, pp. 503-508.

Asociación Española de Psicología Conductual. Granada, España

${ }^{37}$ Podemos citar el libro "Métodos y técnicas de investigación. Una propuesta ágil para la presentación de trabajos científicos en las áreas de arquitectura, urbanismo y disciplinas afines" de la autora Esther Maya publicado en el año 2014 como uno de los estudios más detallados para poder definir las metodologías de investigación afines a la arquitectura. En él se trata de abordar la enseñanza del pensamiento científico en los estudiantes de arquitectura destacando el procedimiento que propone el método científico:

Seleccionar un fenómeno u objeto de investigación

Observarlo y analizarlo, destacando sus características más importantes.

Recabar toda la información que exista sobre el objeto que se investiga, considerando sus cambios y/o transformaciones.

d. Formular hipótesis a partir de la información recabada y, de ser posible, su desenvolmiento futuro.

e. Establecer los métodos que permitan determinar la validez de la(s) hipótesis

f. Proponer nuevos problemas de investigación.
} 
Como nos exponen Madrazo y Avellaneda ${ }^{38}$, en ámbitos de larga tradición como las ingenierías, las técnicas constructivas, los materiales de construcción y la historia de la arquitectura, las metodologías de investigación han sido el resultado del encuentro entre los métodos surgidos y desarrollados en las ciencias sociales y experimentales con aquellos ámbitos de la arquitectura que mejor se han adecuado a ellos.

En la mayoría de las ocasiones, la investigación en torno al objeto arquitectónico requiere de una visión global, se distingue de la investigación en otras disciplinas por la posibilidad de aglutinar una diversidad de conocimientos, no solo los específicos de las técnicas y ciencias de los materiales o de la ingeniería de la construcción. Siendo necesario, en muchos casos, el trabajo de análisis desde perspectivas distintas que enriquecen y completan la investigación mediante las metodologías específicas a cada área.

Dado que el enfoque de esta tesis ha sido abordado tanto desde mi formación en Bellas Artes como en Arquitectura, podemos afirmar que la presente investigación se ha abordado desde un punto de vista transdisciplinar ${ }^{39}$, integrando los conocimientos, medios y procesos afines a las dos áreas de conocimiento.

La realización de investigaciones arquitectónicas fuera de los límites de la propia disciplina es un fenómeno reciente, tal como exponen Groat y Wang en su libro de referencia Architectural Research Methods ${ }^{40}$, a pesar de que el diseño del clima y el desarrollo de productos y sistemas constructivos parecen haber sido un punto focal de investigación en los años cincuenta, la investigación en arquitectura se desarrolló en los años sesenta y principios de los setenta en una amplia gama de áreas temáticas, incluidas las cuestiones socioeconómicas, el urbanismo sostenible, los métodos de diseño y el consumo de energía.

\section{Strategies: Metodologías de investigación histórica, de caso y experimental}

Los términos método o metodología de investigación se refieren a las estrategias o procesos de investigación que son comunes a toda una rama de la ciencia, en este caso a toda la gama de la investigación arquitectónica, desde la aplicación práctica a la investigación teórica, incluyendo áreas de contenido afines a las ciencias puras, las ingenierías y las humanidades. Una determinada metodología o estrategia de investigación puede abordarse según cada circunstancia o contexto mediante diferentes tácticas o técnicas de recopilación, análisis y síntesis de la información.

\footnotetext{
${ }^{38}$ Madrazo, L.; Avellaneda, J.; Gonzalez, J.M. (2006) Bar_Code housing system: la creación de un espacio interdisciplinar en torno al proyecto de arquitectura. Segundas Jornadas sobre Investigación en Arquitectura y Urbanismo. Universitat Politècnica de Catalunya. Escola Tècnica Superior d'Arquitectura del Vallès

${ }^{39}$ Jaime Munárriz en su libro Investigación y tesis doctoral en Bellaa Artes distingue tres características de la investigación que implica a distintas disciplinas:

Multidisciplinar: Distintos factores se analizan desde distintas disciplinas

Interdisciplinar: El mismo objeto se analiza desde distintas disciplinas.

c. Transdisciplinar: Las distintas disciplinas trabajan conjuntamente, integrando sus conocimientos, medios y procesos.

Fuente: Munárriz Ortiz, Jaime (2013) Investigación y tesis doctoral en Bellas Artes. Universidad Complutense de Madrid. España. pp5

${ }^{40}$ Groat, Linda; Wang, David (2013) Architectural Research Methods. John Wiley \& Sons, Inc., Hoboken, New Jersey. ISBN-13: 978-0750658515 pp 7, 15
} 
Groat y Wang definen siete grandes estrategias, metodologías o métodos de investigación:

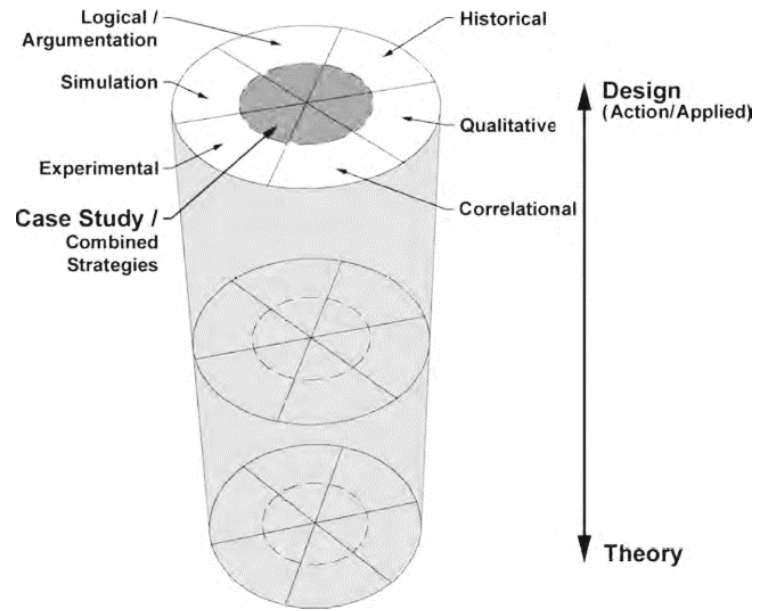

- Investigación histórica

- Investigación cualitativa

- Investigación correlacional

- Investigación experimental y cuasi-experimental

- $\quad$ Simulación de la investigación

- $\quad$ Argumentación lógica

- Estudios de caso

y estrategias combinadas

16. Marco conceptual de los métodos de investigación

Fuente: Groat y Wang (2013) pp15

Según la definición gráfica de Groat y Wang ${ }^{41}$, el elemento circular se divide mediante cuñas en forma de tarta, una para cada una de las seis principales estrategias de investigación. En el centro del círculo, el "núcleo" representa estudios de casos y/o estrategias combinadas. La periferia del círculo representa los ejemplos más distintivos y enfocados de cada estrategia en particular. A continuación, la dimensión vertical del cilindro representa el propósito o resultado de la investigación, desde un perfil teórico a un enfoque dirigido al diseño o aplicación práctica.

La investigación arquitectónica puede llevarse a cabo para diferentes propósitos y en diferentes contextos. En muchas ocasiones el estudio de un concepto teórico sirve como base para la iniciación a un resultado de investigación enmarcado en el contexto de lo práctico, resultando en la aplicación concreta de las conclusiones teóricas.
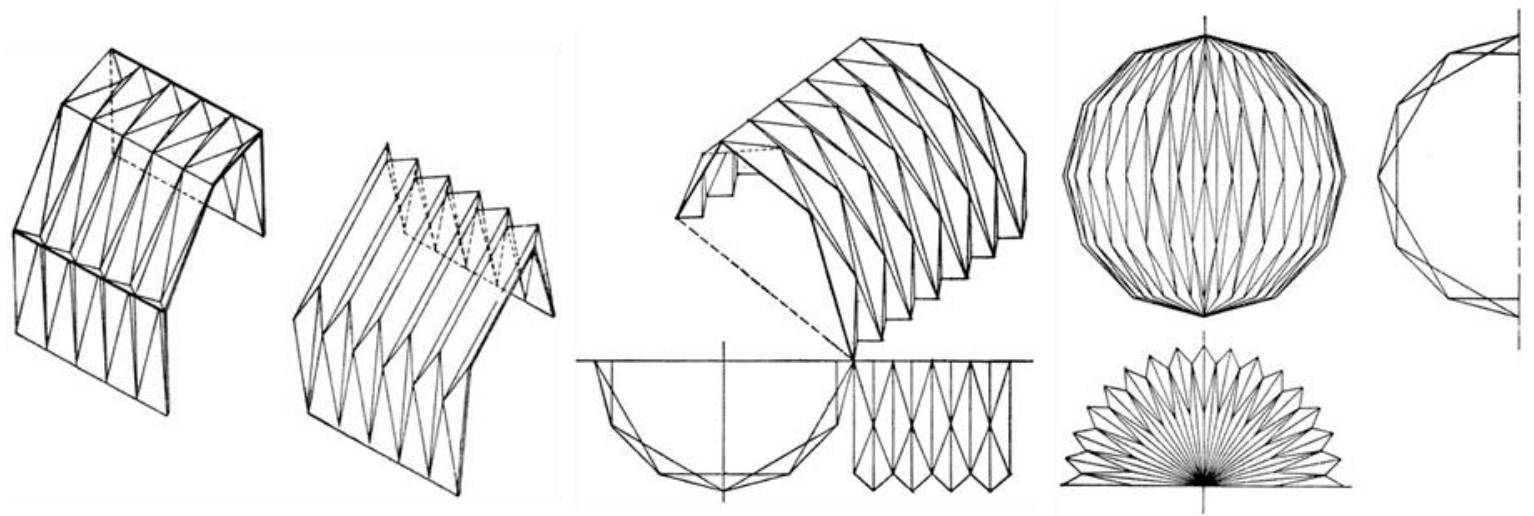

17. Plegaduras aporticadas, de cañon y esférica según clasificación de Fred Angerer

Fuente: Angerer, Fred (1972) Construcción laminar. Elementos y estructuración, detalles de las páginas 75, 76 y 77

${ }^{41}$ Groat, Linda; Wang, David (2013) Architectural Research Methods. John Wiley \& Sons, Inc., Hoboken, New Jersey. ISBN-13: 978-0750658515 pp 15 
Siguiendo la clasificación de Groat y Wang, la presente investigación se ha basado en una metodología de análisis histórico descriptivo de las distintas fuentes documentales, sobre estas líneas se muestra un detalle del libro Construcción Laminar de Fred Angerer ${ }^{42}$, un análisis de caso de algunos de los proyectos más emblemáticos que pudieran servir de ejemplo de las diferentes clasificaciones y una investigación experimental en el que se han realizado prototipos mediante la manipulación de variables independientes, que son las proporciones del módulo de patrones regulares elementales del origami modular (plisado, yoshimura, miura y espina de pez) que se han modificado para generar un efecto sobre la variable dependiente, en este caso la forma constante de cada patrón y sus posibilidades formales al ser plegado.
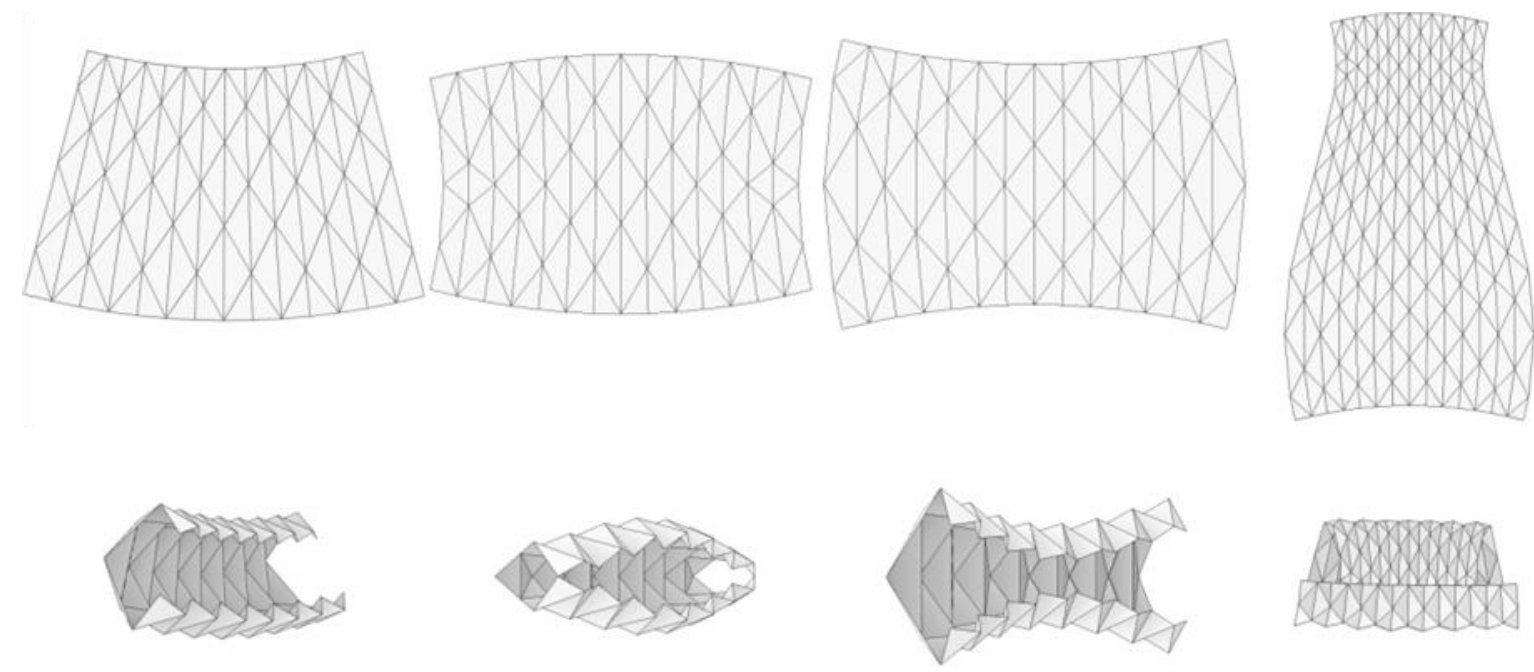

18. Transformaciones topológicas del patrón regular de plegado Yoshimura Circular (1), convexa (2), cóncava (3) y combinatoria (4).

Simulaciones con Rigid Origami, software diseñado por Tomohiro Tachi.

El propósito de la investigación de metodología experimental ha sido el de aplicación práctica destinado al diseño de nuevas formas arquitectónicas derivadas de la evolución y combinación de los patrones y modelos de pliegue analizados.

Tal como exponen Gray y Malins ${ }^{43}$, dentro de la metodología de investigación experimental, la aplicación de las tecnologías de la información y comunicación puede facilitar la investigación sobre el proyecto de arquitectura, entendido como un espacio que resulta de las interrelaciones entre forma, función y técnica. La arquitectura tiene ámbitos de investigación que surgen de la propia disciplina y de las relaciones y necesidades que se establecen en la realización de un proyecto arquitectónico. Unas relaciones entre forma, función y técnica (o en su versión Vitruviana de venustas por forma, apariencia y cualidades estéticas, utilitas por función, firmitas por técnica) entendidas no solo desde la etapa de concepción y representación, sino también como estrategia de acción para dar respuesta al programa arquitectónico.

\footnotetext{
42 Angerer, Fred (1972) Construcción laminar. Elementos y estructuración, Barcelona: Gustavo Gili (Bauten mit tragenden flächen konstruktion und gestaltung, 1960).

43 Gray, Carole et Malins, Julian (1993, trad. 2013) Procedimientos / Metodología de Investigación para Artistas y Diseñadores. The Centre for Research in Art \& Design. Gray's School of Art, Faculty of Design, The Robert Gordon University, Aberdeen, Scotland, UK. pp. 6
} 
La aplicación de estas tecnologías necesariamente obliga a una definición de los procesos de generación formal de un proyecto o de los métodos empleados en su construcción. De esta manera, las tecnologías informáticas, más que proveer instrumentos para solucionar problemas concretos, inducen a profundizar en la comprensión de los procesos de concepción y materialización del proyecto en arquitectura.

Los talleres experimentales realizados en la Universidad de Tesalia, Grecia, junto a la profesora Sophia Vyzoviti en los cursos 2012-13 y 2013-14, los realizados en la Universidad Europea de Canarias los cursos 2014-15 y 2016-17, han ayudado a generar familias de patrones, a explorar sus capacidades combinatorias y a poner en práctica estos nuevos patrones que han surgido en el transcurso de la investigación, estudiado las variables espaciales, constructivas y estructurales.
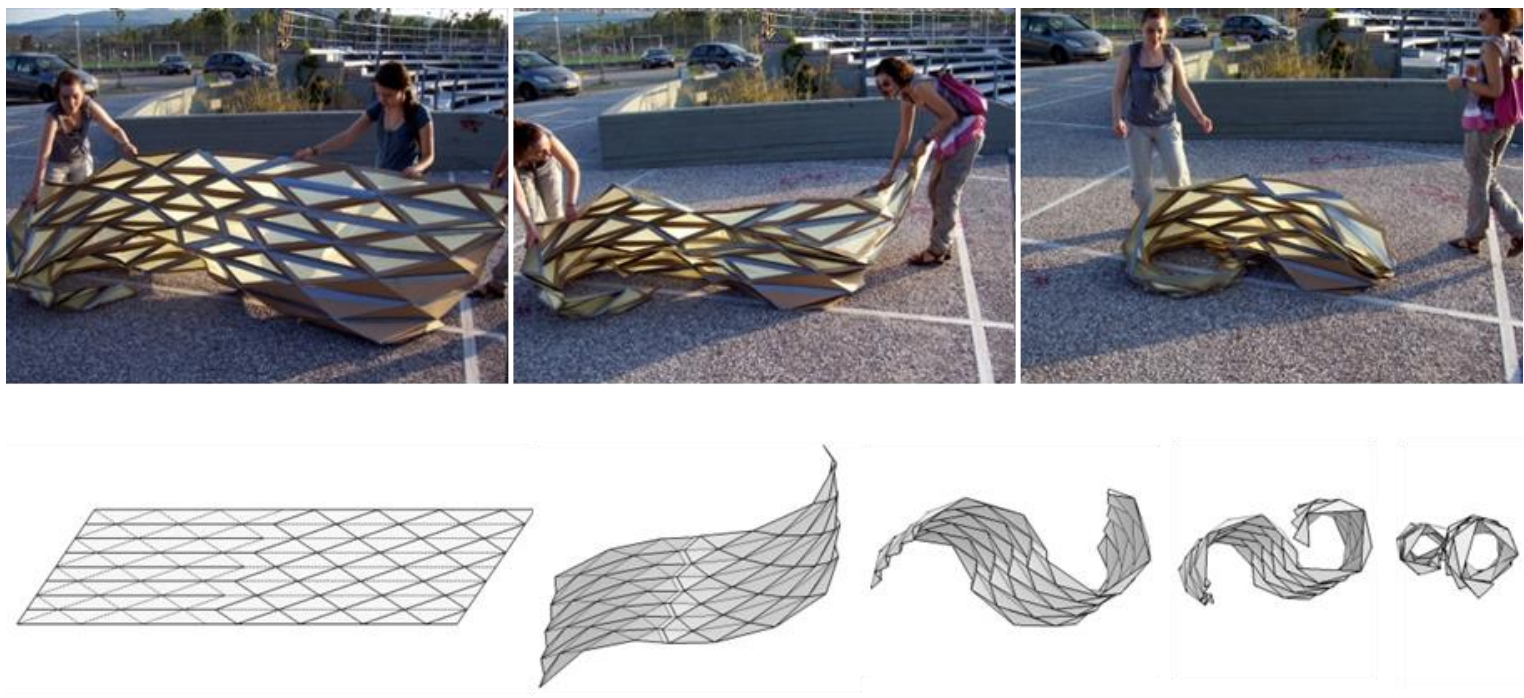

19. Ejercicios de Origami Arquitectónico. Curso "Folding Architecture" 2012-2013

Patrón geométrico: Yoshimura diagonal regular combinado con Miura.

Profesores Sophia Vyzoviti y Pablo De Souza.

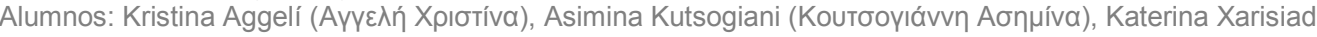

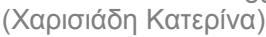

Departamento de Arquitectura de la Universidad de Tesalia en Volos, Grecia. 
Tactics: Técnicas de estudio performativas, sintéticas, históricas y experimentales.

Atendiendo a la clasificación de Jaime Munárriz ${ }^{44}$ en su documento "Investigación y Tesis Doctoral en Bellas Artes", el trabajo de investigación de esta tesis se ha realizado mediante las siguientes tácticas o técnicas de estudio:

- Histórica: Donde se ha estudiado la evolución, etapas y desarrollo del proceso de utilización de patrones derivados del pliegue de papel en la arquitectura.

- Sintética: Donde se ha estudiado las conexiones entre hechos históricos, sociales y culturales como por ejemplo, las relaciones entre la apertuda económica y política de Japón a finales del siglo XIX con los nuevos modelos educativos Froebelianos y la eclosión de las vanguardias.

- Performativa: En la cual se ha estudiado la generación de significado del objeto arquitectónico desde el propio contexto comunicativo, en sus implicaciones sociales y culturales.

- Sistémica: Donde se ha estudiando las distintas partes que conforman el objeto arquitectónico a analizar y su cometido funcional en la totalidad, en diversos niveles, tanto semánticos, constructivos como formales, lo que ayuda a conocer la función de cada parte en el mecanismo interno de cada patrón de pliegue.

A las que hay que añadir:

- Investigación cuantitativa experimental de diseño: En la que se realiza un análisis dimensional de variables cuantitativas mediante un ensayo analítico, prospectivo, caracterizado por la manipulación artificial del factor de estudio por el investigador.

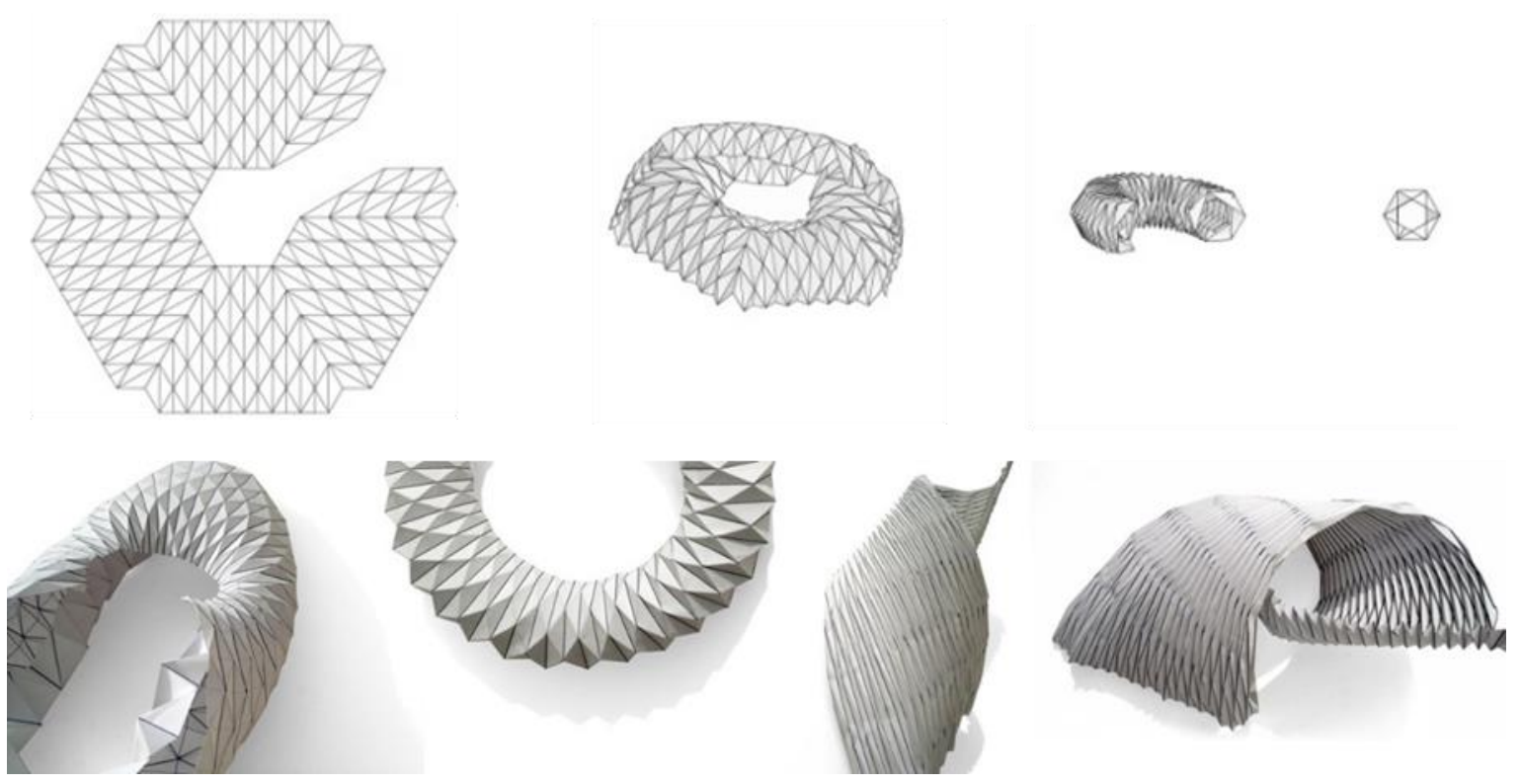

20. Patrón polar hexagonal yoshimura y variaciones polares en papel.

Autor Pablo de Souza, 2012. Simulaciones realizadas con el programa Rigid Origami de Tomohiro Tachi.

${ }^{44}$ Munárriz Ortiz, Jaime (2013) Investigación y tesis doctoral en Bellas Artes. Universidad Complutense de Madrid. España. pp5 


\section{Exposición de la investigación.}

La exposición de la investigación se ha fundamentado en base a las imágenes de las referencias, ejemplos y proyectos más significativos. Imágenes que participan gráficamente en la narración y transmisión de los resultados y conclusiones. En palabras de Juan Bordes de su libro La infancia de las Vanguardias, las imágenes que se muestran "no dejan de ser arqueología moderna que aquí se ofrece al lector como los fragmentos de una vasija a la que aún le faltan muchas piezas" ${ }^{45}$.

Son las imágenes el corpus central, las protagonistas de la narración, ha sido mi intención la de mostrar toda la información disponible de cada una al lado del texto para que los datos aportados sean partícipes de la narración, por este motivo las imágenes se acompañan en la medida en que se conocen, por el título, autor (de la obra representada en la imagen o de la fotografía) junto a una clasificación del patrón de pliegue utilizado en su caso y la fuente y la fecha en la que se ha encontrado. Así mismo muchas de las imágenes se han obtenido al escanear documentos bibliográficos, estas han sido trabajadas para contrastar, enfocar y mejorar en lo posible su calidad.

Y citando de nuevo a J. Bordes: "esta no es una historia cerrada", quiere generar muchos interrogantes y abrir caminos para posibles investigaciones y aplicaciones en el diseño y la arquitectura futura, pretende "rescatar (...) el paisaje infantil que vivieron los vanguardistas, desempolvando sus viejos libros escolares y juguetes", busca recuperar una de las influencias, de las enseñanzas y de las inspiraciones creativas que modificaron y siguen aportando nuevas visiones y creaciones en el mundo del arte y la arquitectura.

"Quizás el lector piense que es una historia ingenua", que resumir las intenciones creativas de grandes maestros como Frank Lloyd Wright o Eduardo Torroja Millet en una serie de obras aparentemente inspiradas en la papiroflexia o el origami es como poco tendencioso e incierto. Nada más lejos de la realidad, con esta investigación quiero resaltar con más fuerza el caleidoscópico mundo de la creación arquitectónica, rescatando del olvido, y mediante una exposición cronológica, semántica y descriptiva, las aportaciones conceptuales y morfológicas, que en el mundo de la arquitectura se dieron gracias al desarrollo y expansión de los conocimientos geométricos del pliegue.

\footnotetext{
${ }^{45}$ Bordes Caballero, Juan. (2007) La infancia de las vanguardias. Cátedra Ediciones. Madrid. ISBN: 978-84-376-2426-6.
} 


\section{Bibliografía del capítulo INTRODUCCIÓN}

\section{- APROXIMACIÓN CONCEPTUAL}

Angerer, Fred (1972) Construcción laminar. Elementos y estructuración, Barcelona: Gustavo Gili (Bauten mit tragenden flächen konstruktion und gestaltung, 1960).

Deleuze, Gilles. (1989) El pliegue. Leibniz y el Barroco, Edit. Paidós Básica, España.

Eisenman, Peter (Enero 1992) Visions Unfolding: Architecture in the Age of Electronic Media. Domus No. 734.

Engel, Heino (1970). Tragsysteme, Structure Systems. (Sistemas de estructuras) Trad. Fernando de Aguirre e Yraola, Juan Batanero García/Geraldo. Edit. Blume, 1970. Madrid, España. pp 214 capítulo Superficies Activas

Escrig, Félix et Sanchez, José. (2002) Mobile and rapidly assembled architecture. Arquitectura móvil y de rápido montaje. Star Structural Architecture 1. Editorial Starbooks. ISSN: 1137-201 X

Faber, Colin (1963) Candela: The Shell Builder. New York Reinhold Publishing Corporation.

García, García. Rafael. (enero-marzo 2013) Dos décadas de estructuras plegadas de hormigón. Inicio y ocaso de un movimiento. Informes de la Construcción, Vol. 65, 529, 27-39, ISSN: 00200883. eISSN: 1988-3234. doi: 10.3989/ic.11.083.

García, García. Rafael (2011) Usos sutiles de la construcción laminar. Ejemplos en los maestros de la arquitectura moderna. Actas del Séptimo Congreso Nacional de Historia de la Construcción, Santiago 26-29 octubre 2011, eds. S. Huerta, I. Gil Crespo, S. García, M. Taín. Madrid: Instituto Juan de Herrera, 2011 pp 496

Gausa, Manuel. Guallart, Vicente. Müller, Willy et all. (2002) Diccionario Metápolis de Arquitectura Avanzada. Actar Editorial, Barcelona., ISBN: 8495273934.

Lister, David. (20 de Marzo de 2005) History of Origami: outline suggestions for a basic, essential history. Fuente: British Origami Societ; http://www.britishorigami.info/

Lynn, Greg. (1993) Folding in Architecture. Números 1 a 4, Volúmen 63 de la revista Architectural Design. Academy Editions. Wiley-VCH Publishers. Londres.

Moussavi, Farshid et Kubo, Michael (2008) La función del ornamento. Ed. Actar. Barcelona.

Moussavi, Farshid. (2009) The Function of Form. ACTAR, Harvard Graduate School of Design.

Sancho, J. Carlos et Madridejos, Sol. (2001) Sancho / Madridejos, Suite en 3 movimientos. Editorial Rueda, Madrid.

Verb ACTAR (octubre 2001) Architecture Booganzine. Edit. Actar. Roca i Batlle 2, Barcelona. pp.1718.

Vyzoviti S. et De Souza P. (2012) Origami Tessellations in a Continuum. Integrating design and fabrication in architectural education. pag 165-175. Transactions on Architectural Education No59. European Association for Architectural Education. EAAE. Münster. 


\section{- METODOLOGÍA HISTÓRICA, DE CASO Y EXPERIMENTAL}

Angerer, Fred (1972) Construcción laminar. Elementos y estructuración, Barcelona: Gustavo Gili (Bauten mit tragenden flächen konstruktion und gestaltung, 1960).

Bordes Caballero, Juan (2007) La infancia de las vanguardias. Cátedra Ediciones. Madrid. ISBN: 978-84-376-2426-6.

Cuvardic García, Dorde (2012) El flâneur en las prácticas culturales, el costumbrismo y el modernismo. Éditions Publibook. 14, rue des Volontaires 75015 PARIS - France pp17-18

Engel, Heino. (1970). Tragsysteme, Structure Systems. (Sistemas de estructuras) Trad. Fernando de Aguirre e Yraola, Juan Batanero García/Geraldo. Edit. Blume, 1970. Madrid, España.

Gea, Juan Carlos (2006) Flaneur con causa o Tokyo refundado. Catálogo de exposición de fotografía de Ken-ichiro Suzuki: Nowhere in Tokyo. Fuente: http://www.enfocarte.com/6.29/suzuki/suzuki2.html 2016/12/05

Gray, Carole et Malins, Julian (1993, trad. 2013) Procedimientos / Metodología de Investigación para Artistas y Diseñadores. The Centre for Research in Art \& Design. Gray's School of Art, Faculty of Design, The Robert Gordon University, Aberdeen, Scotland, UK. pp. 6

Groat, Linda; Wang, David (2013) Architectural Research Methods. John Wiley \& Sons, Inc., Hoboken, New Jersey. ISBN-13: 978-0750658515 pp 15

Maya, Esther (2014) Métodos y técnicas de investigación. Una propuesta ágil para la presentación de trabajos científicos en las áreas de arquitectura, urbanismo y disciplinas afines. Facultad de Arquitectura. Universidad Nacional Autónoma de Mexico.

Madrazo, L.; Avellaneda, J.; Gonzalez, J.M. (2006) Bar_Code housing system: la creación de un espacio interdisciplinar en torno al proyecto de arquitectura. Segundas Jornadas sobre Investigación en Arquitectura y Urbanismo. Universitat Politècnica de Catalunya. Escola Tècnica Superior d'Arquitectura del Vallès

Montero, Ignacio; León, Orfelio G. (febrero-marzo, 2002) Clasificación y descripción de las metodologías de investigación en Psicología. International Journal of Clinical and Health Psychology, vol. 2, núm. 3, pp. 503-508. Asociación Española de Psicología Conductual. Granada, España

Munárriz Ortiz, Jaime (2013) Investigación y tesis doctoral en Bellas Artes. Universidad Complutense de Madrid. España.

Salvadori, Mario. et al (1980) Why buildings stand up: the strength of architecture. W. W. Norton. New York. 
La papiroflexia didáctica: Friedrich Fröebel.

Patrones de pliegue estructurales: La Bauhaus.

La papiroflexia matemática y los juegos de construcción.

Abstract Origami: Origami rígido, curvo, modular y en mosaico

\section{EL PLIEGUE EN LAS PUBLICACIONES DEL S. XX Y XXI}

Modelos y casos en las publicaciones periódicas de arquitectura.

El pliegue moderno y su divulgación en textos didácticos.

\section{EL PLIEGUE COMO CONCEPTO ARQUITECTÓNICO}

Vivir en lo oblícuo.

El pliegue y el barroco. La autonomía del espacio interior

Curvilinealidad arquitectónica: lo plegado, lo flexible y lo elástico.

Pliegues, repliegues, despliegues.
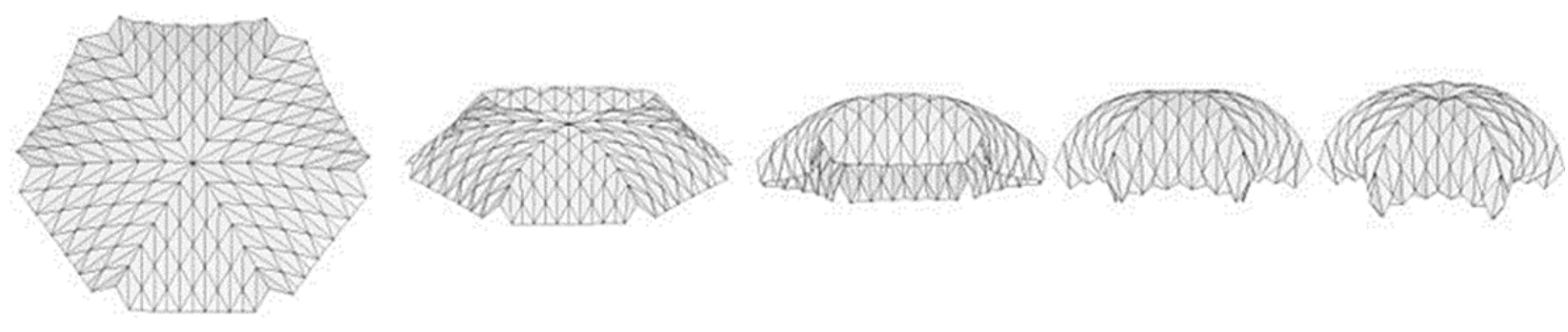


\subsection{DEL ORIKATA AL ORIGAMI}



21. Mujeres jugando a realizar diferentes figuras tradicionales de Origami

Xilograbado sobre papel. Autor y año desconocido. Posiblemente siglo XIX.

Fuente: Art Club Blog. Origami History.

http://artclubblog.com/about/origami-history-folding-tips-paper-shops/ 


\section{De los pliegues ceremoniales al arte lúdico del origami japonés.}

Como nos relata la Enciclopedia del Origami de Nick Robinson ${ }^{46}$, la primera referencia que tenemos del uso del doblado de papel por motivos estéticos y simbólicos se encuentra en "La historia del Príncipe Genji". Datada alrededor del año 1000 en el período Heian, está escrita por Murasahi Shikibu y en ella se describen los delicados y significativos plegados de esmerados papeles utilizados para escribir cartas de amor, felicitaciones y poesías.

Durante el período Kamakura (1183-1333) se popularizaron los Shide y los Noshis, ofrendas religiosas de alimentos que se colocaban envueltas en cintas y papeles de colores esmeradamente doblados en los templos budistas y en los objetos festivos.
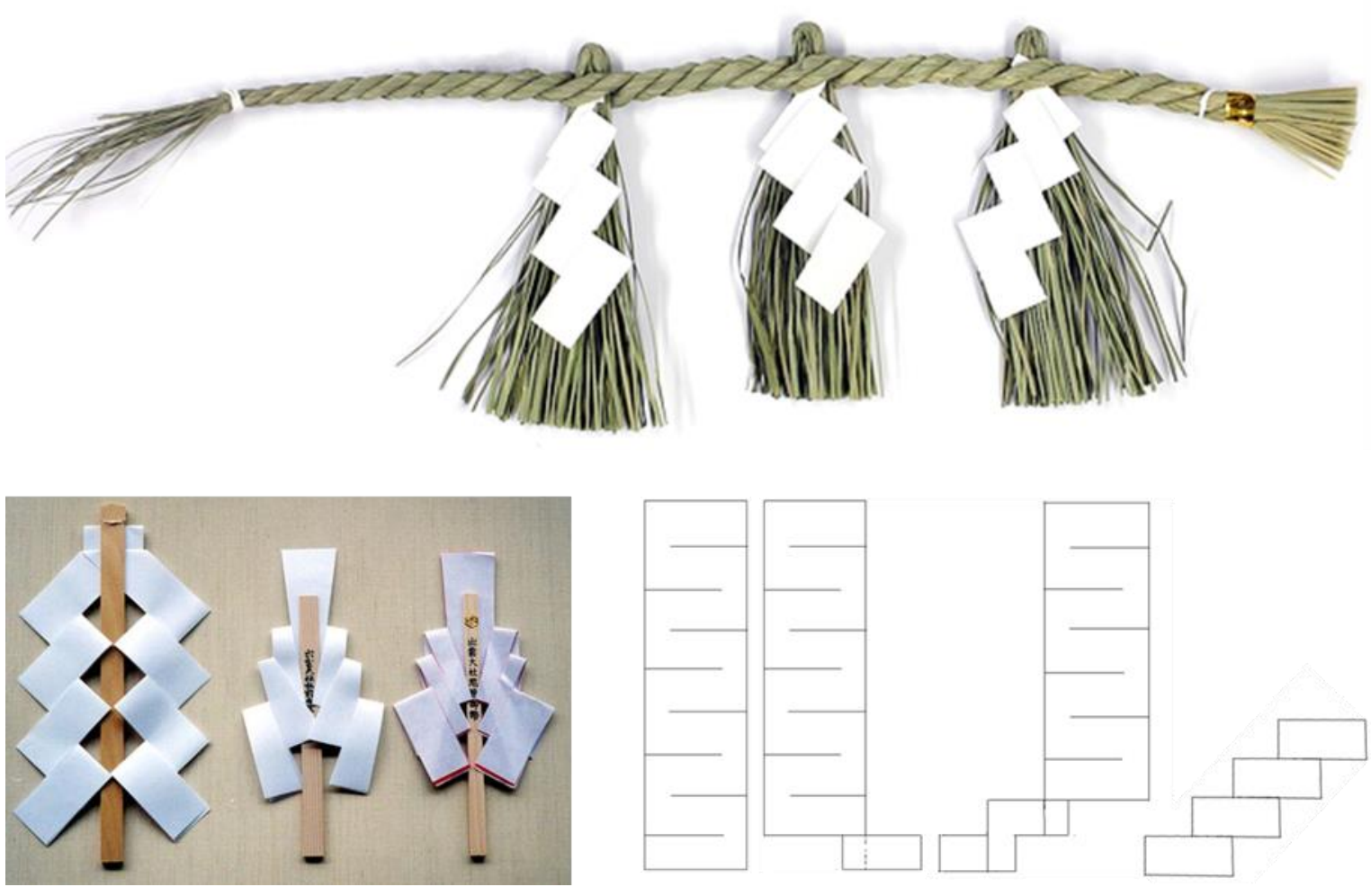

22. Tiras de Shide envolviendo un Gohei y patrón de plegado.

Fuente: Takemoto, Timothy. (2009) Shinto Ritual in words and Pictures. Master Thesis.

Web Nihon Bunka. Japanese Culture on the Internet. http://www. nihonbunka.com/shinto/

Los Shide son tiras de papel plegadas en forma de zig-zag que se pueden enlazar a una cuerda de paja para designar lugares sagrados (Shimenawa), o atar a una vara de madera llamada Gohei para utilizarse en rituales Sintoistas de purificación. La técnica de plegado puede considerarse un adelanto de lo que hoy en día se conoce por kirigami pues combina el corte y pliegue de papel.

Las diferentes festividades rurales tradicionales y religiosas, que hoy en día se continúan celebrando en Japón para conmemorar los cambios de las estaciones, se asocian a una cultura que valora en gran medida la formalidad y las buenas maneras en la presentación y constituyeron parte esencial para mostrar las maneras formales y el sentido del decoro

\footnotetext{
${ }^{46}$ Robinson, Nick (2005). Enciclopedia de Origami: guía completa y profusamente ilustrada de la papiroflexia Barcelona: Editorial Acento. ISBN 978-84-95376-62-6.
} 
de la sociedad marcial del periodo Muromachi comprendido entre los siglos XIV a XVI, de este modo, la elección del papel y su plegado debían estar en consonancia con el mensaje que representaban tanto religioso, como conmemorativo o personal.

Fue en esa época Muromachi ${ }^{47}$ cuando se desarrolló la costumbre de envolver bellamente los regalos en papel, costumbre del plegado decorativo, llamado orikata u origata. Este arte se transmitió de padres a hijos de generación en generación que, inspirándose en figuras de la naturaleza, fue enriqueciéndose en variabilidad formal.
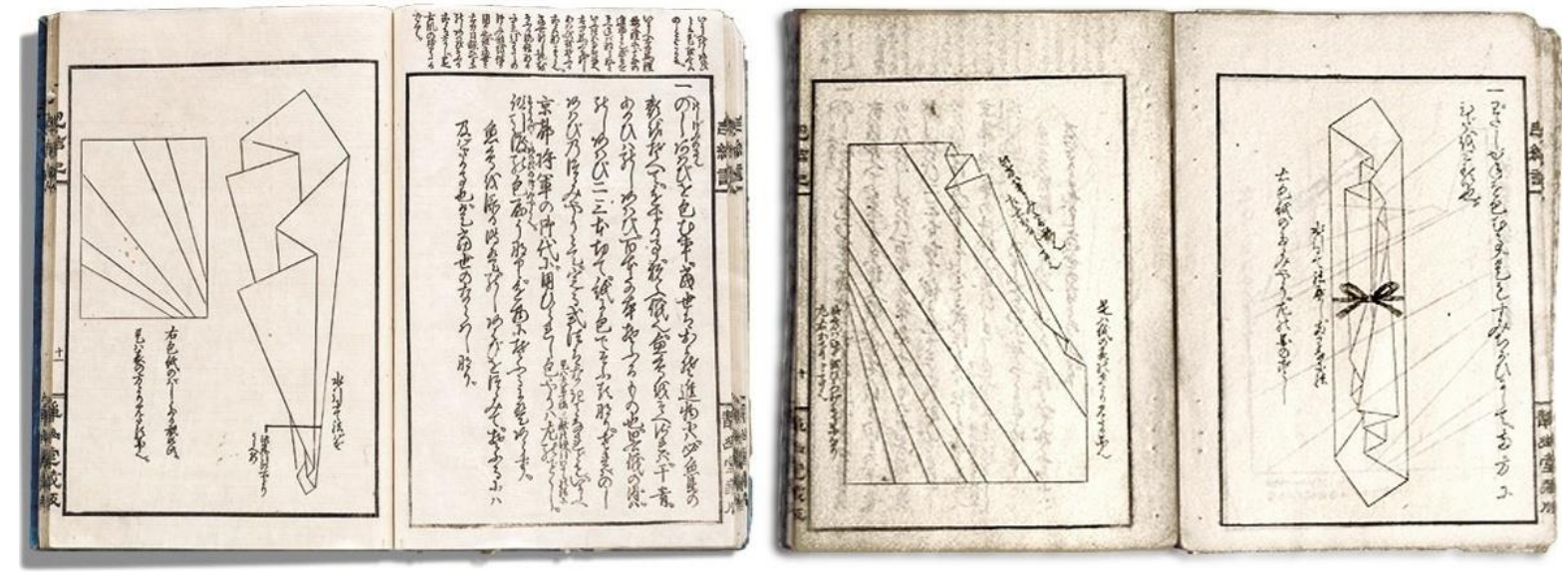

23. Páginas del libro Hoketsuki. (Cómo envolver y atar).

Autor: Ise Sadataka. 1764

Fuente: Origata Design Institute, Nobuhiro Yamaguchi. http://www.origata.com/. 48

Según el Origami Resource Center ${ }^{49}$ el primer libro publicado conocido dedicado íntegramente a métodos de pliegue de papel data del año 1764. El libro "Tsutsumi-no Ki", también citado con el nombre de "Hoketsuki" por el Instituto de Diseño Origata ${ }^{50}$, fue escrito por Sadatake Ise (1717-1784), un prolífico escritor de extensos libros que detallaban las normas de etiqueta y las tradiciones japonesas.

Sadatake fue el jefe de la familia Ise, cuyos miembros fueron consejeros en asuntos de etiqueta en el shogunado de Edo, actual Tokio. Y en el libro Hoketsuki nos muestra una colección de métodos de plegado de objetos sagrados, con bellas instrucciones ilustradas para la realización de trece pliegues ceremoniales conocidos por Tsutsumi.

El libro Hoketsuki inspiró a numerosas publicaciones durante los Siglos XVIII y XIX que mostraban diferentes técnicas para envolver paquetes junto a hermosos textos e ilustraciones que explicaban cómo hacer decoraciones formales. Así el plegado orikata se desarrolló hasta convertirse en un pasatiempo habitual iniciando lo que ahora conocemos como el arte del origami. ${ }^{51}$

\footnotetext{
47 Tokio Origami Museum. History of Origami. NIPPON ORIGAMI ASSOCIATION Co. Fuente: http://www.origami-noa.jp/

${ }^{48}$ NIPPONIA No. 41 (15 de junio, 2007) El libro "Hoketsuki" de 1764, es Propiedad del Instituto de Diseño "Origata". Fuente: www.web-japan.org

${ }^{49}$ Origami Resource Center. http://www.origami-resource-center.com/history-of-origami.html

${ }^{50}$ NIPPONIA No. 41 (15 de junio, 2007)

${ }^{51}$ Lister, David. (20-03-2005) History of Origami: outline suggestions for a basic, essential history.

British Origami Society; http://www.britishorigami.info/
} 

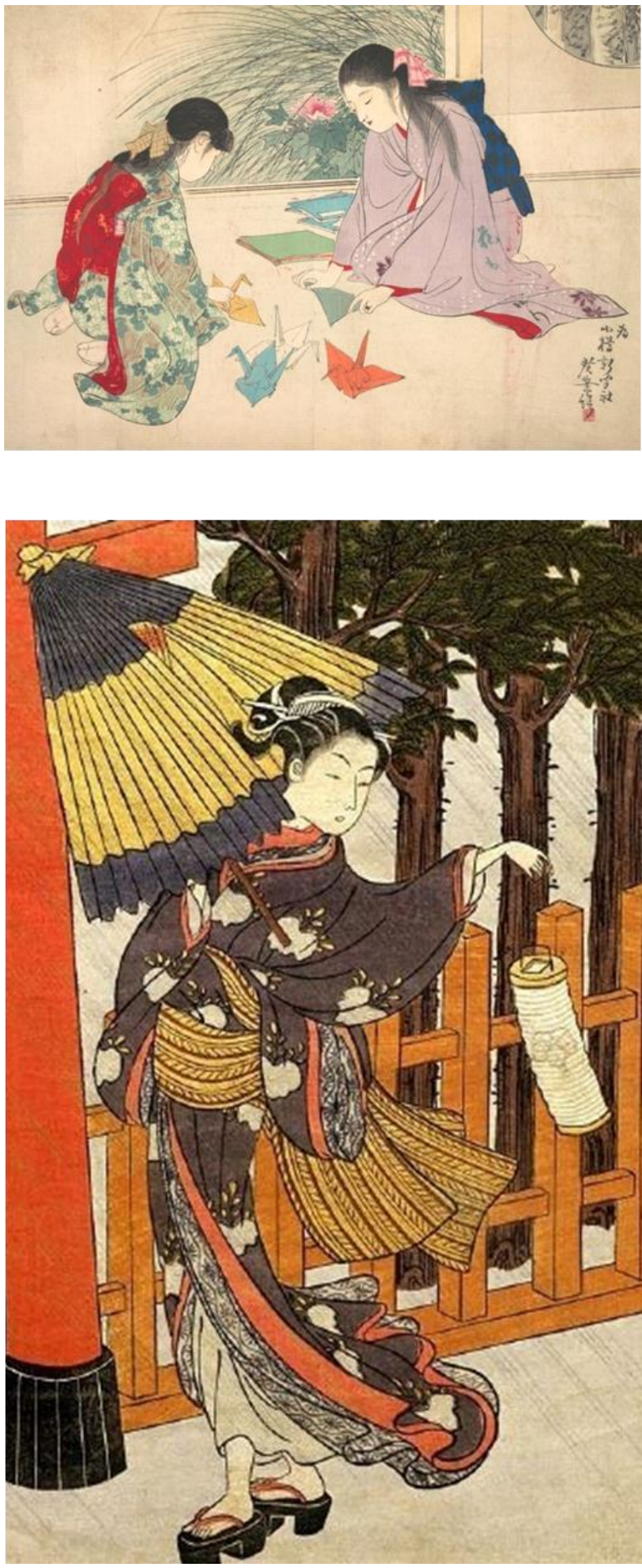

24. Young Girls Making Paper Cranes. (1906).

llustración en la que se muestra a dos niñas jugando a hacer grullas de papel realizada con xilograbado y tinta sobre papel. Autor: Terazaki (1866-1919). Fuente: The Metropolitan Museum of Art. New York. http://metmuseum.org/collections

La fabricación de papel en Japón se realizó inicialmente a partir de la corteza del Kozo y el Gampi, arbustos de origen oriental de la familia de las moreras. Las fibras extraídas de la corteza interna de la planta son largas y sedosas y mediante la superposición de capas y la colocación de las fibras en diferentes direcciones se consiguió un papel lo suficientemente resistente y a la vez translúcido que ofrecía múltiples utilidades para la construcción de objetos de la vida diaria.

Este papel, llamado Washi, sirvió para la fabricación de las tradicionales puertas correderas Shoji, que cierran formalmente los espacios habitables manteniéndolos comunicados gracias a su ligera transparencia que permite pasar suavemente la luz, los farolillos Chochin, las lámparas Andon ${ }^{52}$ y las sombrillas Wagasa, objetos ampliamente utilizados a partir de finales del siglo XII ya que, gracias a su consistencia, aguantaban el repetido plegado y desplegado requerido. De este modo el uso del papel Washi se popularizó hasta servir para construir figuras en papel.

25. Woman visiting the shrine in the night Detalle del Xilograbado:

Mujer visitando un santuario por la noche. Harunobu, Suzuki. Siglo XVIII. Japón.

Fuente: Tokio National Museum

${ }^{2}$ NIPPONIA No. 41 (15-06-2007)

Reportaje Especial Origami. http://web-japan.org/nipponia/nipponia41/es/feature/feature01.html 

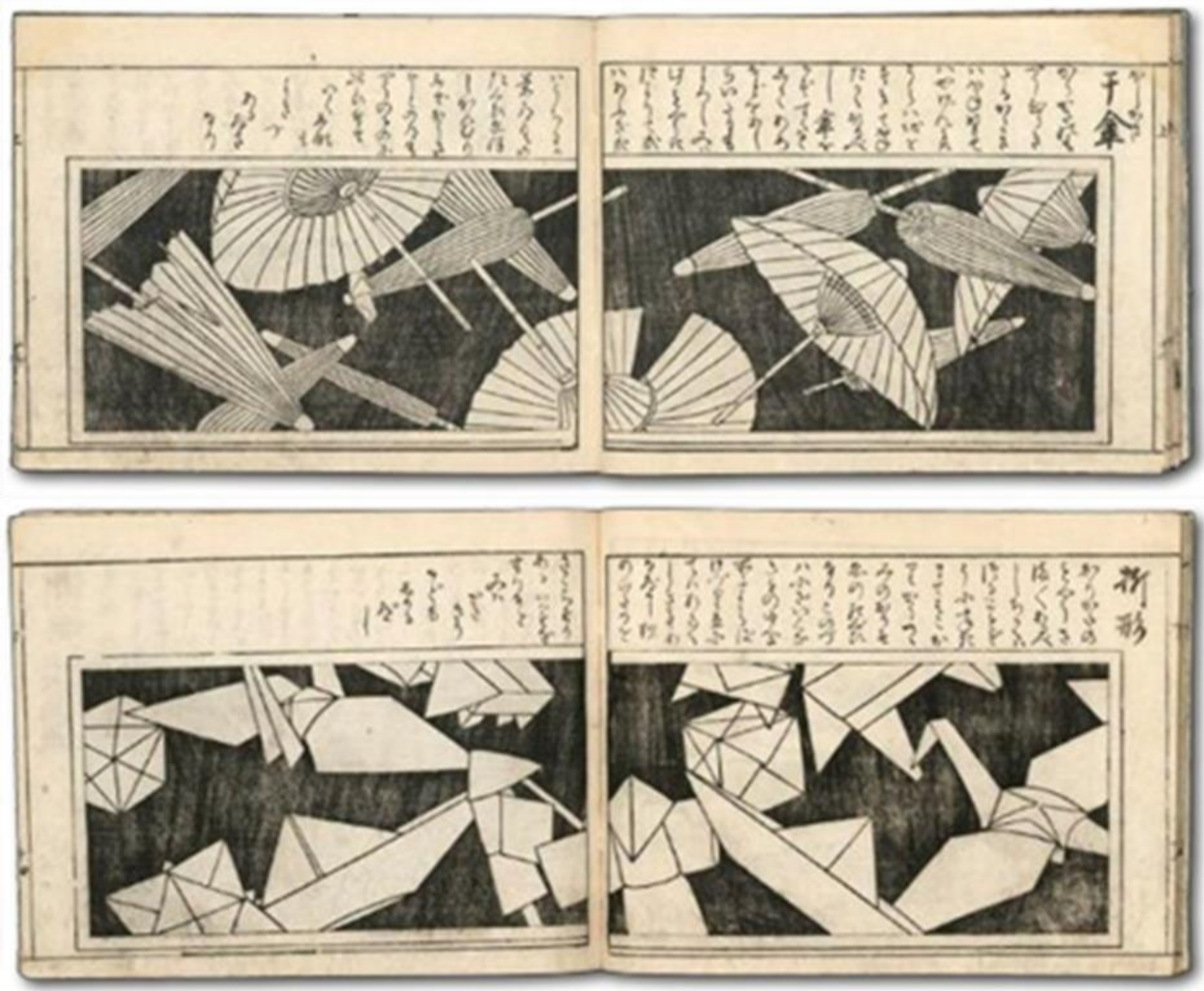

26. Ranma zushiki (diseños para paneles decorativos).

Shunboku, Ôoka (1680-1763) Periodo Edo, sobre 1734. Xilograbado en tinta negra sobre papel.

Fuente: Museum of Fine Arts Boston.

http://www.mfa.org/collections/object/ranma-zushiki-designs-for-decorative-transoms-493254

El libro Ranma Zushiki de Shunboku Ooka publicado en 1734 y realizado con la técnica del xilograbado, muestra diferentes diseños para paneles decorativos entre los que se encuentran varias láminas que representan objetos realizados en papel, algunos tradicionales como las sombrillas Wagasa y otros claramente identificables con diseños de origami como son el barco, la grulla, etc.

Sobre estos diseños llama la atención una serie de representaciones de un cubo y sus pliegues modulares conocido con el nombre de tamatebako o baúl mágico. De muy compleja elaboración, este cubo se considera uno de los primeros modelos de origami modular derivado del plegado triangular Menko.

En la página siguiente se muestra la complejidad de este plegado el cual se diferencia del tradicional diseño waterbomb recogido por Isao Honda ${ }^{53}$ en su primer libro sobre origami de 1931.

\footnotetext{
${ }^{53}$ Honda, Isao (diciembre 1931) "おりがみ. 上" [On Origami] Japan Toy Association. Tokyo.

El reconocido historiador de origami David Lister de la British Origami Society recoge 26 libros publicados por Isao Honda en inglés y 8 publicaciones en japonés. El presente libro sería, según David Lister, el primero publicado por Honda.
} 

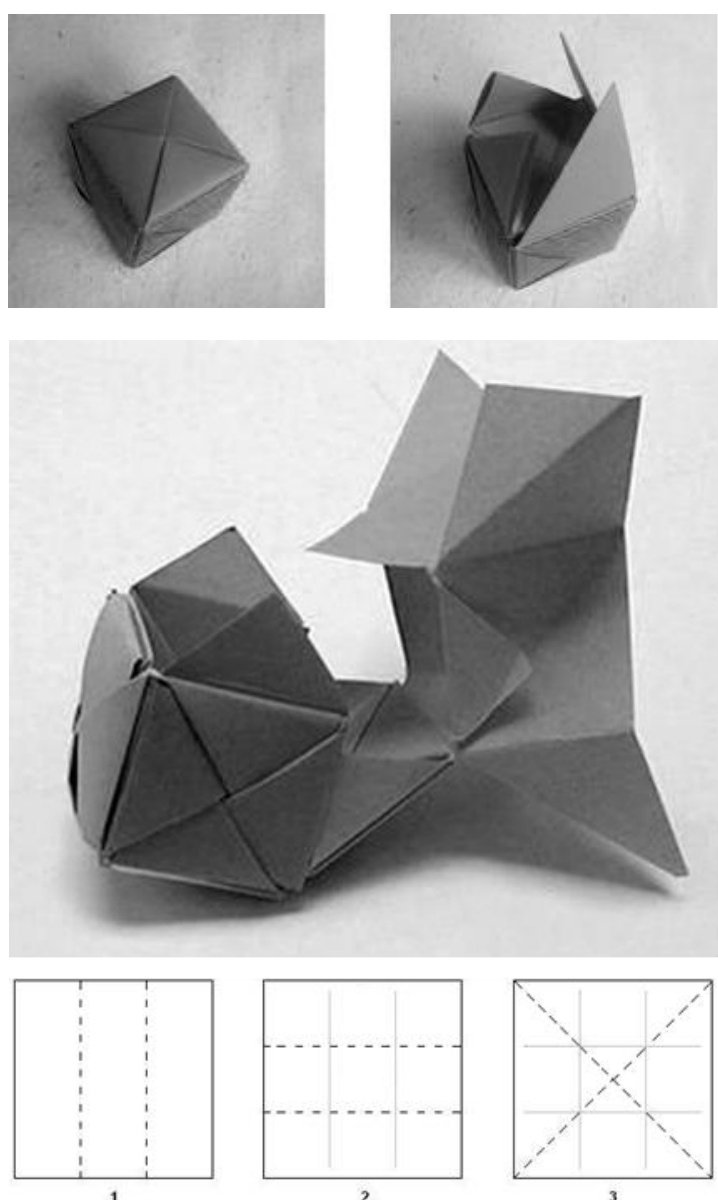

2
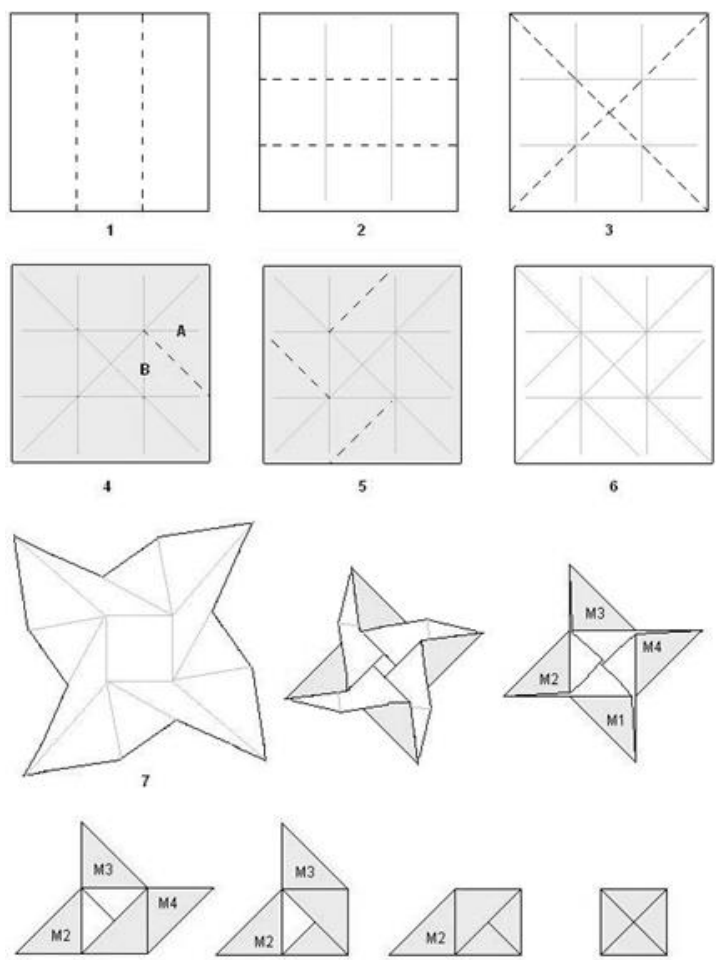

8
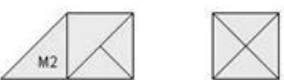
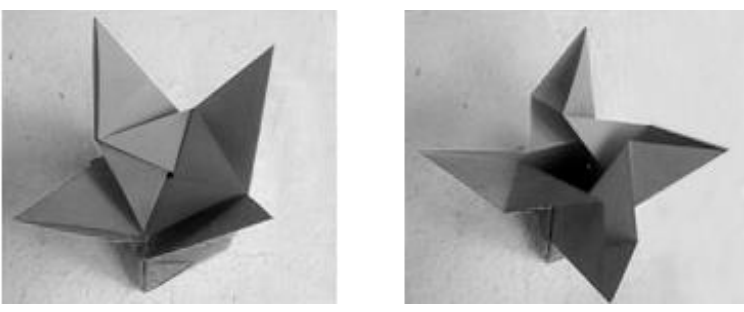

27. Despliegue de un Tamatebako

Autora: Eva Duarte, 18/08/2008

Fuente: https://dobrinhas.wordpress.com/2008/08/18/batidasna-porta-da-frente-e-o-tempo-3/

28. An unglued Tamatebako coming apart Autor: Wombat1138. 13 de octubre de 2006 Fuente: https://en.wikipedia.org/wiki/Tamatebako
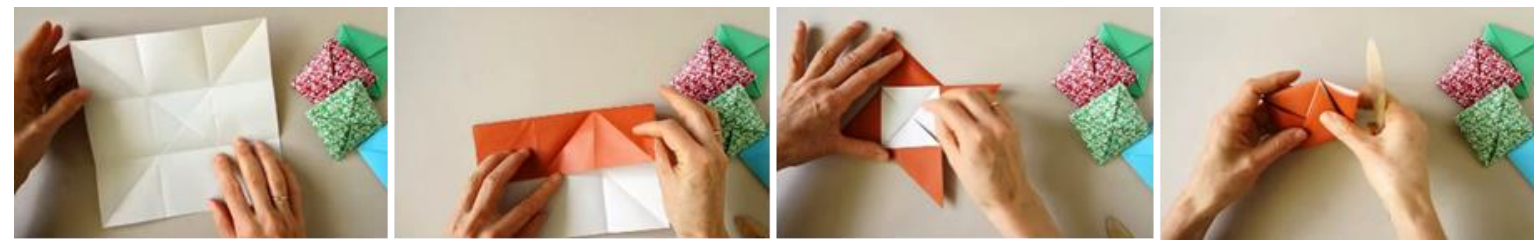


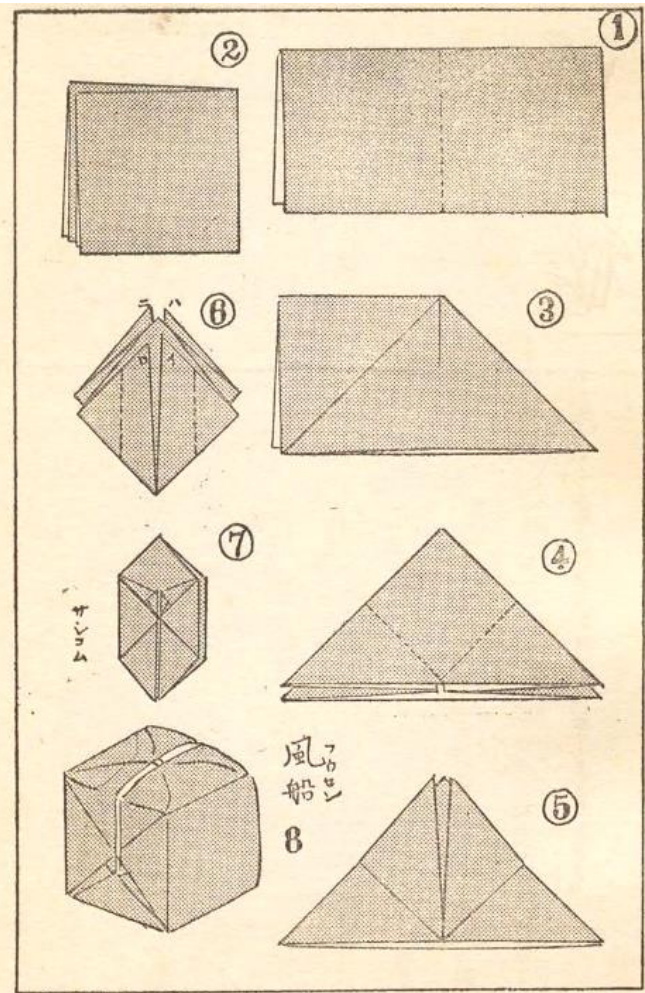

Hay pocas evidencias del uso lúdico de la técnica del pliegue de papel antes del siglo XVII. Pero a partir del siglo XVIII este arte se extendió ampliamente en la cultura Japonesa, de tal modo que, como podemos ver en publicaciones como el muestrario comercial Ranma Zushiki de mediados del siglo XVIII, se popularizaron los motivos decorativos de estampaciones para telas y paneles de papel sobre soportes de madera con figuras de origami, de Wagasas (sombrillas tradicionales de papel), o incluso de historietas que representaban gráficamente personajes como si hubieran sido realizados por medio del arte del origami.

31. Pliegue tradicional waterbomb. Isao Honda 1931

Fuente: Honda, Isao (diciembre 1931) "おりがみ. 上" [On Origami] Japan Toy Association. Tokyo. pp 35

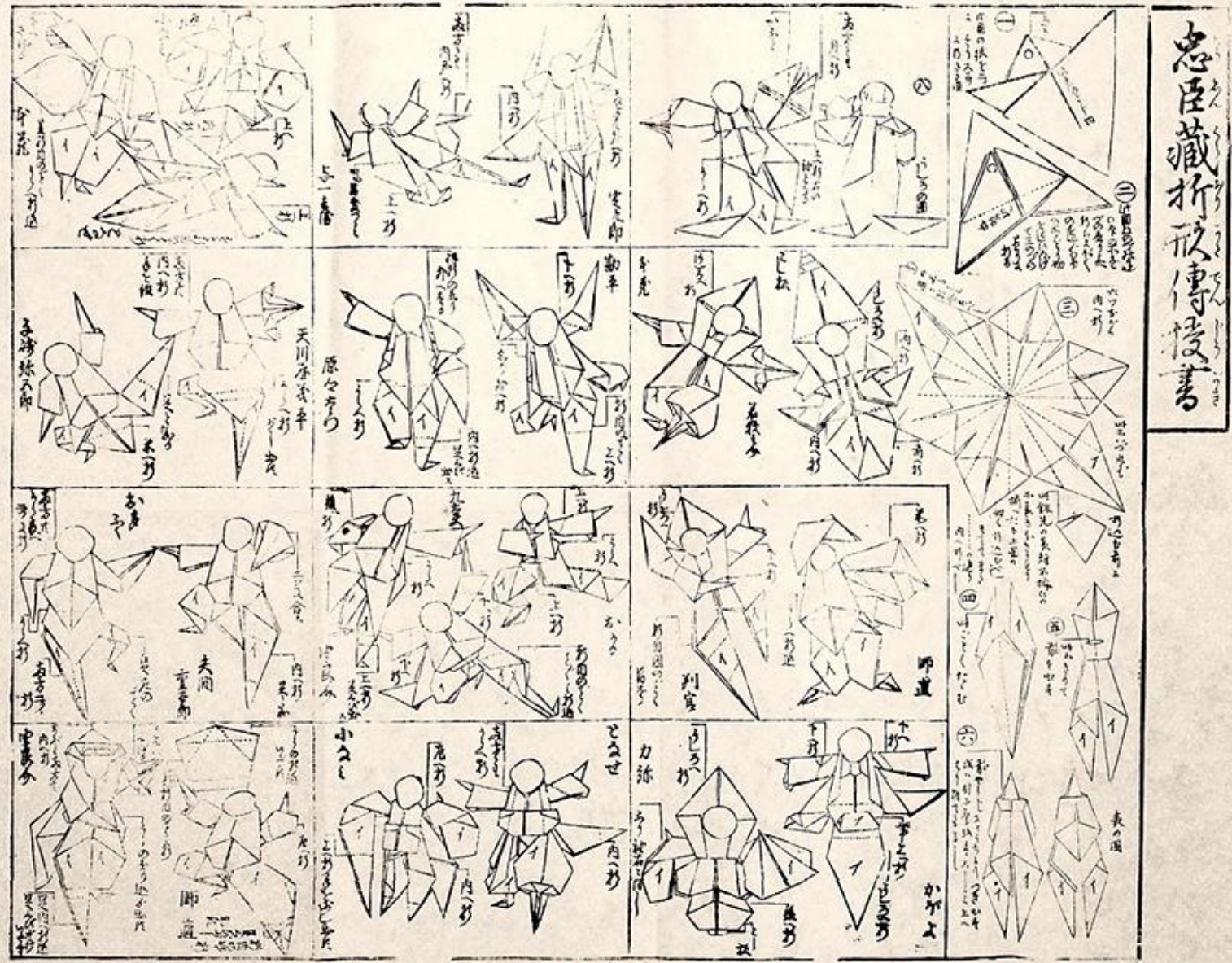

32. Xilograbado japonés representando una historia con figuras de origami.

"Shinsen person Origata model Chushingura" (Yoshinori collection)

Período Meiji. Siglo XIX

Fuente: Tokyo Origami Museum. http://www.origami-noa.jp/ 

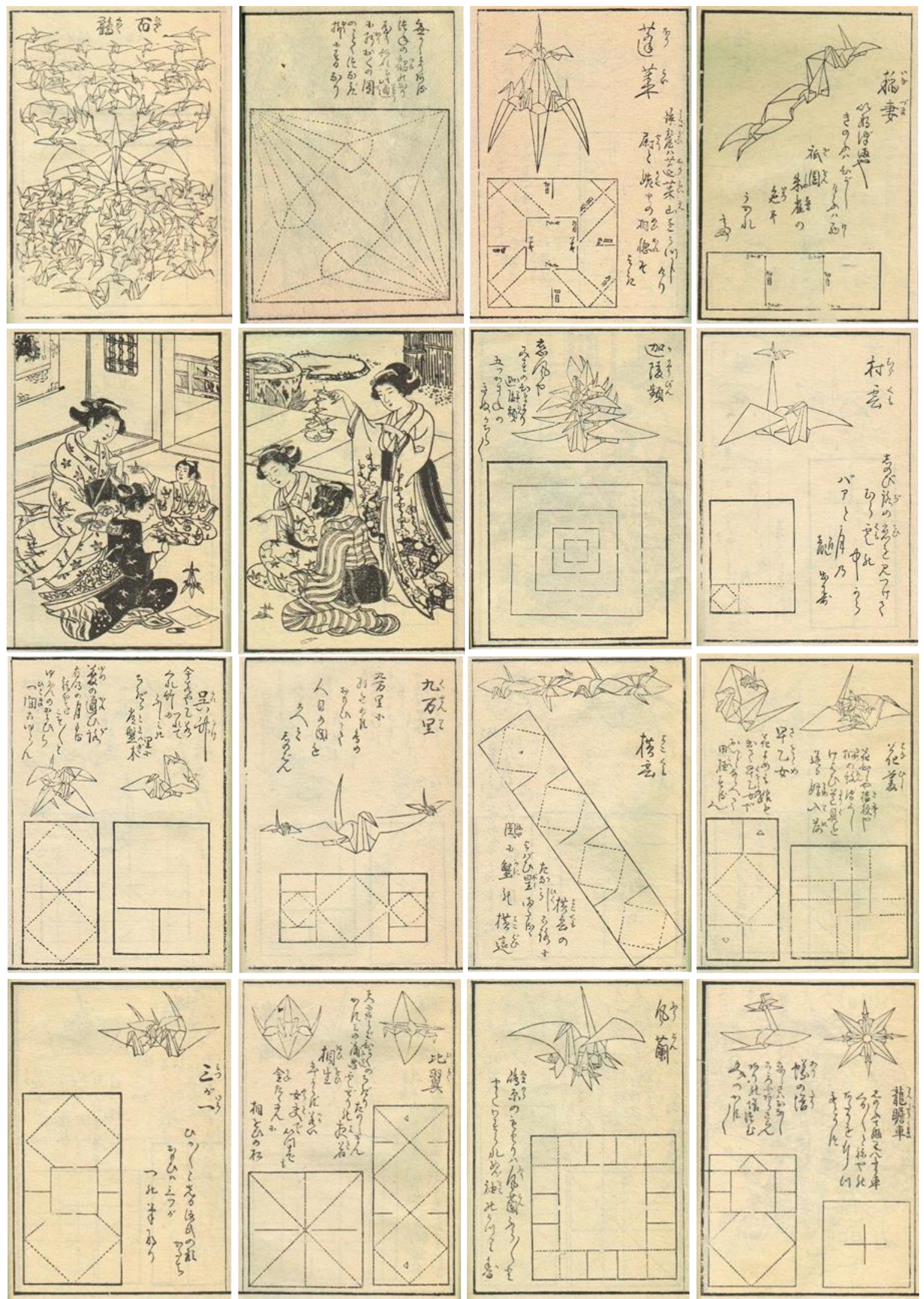

\section{Hiden Senbazuru Orikata}

Selección de páginas, de izquierda a derecha, de arriba abajo: 61, 7, 12, 15, 21, 22, 23, 27, 28, 29, 44, 46, 47, 50, 51, y 55. Enero de 1797. Autor desconocido, algunas fuentes citan a un monje roakan japonés.

Fuente: http://web.archive.org/web/20080501175749/origami.gr.jp/Model/Senbazuru/index-e.html 
Considerado el primer libro que se conserva con intrucciones de origami ${ }^{54}$, el Libro Hiden Senbazuru Orikata conocido en inglés por "The Secret (por la palabra Hiden, escondido) of One Thousand Cranes Origami", tendría su traducción al español en la expresión "El secreto de cómo hacer grullas con papiroflexia".

Explica cuarenta y nueve métodos para doblar grullas de papel de modo que queden juntas. La grulla está considerada un pájaro sagrado en Japón, es símbolo de salud y también de paz, como para la cultura occidental es la paloma blanca. Existe así una creencia popular en la que, si una persona pliega mil grullas, le será concedido un deseo. Así pues, este libro está considerado esencial para entender la base de la cultura tradicional japonesa y sus ilustraciones han sido ampliamente difundidas.

Impreso por la técnica del xilograbado consta de 63 páginas en las que intercala bellos dibujos de momentos lúdicos protagonizados por mujeres jugando a realizar las distintas combinatorias y constelaciones de grullas, con cuidados diseños de los patrones acompañados por las instrucciones de plegado.

Mediante concisos esquemas que parten del patrón inicial de plegado de una grulla, se sirve del kirigami (arte del plegado de papel en el que se hace una o varias incisiones o cortes en la superficie original) para, manteniendo la unión de las diferentes partes del papel, plegar las grullas creando diferentes agrupaciones ricas en variabilidad formal.

El libro Senbazuru Orikata supone un avance significativo en la creación de unos códigos gráficos que, aún faltos por depurar, tratan de exponer problemas complejos mediante la simplificación del patrón inicial de una grulla al representarlo en un cuadrado, fácilmente modulable, repetible y escalable.

Surgen así mapas de plegado que repiten el cuadrado inicial girándolo, invirtiéndolo, maclándolo... para conseguir múltiples y variadas composiciones de conjuntos de grullas unidas algunas veces por sus alas, picos, cola o cuerpo, formando complejas configuraciones de conjuntos de figuras encadenadas, invertidas, especulares, matriciales, escalares, etc.
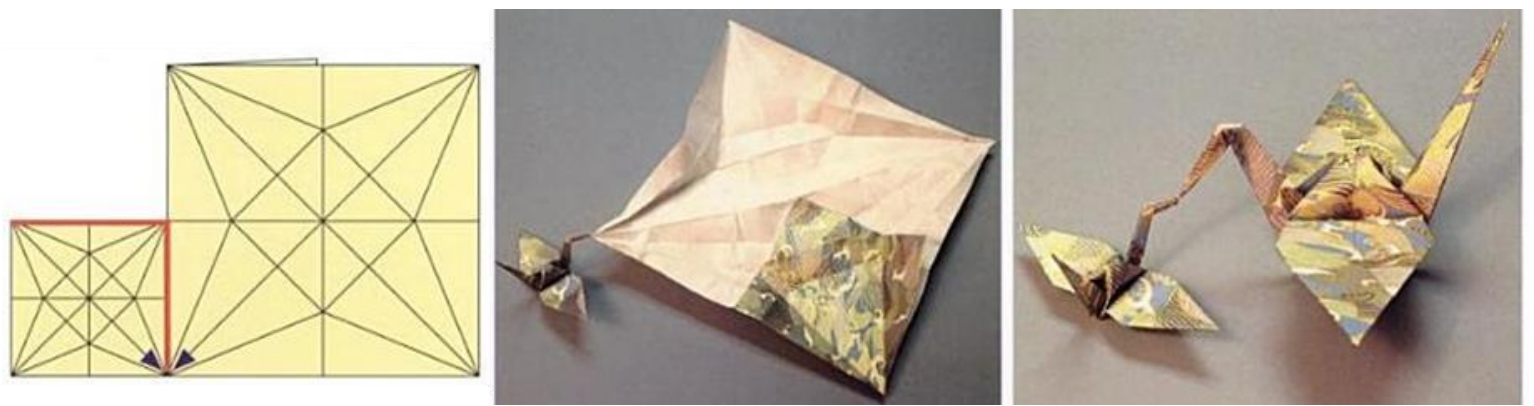

34. Detalle de plegado contemporáneo de dos grullas encadenadas.

Fuente: Japanese Paper Crafting: Create 17 Paper Craft Projects \& Make Your Own Beautiful Washi Paper

Michael G. LaFosse, Richard L. Alexander, Greg Mudarri

Tuttle Publishing, 2007. Página 59.

${ }^{54}$ Hatori, Koshiro (21-06-2011) History of Origami in the East and the West before Interfusion. Origami 5: Fifth International Meeting of Origami Science, Mathematics, and Education. A. K. Peters/CRC Press; ISBN-10: 1568817142. 

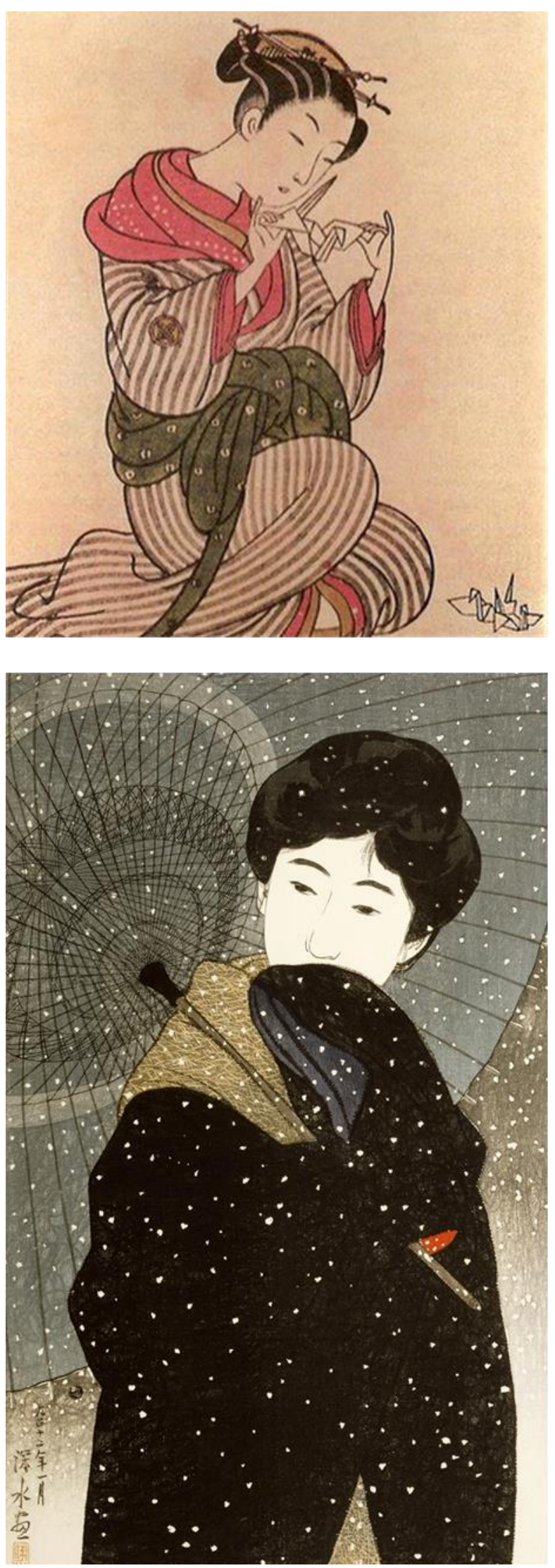

35. Detalle serigrafía japonesa.

Posiblemente de finales del S. XIX

Autor desconocido.

Fuente: Origami IN UA.

Las artes plásticas occidentales descubrieron las técnicas gráficas japonesas, estampaciones, grabados y litografías durante la Exposición Universal de París de 1878 que marcó un hito en la apertura cultural de Japón ${ }^{55}$. Los temas generalmente amables, de la vida cotidiana, de mujeres 0 paisajes, plasmados con excelsa y frágil belleza, expresaban plenamente el mundo efímero que el Ukiyo-e deseaba fijar por un instante: hojas mecidas por el viento, el movimiento de las olas del mar, el sutil plegado de una grulla, una ligera lluvia de copos de nieve, la suave iluminación de un farolillo de papel, un gesto detenido a medio camino, etc.

Mientras tanto, los trabajos en papel ahondaban en la reproducción de figuras animales, podemos suponer cargadas de la esencia del Ukiyo-e ${ }^{56}$, el contenido ligero, trasnslúcido, etéreo, simbólico, efímero que le aportaba el material con el que eran realizadas, pero también la abstracción geométrica con la que se construían.

36. Shinsui, Ito (1923) Snowy Night.

Twelve Figures of Modern Beauties.

Período Taisho. Xilograbado,

Fuente: Robert O. Muller Collection S2003.8.265

The Smithsonian's Museums of Asian Art. http://origami.in.ua/ru/system/files/1219042661 japan_girl.jpg

\footnotetext{
${ }^{5}$ NIPPONIA No. 41 (15-06-2007) www.web-japan.org

${ }^{56}$ Smith, John (1972). Notes on the History of Origami. http://www.nickrobinson.info/clients/smithy/history notes.php
} 
El pliegue de papel en China.

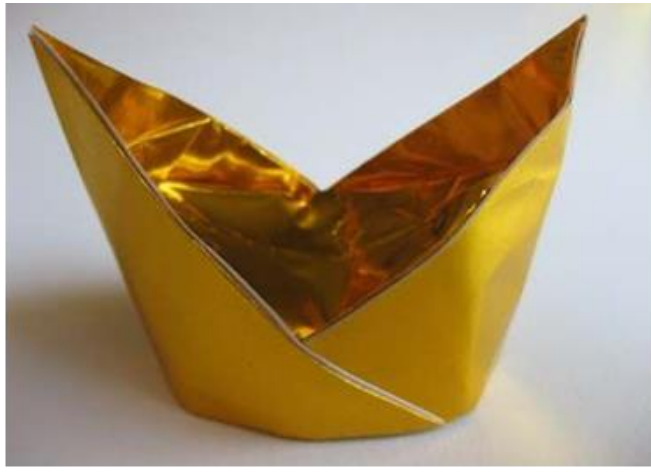

Al contrario que otras formas de arte, la historia del origami no es fácil de desvelar, ya que el papel se degrada rápidamente y no nos deja rastro de los objetos que nos puedan sugerir dónde se originó y quién inventó el plegado de papel por motivos estéticos, lúdicos o sagrados. Personalidades de la talla de David Lister, fundador de la British Origami Society ${ }^{57}$ y Lillian Oppenheimer, quien popularizara en los años 50 el término japonés Origami, exponen que el papel
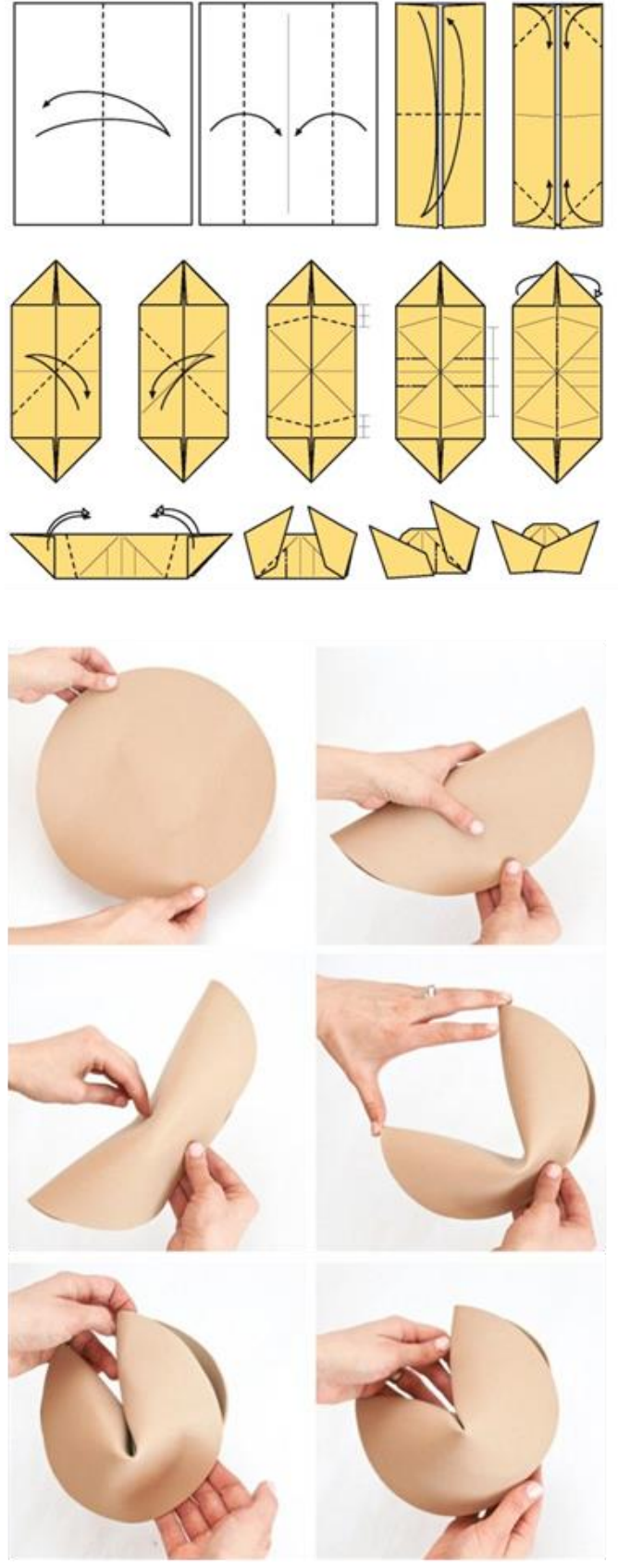
fue inventado en China por Cai Lun (también conocido por Ts'ai Lun) en el año 105 d.C. aunque, tal como recoge Koshiro Hatori en History of Origami in the East and the West before Interfusion 58 algunas evidencias arqueológicas actuales nos sugieren que pudo ser inventado en el 5000 a.C.

Hay muy pocos ejemplos históricos de objetos plegados con papel, el primer ejemplo lo tenemos en el Yuan Bao (pepita de oro en forma de barco), que es realizado en papel dorado y quemado como ofrenda a los difuntos. Esta tradición empezó probablemente en el año 1000 d.C. y continúa hasta hoy.

\section{Yuan Bao.}

Diagramas diseñados por Joseph Wu en 1998

Fuente: http://www.origami.as/home.html

Las tradicionales galletas de la fortuna de la cultura china son también un bello y sencillo ejemplo de pliegue en el que no se busca una representación figurativa sino, tal como ocurriera en el origata, en los inicios de esta tradición en Japón, son objetos con una función, que se representan a sí mismos sin necesidad de buscar una referencia externa. El origami chino se mantuvo durante siglos dentro de las coordenadas de pequeños objetos tradicionales. No se aprecia una evolución en este arte ni en el número de figuras, ni en el número de aplicaciones, ni de publicaciones realizadas.

${ }^{57}$ http://www.britishorigami.info/academic/lister/

${ }^{58}$ Hatori, Koshiro (2011) History of Origami in the East and the West before Interfusion. Origami 5. Fifth International Meeting of Origami Science, Mathematics and Education. Edited by Patsy Wang-Iverson Robert J. Lang and Mark Yim. 
Otra característica de la papiroflexia china es la cualidad volumétrica de estos objetos, la intención de adquirir volumen, de ensancharse y alojar espacio interior. Bajo estas líneas podemos ver, de izquierda a derecha, los conocidos ejemplos de la caja, el vaso, la bomba de agua y el bote cubierto.
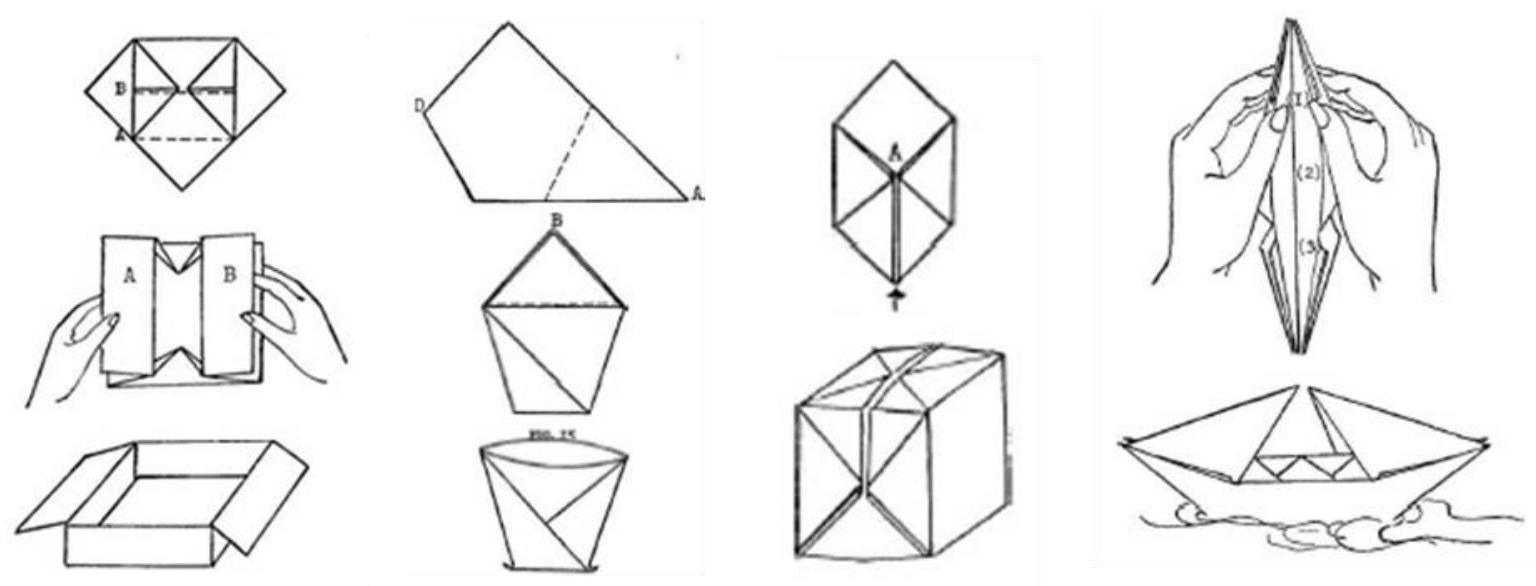

39. Ejemplos de Zhezhi u origami chino: la caja, el vaso, la bomba de agua y el bote cubierto

Hsi Soong, Maying (1948) The art of Chinese paper folding for young and old. Editorial Harcourt, Brace

Fuente: Edit. Artella. 2013. artellawordsandart.com

Tanto la caja y el bote cubierto alcanzan su forma final mediante empujes externos desde dos puntos contrapuestos. Mientras que el vaso adquiere su forma al empujar hacia adentro también por los dos extremos. El objeto con una característica más particular es la bomba de agua. Llamada así porque se conforma insuflándole aire a su interior y, una vez adquirido el volumen, se puede llenar de agua para ser lanzada a modo de bomba de agua en fiestas populares. Al ser diseños de objetos volumétricos que acogen un espacio al desplegarse mediante fuerzas externas, los pocos patrones chinos que se conservan tienen un atractivo especial para la realización de proyectos de arquitectura plegables. Bajo estas líneas se puede ver el prototipo de refugio para situaciones de emergencia del diseñador Doowon Suh realizado en policarbonato en Hong Kong en el año 2012 e inspirado en el patrón de la caja.
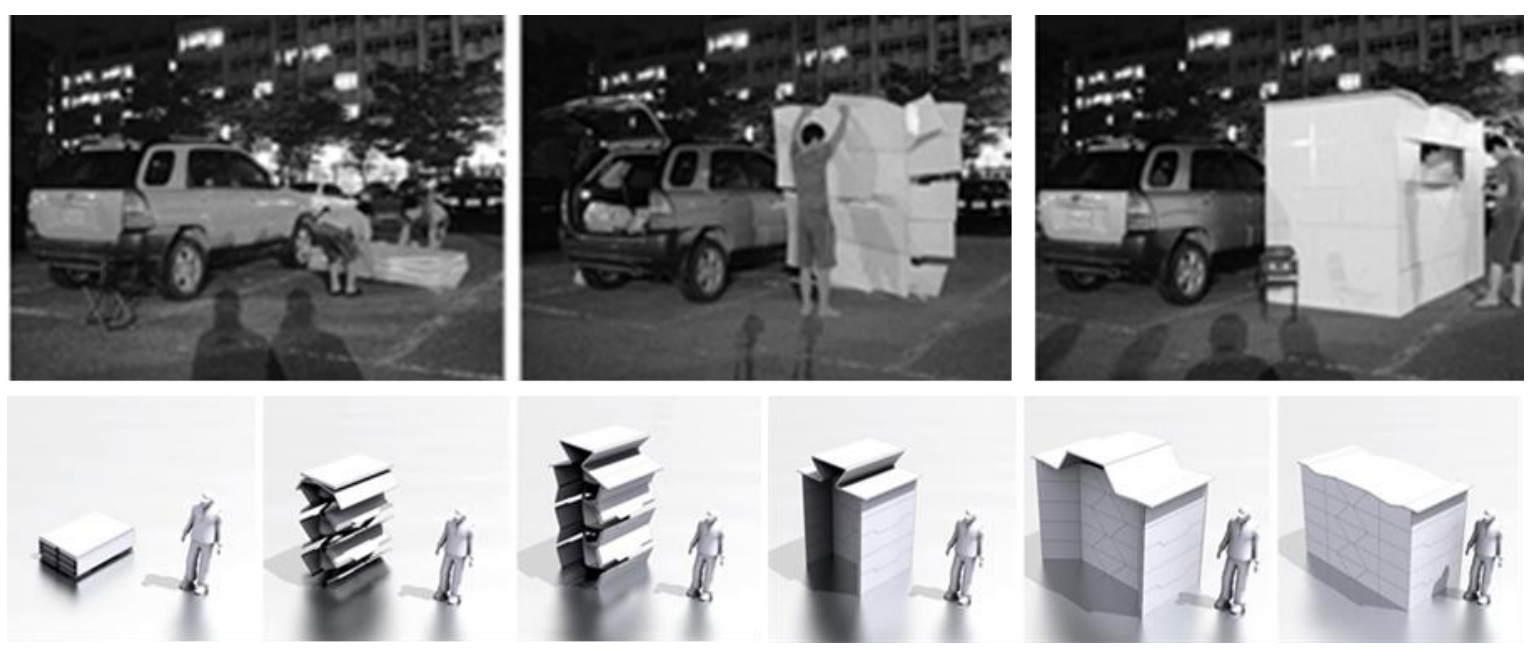

40. Origami Shelter. Doowon Suh. 2012

Fuente: Origami to the rescue! Troy Turner 08/02/2012

http://www.yankodesign.com/2012/08/02/origami-to-the-rescue/ 
Otro proyecto experimental de refugio para situaciones de emergencia inspirado en los modelos chinos es la propuesta del arquitecto David Ávila diseñada en 2008. Inspirado en la tradicional bomba de agua. Ávila sintetiza los mecanismos de apertura y cierre del modelo tradicional chino con una estructura metálica de aluminio que se recoge y pliega, facilitando el montaje y desmontaje de la vivienda. Además utiliza el patrón de pliegue del modelo de bomba de agua para distinguir las superficies resultantes y conferirles características materiales distintas al textil que las conforma. En al gunos casos utiliza el elementos textiles translúcidos, en otros opacos y en otros transpirables.
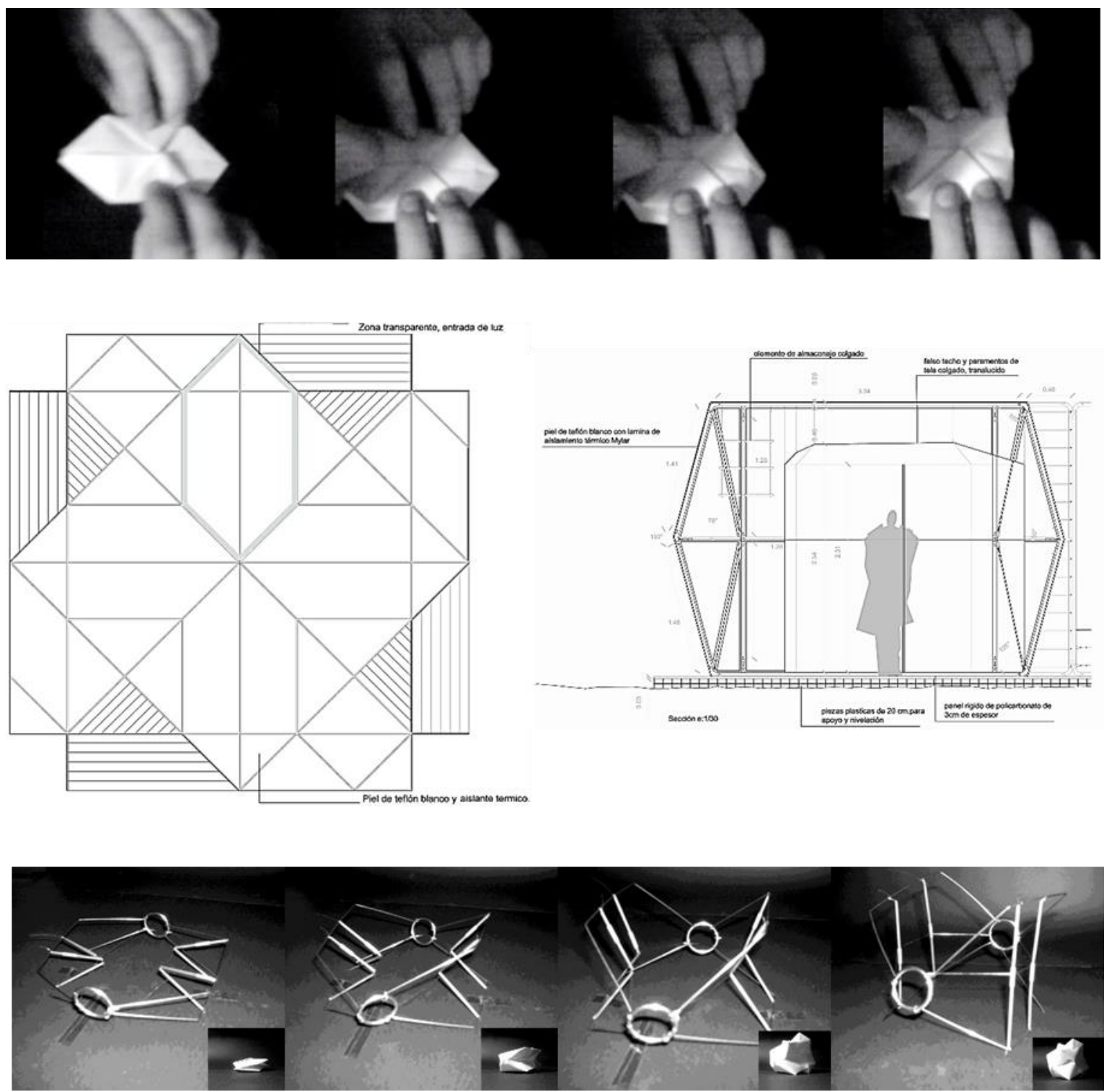

41. Proyecto de vivienda de emergencia inspirado en la base de origami chino Waterbomb Autor: Arquitecto David Ávila. 2008

Fuente: Fotografías y dibujos cedidos por el autor. 


\section{La tradición de plegado en Europa.}

Nick Robinson, en su Enciclopedia de Origami ${ }^{59}$, esboza los trazos de una nueva lectura de la historia de la papiroflexia en occidente en la que, citando a referencias del historiador y divulgador Francisco Palacios, se pueden ver las relaciones geométricas de los patrones tradicionales de origami chino con los occidentales a los que, desde España, se aportó con la conocida pajarita que popularizara Miguel de Unamuno en el siglo XX. Características como los patrones de ángulos rectos y diagonales de 45 grados, sobre superficies cuadradas sin cortes, construyendo, en general, objetos autorepresentativos que se utilizaban para guardar pequeños objetos o escribir mensajes. Para Palacios la papiroflexia inspira sus normas en Occidente, en la idea de creación de la nada. "No podemos crear -evidentemente- de la nada, pero sí de casi nada. En Oriente, desde antiguo fascinaba la contemplación de una hoja de papel con su perfección y aplicaban la imaginación y la habilidad para añadirle nuevo encanto". ${ }^{6}$

Según Robinson ${ }^{61}$, el arte de la fabricación de papel se extendió hacia occidente gracias al contacto entre la cultura árabe y la oriental, siguiendo la ruta de la seda. En el siglo XII los árabes establecieron la primera fábrica de papel de Europa en Játiva, España. A través de la ocupación árabe de Sicilia este conocimiento llegó a Italia. Extendiéndose, para la segunda mitad del siglo XIV, el uso del papel con fines literarios en toda Europa. El historiador Koshiro Hatori ${ }^{62}$ en su artículo sobre la historia del origami concluye que éste no se puede considerar un arte japonés, puesto que se desarrolló en paralelo y con característimas muy diferenciadas tanto en occidente como en oriente. Algunas pruebas avalan esta aseveración, pues disponemos de pruebas de publicaciones realizadas incluso antes de las realizadas en Japón. Debemos remontarnos a 1629 para descubrir la primera publicación conocida de diferentes grabados de plegados en acordeón claramente desvinculados de la tradición oriental. Didier Boursin ${ }^{63}$ cita el libro Li tre trattati publicado por Mattia Geigher donde se hace referencia a un banquete presidido por el Papa Gregorio XIII en 1572 en el que la mesa es decorada por bellas servilletas dobladas.
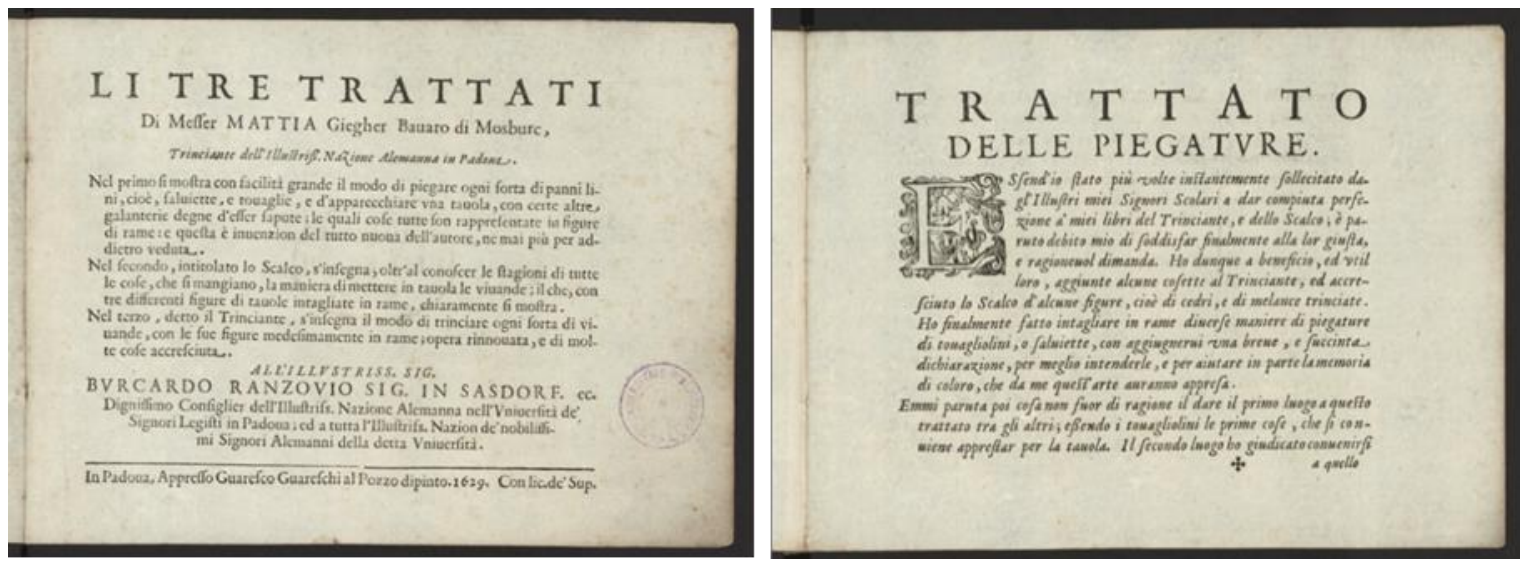

42. Portadas del libro y del Tratatto delle Pliegatture di Mattia Giegher, Padua 1639

Fuente: Universitätsbibliothek Basel. http://dx.doi.org/10.3931/e-rara-16355

\footnotetext{
${ }^{59}$ Robinson, Nick (2005). Enciclopedia de Origami: guía completa y profusamente ilustrada de la papiroflexia. Barcelona: Editorial Acento. ISBN 978-84-95376-62-6.

${ }^{60}$ Palacios, Vicente (2006) Papiroflexia, iniciación. Editorial Salvatella. Barcelona. ISBN 8484124399 página 3

61 http://www.nickrobinson.info/clients/smithy/history_notes.php

${ }^{62}$ Hatori, Koshiro (21-06-2011) History of Origami in the East and the West before Interfusion. Origami 5: Fifth International

Meeting of Origami Science, Mathematics, and Education. A. K. Peters/CRC Press; ISBN-10: 1568817142. pp 10

${ }^{63}$ Boursin, Didier (2004) Le pliage de serviettes. Edit. Divers ISBN-10: 2047201012.
} 

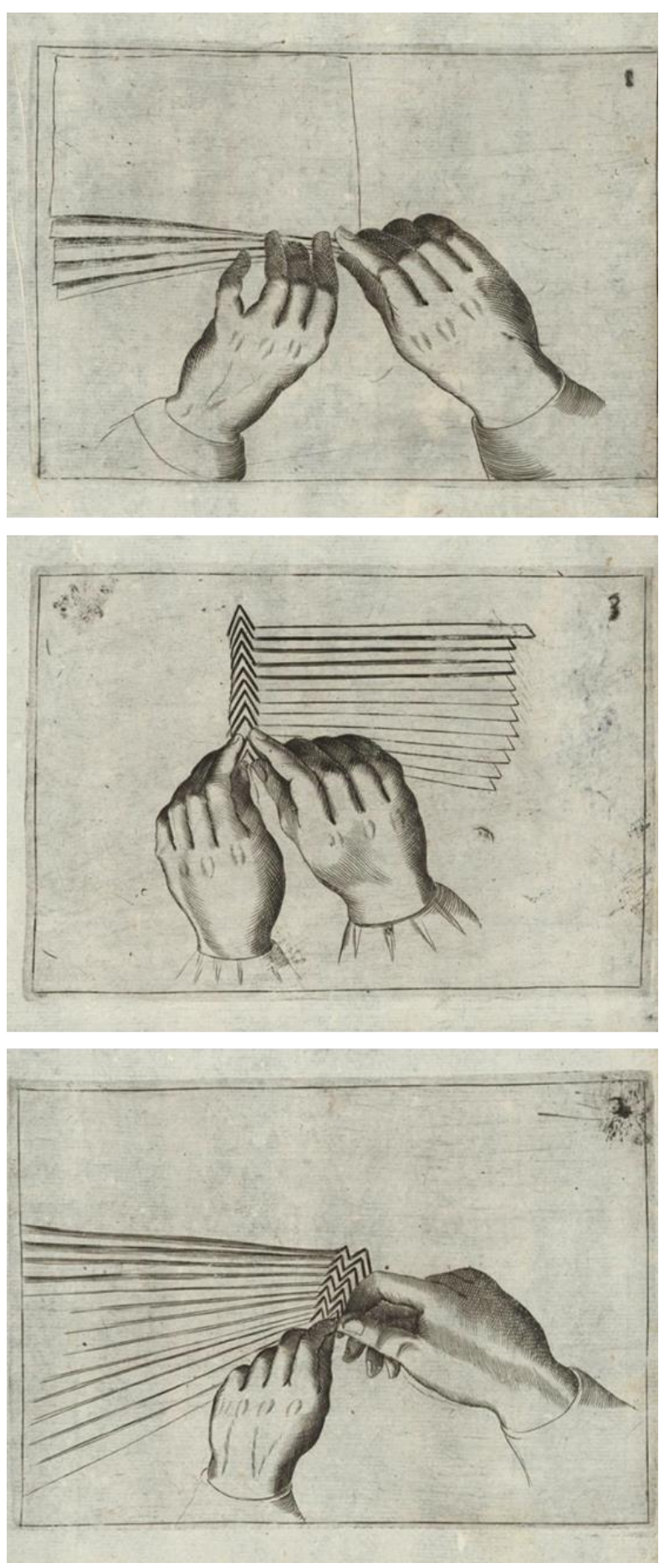

Geigher publicó Li tre trattati ${ }^{64}$ con un capítulo, Trattato delle piegature (Tratado de la plegadura), dedicado al plegado de servilletas. $Y$ enseñó esta técnica en la Universidad de Padua, utilizando el papel. El Tratatto delle Pliegatture es el primero de los tres tratados que Mattia Giegher publica conjuntamente sobre las buenas maneras de servir una mesa, del buen comer y buen trinchar, confiriendo gran importancia a la elegancia del plegado como signo de distinción y refinamiento. Los centros de mesa realizados mediante telas y papeles plegados tenían un sentido simbólico que era señalado por el anfitrión del banquete. Los objetos plegados tenían un objetivo comunicativo, y debían servir para fomentar el debate, comentarios y reflexiones de los invitados sobre temas mitológicos, históricos, filosóficos, etc.,

Estos grabados son la más antigua referencia gráfica al uso y publicación de técnicas de plegado para su enseñanza en nuevas aplicaciones, y hacen especial incapié en la enseñanza de la técnica del plegado sin especificar ninguna instrucción de plegado de algún modelo específico, los ejemplos se muestran para inspirar en que el lector desarrolle sus propios modelos con formas decorativas abstractas, animales y mitológicas mediante el doblado de servilletas de tela.

43. Grabados interiores del Tratatto delle Pliegatture di Mattia Giegher, Padua 1639.

Fuente: $\quad$ Universitätsbibliothek http://dx.doi.org/10.3931/e-rara-16355

${ }^{64}$ Giegher, Matthias (1629) Li tre trattati di messer Mattia Giegher Bavaro di Mosburc, trinciante dell' illustriss. Nazione Alemanna in Padova. Universitätsbibliothek Basel. http://dx.doi.org/10.3931/e-rara-16355 

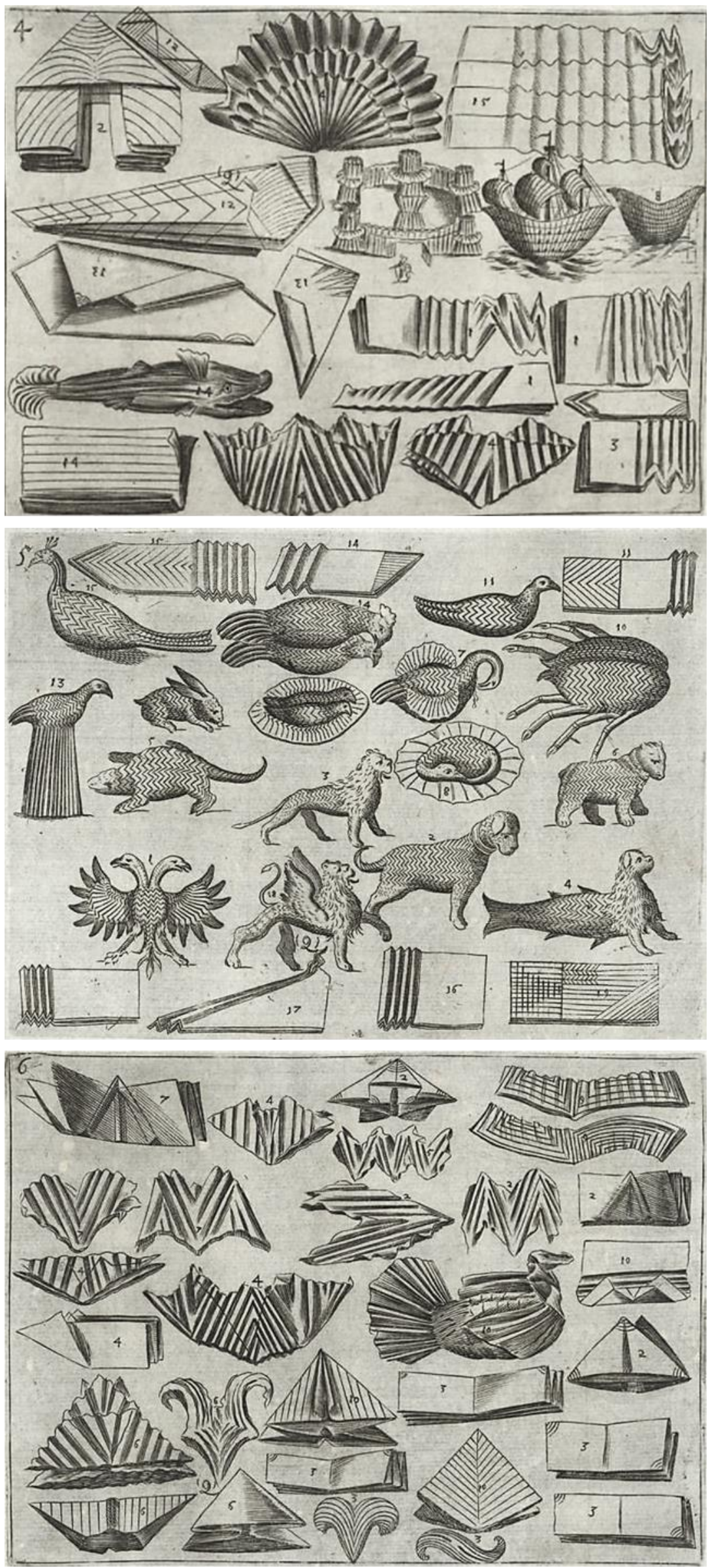

44. Grabados 4, 5 y 6 del Tratatto delle Pliegatture. Mattia Giegher, Padua 1639

Fuentes:

Universitätsbibliothek Basel. http://dx.doi.org/10.3931/e-rara16355

Los grabados 5 y 6 también se citan en:

Boursin, Didier (2004) Le pliage de serviettes. Edit. Divers ISBN10: 2047201012. Citado también en "Les Plis" obra de Nadine Vasseur que trata de desentrañar los caminos históricos y conceptuales del pliegue desde la perspectiva de las bellas artes $y$ los procesos artísticos. 
El grabado inferior es un detalle de una publicación del escritor inglés Roger L'estrange sobre deportes y pasatiempos (sports and pastimes) publicado el 4 de febrero de 1675 (o 76 pues no queda clara la fecha). En él podemos ver diferentes configuraciones formales del objeto conocido por the magic fan (el abanico mágico, haciendo referencia a una de las formas que adopta), papel multiforme o papier multiforme ${ }^{65}$, o más popularmente por troublewit, según recogen Robinson ${ }^{66}$ y Eric Kenneway ${ }^{67}$, ésta es la primera mención de un popular entretenimiento del siglo XVII que consistía en una teatralización, generalmente realizada por ilusionistas o magos, de historias apoyadas en rápidas manipulaciones del troublewit para representar, en secuencia, una variedad de objetos con una simple hoja de papel plisado.

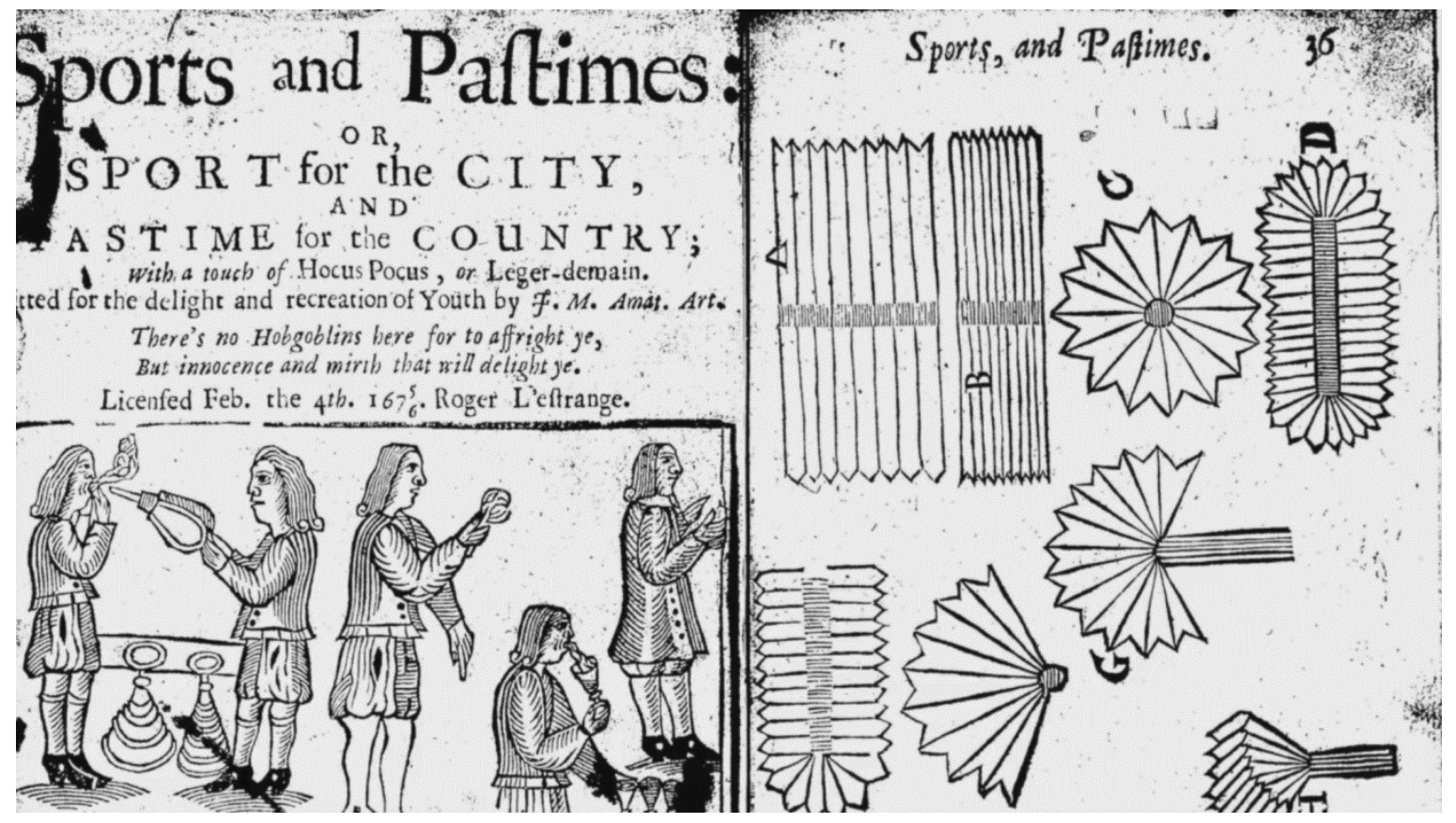

45. Sports and pastimes. Roger L'estrange. 1675

Fuente: Kenneway, Eric (1987) Complete Origami: An A-Z of Facts and Folds, with Step-by-Step Instructions for Over 100 Projects. Edit. St. Martin's Griffin. New York. pp 174

Es significativa la referencia que se hace en la portada del texto: "with a touch of Hocus Pocus, or Leger-demain", La expresión Hocus Pocus es la versión inglesa de Abracadabra en español, una palabra usada para ambientar encantamientos y magias. Su origen no está claro, pero puede querer parecerse a una expresión latina ajena al vocabulario común anglosajón y así significarse como algo enigmático y poderoso. Por otra parte Legerdemain proviende del francés, y literalmente significa "mano ligera o diestra" y se refiere a personas capaces de engañar a otros con ilusiones de digitación rápida. Así pues, según explica la portada, la utilización de un objeto plegado, dinámico y cambiante en su forma como era el troublewit le confería a la representación teatral un toque de inocente, enigmática y exótica magia a la par de una atractiva destreza para el disfrute y ocio de la juventud.

\footnotetext{
${ }^{65}$ Houdini, Harry (1922) Houdini's paper magic. The whole arte of performing with paper, including paper tearin, paper folding and paper puzzles. E.P. Dutton \& Company. New York. pp 130

${ }^{66}$ Robinson, Nick (2005). Enciclopedia de Origami: guía completa y profusamente ilustrada de la papiroflexia.

Barcelona: Editorial Acento. ISBN 978-84-95376-62-6.

${ }^{67}$ Kenneway, Eric (1987) Complete Origami: An A-Z of Facts and Folds, with Step-by-Step Instructions for Over 100 Projects. Edit. St. Martin's Griffin. New York. pp 174-175
} 

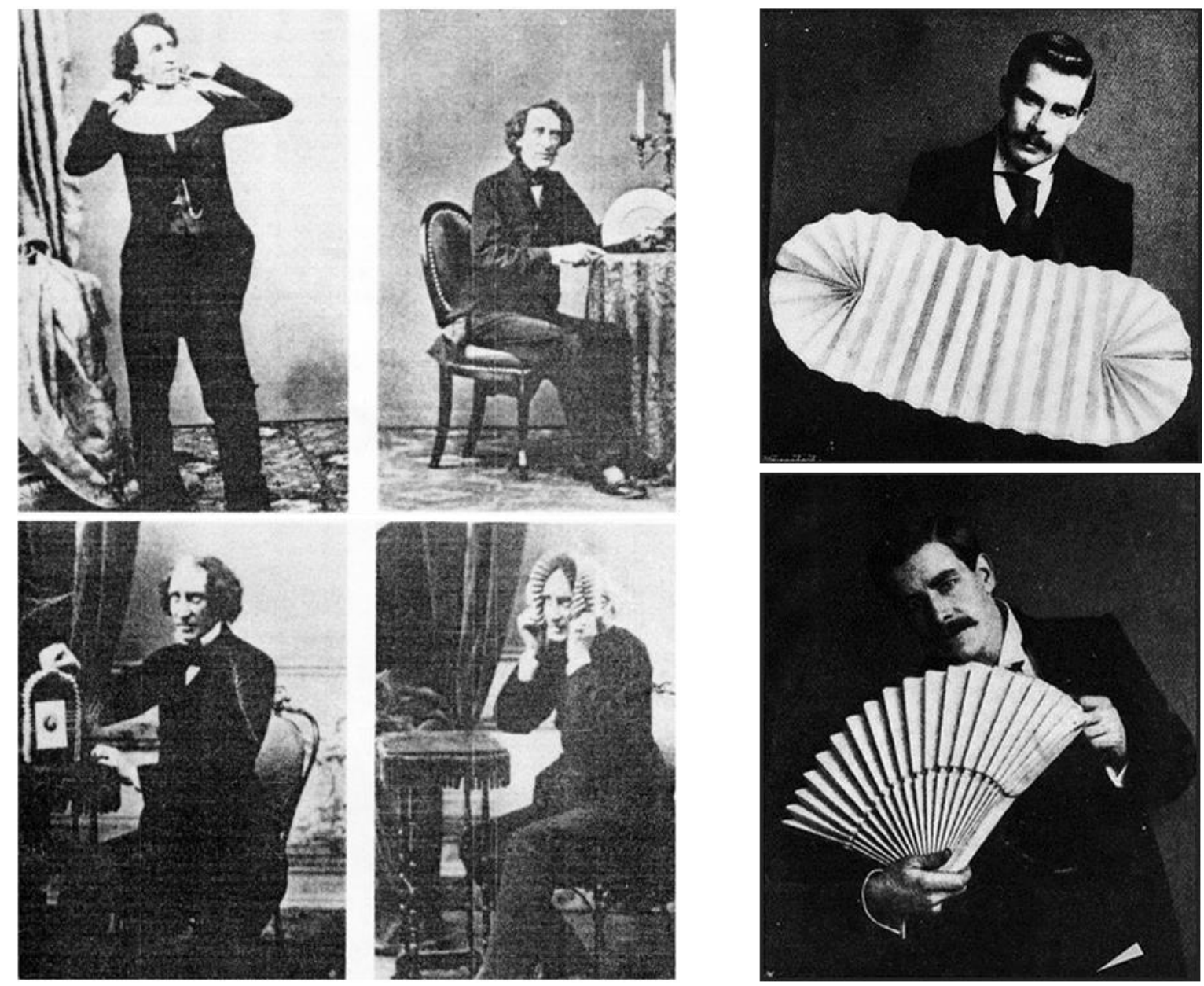

46. Professor Hofzinser en 1850 y David Devaine en 1880.

Fuente: Fischer, O. (1985, $1^{a}$ ed. 1942) The magic of Johann Nepomuk Hofzinser (R. Hatch, Trans.). Omaha.
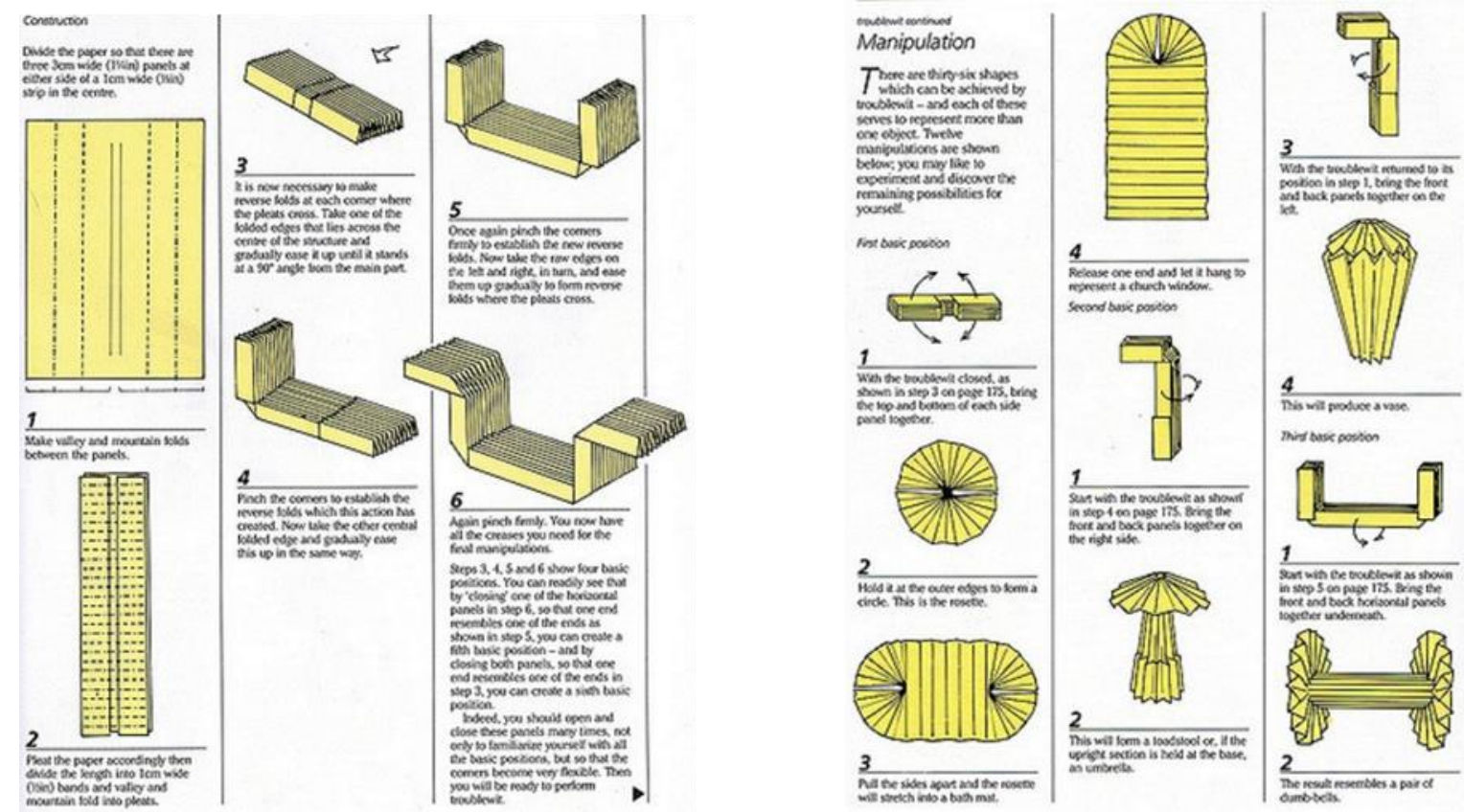

47. Proceso de pliegue de un Troublewit y diferentes configuraciones.

Fuente: Kenneway, Eric (1987) Complete Origami: An A-Z of Facts and Folds, with Step-by-Step Instructions for Over 100 Projects. Edit. St. Martin's Griffin. New York. pp 175-177 
En la página anterior podemos ver fotografías del Hofzinser y Devaine, famosos magos ilusionistas del siglo XIX mostrando algunas de las posibilidades formales del troublewit. También varias páginas de la extensa monografía sobre origami publicada por Eric Kenneway con instrucciones de plegado de más de 100 modelos.

Tanto la publicación de Geigher, Tratado de la plegadura de 1639, como la publicación de L'estrange de 1675 se adelantan casi un siglo a las publicaciones de origami japonés conocidas. Además de mostrar el plisado o pleat como el patrón de pliegue principal, el troublewit o papel multiforme comparte una característica común a otros objetos plegados de la cultura occidental, que es una cierta capacidad cinética y un objetivo principal de ser manipulados, transformados, para mostrar diferentes caras y mensajes.

Los Valentine Puzzle Purses, declaraciones de amor en papel plegado formando estuches o monederos y los tradicionales comecocos o ticoticos forman también parte de esta tradición europea.
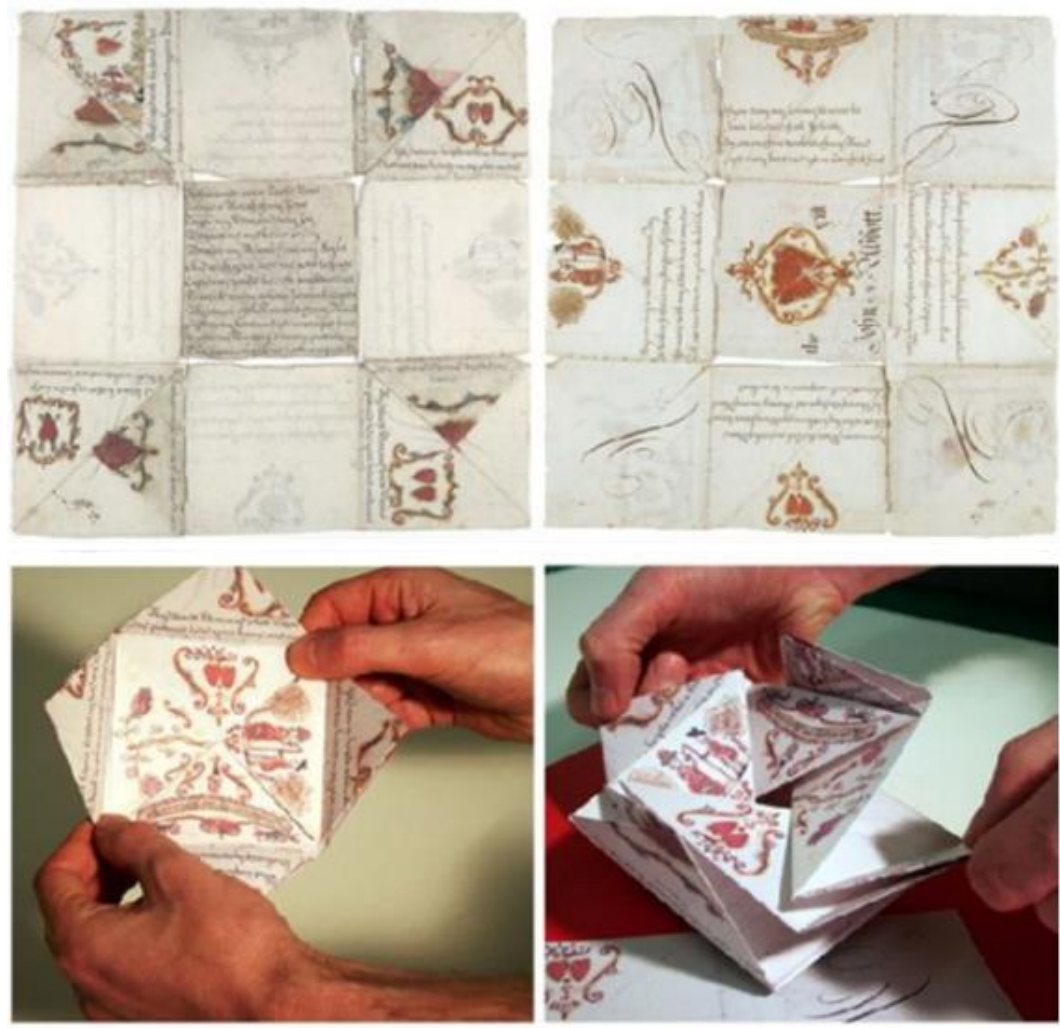

48. S.XVII

The gift of John Abbott.

Declaración de amor en papel plegado perteneciente al Henning Family of Sherborne archive y custodiado en el Dorset History Centre.

http://news.bbc.co.uk/1/hi/ england/dorset/6360153.stm

http://www.nickrobinson.info/clients/ smithy/history notes.php

http://hyperallergic.com/229147/ the-intricate-designs-of-an-18thcentury-love-token/

Este objeto de papel decorado con arrebatados versos románticos en inglés y delicados dibujos realizados con acuarelas es uno de los más antiguos ejemplos de juegos de papiroflexia en occidente. Datado del siglo XVII, según el centro de Historia de Dorset ${ }^{68}$, Pretende ser desdoblado de una forma particular para narrar una historia ilustrada que, al desplegarse, muestre una combinación de dibujos con un último verso destacado revelando una propuesta de matrimonio.

\footnotetext{
${ }^{68}$ Collections at Dorset History Centre. Fuente: https://www.dorsetforyou.gov.uk/dorsethistorycentre/collections
} 
Variaciones del mismo patrón de plegado realizado sobre una superficie cuadrada dividida en nueve partes iguales y plegada con líneas perpendiculares y diagonales fueron utilizadas también en la elaboración de certificados de bautizo en Alemania desde el siglo $\mathrm{XVII}$, estos certificados pseudo-oficiales eran dados por los padrinos a los bebés, y contenían información sobre el ahijado y las responsabilidades de los padrinos para asegurar una educación justa.
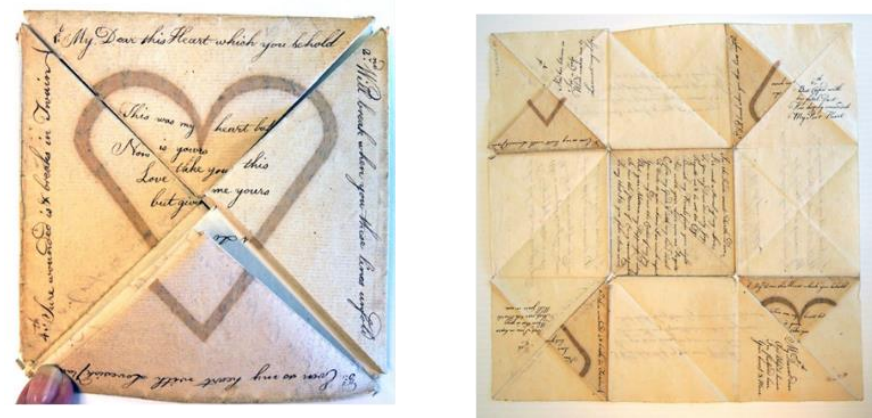

49. Valentine Puzzle. sin fecha [1700]. autor no identificado.

Lápiz sobre papel. Graphic Arts Collection GA 2010.01172. Papel de base cuadrada plegado a modo de monedero de bolsillo con una carta de amor escrita por partes en cada faceta del papel plegado.

Fuente: My Dear this Heart which you behold... A Puzzle

https://graphicarts.princeton.edu/2015/09/18/mydear-this-

heart-which-you-behold-a-puzzle/

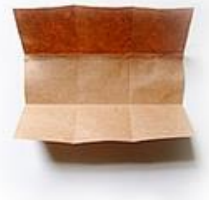

3

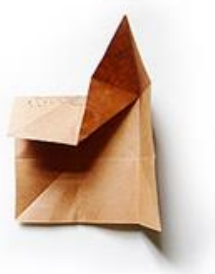

2
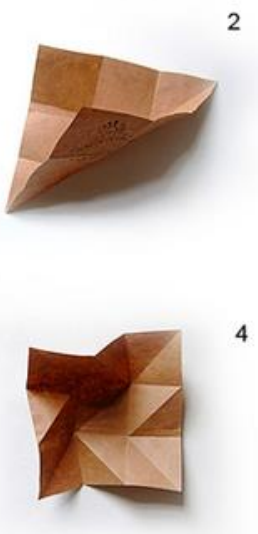

5
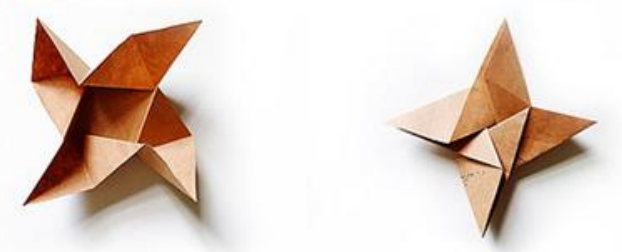

7

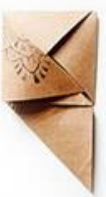

50. Patrón y plegado de un Valentine puzzle.

Fuente: https://graphicarts.princeton.edu/2015/10/27/the-answer-to-the-folding-puzzle/
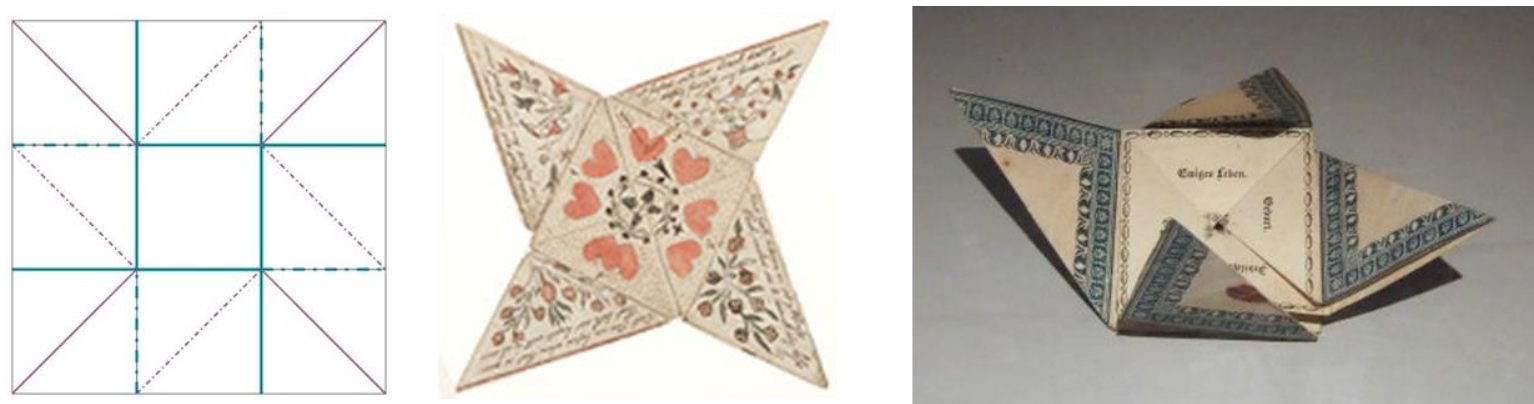

51. Certificados de bautizo en Alemania del siglo XVIII

Fuente: https://graphicarts. princeton.edu/2015/10/27/the-answer-to-the-folding-puzzle/ 


\section{- DEL ORIKATA AL ORIGAMI}

Autor desconocido, algunas fuentes citan a un monje roakan japonés (Enero de 1797) Hiden Senbazuru Orikata

Fuente: http://web.archive.org/web/20080501175749/origami.gr.jp/Model/Senbazuru/index-e.html

Boursin, Didier (2004) Le pliage de serviettes. Edit. Divers ISBN-10: 2047201012.

Giegher, Matthias (1629) Li tre trattati di messer Mattia Giegher Bavaro di Mosburc, trinciante dell' illustriss. Nazione Alemanna in Padova. Universitätsbibliothek Basel. http://dx.doi.org/10.3931/erara-16355

Hatori, Koshiro (21-06-2011) History of Origami in the East and the West before Interfusion. Origami 5: Fifth International Meeting of Origami Science, Mathematics, and Education. A. K. Peters/CRC Press; ISBN-10: 1568817142.

Honda, Isao (diciembre 1931) "おりがみ. 上" [On Origami] Japan Toy Association. Tokyo. Robinson, Nick (2005). Enciclopedia de Origami: guía completa y profusamente ilustrada de la papiroflexia. Barcelona: Editorial Acento. ISBN 978-84-95376-62-6.

Houdini, Harry (1922) Houdini's paper magic. The whole arte of performing with paper, including paper tearin, paper folding and paper puzzles. E.P. Dutton \& Company. New York.

Hsi Soong, Maying (1948) The art of Chinese paper folding for young and old. Editorial Harcourt, Brace. Fuente: Edit. Artella. 2013. artellawordsandart.com

Kenneway, Eric (1987) Complete Origami: An A-Z of Facts and Folds, with Step-by-Step Instructions for Over 100 Projects. Edit. St. Martin's Griffin. New York.

Lister, David (20-03-2005) History of Origami: outline suggestions for a basic, essential history.

Michael G. LaFosse, et all. (2007) Japanese Paper Crafting: Create 17 Paper Craft Projects Make Your Own Beautiful Washi Paper. Tuttle Publishing.

NIPPONIA No. 41 (15 de junio, 2007) El libro "Hoketsuki" de 1764, es Propiedad del Instituto de Diseño "Origata". Fuente: www.web-japan.org

Robinson, Nick (2005). Enciclopedia de Origami: guía completa y profusamente ilustrada de la papiroflexia. Barcelona: Editorial Acento. ISBN 978-84-95376-62-6.

Sadataka, Ise (1764) Hoketsuki. (Cómo envolver y atar). Fuente: Origata Design Institute, Nobuhiro Yamaguchi. http://www.origata.com/.

Shunboku, Ôoka (Periodo Edo, sobre 1734) Ranma zushiki (diseños para paneles decorativos). Xilograbado en tinta negra sobre papel. Fuente: Museum of Fine Arts Boston. http://www.mfa.org/collections/object/ranma-zushiki-designs-for-decorative-transoms-493254

Smith, John (1972). Notes on the History of Origami. http://www.nickrobinson.info/clients/smithy/history_notes.php

Vasseur, Nadine (16 octobre 2002) Les Plis. Editeur Seuil ISBN-10: 202049938X 


\subsection{EL ORIGAMI ABSTRACTO}

"Origami is a metamorphic art form." Michael G. Lafosse. ${ }^{69}$

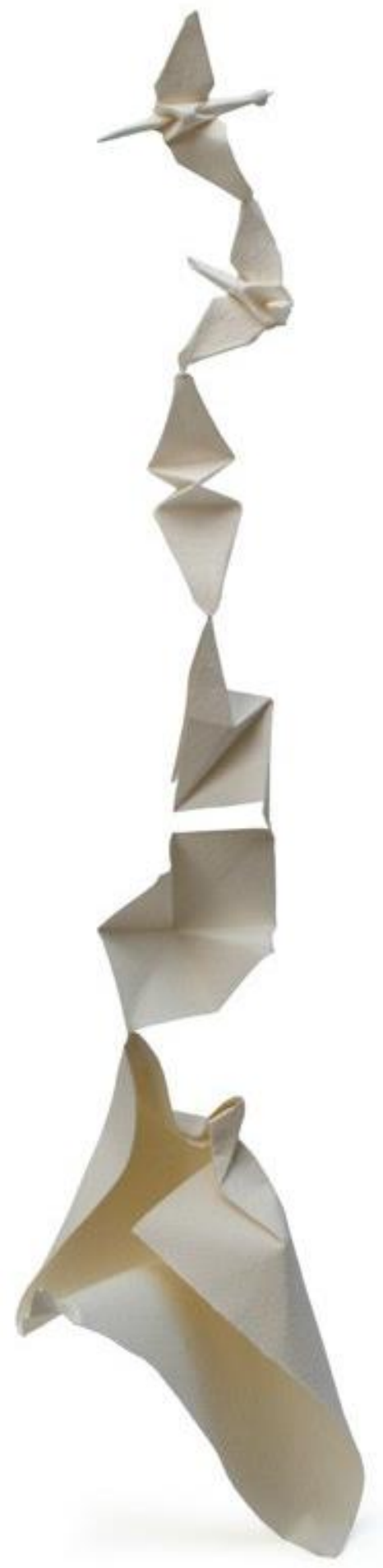

52. Fly, (2010) Giang Dinh, USA, Papel de acuarela

Fuente: McArthur, M.; Lang. Robert J. (2013) Folding Paper. The Infinite Possibilities of Origami. Ed. Tuttle p.15

${ }^{69}$ Folding Paper. The Infinite Possibilities of Origami. International Arts \& Artists Edition. Michael G. Lafosse artist, excerpt from Between the Folds. Fuente: www.artsandartists.org 


\subsubsection{La papiroflexia didáctica: Friedrich Fröebel}

A mediados del siglo XIX, el pedagogo alemán Friedrich Fröebel, incorpora y desarrolla ejercicios de plegado en sus técnicas de enseñanza a nivel escolar. Consideramos estos ejercicios como el origen de un nuevo camino creativo que llamamos origami abstracto pues están claramente separadas del enfoque narrativo figurativo del origami tradicional. Estos ejercicios se vinculan al desarrollo y aprendizaje de conocimientos matemáticos y geométricos y de habilidades creativas y espaciales. Como nos explica Juan Bordes Caballero ${ }^{70}$, las fuentes de Fröebel para esta actividad no están aclaradas, ya que las líneas comerciales entre Europa y Japón no se reabrieron hasta después de su muerte en 1852. Por lo que, aunque resulta sorprendente la utilización en los Kindergarten de estas técnicas del plegado de papel, parecen acercarse a algunos de los procedimientos de pliegue del origami chino y a la tradición de plegado de occidente.

De lo que no cabe duda es que a finales del S. XIX los conocimientos occidentales de plegado se fusionaron con los Orientales gracias al traslado al Japón del programa de Fröebel en torno a 1880. Siendo adoptado rápidamente en las escuelas japonesas por su utilidad para enseñar figuras geométricas y potenciar capacidades espaciales, fomentando la curiosidad científica. Los términos utilizados entonces para designar la ocupación de papierfalten ${ }^{71}$ (plegado de papel en terminología alemana) fueron tatamigami y kamitatami, denominaciones diferentes de los ya usados en Japón, de esta forma se dio el reconocimiento propio de una nueva aportación a las antiguas técnicas de su tradición.

Creador de la primera escuela infantil en Alemania en 1837 (Kindergarten, literalmente jardín de infancia), Friedrich Fröebel basó sus ideas sobre la educación en la creencia filosófica de que existía una profunda armonía entre la naturaleza y el espíritu humano. Defendía la concesión de una mayor libertad al niño, una educación más libre e integral que permitiera una reconstrucción de la ciencia y la cultura, a fin de que mediante el espontáneo desarrollo de sus facultades naturales y la ayuda de la familia y los educadores llegara a un cabal conocimiento de sí mismo y del mundo.

Según nos cuentan Norman Brosterman en "Inventing Kindergarten" ${ }^{\text {"2 }}$ y Juan Bordes en "La infancia de las vanguardias" 73 , las teorías de F. Fröebel sobre el juego y el aprendizaje revolucionaron la enseñanza artística. Las nuevas metodologías didácticas junto con las enseñanzas aplicadas en una serie de objetos y ejercicios creativos implantadas por Fröebel, fueron el caldo de cultivo de los movimientos artísticos del Siglo XX, influyendo en artistas, filósofos y arquitectos de la talla de Georges Braque, Piet Mondrian, Paul Klee, Wassily Kandinsky, Frank Lloyd Wright y Le Corbusier y en escuelas como la Staatliche Bauhaus (Casa de la Construcción Estatal), o más comúnmente conocida por la Bauhaus (de la unión de las palabras en alemán Bau, "construcción", y Haus, "casa") fue la escuela de artesanía, diseño, arte y arquitectura fundada en 1919 por Walter Gropius en Weimar (Alemania) que promulgaba la unión de todas estas artes en la recuperación de una formación técnica, artística y artesana global.

\footnotetext{
${ }^{70}$ Bordes Caballero, Juan. (2007) La infancia de las vanguardias. Editorial Cátedra. Madrid. ISBN: 978-84-376-2426-6. Ver Capítulo Dibujo Froebeliano, Séptima ocupación: el Plegado.

${ }^{71}$ Kindsein. La Revista $n^{\circ}$ 2. 19-12-2005. ISSN 1885-6535. Fuente: http://kindsein.com/es/2/80/147/

${ }^{72}$ Brosterman, Norman; fot. Kiyoshi Togashi. (1997, $1^{\text {a }}$ edición 1952) Inventing kindergarten. Ed. Harry N. Abrams, York

University. New York. Fuente: http://wiki.math.yorku.ca/index.php/Inventing_Kindergarten_by_Norman_Brosterman

${ }^{73}$ Bordes Caballero, Juan. (2007) La infancia de las vanguardias. Editorial Cátedra. Madrid. ISBN: 978-84-376-2426-6.
} 


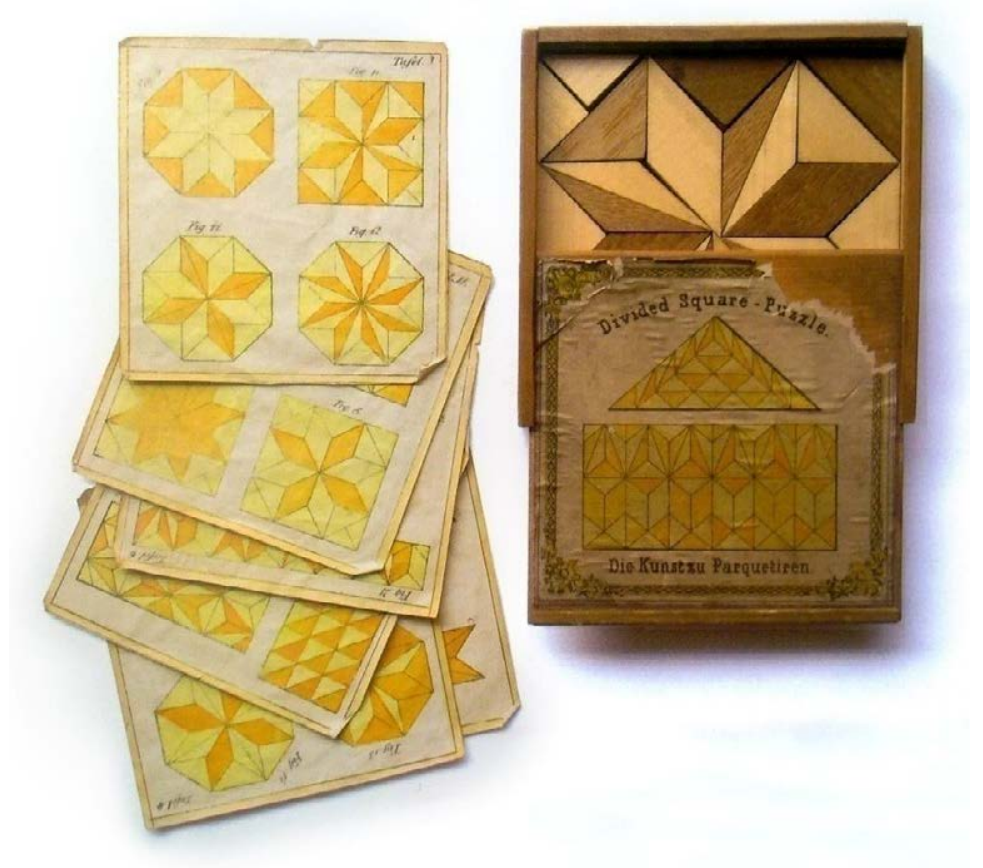

53. Divided Square Puzzle Die Kunst zu Parquetiren.

Juegos de parquets derivados del séptimo don:

Teselado del plano.

Fuente: Bordes Caballero, J. (2007) La infancia de las vanguardias. Ed. Cátedra. Madrid. p 86

Los objetos didácticos de F. Fröebel estaban constituidos por toda una gama de cajas de madera con "sorpresas" y "regalos" que, como explica J. Bordes, se estructuraban en "Dones" y "Ocupaciones", en las que aparte de la conocida "caja de bloques" que reúne los "dones de la arquitectura", se encontraban el Teselado con piezas planas de madera, el trenzado con bandas de papel, el plegado ( $7^{a}$ ocupación), el collage, etc. Fröebel escribió: "Los regalos llevan al descubrimiento; la ocupación al invento. Los regalos conducen al entendimiento; la ocupación ofrece poder". ${ }^{74}$

Fröebel secuenció la serie de dones del volumen al punto, pues esperaba que los alumnos descubrieran las superficies, las líneas y los colores, mediante la observación, el análisis y la abstracción de los cuerpos geométricos en tres dimensiones. Así el séptimo don introduce al niño en las operaciones con la superficie. Este don estaba incluido en lo que Fröebel llamaría "cajas matemáticas". Tablillas con caras de dos colores diferentes que algunos fabricantes realizaron también con papeles de colores. (véase capítulo 2.2.1. Friedrich Fröebel y las primeras nociones espaciales).

Fröebel invirtió este orden en las ocupaciones, la cuarta ocupación "el trenzado", la séptima ocupación "el plegado" y la décima ocupación "el modelado" fueron los ejercicios propuestos por F. Fröebel que se inspiraron claramente en el uso de papel y el plegado para enseñar conocimientos geométricos, matemáticos y espaciales que ayudaron al desarrollo creativo de una nueva generación de artistas.

${ }^{74}$ Fuente: http://www.kindsein.com/es/2/80/147/ 

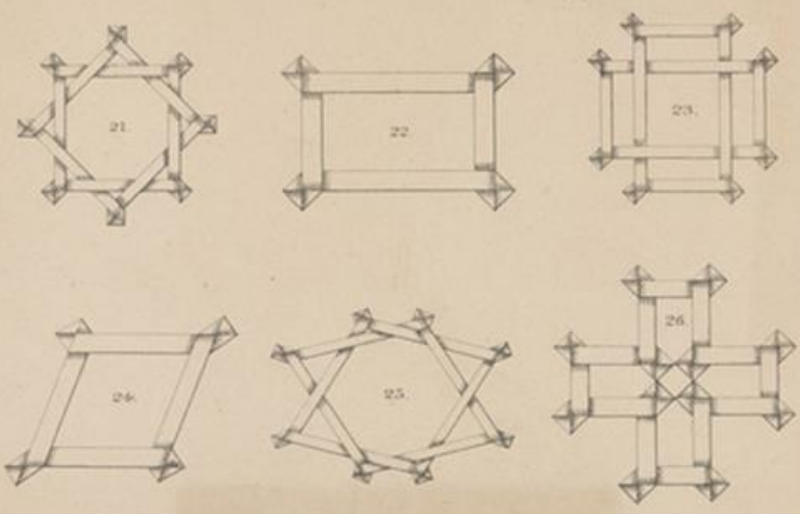

STBIGXn's Designs for Interwining Ple k
$210-440$.

Bradley's Kindergarten Material. GXN"T NOA. $18 \cdots 18$, FOLDING PAPIERS.

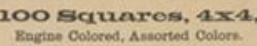

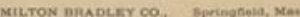

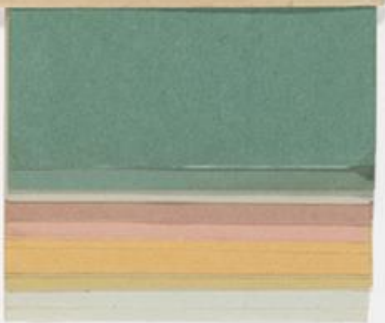

54. Regalos 17 y 18 inspirados en las teorías educativas de Friedrich Fröebel.

Izquierda: "Gift 17: Interlacing Kindergarten material based on the educational theories of Froebel".

Editor E. Steiger and Co. Año: 1880-1890. Cartón y papel. (21.6 x $15.2 \mathrm{~cm})$

Derecha: "Gift 18: Folding Kindergarten material based on the educational theories of F. Froebel".

Editor: Milton Bradley Co., Springfield, MA. Año: 1920 Cartón y papel $(10.2$ x $10.2 \mathrm{~cm})$.

Fuente: Museum of Modern Art. MoMA. New York. Donación de Lawrence Benenson.
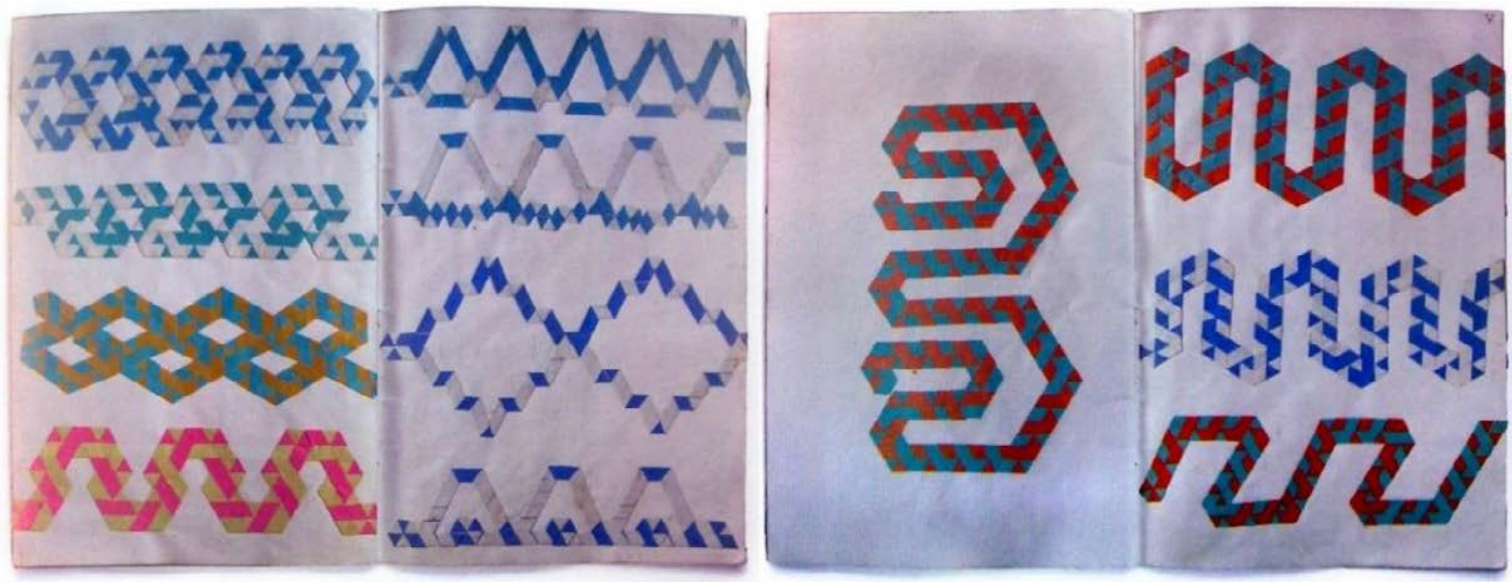

55. Álbum Froebeliano con modelos para la cuarta ocupación "el trenzado".

Fuente: Bordes Caballero, J. (2007) La infancia de las vanguardias. Ed. Cátedra. Madrid. p 101

La cuarta ocupación "el trenzado", realizada con bandas de papel de colores es una aproximación al trabajo en superficie parecida a los dones de los listones y tablillas de madera, pues las superficies de colores del don $n^{\circ} 7$ se usarán aquí de una forma contínua, debiendo ser plegadas y replegadas entre sí en ángulos de 60 y 45 grados para crear ricos patrones de superficies ornamentales generando módulos triangulares, romboidales y cuadrados. 
Edward Wiebé ${ }^{75}$ calificó las operaciones de esta ocupación y de las de pliegue de papel como "percepciones matemáticas" y consideraba que constituían un buen compendio de geometría elemental muy útil y eficaz para la enseñanza de las matemáticas. Esta ocupación "se puede emplear en la representación de todos los diversos tipos de líneas, ángulos y figuras matemáticas, incluso la belleza de las formas de vida puede ser presentada". Para Wiebé uno de los objetivos de esta ocupación es la adquisición de habilidad para el trabajo, ya que las operaciones sucesivas de doblado del papel requieren una gran precisión para conseguir el resultado final, pues los errores se acumulan y cada pliegue multiplica las desviaciones del objetivo.

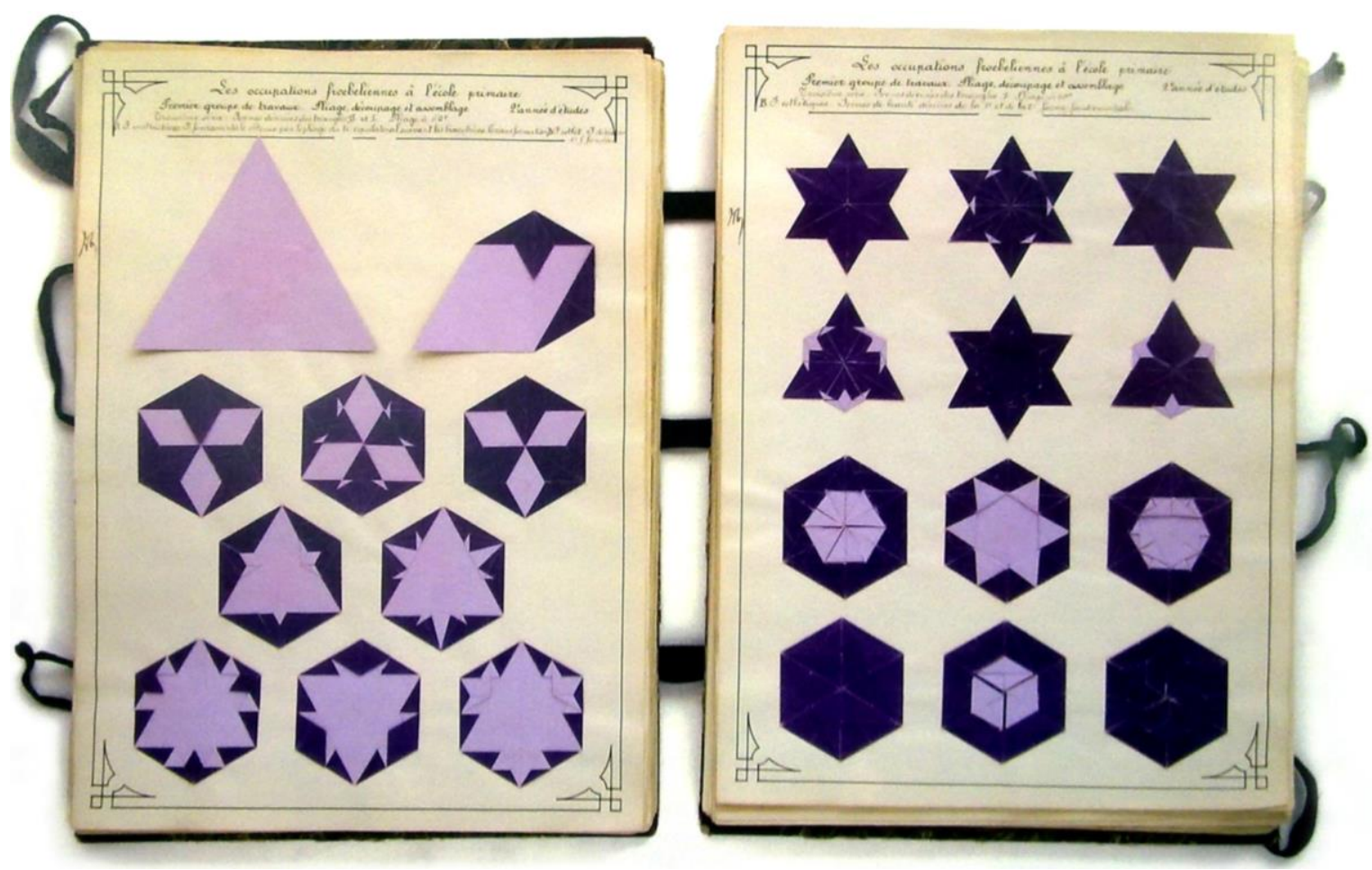

56. Álbum Froebeliano con modelos para la séptima ocupación, "el plegado".

Fuente: Bordes Caballero, J. (2007) La infancia de las vanguardias. Ed. Cátedra. Madrid. p 106

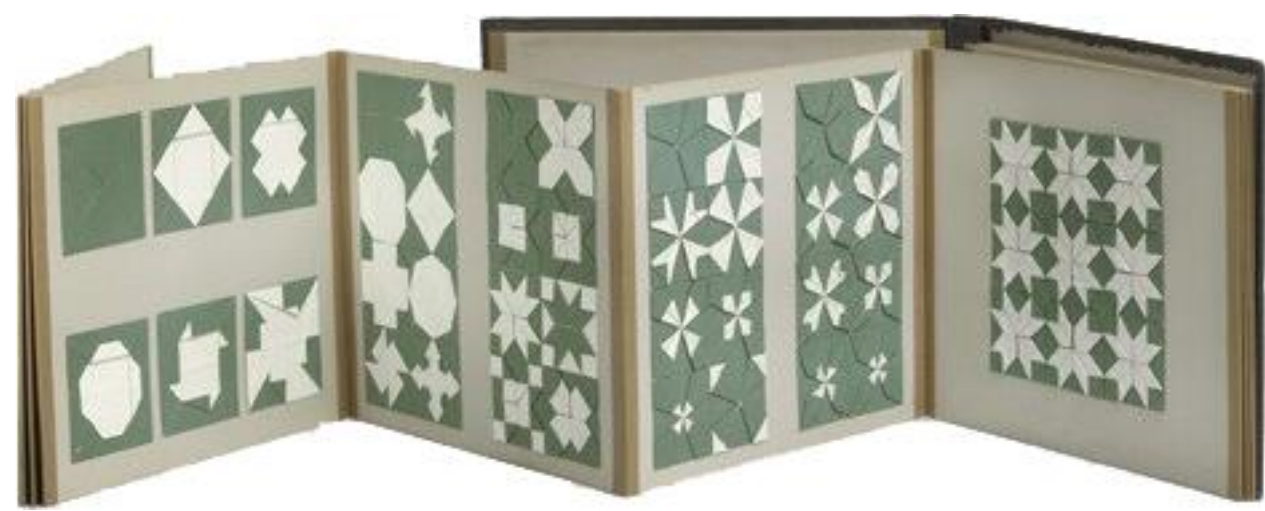

57. Paper folding Kindergarten material based on the educational theories of $F$. Froebel. Autor: Fannie E. Kachline. Año 1890. Cartón y papel. $(24.1$ x $29.2 \mathrm{~cm})$

Fuente: Museum of Modern Art. MoMA. New York. Donación de Lawrence Benenson.

75 Wiebé, Edward (1869) The paradise of childhood: a manual for self-instruction in Friedrich Froebel's educational principles, and a practical guide to kinder-gartners. Publisher Springfield, Mass.: M. Bradley \& Company. Book contributor University of California Libraries. Página 66 
El desarrollo de la creatividad es la base de todo el programa pedagógico de Fröebel, y con este objetivo principal diseña una serie de ejercicios de final abierto que ofrezcan múltiples soluciones formales. En la ocupación numero 7 los puntos de partida son el cuadrado y el triángulo, el alumno se ejercita en las formas fundamentales con un ejercicio de plegado de papel que en apariencia parece un juego insípido, una ocupación insignificante, pero que su proceso de plegado y descubrimiento de nuevas formas hace que un simple recorte de papel se convierta en una profunda lección de geometría. Con el plegado el niño ejercita la mano mientras las explicaciones geométricas desarrollan la inteligencia, y la creación de la forma estética despierta sus sentimientos artísticos.

Durante el proceso del plegado el niño debe sentir cómo una forma saca su desarrollo de otra y cómo encuentra en una figura transformada todas las modificaciones que ha sufrido. Como nos resalta Bordes, "el niño es naturalmente imitador e inventor; se divierte cuando descubre algo nuevo; esta diversión fija su atención, activa su inteligencia, sus sentidos y sus miembros. Su actividad es la vida de su espíritu, la no acción es su sueño, isu muerte! Es por lo que el niño no aprende nada en las lecciones que le dejan en una pasividad completa" 76
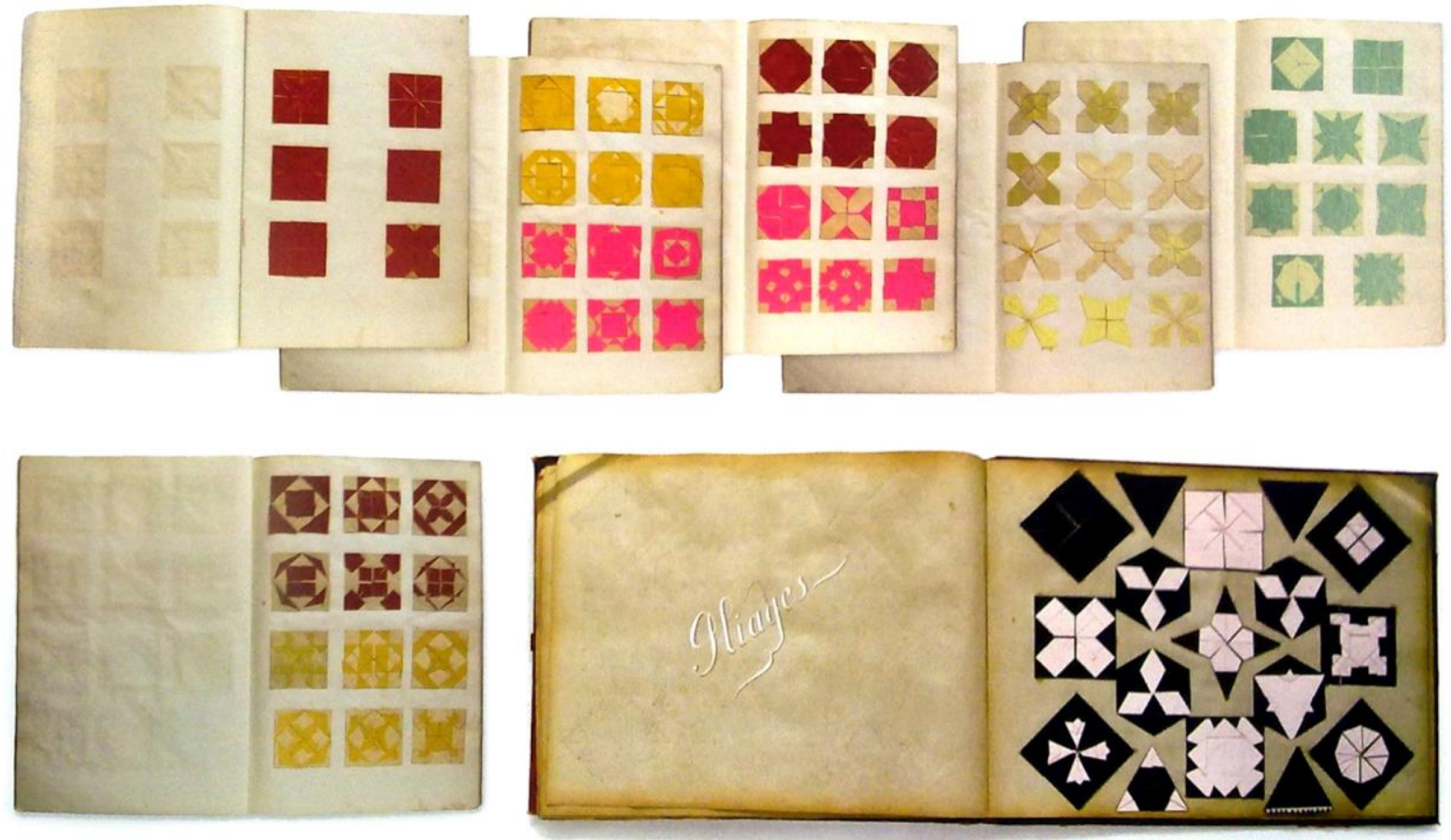

58. Tres álbunes froebelianos con modelos para la ocupación $n^{\circ} 7$

Fuente: Bordes Caballero, J. (2007) La infancia de las vanguardias. Ed. Cátedra. Madrid. p 107

\footnotetext{
${ }^{76}$ Bordes Caballero, Juan. (2007) La infancia de las vanguardias. Ed.Cátedra. Madrid. p 107
} 
La décima ocupación "el modelado" realizada con arcilla, arena y en mayor medida con papel y cartón, supuso la mejor aplicación de teorías geométricas y matemáticas para la generación y exploración de morfologías complejas, ya que para esta técnica se requiere proyectar primero el desarrollo superficial sobre plano, para lo que son necesarios ejercicios de construcción y trazado de los cuerpos geométricos regulares. Asimismo, la construcción de las figuras cristalográficas en cartón era también una práctica que acompañaba a las lecciones de cristalografía.

Podemos intuir su origen en divertimentos constructivos en papel desarrollados con anterioridad a la incorporación al programa de Fröebel, como lo demuestra el pequeño libro "Papyro-plastics. The art of modelling in paper" ${ }^{77}$ editado primero en alemán y traducido al inglés en 1824 y del que las sucesivas ediciones que se realizaron al menos hasta 1836 dan cuenta de la difusión de esta publicación.
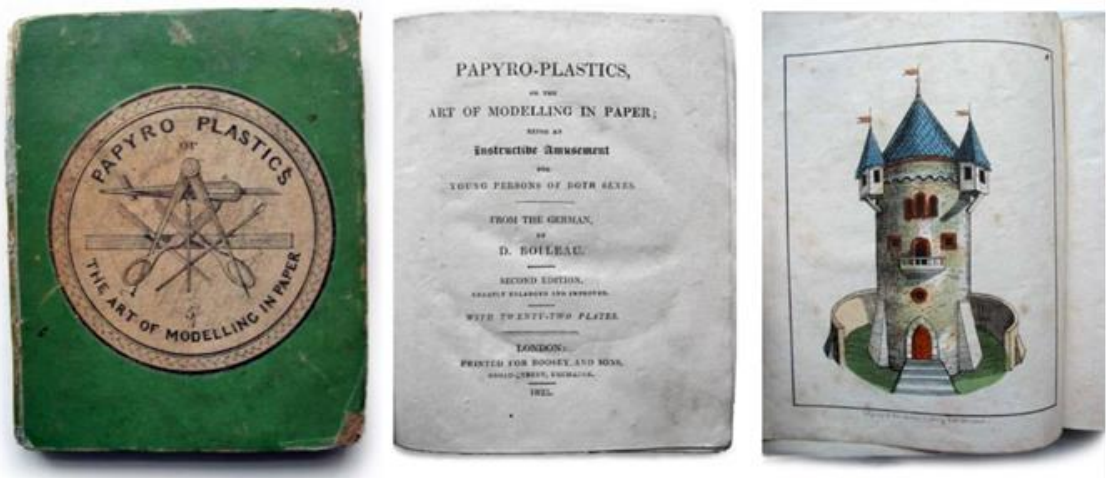

59. Portada y páginas del libro: Papiro-plastics, The art of modelling in paper.
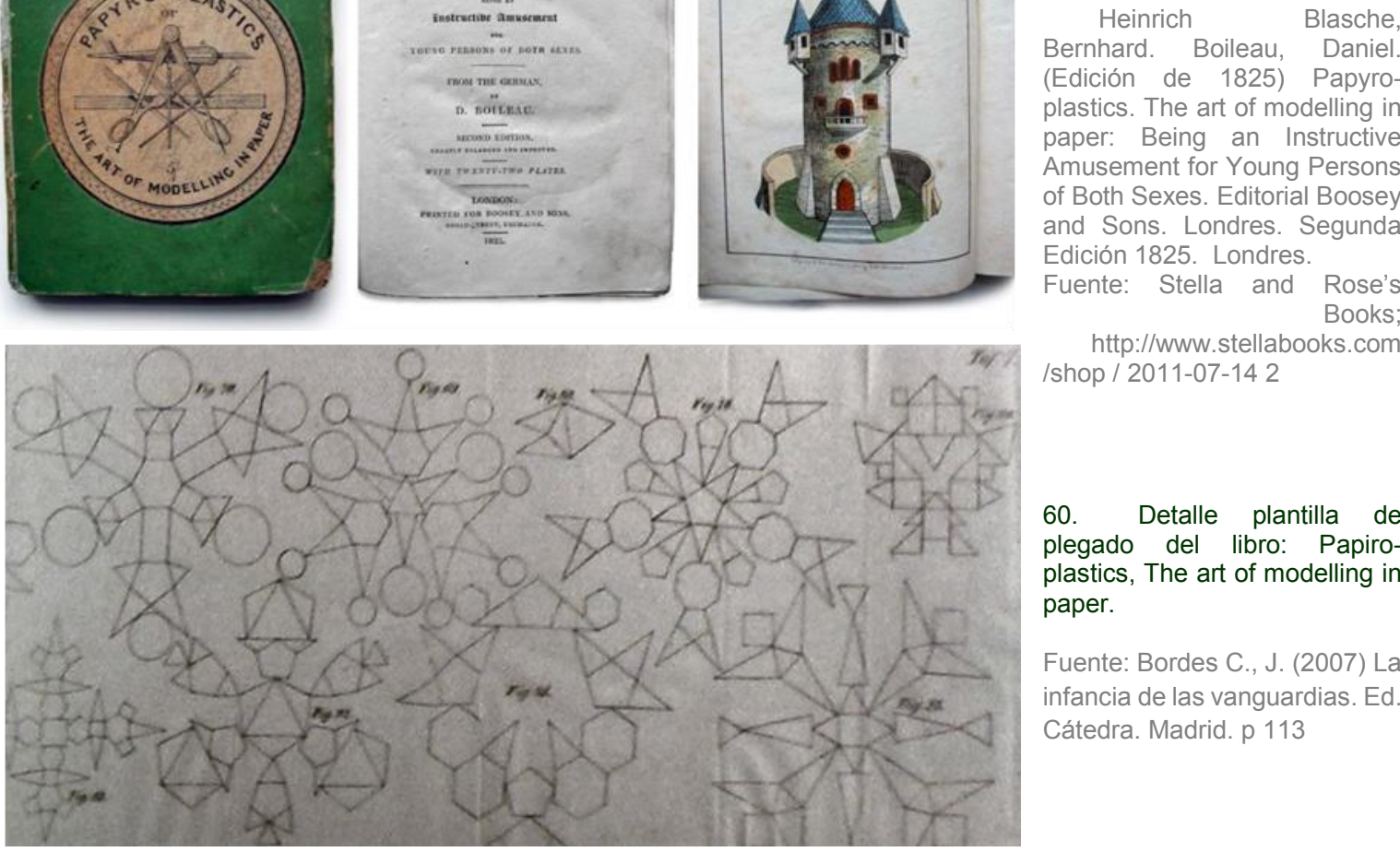

http://www.stellabooks.com /shop / 2011-07-14 2

60. Detalle plantilla de plegado del libro: Papiroplastics, The art of modelling in paper.

Fuente: Bordes C., J. (2007) La infancia de las vanguardias. Ed. Cátedra. Madrid. p 113

Este libro también es citado por Juan Bordes en "La infancia de las vanguardias", en el cual se reproduce la portada de una edición posterior de 1830. La traducción de su título podría ser así: La plástica del papel, el arte de modelar en papel: un instructivo divertimento para jóvenes de ambos sexos. Incluye 22 plantillas de recorte y plegado coloreadas a mano. ${ }^{78}$

\footnotetext{
${ }^{77}$ Heinrich Blasche, Bernhard. Boileau, Daniel. (1825, 1830, 1834 y 1836) Papyro-plastics. The art of modelling in paper: Being an Instructive Amusement for Young Persons of Both Sexes. Editorial Boosey and Sons. Londres. Segunda Edición 1825. Fuente: Amazon books. http://www.amazon.co.uk/ 2011-07-15

${ }^{78}$ Stella and Rose's Books; http://www.stellabooks.com/shop/ 2011-07-14 "Boosey and Sons. 1825. Good condition with no wrapper. Second edition, greatly enlarged and improved. The Art of Modelling in Paper; Being an Instructive Amusement for Young Persons of Both Sexes. Translated from the German. Hand-coloured frontis plus twenty-two fold-out plates to rear. Small format. Green paper boards. Boards heavily marked, corners worn. Spine worn with loss of backstrip to top half. Inscription in ink to front pastedown. Erased pencil doodles of people to endpapers. Front hinge starting to split from top. Prelims are grubby, scattered foxing. All plates present. A good working copy".
} 
Tal como nos cuenta Juan Bordes, en la décima ocupación: "el modelado", Friedrich Fröebel vuelve su mirada de nuevo a la cristalografía al partir de una caja con catorce sólidos regulares derivados del cubo que ofrece como resumen de formas cristalográficas. En palabras de Fröebel "las formas regulares, las formas matemáticas han dado nacimiento a las formas artísticas".

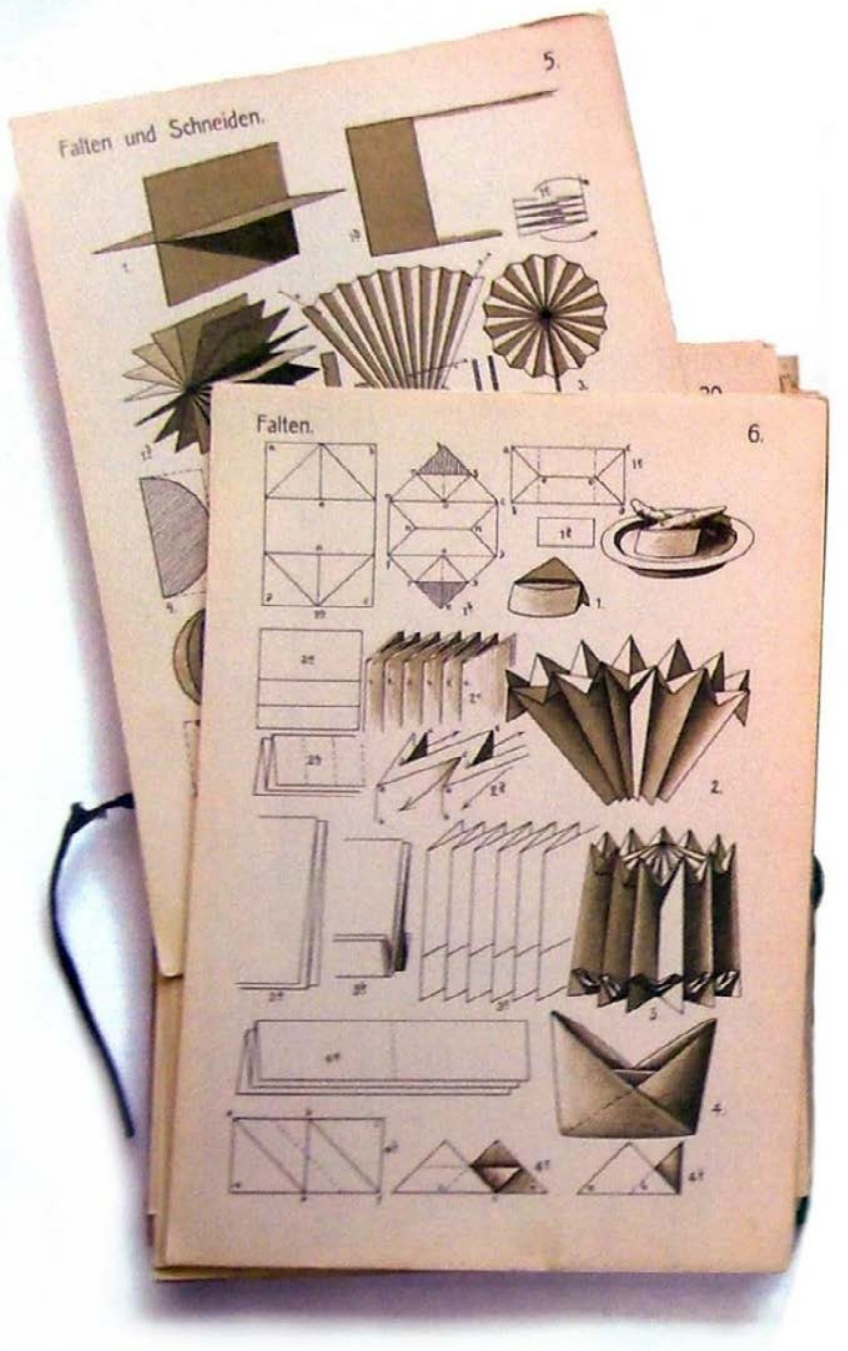

“...Estos ejercicios producen frecuentemente una diversión aún mayor. Incluso cuando no se dé el talento mecánico, el placer de ser capaz de hacer algo, es para muchos una excitación suficiente: y lo mismo el dibujo que el modelado, si se enseñan según principios fundados en la naturaleza, tendrán mayor uso cuando los discípulos hayan de abordar otras ramas de la instrucción (como la geometría o la geografía) (...) la doctrina de los sólidos geométricos, que no puede ser de ningún modo enseñada sin modelos ilustrativos, es mucho mejor comprendida y mucho más profundamente impresa en el espíritu cuando tienen los discípulos alguna idea de la construcción de los modelos y cuando son capaces de fabricar al menos los que ofrecen menor complicación...el modelado es la más inmediata manifestación del poder creativo que el hombre puede mostrar (...) el universo material es transformado por él" El mundo externo es 'formable', capaz de recibir una nueva forma de las manos del hombre". ${ }^{79}$

61. Álbum Froebeliano. Décima ocupación: el modelado. Fuente: Bordes, J. (2007) La infancia de las vanguardias. Ed. Cátedra. Madrid. p 112

Como veremos en un capítulo posterior esta ocupación parece adelantar e inspirar las futuras configuraciones formales arquitectónicas de los miembros de la cadena de cristal; Wassili Luckhardt y Bruno Taut. De este modo, su inspiración original no parece partir de las formas cristalográficas en sí, si no de la exploración y creación de estas formas facetadas con un material, el papel, que acoge espacios huecos, vacíos envueltos y generados por superficies planas plegadas, que son a la postre los que tenían la potencialidad de inspirar nuevas arquitecturas.

\footnotetext{
${ }^{79}$ Bordes Caballero, Juan. (2007) La infancia de las vanguardias. Ed.Cátedra. Madrid. ISBN: 978-84-376-2426-6. p 112
} 


\subsubsection{Patrones de pliegue estructurales: La Bauhaus}

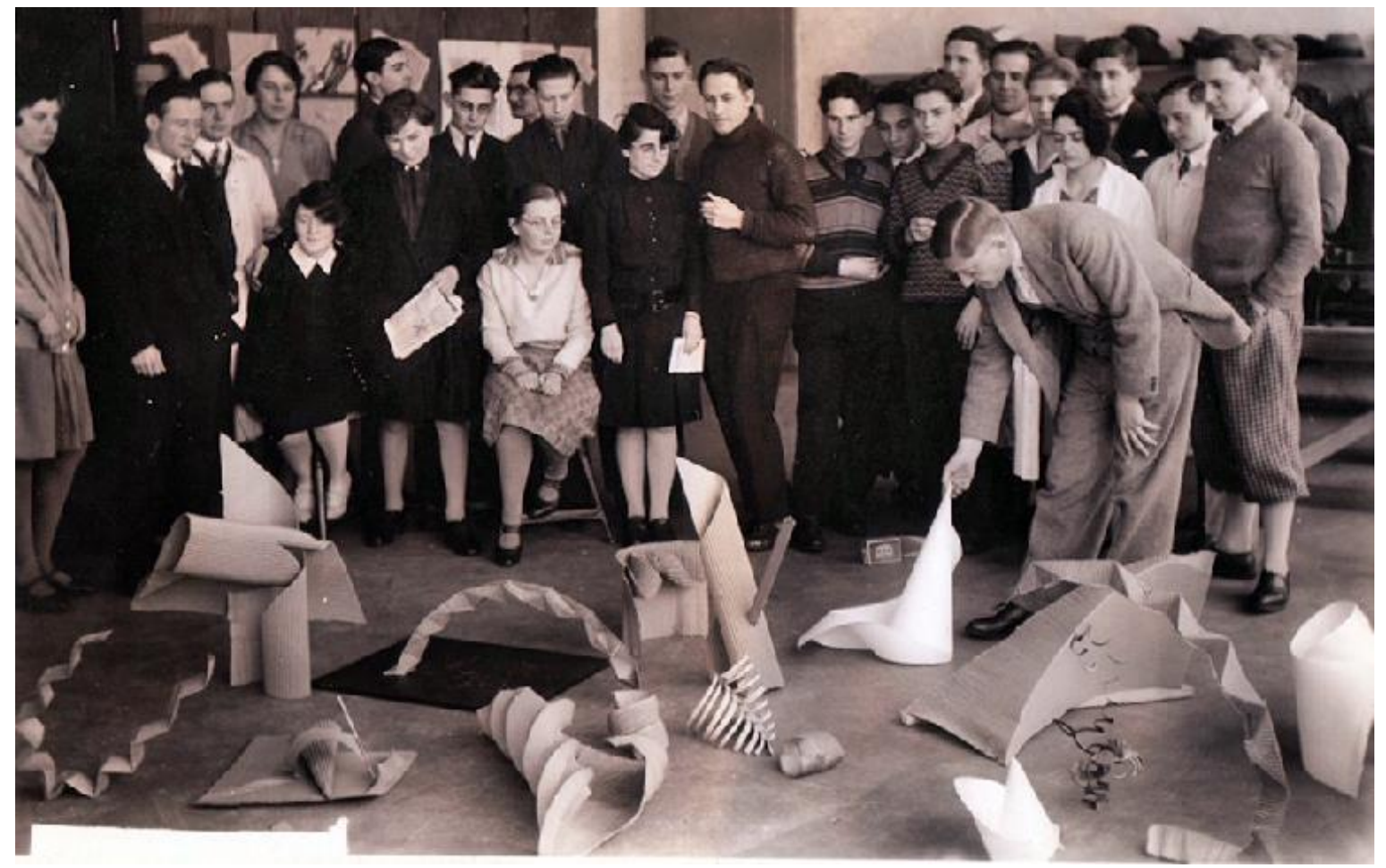

62. Sesión crítica del curso preparatorio dirigido por Josef Albers. (1928 - 1929)

Fotografo: Umbo (Otto Umbehr) Impresión en gelatina de plata $(11.3 \times 17.4 \mathrm{~cm})$. The Josef and Anni Albers Foundation, Bethany, Conn. Fuente: Bauhaus 1919-33: Workshops for modernity.

Los Vorkurse o cursos preparatorios que se impartieron en la Escuela de la Bauhaus fueron unas de las experiencias más innovadoras y originales de la trayectoria docente de esta escuela de arquitectura, donde también se impartieron, compartiendo metodologías didácticas y proyectos comunes, las especialidades de diseño, arte y artesanía. Los cursos preliminares empezaron a impartirse un año después de la fundación de la escuela por Walter Gropius en 1919 en Weimar (Alemania), y no tardaron en consolidarse como una de las experiencias docentes más innovadoras de la escuela, pues integraban a todos los alumnos de todas las ramas y ofrecían la oportunidad a sus profesores de explorar y mostrar con total libertad los nuevos caminos creativos de las vanguardias artísticas de principios del siglo XX. 
Para entender este afán por integrar los conocimientos de las diferentes ramas creativas de las artes plásticas debemos remitirnos al manifiesto fundacional firmado por Gropius en 1919: "Arquitectos, escultores, pintores, todos nosotros debemos volver al trabajo artesanal. Establezcamos, por lo tanto, una nueva cofradía de artesanos. La Bauhaus aspira a reunir todas las manifestaciones artísticas en una unidad, ambiciona la reunificación de todas las disciplinas artísticas (escultura, pintura, artes aplicadas y artesanía) en una nueva arquitectura formada por estos componentes inseparables. El objetivo último de la Bauhaus, aunque lejano, es la obra unitaria, la gran construcción en la que hayan desaparecido las barreras entre arte monumental y arte decorativo". 80

El primer director de los Vorkurse fue el pintor, diseñador y escritor suizo Johannes Itten, quien los concibió como uno de los elementos que marcaron toda la escuela. Empezaron a funcionar en verano de 1920; en un principio con una duración de un semestre prolongándose posteriormente a un año. La evolución de estos cursos permite, en esencia, hacer un seguimiento de casi la totalidad de los cambios programáticos de la escuela. En la opinión de J. Itten, "no se trataba solamente de preparar técnicamente a los nuevos alumnos para un taller en particular, ni de liberarles del lastre educativo que traían consigo. El objetivo era la formación de personalidades integras". ${ }^{81}$

Pese a algunas reformas, en las escuelas de arte de la época, la enseñanza tradicional seguía consistiendo básicamente en una formación profesional especializada en la que se practicaban las habilidades técnicas, principalmente el dibujo y las reproducciones a partir de modelos en yeso, desnudos y ejemplos históricos. Por el contrario, J. Itten, que se basaba en los años de experiencia adquiridos en su propia escuela de arte privada en Viena, quería fomentar las capacidades creativas de sus alumnos en una primera fase más allá de todo sentido práctico, conforme al espíritu crítico con la cultura de la época. La práctica especializada vendría más tarde, a través del trabajo realizado en cada taller.

El trabajo con papel era muy frecuente en la escuela de la Bauhaus, pero muy especialmente en los Vorkurse debido a la escasez de materiales y financiación necesarios para experimentar con otras técnicas. Laszlo Moholy-Nagy y Josef Albers, quienes sustituyeron a Itten en la dirección de estos cursos preparatorios, hicieron del papel uno de los materiales de trabajo más importante, usándolo como un buen modo de introducir a los estudiantes en las posibilidades de explorar el espacio directamente con el manejo del material. Es en estos cursos donde el arte del origami se pensará con un uso alternativo al desprenderse de su capacidad representativa de objetos y animales y utilizarse explícitamente y gracias a las características estructurales del pliegue, para la experimentación formal y la exploración y representación de nuevos espacios y modelos arquitectónicos de gran valor expresivo, formas complejas y agresivas, cargadas de ritmos, quiebros y singularidades.

\footnotetext{
${ }^{80}$ Fiedler, Jeannine et Feierabend, Peter (2006) Bauhaus. Editor: Ullmann Publishing ISBN-13: 978-3-8331-4347-2 p. 191 ${ }^{81}$ lbídem p.360
} 
En estos cursos Moholy-Nagy y Albers "proponían a los estudiantes crear esculturas en papel para familiarizarlos con la potencia creativa de las formas abstractas, los espacios positivos y negativos provocados por la tensión y la resistencia del papel" 82 abandonando de este modo la carga idealista y filosófica de las enseñanzas de Itten, e insuflando un carácter más práctico a las enseñanzas de los vorkurse, diferenciando entre la disposición interna del material (estructura) y su superficie natural (textura) y artificial (factura).

Para la práctica de la creación, quizás este tercer aspecto fuera el más significativo para los dos profesores, por lo que fomentaron su conocimiento con ejercicios elementales en los que destacaban por la presencia del papel los dos primeros ejercicios:

1. Elaboración de facturas de papel con herramientas elegidas libremente (agujas, tenazas, tamiz) y el procedimiento de trabajo preferido (punzados, presiones, frotamientos, limaduras, perforaciones, etc.).

2. Elaboración de facturas de papel con una sola herramienta (aguja, cuchillo, tenazas...; o bien con doblados y similares).

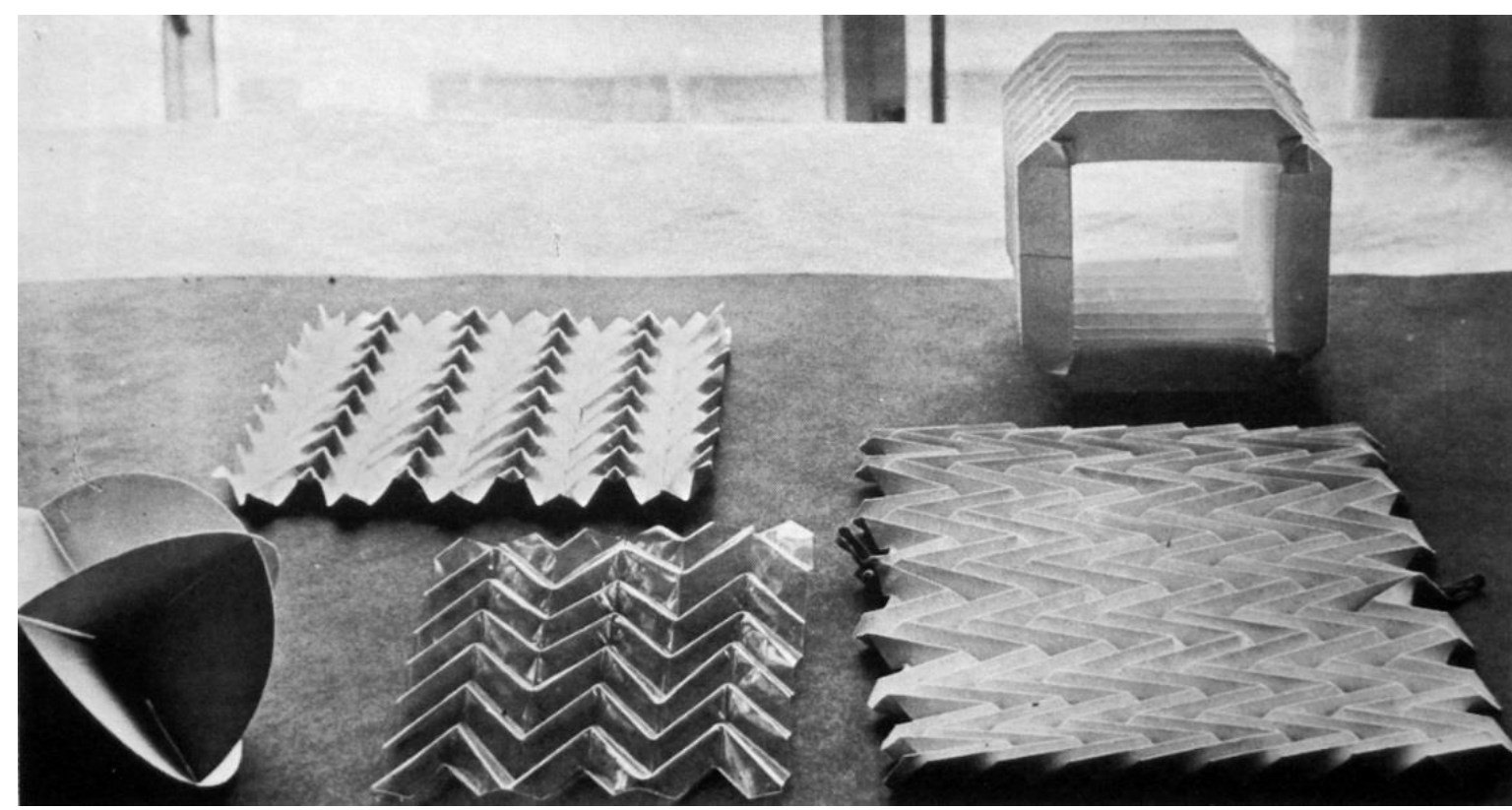

63. Trabajos de los alumnos de la Bauhaus.

Patrones de pliegue miura (suelo) y yoshimura de 45 grados extendido (figura del fondo)

Fuente: Wingler, Hans M. et Wingler, Hedwig (1991, $1^{\text {a }}$ ed. 1969) Bauhaus: Weimar, Dessau, Berlin, Chicago. Edit. MIT Press. ISBN-13: 978-0262730471

Citado en: http://erikdemaine.org/curved/history/ el 28 de noviembre del 2010 por Erik Demaine.

\footnotetext{
${ }^{82}$ Boyaki, Amanda. (Mayo 2010) Ahna Buscher Siedhoff: An Examination of Children's Design and Gender at the Bauhaus during the Weimar Period. Capítulo: Paper Toys: Mechanical Crane and Sailboat [Bastelbogen] c. 1925, pág. 142. Texas Tech University, Estados Unidos.
} 

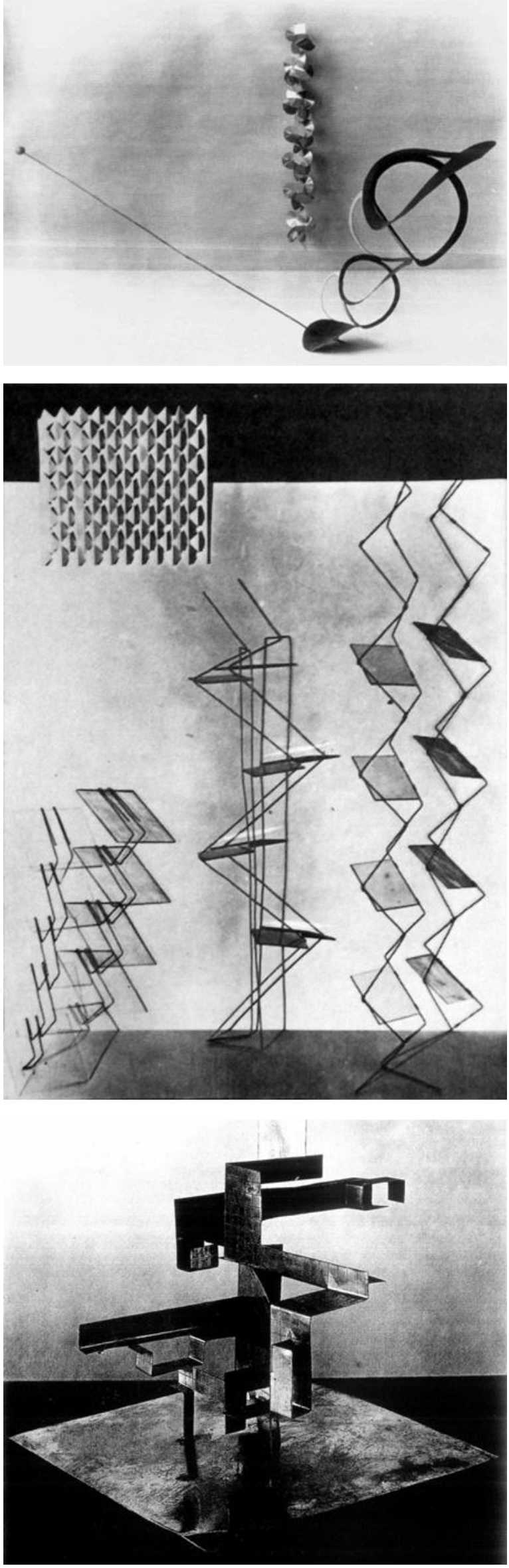

Mientras que estos ejercicios formaban principalmente el conocimiento de la apariencia puramente exterior del material, los denominados ejercicios de equilibrio plástico tenían como objetivo sus tensiones constructivas y su equilibrio en la creación espacial. Estos collages espaciales estaban destinados a conseguir el aprovechamiento más complejo $\mathrm{y}$, simultáneamente, más eficaz económicamente de las cualidades materiales específicas de los materiales de trabajo, tanto tradicionales como modernos, industriales y sintéticos.

Moholy-Nagy procedía del entorno del constructivismo, movimiento que pretendía ampliar las ventajas "nobles" de los cánones académicos a los materiales de una cultura industrial celebrada empáticamente. Construir significaba ante todo la configuración conjunta y consciente de una realidad vital caracterizada por la independencia y por la industria. Por tanto, los estudios de construcción no deben confundirse con "ejercicios de estilo" de formas abstractas. Son diseños de una realidad técnica y utópica.

64. Ejercicios del curso dirigido por J. Albers. Werner Zimmermann and Paul Reindl, 1929 Fotografo: Erich Consemilller.

Impresión en gelatina de plata $(11.5 \times 15.3 \mathrm{~cm})$

The Josef and Anni Albers Foundation, Bethany, Conn.

65. Ejercicio de construcción y material Anónimo, hacia 1927 (destruido).

Superficie de hojalata cortada y doblada. Fotografía de Erich Consemüller, Bremen. 
El vanguardismo de László Moholy-Nagy quedaba también reflejado en el fruto de sus clases. El movimiento y la extremada diagonalidad de los estudios de la alumna Anni Wildberg, mostrados bajo estas líneas, parecen simbolizar el optimismo de su profesor ante el progreso y la inmersión del arte en la sociedad moderna industrial. Se percibe en estas obras un afán por desprenderse de cualquier representación figurativa y tradicional del arte y una búsqueda por expresar mediante estructuras cinéticas y juegos luminosos, el dinamismo, la luz y la modernidad propios de una visión optimista de la vida y del futuro del arte. La pintura de caballete y la escultura de peana son sustituidas por un arte global como expresión de la industrialización de los nuevos tiempos.

Si la primera época de Itten estuvo marcada por el estilo expresionista, en esta nueva etapa se introducen las bases del Constructivismo para un arte basado más en la idea, las relaciones matéricas y las capacidades expresivas de las formas que en la inspiración. Moholy-Nagy, con el apoyo de Josef Albers, ofrecen un enfoque más industrial y práctico al curso preparatorio, impregnando desde la base a la escuela de la Bauhaus de esta nueva filosofía.
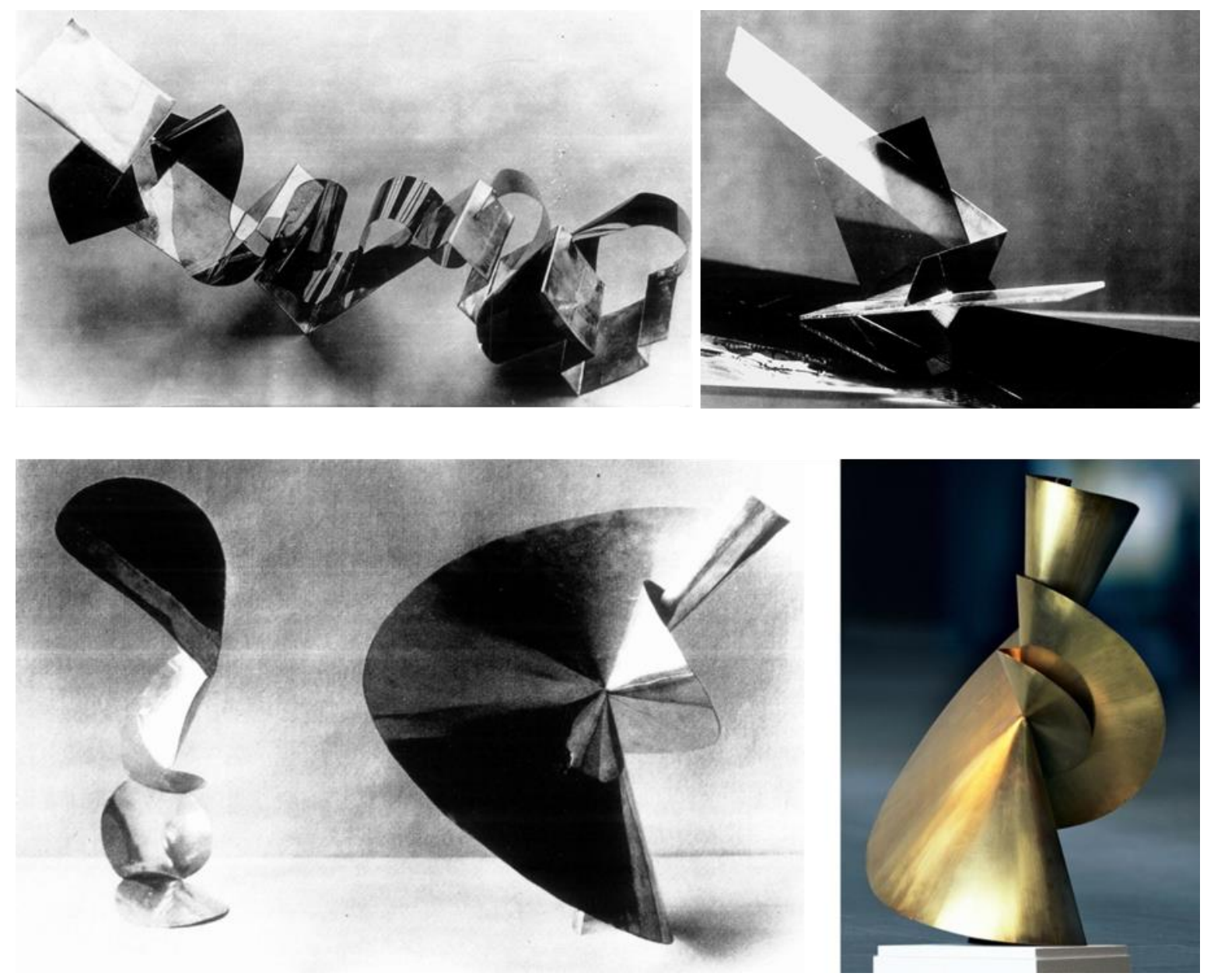

66. Estudios de equilibrio.

Autor: Anni Wildberg, 1924 (destruido).

Metal y cristal, fotografía de Lucia Moholy, BHA 
Comparado con el abismo ideológico que separaba a Itten y Moholy, incluso en la práctica pedagógica, las diferencias entre las nociones de Moholy y de Josef Albers pueden calificarse de poco significativas. Los recuerdos de Hannes Beckmann, estudiante de la Bauhaus, ofrecen un panorama bastante gráfico de los contenidos educativos y del estilo personal del ex alumno de Itten, Josef Albers.

"Entraba en la sala con un montón de periódicos bajo el brazo que mandaba repartir entre los estudiantes... "Señoras y señores, somos pobres, no ricos. No podemos permitirnos malgastar material ni tiempo. Debemos convertir lo peor en lo mejor. Cada obra de arte cuenta con un determinado material de partida y, por tanto, primero debemos investigar cómo está hecho este material. Para ello, primero deberemos experimentar, sin confeccionar nada. En estos momentos preferimos la habilidad a la belleza. El lujo dependerá del material con el que trabajemos. Piensen que en general conseguirán más cuanto menos hagan. Nuestro estudio debe fomentar el pensamiento constructivo. ¿Me han entendido? Ahora quiero que tomen los periódicos que les he dado y los conviertan en algo más de lo que son ahora. También quiero que respeten el material, que lo configuren de forma razonable y que tomen en consideración sus propiedades. Si pueden hacerlo sin ningún tipo de ayuda, como un cuchillo, tijeras o cola, mejor. ¡Diviértanse!”

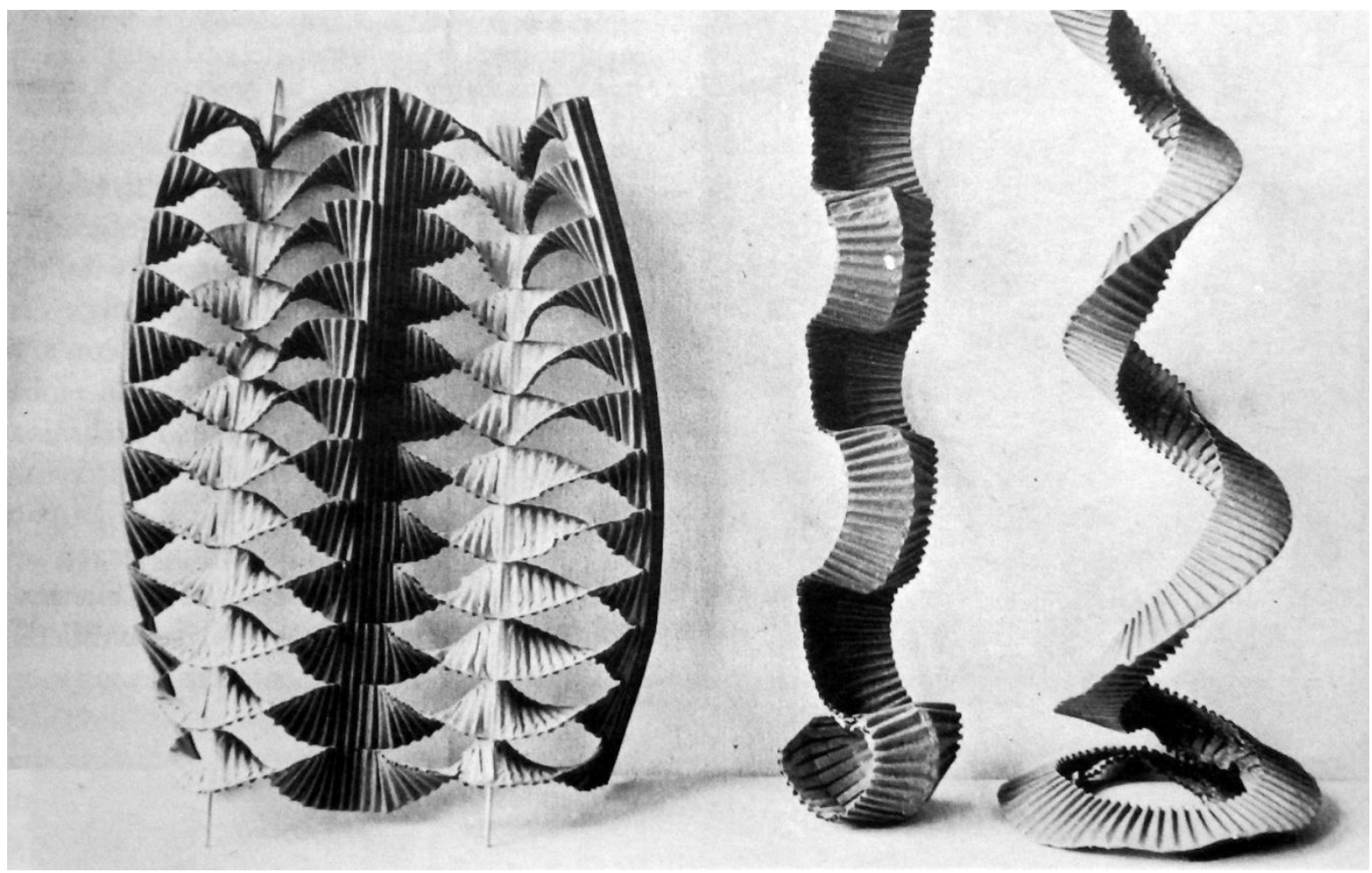

67. Ejercicio del curso dirigido por J. Albers. 1929.

Estudiantes Werner Zimmermann/Paul Reindl. Ejercicios de plisados.

Fotografo: Erich Consemilller.

Impresión en gelatina de plata $(11.9 \times 16.3 \mathrm{~cm})$

The Josef and Anni Albers Foundation, Bethany, Conn.

Fuente: Bauhaus 1919-33: Workshops for modernity. Pág 27. 
Horas después volvió y nos mandó que repartiéramos los resultados de nuestros esfuerzos por el suelo, delante de él. Había máscaras, barcos, castillos, aviones, animales y distintas figurillas muy imaginativas. Las calificó de baratijas de parvulario y afirmó que, en muchos casos, el resultado hubiera sido mejor con otro material. Entonces señaló una construcción de aspecto extremadamente simple que había confeccionado un joven arquitecto húngaro. Se había limitado a doblar el periódico a lo largo para que se sostuviera de pie en la forma de unas alas. Josef Albers nos explicó lo bien que había entendido el material, lo bien que lo había utilizado y lo natural que era el procedimiento de doblado en el papel, puesto que con él se conseguía dar rigidez a un material flexible, tanta fuerza que lograba mantenerse de pie sobre su punto más estrecho, el borde. Además, aclaró que un periódico sobre una mesa sólo tenía una cara visualmente activa, que el resto resultaba invisible. Ahora que el papel estaba de pie, resultaba activo visualmente por ambas caras. De este modo el papel había perdido su aspecto exterior aburrido y cansado.

El curso preliminar era como una terapia de grupo. Con la comparación ideológica de las soluciones de los demás estudiantes, aprendimos rápidamente a encontrar la más deseable para cada ejercicio. Y aprendimos a criticamos a nosotros mismos; una crítica que considerábamos más importante que las de los demás. Sin duda, esta especie de "lavado de cerebro" que experimentamos durante todo el curso preliminar nos ayudó a pensar con más claridad" 83

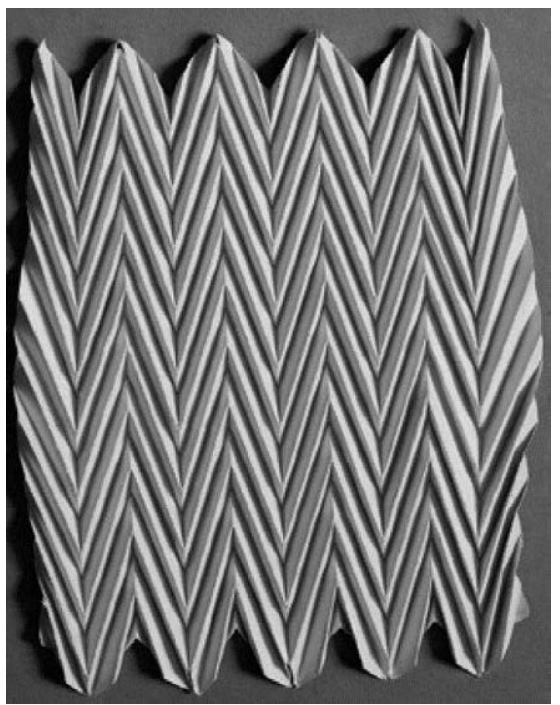

La clase descrita seguía aplicando las metodologías probadas en las clases de Itten, aunque con distinto contenido. Al igual que el cambio que tuvo lugar entre Itten y Moholy, también en este caso la cuestión sobre continuidad y ruptura planteada con tanta frecuencia en la Bauhaus se describe mucho mejor como una nueva interpretación ideológica, con un procedimiento ${ }^{84}$, este tipo de exploraciones fueron las que se llevaron a cabo en los primeros cursos de la Bauhaus y, como ya se ha explicado en páginas anteriores, el trabajo y experimentación con papel fueron uno de sus más exitosos ejercicios para formar a los alumnos en el desarrollo de habilidades espaciales, perceptivas y creativas.

68. Pliegues encadenados Miura.

Konrad Püschel, papel doblado, 1926-27. $(25$ × 25 cm)

Material para ejercicios preliminares del curso impartido por Josef Albers, Bauhaus Dessau.

\footnotetext{
${ }^{83}$ Bauhaus 1919-33: Workshops for modernity. (2009) Edit. David Frankel. MOMA, New York.

Fuente Original: Hannes Beckmann, "Dei Gründerjahre". En: Bauhaus und Bauhäusler, ed. Eckhard Neumann. Bema, 1971, p. 159 y s. Memories of Hannes Beckmann, a student at the Bauhaus

${ }^{84}$ Fiedler, Jeannine et Feierabend, Peter (2000) Bauhaus. Edit. Konemann, Colonia. ISBN 10: 3829025939 ISBN 13 9783829025935
} 

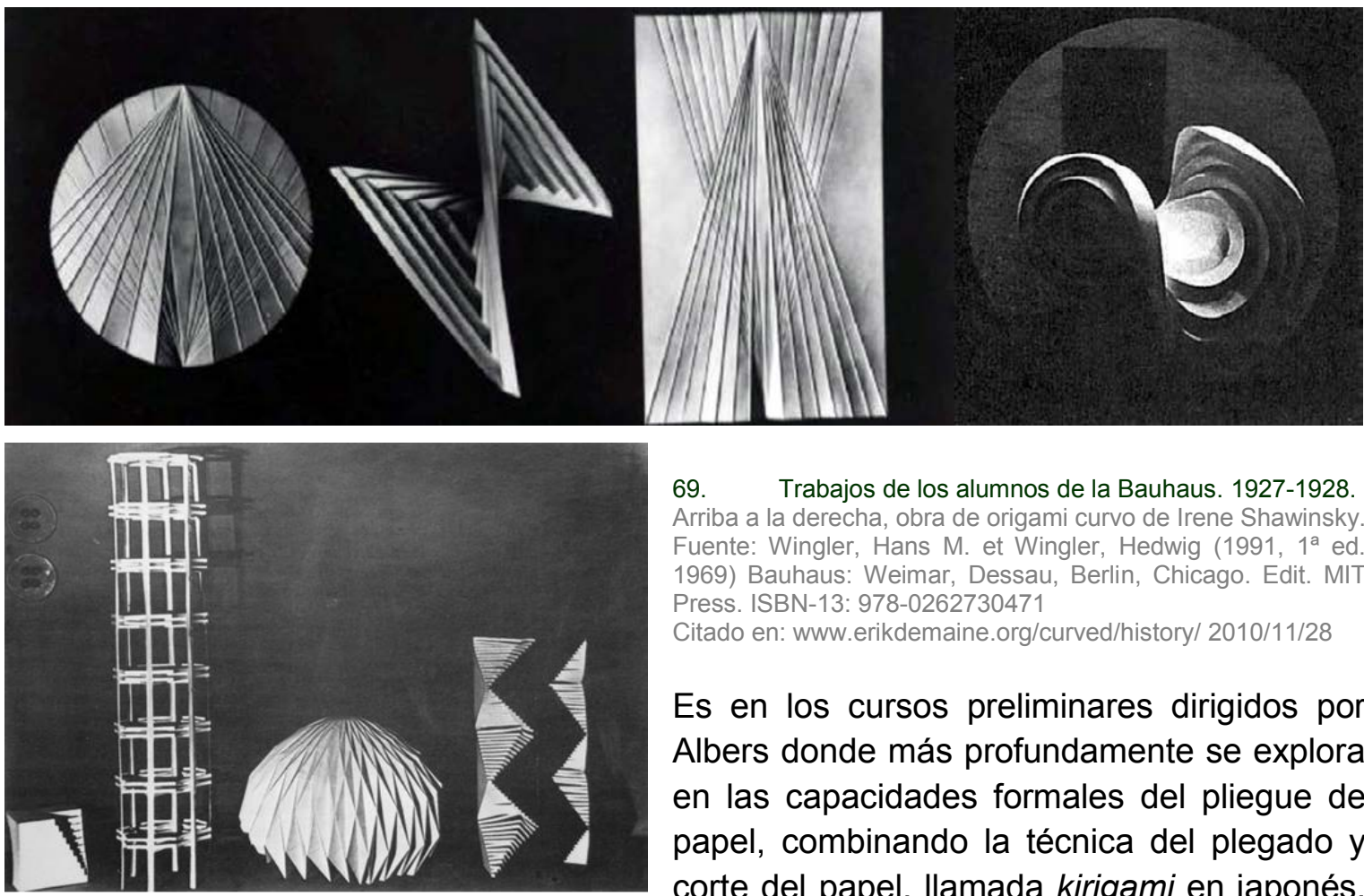

69. Trabajos de los alumnos de la Bauhaus. 1927-1928. Arriba a la derecha, obra de origami curvo de Irene Shawinsky. Fuente: Wingler, Hans M. et Wingler, Hedwig (1991, $1^{\text {a }}$ ed. 1969) Bauhaus: Weimar, Dessau, Berlin, Chicago. Edit. MIT Press. ISBN-13: 978-0262730471

Citado en: www.erikdemaine.org/curved/history/ 2010/11/28

Es en los cursos preliminares dirigidos por Albers donde más profundamente se explora en las capacidades formales del pliegue de papel, combinando la técnica del plegado y corte del papel, llamada kirigami en japonés,

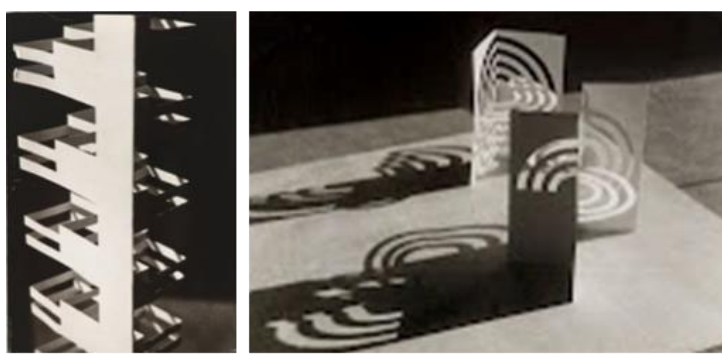

con el uso de plisados o pliegues en acordeón, junto con los patrones de pliegue en diamante y encadenados, estos dos últimos patrones se conocerán a finales del siglo XX por pliegues yoshimura y miura respectivamente.

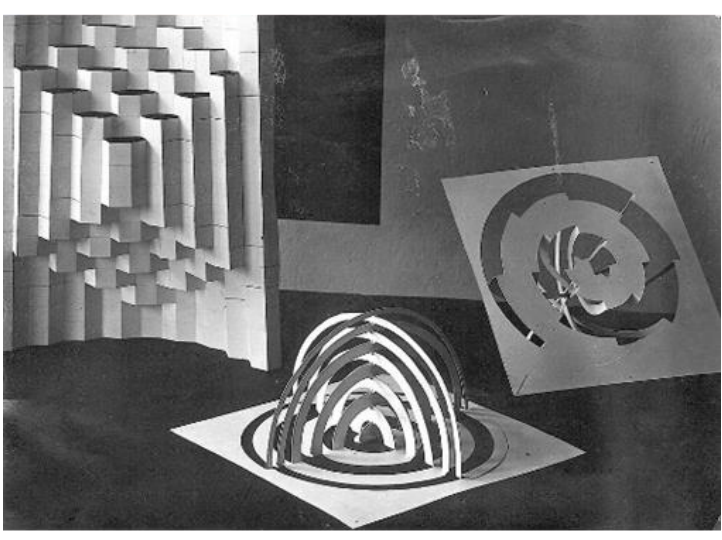

70. Ejercicios de Kirigami de Walter Tralau (izq.) y Ariel Sharon (abajo) (1927)

Fuente: Siebenbrodt, Michael, et all (2009) Bauhaus: A Conceptual Model. Edit. Hatje Cantz ISBN-13: 9783775724159 (foto: Erich Consemüller).

A la izquierda podemos ver obras en kirigami de los alumnos Walter Tralau (izq.) y Ariel Sharon (abajo) en las que se puede apreciar la rica y compleja variedad de patrones, técnicas de plegado y corte de papel utilizadas para generar nuevas formas vinculadas a procesos de formalización geométrica y matemática, donde se sucedían las repeticiones de un módulo, las simetrías y los patrones con ritmos binarios contínuos. Además hay que añadir que las primeras referencias conocidas de Origami Curvo contínuo se dieron en estos cursos, como se puede apreciar en el trabajo de la alumna Irene Shawinsky, imagen superior derecha. 
También en los talleres dirigidos por el artista Wassily Kandinsky se pueden apreciar complejas configuraciones espaciales visuales y escultóricas como la expuesta bajo estas líneas, una obra del alumno Henri Nouveau realizada en la Bauhaus de Dessau en 1928 en la que, mediante el pliegue de una lámina contínua de metal, se busca la representación plástica de los compases 52 y 53 de la fuga en mi bemol menor de J. S. Bach. En dos zonas situadas una detrás de otra se muestran gráficamente: (1) en horizontal, el proceso constructivo, (2) en vertical, el distanciamiento de cada tono del tono fundamental o tónica, (3) de delante hacia atrás (tanto en la base como en un ángulo ascendente de $45^{\circ}$ ) el distanciamiento de las voces entre ellas".
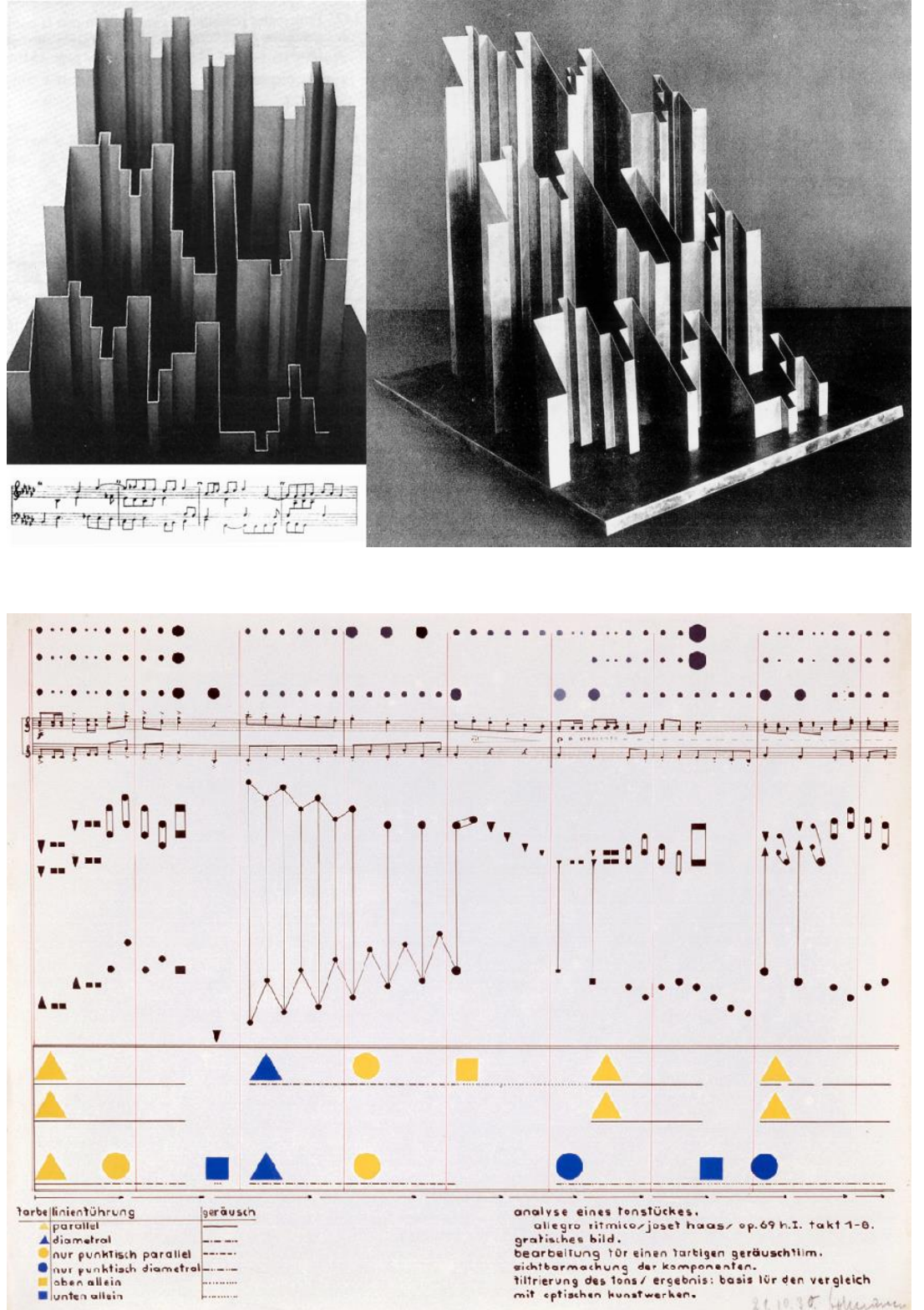

71. Representación plástica de la fuga en mi bemol menor de J. S. Bach.

Henri Nouveau (es decir Heinrich Neugeboren), 1928. Fotografía de Robert Binnemann, BHA.

Reconstrucción según el modelo de Gerda Marx, Bauhaus. Dessau.

Fuente: Fiedler, Jeannine et al (2000, Edición Española) Bauhaus. Edit. Konemann.
72. Heinrich-Siegfried Bormann - análisis visual de una pieza de música

Clase de teoría del color de Vasily Kandinsky - 21 de octubre de 1930

Fuente: MoMA catalogue Bauhaus: workshops for modernity - 2009 pag 18

https://www.moma.org/interactives/exhibitions/2009/bauhaus/assets/pdf/checklist.pdf 


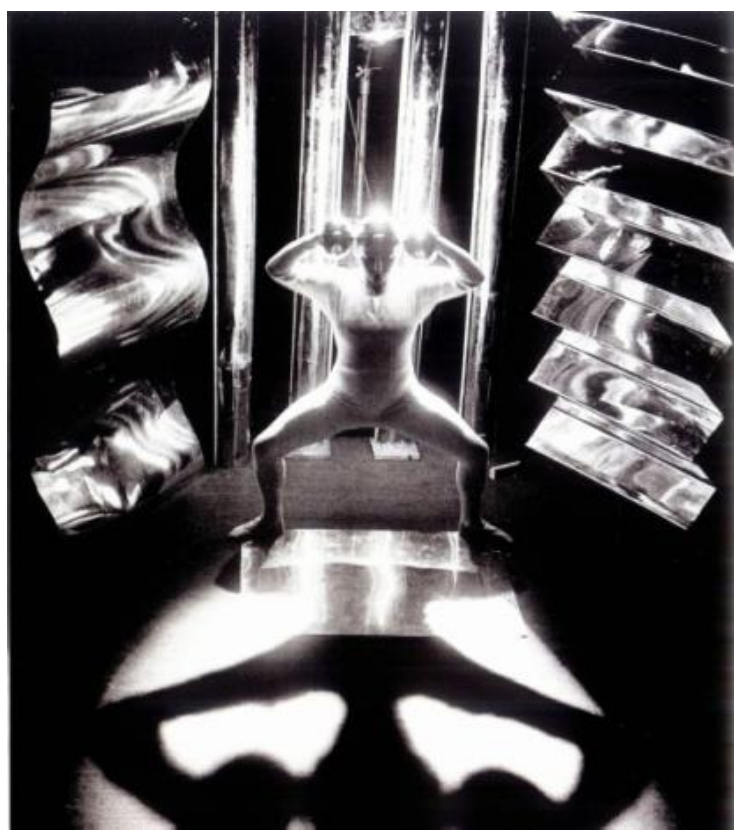

Otros usos que se dieron a los pliegues de superficies metálicas, plásticas y de papel se vieron en las escenografías del pintor, escultor y diseñador alemán Oskar Schlemmer, quien fue contratado en 1923 como maestro del taller de teatro.

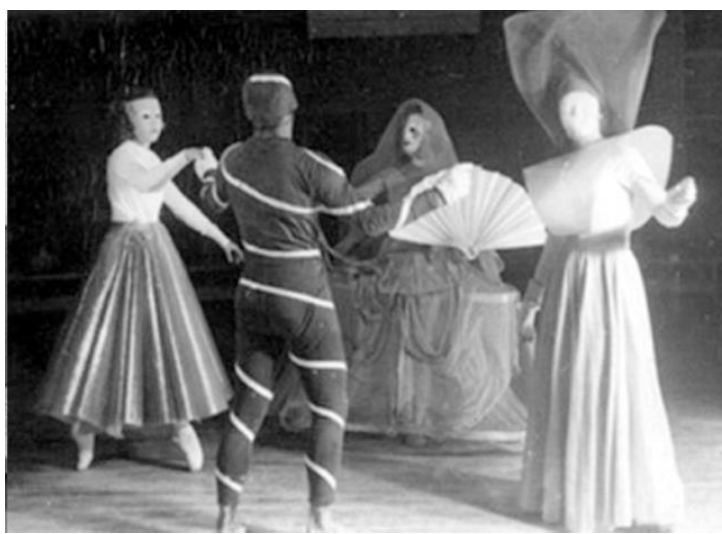

Posteriormente, y gracias a Josef Albers, estos patrones fueron utilizados también en el diseño de vestuarios teatrales $y$ carnavalescos en escuelas herederas de las experiencias pedagógicas de la Bauhaus como fue el Black Mountain College fundado en Carolina del Norte en 1933. Una institución universitaria que aplicaba un nuevo sistema experimental basado en una educación interdisciplinaria en la cual el arte era el

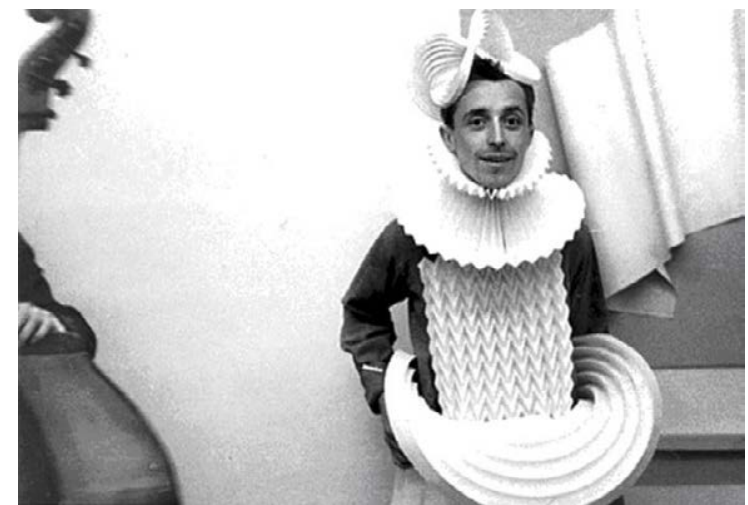
núcleo de la eduación, lo que atrajo a varios artistas, poetas y diseñadores que se convirtieron en profesores del College, como es el caso de Albers y Buckminster Fuller, los cuales impartieron sendos talleres en los años 50 .

74. Diseños de vestuario del Black Mountain College (izq 1955) y de la Bauhaus

Fuente: http://www.detnk.com/node/9557 


\subsubsection{Los juegos de construcción en papel y cartón}

\section{The toy. El juego de arquitectura de los Eames.}

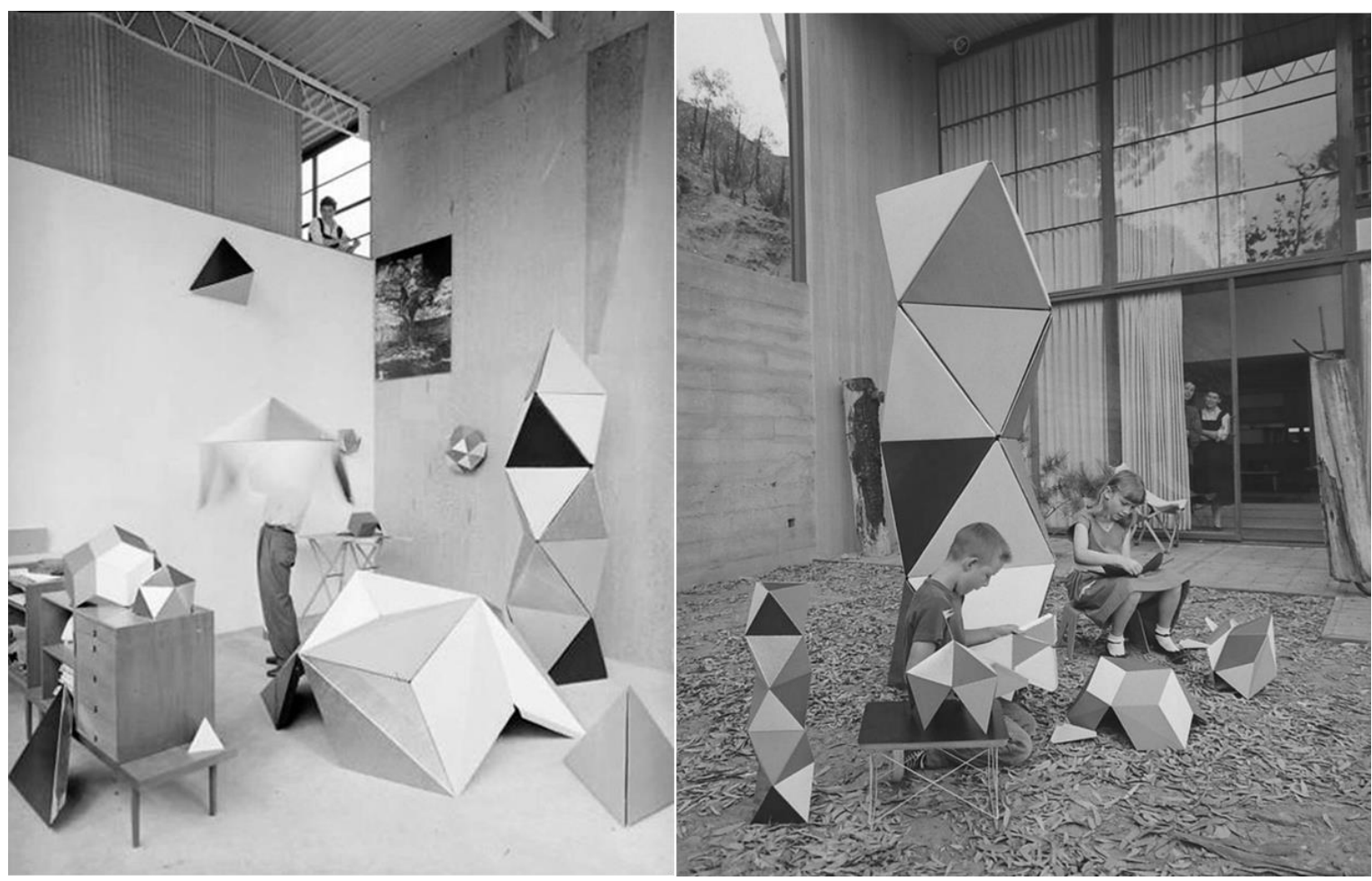

75. The Toy, Charles and Ray Eames. 1951

Ray Eames con la primera versión del prototipo The Toy realizada en triángulos de cartón, en el exterior de la casa de los Eames, 1951.

"Los juguetes no son tan inocentes como parecen. Suelen ser los precursores de grandes cosas". ${ }^{85}$ Esta sentencia de Charles Eames resume la potencia creadora y formadora que tienen los juguetes. Entre los años 40 y 60 los juegos de construcción con cartón y papel constituyeron uno de los mejores medios para dar a conocer e instruir a las nuevas generaciones en el conocimiento y desarrollo de los conceptos de origami modular y geométrico. Artistas y arquitectos diseñaron y produjeron múltiples y variados juegos que buscaban la máxima del célebre matrimonio Eames “Take your pleasure seriously"-tómate tu placer seriamente-.

85 "Toys are not as innocent as they appear. They are often the precursor to bigger things" 
Los Eames fueron una de las parejas más fructíferas de la historia del diseño. Charles Eames (1907-1978) y Ray Kaiser (1912-1988) desarrollaron su obra arquitectónica y artística expandiendo su labor durante casi 40 años, abarcaron un amplio abanico de disciplinas, diseño de interiores y expositivo, diseño gráfico, textil y de mobiliario, fotografía y cine. Sus obras fueron producidas con gran éxito por la empresa estadounidense fabricante de muebles y equipo de oficina Herman Miller, y posteriormente comercializadas también por Vitra para Europa y Oriente.

Con una perspectiva creativa vinculada a los parámetros de la Escuela de la Bauhaus, su labor no solo se centró en el diseño y fabricación de objetos funcionales, sino que entendían que el diseño debía participar pedagógicamente en la formación de la infancia, explorando el desarrollo de juegos y juguetes educativos con alto valor artístico. Para los Eames, la belleza de los juguetes se debía a que están hechos para proporcionar placer, para el ocio tanto de los niños como de los adultos. Y por medio del juego se accede al conocimiento y a las infinitas posibilidades de la creación artística como gérmen para grandes ideas.
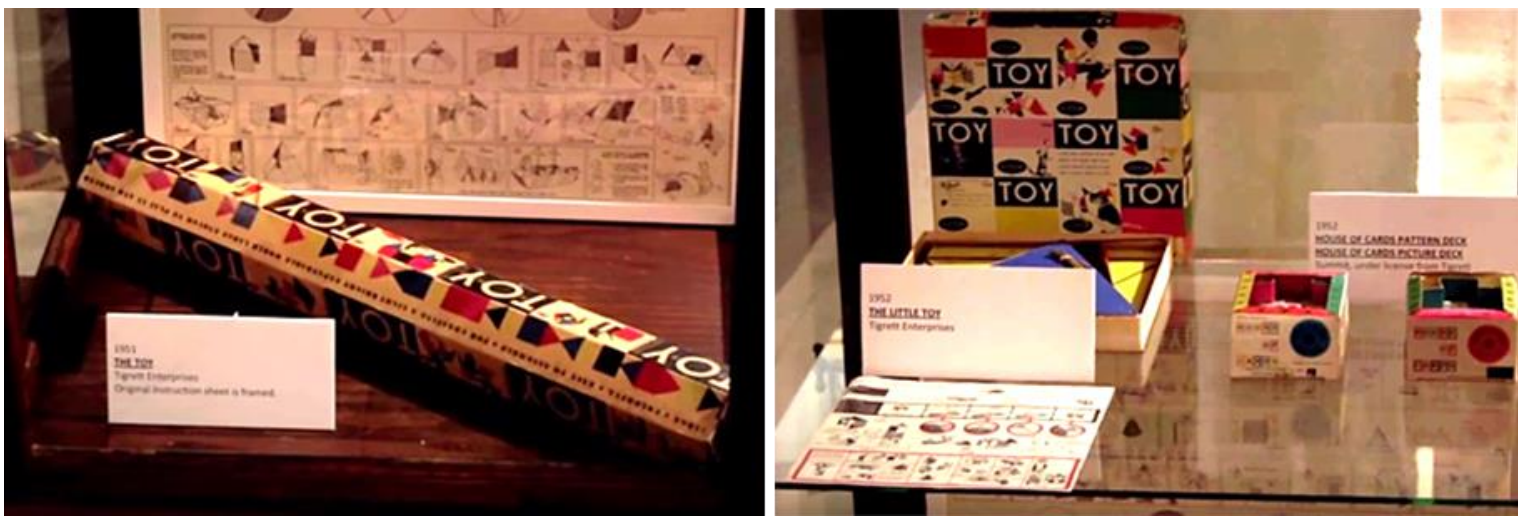

76. The Toy, Charles and Ray Eames. 1951

Ray Eames con la primera versión del prototipo The Toy realizada en triángulos de cartón, en el exterior de la casa de Ios Eames, 1951. Fuente: Jason Cohn y Bill Jersey en el documental "EAMES: The Architect and the Painter. (C) 2011 Eames Office, LLC

The Toy (el juguete) fue un proyecto de auto-ensamblaje realizado en 1951 por Charles y Ray Eames y vendido por Sears, Roebuck and Co. Este kit de construcción para los niños resume la sencillez y la alegría de la mayoría de las obras de la Eames. La oficina de Eames diseñó el juguete para adultos, adolescentes y niños de tal modo que pudiera utilizarse como un objeto escenográfico para favorecer la construcción de historias infantiles, como divertimento decorativo para interiores o como ligera y efímera arquitectura para alojar otros juguetes y objetos. En la etiqueta exterior se podía leer, "Grande, colorido y de fácil montaje para crear un ligero, brillante y expandible mundo lo bastante grande para jugar dentro y alrededor de él." (Large-Colorful-Easy to AssembleFor Creating a Light, Bright Expandable World Large Enough To Play In and Around) 
El juguete incluía paneles cuadrados y triángulos equiláteros de colores brillantes, junto con delgadas varillas de madera con extremos perforados y conectores de plástico. La propuesta inicial del estudio Eames tenía un gran formato y requería de grandes embalajes también especialmente diseñados, pero la empresa Tigrett encargada de la producción y comercialización expuso que este formato dificultaría el envío y almacenaje del juguete por lo que Charles y Ray crearon un tubo hexagonal que se adaptase a las necesidades de las tiendas. Sears, Roebuck \& Company tuvieron el juguete en su catálogo durante varias temporadas, y fue publicitado en un artículo de la revista Life el 16 de julio de 1951, dejándose de producir en 1959.

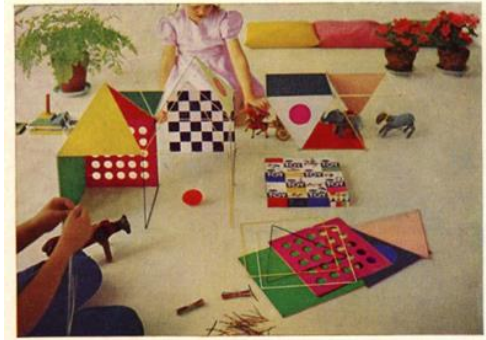

NO. 55 THE UTHE TOY Retall Peice $\$ 1.98$ ONE IN FOUR COLOR DISPLAY BOX

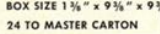

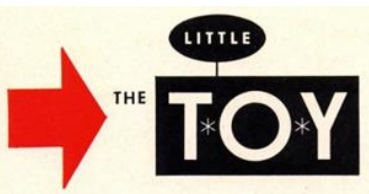

A TOY SIZED VERSION OF THE TOY WHICH, IN COLOR AND SCALE, MAKES BRIGHT ARCHITECTURE FOR A CHILD'S WORLD OF TOYS

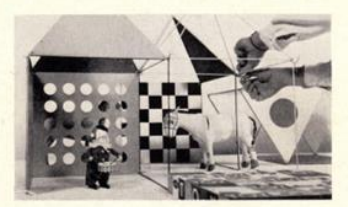

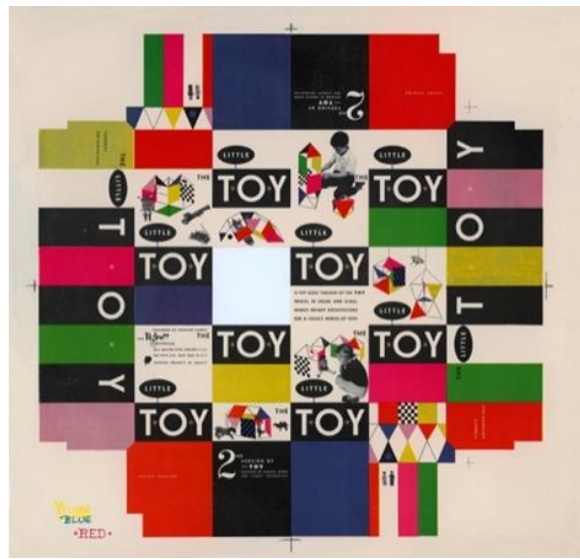

77. The Little Toy, Charles and Ray Eames. 1951.
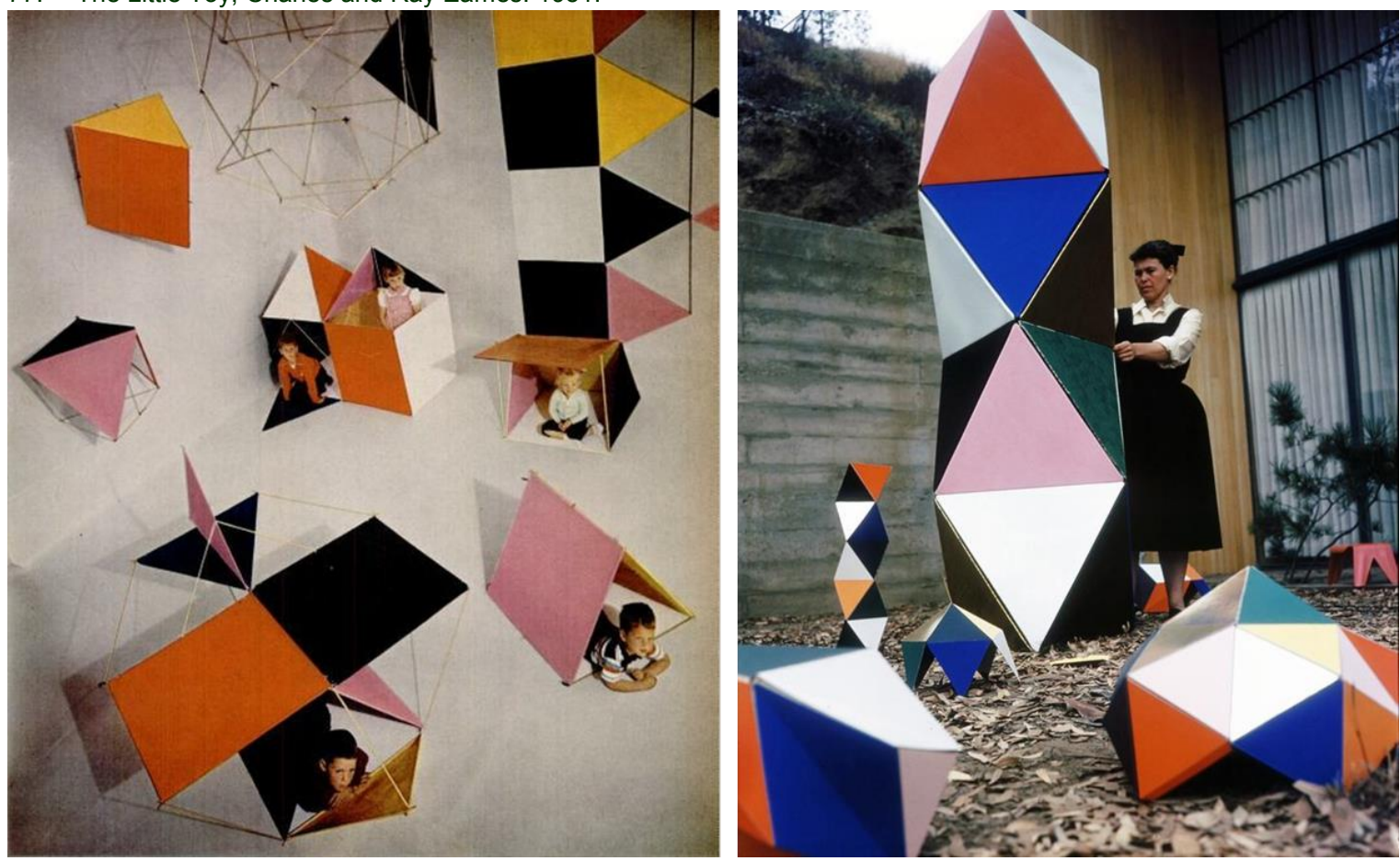

78. The Toy, Charles and Ray Eames. 1951

Ray Eames con la primera versión del prototipo The Toy realizada en triángulos de cartón, en el exterior de la casa de los Eames, 1951. Fuente: Jason Cohn y Bill Jersey en el documental "EAMES: The Architect and the Painter. (C) 2011 Eames Office, LLC 
Las esculturas-juego de Bruno Munari.

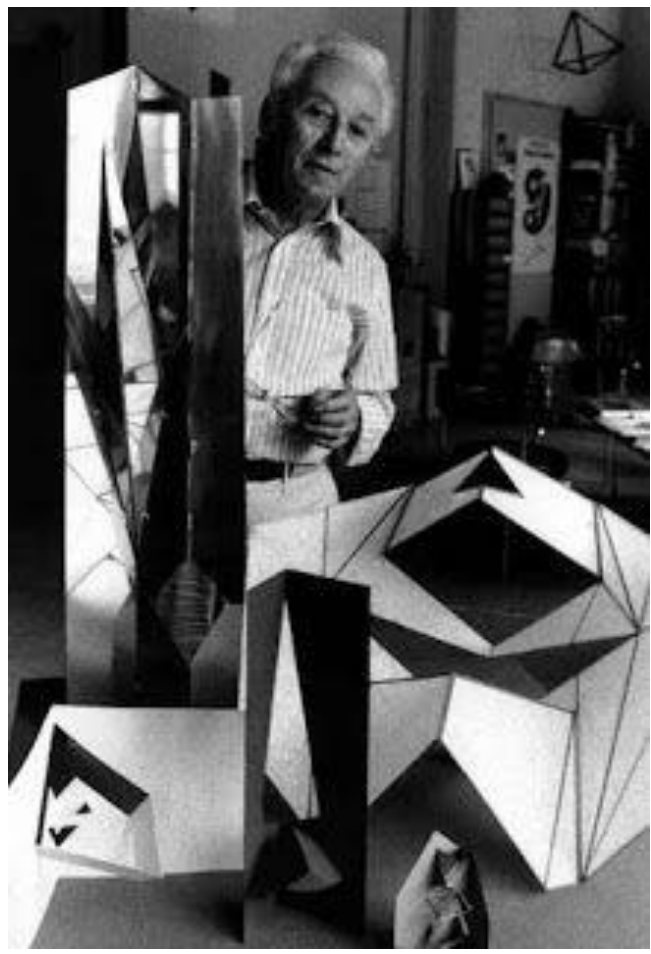

"jJugar es algo serio,

los niños de hoy son los adultos de mañana,

ayudémosles a crecer libres de estereotipos,

ayudémosles a desarrollar todos los sentidos,

ayudémosles a ser más sensibles,

un niño creativo es un niño feliz!"

Bruno Munari, $1986^{86}$
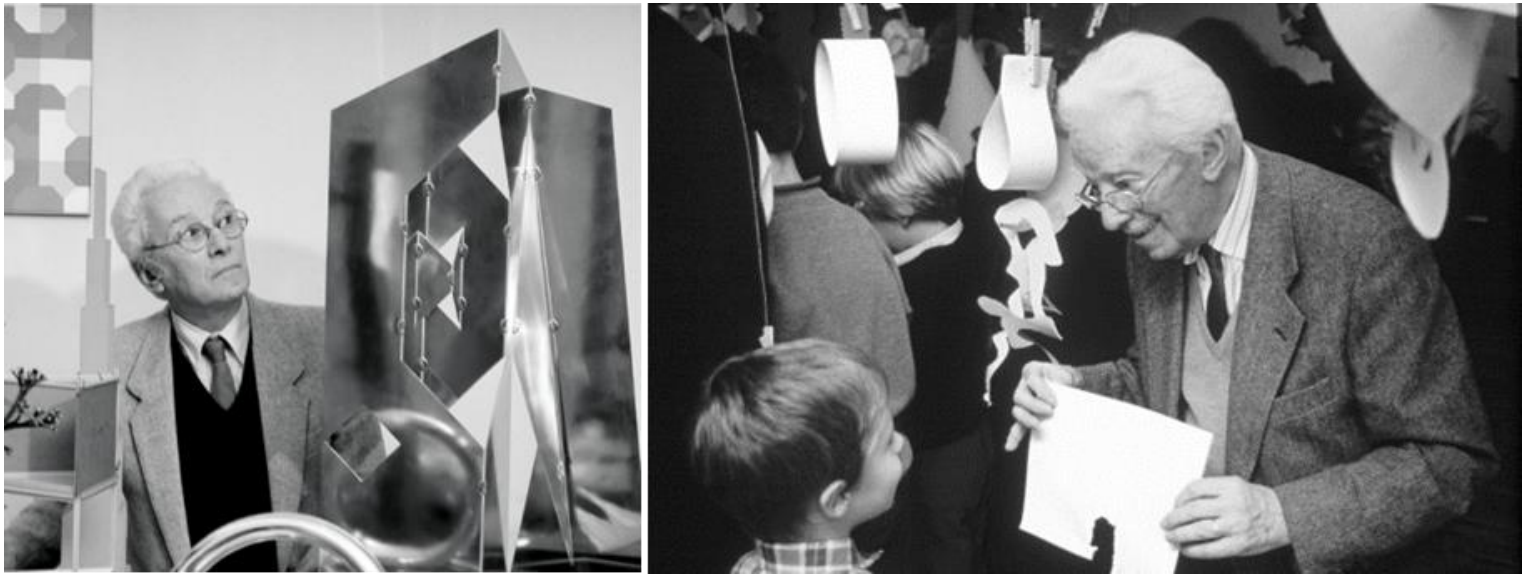

79. Bruno Munari. Escultura de viaje. Fotografías de Ada Ardessi

Fuente: http://www.espoarte.net/arte/munari-raccontato-in-fotografia-incontro-con-ada-ardessi/

Vinculado en sus comienzos al movimiento futurista italiano, Picasso lo describiría como "el Leonardo de nuestro tiempo" ${ }^{87}$. Artista, diseñador, poeta y divulgador humanista, Bruno Munari evolucionó el arte futurista de un arte pictórico que trataba de representar el movimiento a la búsqueda de una obra plástica que fuese en sí misma puro dinamismo tanto visual como corpóreo, creando en el proceso esculturas móviles aéreas colgadas del techo que, como dejará recogido Julio Carlo Argán anuncian el "movimiento natural de los móviles de Calder" ${ }^{88}$.

\footnotetext{
${ }^{86}$ Exposición Munari politécnico. Muestra realizada por Marco Sammicheli en el Museo del Novecento sobre la línea de la obra artísitica de Bruno Munari. Fuente: http://www.domusweb.it/it/arte/2014/05/15/munari politecnico.html

${ }^{87}$ Lichtenstein, Claude et W. Härberli, Alfredo (2000) Far vedere l'aria/ Air Made Visible: A Visual Reader on Bruno Munari. Ed. Lars Müller. Zurich. p. 10.

${ }^{88}$ Argán, Giulio Carlo (1998, $1^{\text {a }}$ ed. 1991) El Arte Moderno. Del iluminismo a los movimientos contemporáneos. Ediciones AKAL. pp 623
} 

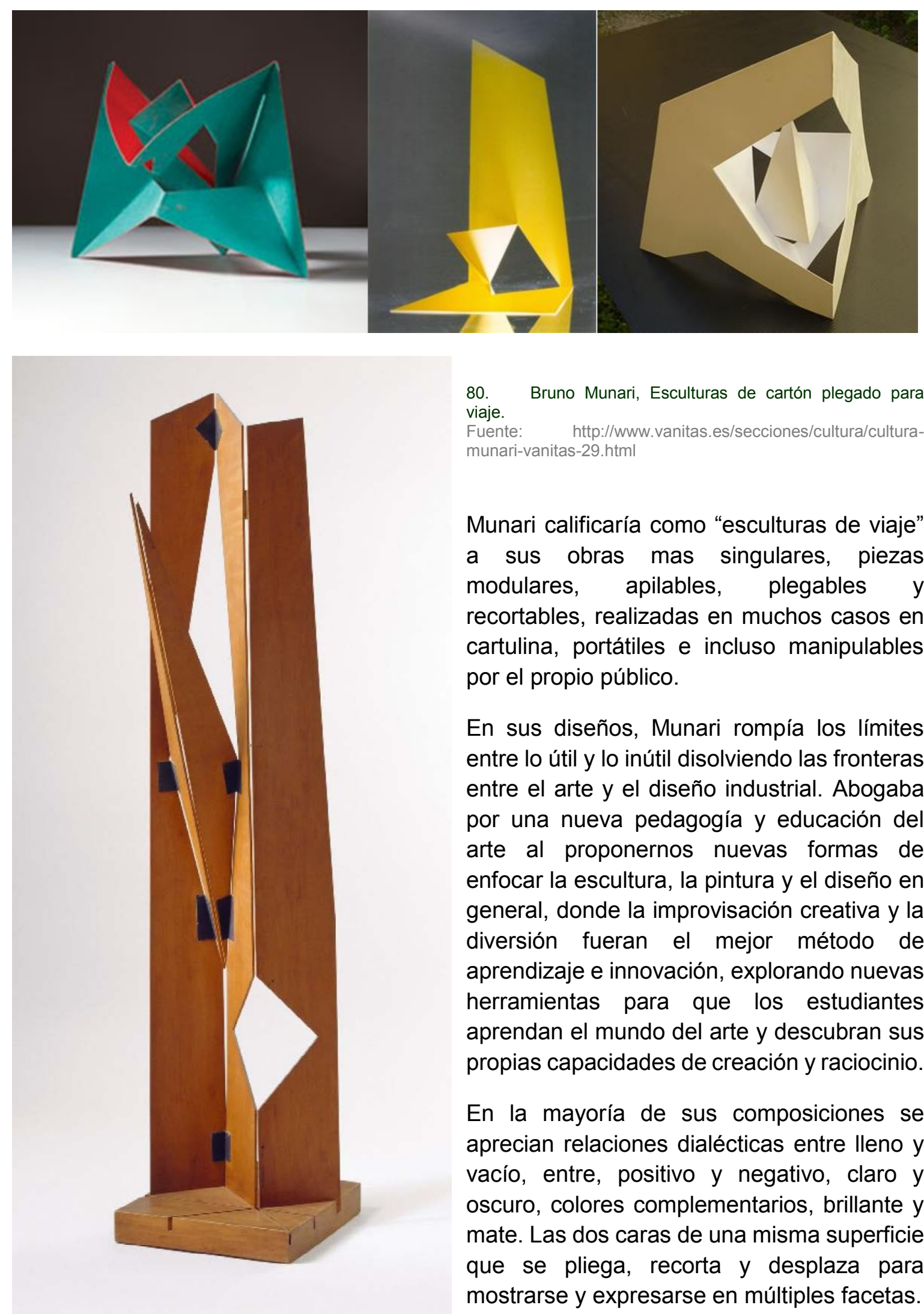

80. Bruno Munari, Esculturas de cartón plegado para viaje.

Fuente: http://www.vanitas.es/secciones/cultura/culturamunari-vanitas-29.html

Munari calificaría como "esculturas de viaje" a sus obras mas singulares, piezas modulares, apilables, plegables y recortables, realizadas en muchos casos en cartulina, portátiles e incluso manipulables por el propio público.

En sus diseños, Munari rompía los límites entre lo útil y lo inútil disolviendo las fronteras entre el arte y el diseño industrial. Abogaba por una nueva pedagogía y educación del arte al proponernos nuevas formas de enfocar la escultura, la pintura y el diseño en general, donde la improvisación creativa y la diversión fueran el mejor método de aprendizaje e innovación, explorando nuevas herramientas para que los estudiantes aprendan el mundo del arte y descubran sus propias capacidades de creación y raciocinio.

En la mayoría de sus composiciones se aprecian relaciones dialécticas entre lleno y vacío, entre, positivo y negativo, claro y oscuro, colores complementarios, brillante y mate. Las dos caras de una misma superficie que se pliega, recorta y desplaza para mostrarse y expresarse en múltiples facetas.

81. Sculptura pieghevole (escultura plegable), 1958.

Madera de peral y cinta adhesiva negra. Edición 10/10, 30x94 cm. Cortesía de la Fondazione J. Vodoz.

Fuente:http://www.espoarte.net/arte/munari-raccontato-in-fotografia-incontro-con-ada-ardessi/ 


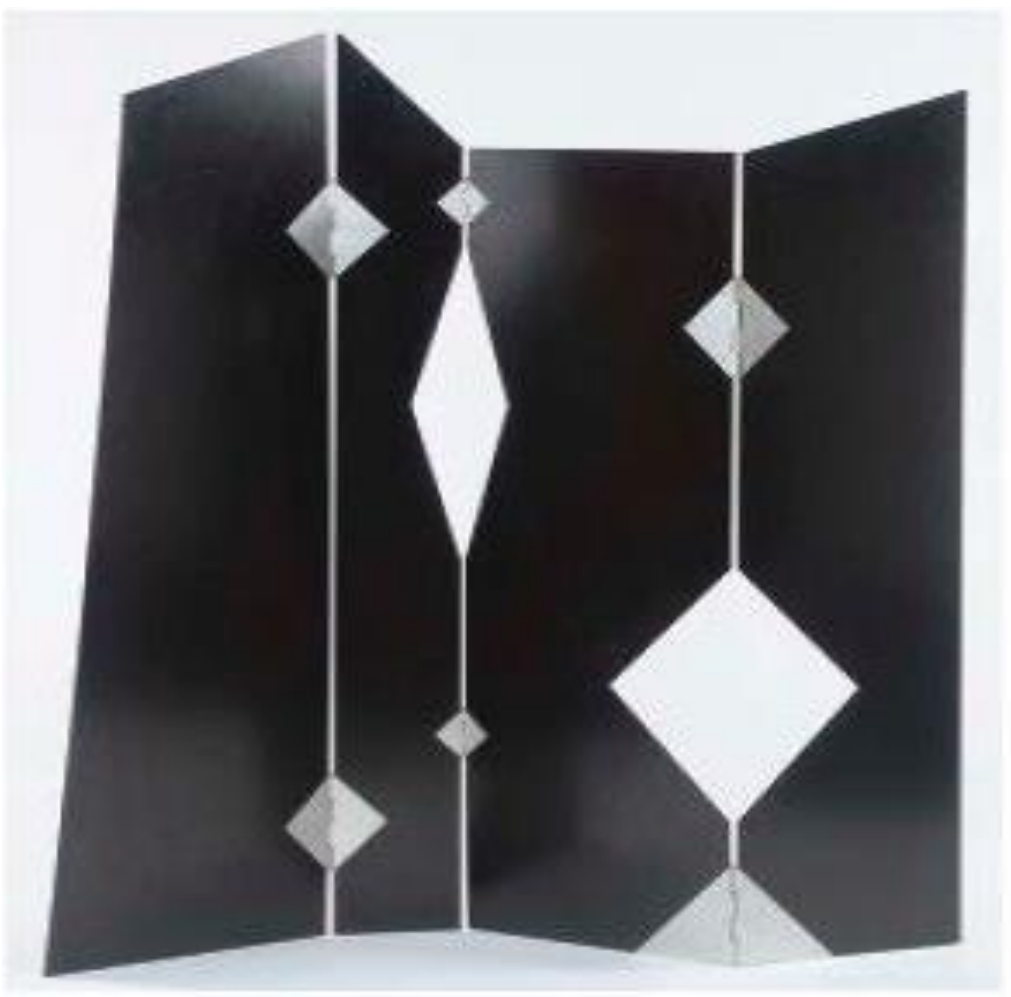

82. Bruno Munari, Biombo -Zanotta - Spiffero- 1986

Partly black-lacquered openworked steel $168 \times 140 \mathrm{~cm}$

Fuente: https://www.1stdibs.com/furniture/more-furniture-collectibles/screens/folding-screen-spiffero-bruno-munarizanotta/id-f_3940613/
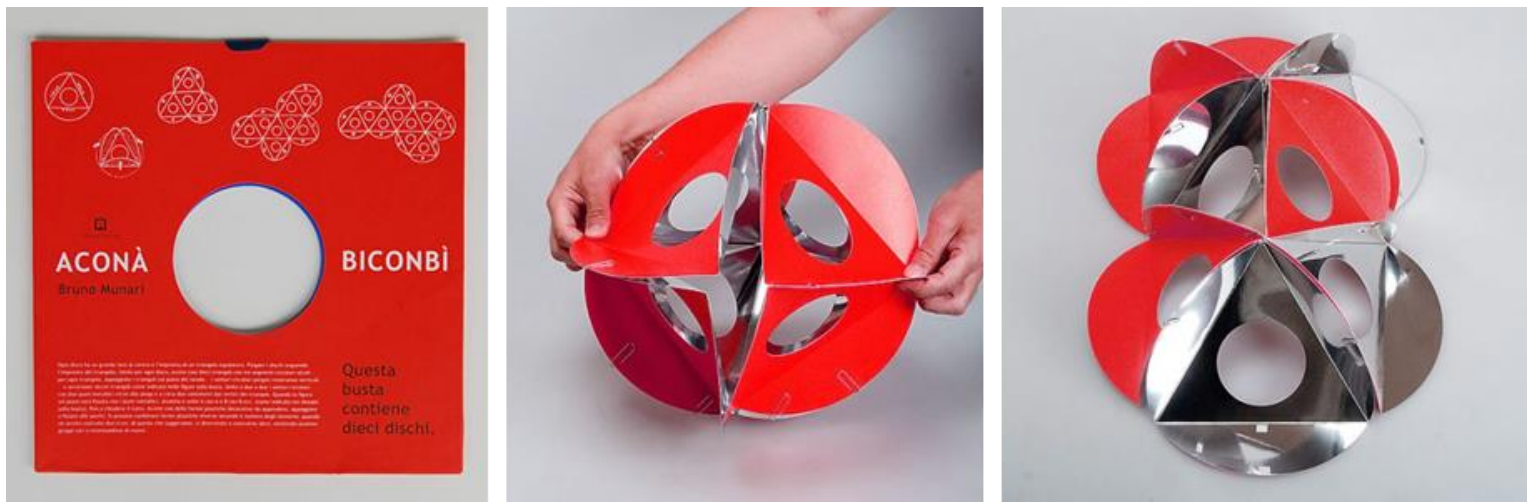

83. Escultura juego "Acona Biconbi” de Bruno Munari. Italia 1960.

Fuente: https://watermeloncates.wordpress.com/tag/70s/

Reeditada en 2007, la versión en cartón de la escultura-juego Ancona Biconbi es un buen ejemplo de la gran cantidad de juegos diseñados por Munari. Creada a finales de los años 50 del pasado siglo, sigue fascinando por su simpleza e infinidad de posibilidades.

Consta de varios discos de cartón de $22 \mathrm{cms}$ de diámetro y una cara de color y otra metalizada. Tras doblarlos para formar en su centro el mayor triángulo equilátero circunscrito, pueden combinarse en muy variadas configuraciones como parte de las exploraciones sobre repeticiones de un módulo que realizó Munari. 
Polypops. Los juguetes de cartón de Roger Limbrick.

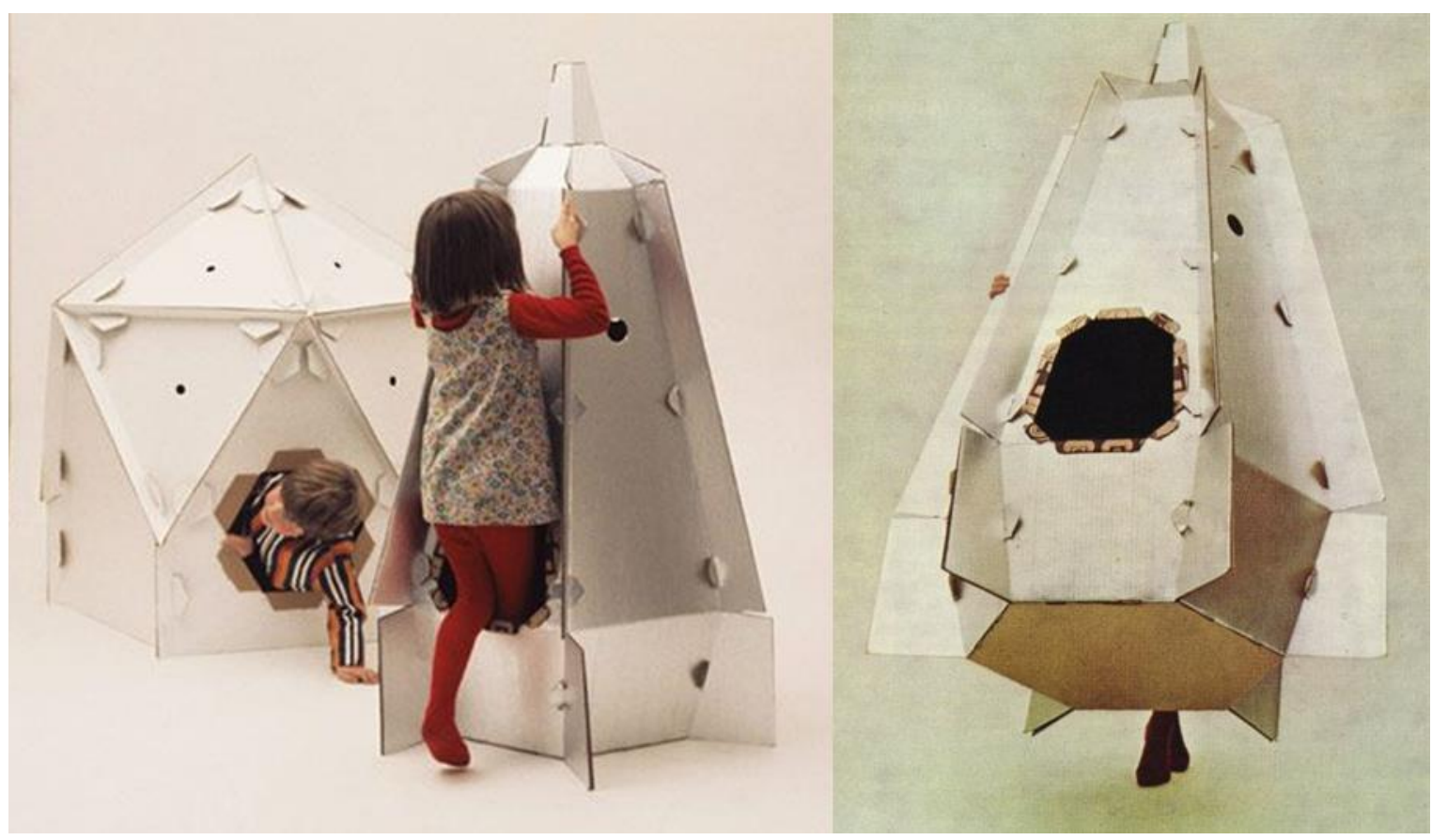

84. "King Castle" Roger Limbrick 1968

Fabricado por Polypops Products Ltd

Fuente: http://www.rogerlimbrick.info/119-polypops-cardboard-toys

En 1966 Roger Limbrick recibió el encargo por parte de la empresa Reed Paper Group de dirigir un proyecto de investigación y diseño enfocado en la exploración de nuevas aplicaciones para el cartón corrugado. Roger estaba particularmente interesado en diseños que implicaran a los niños en juegos activos que fomentaran la interactuación y el movimiento para mejorar su desarrollo motriz y sus capacidades exploratorias. Sus investigaciones le llevaron a diseñar una serie de grandes juguetes de acción para niños que tuvieron un cierto éxito comercial al producirse a nivel mundial una serie de 5 juegos.
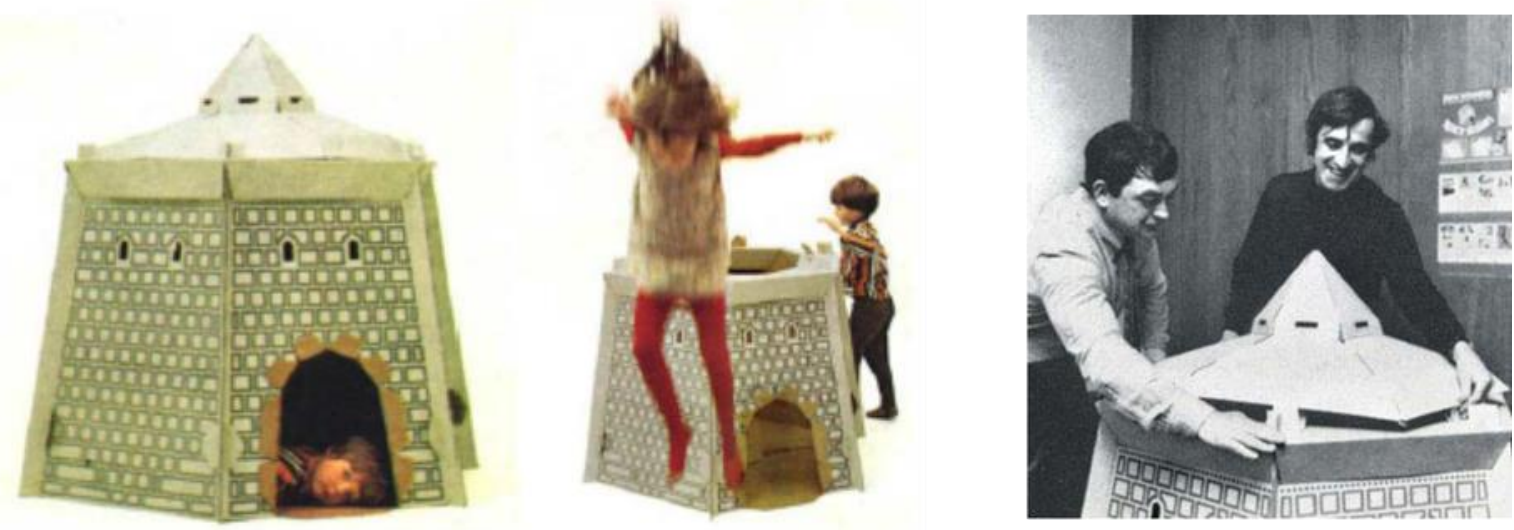

85. "King Castle". Roger Limbrick 1968

Derecha: Fotografía de Roger Limbrick y de un colaborador colocando la cubierta del King Castle.

Fuente: http://www.rogerlimbrick.info/119-polypops-cardboard-toys 
El castillo fue el primer diseño de la serie. Muchos de los avances en la producción de superficies de cartón y de las mejoras en sus características constructivas y estructurales fueron consideradas, exploradas e inplementadas en este diseño - incluyendo el uso de pestañas dobladas y ranuras para crear fuertes uniones. Realizado con 18 paneles preperforados preparados para el montaje, auto doblando y ajustado sin uso de pegamento, disponía de elementos móviles y desmontables como el techo del castillo, las paredes y la cubierta eran lo suficientemente fuertes como para permitir que los niños lo escalaran.
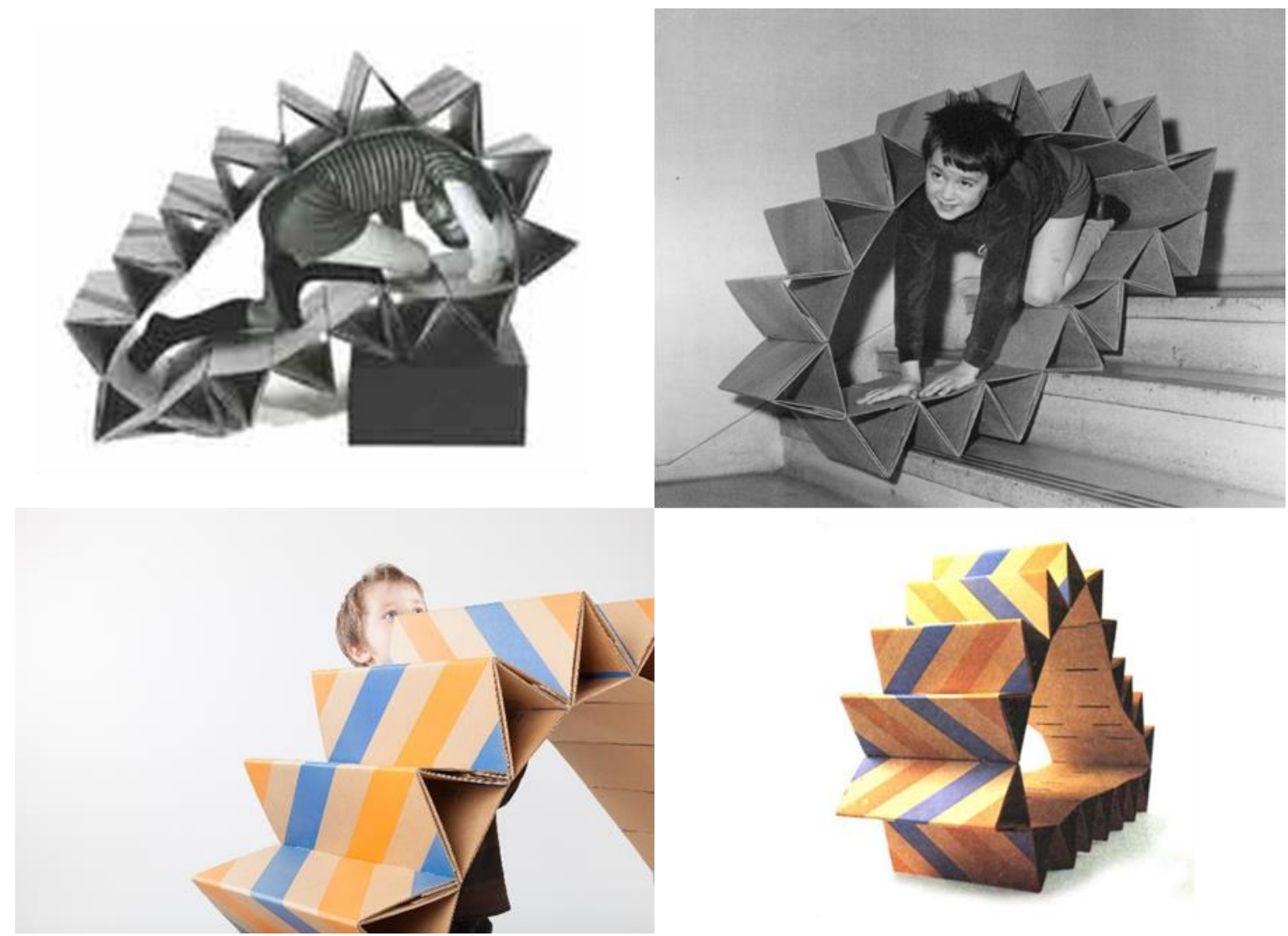

86. "Lunartrack" Roger Limbrick 1968

Fabricado por Polypops Products Ltd Ejemplos de los juegos en acción.

Fuente: http://www.rogerlimbrick.info/119-polypops-cardboard-toys

Ver también: Best, Alastair (01/03/1969) Imaginative toys. Design Journal. issue 243. Article 3. p. 36-39

http://vads.ac.uk/diad/article.php?year=1969\&title=243\&article=d.243.33

El Lunartrack fue otro de los grandes éxitos de Lumbrick, se asemejaba a una especie de correa de tanque o de los vehículos "oruga" parecidos a los que se estaban desarrollando para la carrera espacial. Nuevamente buscaba la acción del niño para que, al arrastrarse por la superficie interior, el objeto avanzaba cual vehículo. Este objeto al igual que otros diseños de cohetes y naves de cartón ${ }^{89}$ respondían al intenso interés de la sociedad de los años 60 en toda la información gráfica y audiovisual sobre los viajes espaciales y los alunizajes programados por la NASA, la agencia espacial de Estados Unidos.

${ }^{89}$ Kinchin, Juliet et O'Connor, Aidan (2012) Century of the Child: Growing by Design, 1900-2000 

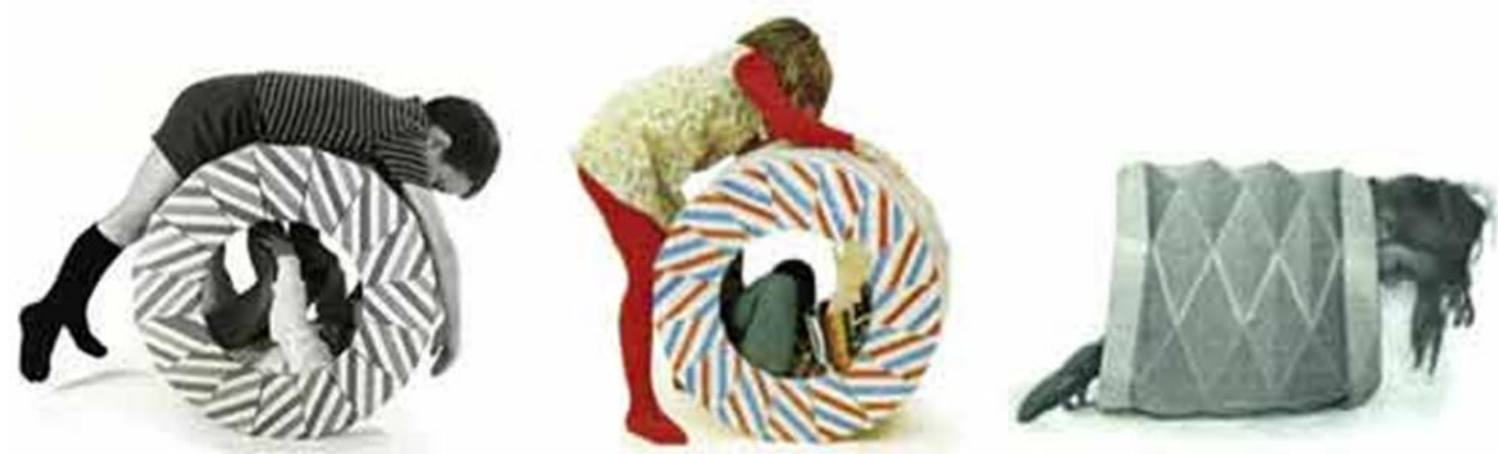

87. "Polyroly" y "Tube". Roger Limbrick 1968

Fabricado por Polypops Products Ltd Ejemplos de los juegos en acción. El Tubo (último a la derecha) es un prototipo no producido finalmente. Fuente: http://www.rogerlimbrick.info/119-polypops-cardboard-toys

Ver también: Design Journal 1969 - issue 243:

http://vads.ac.uk/diad/article.php?year=1969\&title=243\&article=d.243.33
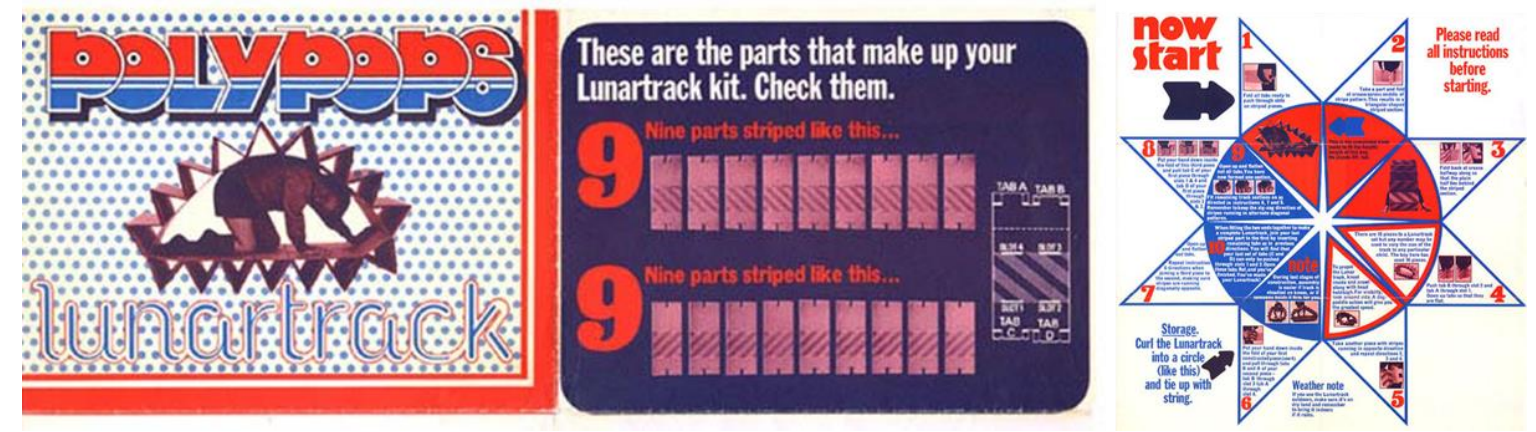

88. Folleto informativo del Lunatrack. Roger Limbrick 1968

Los juguetes de Limbrick se produjeron bajo el nombre POLYPOPS. La empresa iría mejorando las cualidades del simple cartón corrugado, laminando las placas para conseguir un mejor aspecto y una mayor resistencia del producto final a los embates de los niños. A fines de los '60 la empresa contaría con varios productos en el mercado desde mobiliario infantil a casitas de muñecas, todo producido en este material.
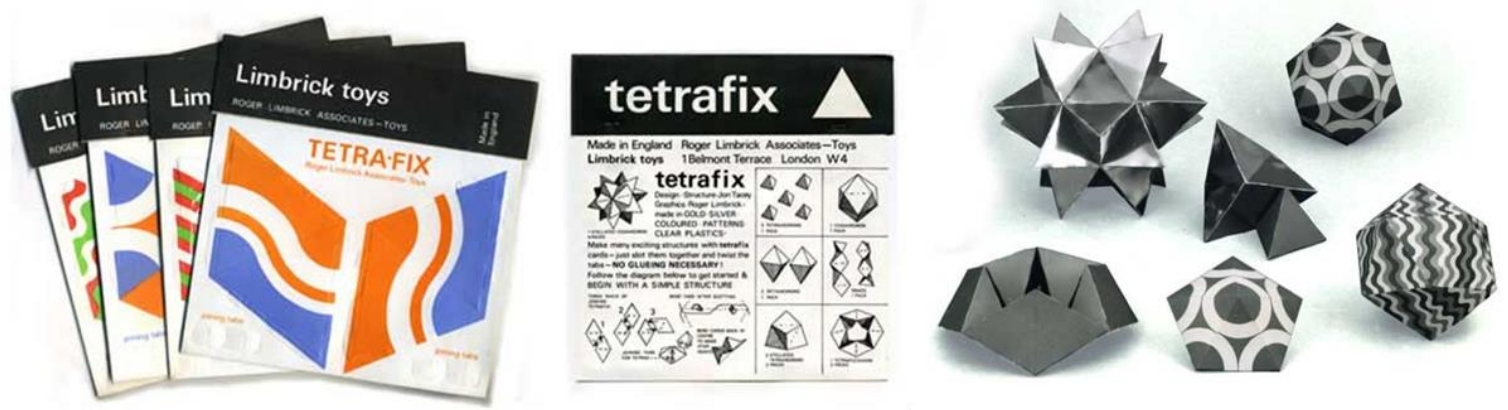

89. Tetrafix. Roger Limbrick 1968

Producido por Roger Limbrick Associates

Limbrick también se interesó en las posibilidades que la papiroflexia u origami abstracto o geométrico podían representar como juegos didácticos y formativos. Para ello desarrolló con su propia empresa una serie de variantes de configuraciones tridimensionales como icosaedros, tetraedros, dodecaedros... que vino a llamar tetrafix. Entre estas figuras se encuentra la que diez años más tarde la matemática Doris Schattschneider calificó de Caleidociclos. 


\section{El Flexagón, los Calidociclos y los Kinetogamis}

Exceptuando los ejercicios de Friedrich Fröebel con un enfoque mucho más instructivo y los libros recortables como el conocido "Papiro-plastics, The art of modelling in paper" que desde mediados del siglo XIX se habían convertido en un popular pasatiempo para la construcción en papel de castillos y casas de estilo vernáculo, ecléctico e historicista. Uno de los primeros ejemplos de construcciones modulares que combinaban objetivos didácticos con los lúdicos los podemos ver en los flexágonos descubiertos por el estudiante de postgrado Arthur Harold Stone en 1939, cuando tenía 23 años de edad, en la Universidad de Princeton (Estados Unidos).

Según nos cuenta Paul Jackson en su famoso libro "Flexagons: Origami flexagon paper folding" 90 , el descubrimiento se debió a la trivial circunstancia de que los folios para archivar estadounidenses eran más anchos que los británicos. Tras recortar la pulgada de más de las hojas estadounidenses que había comprado, para ajustarlas a las dimensiones del bloc de anillas que se había traído de Cambridge, su universidad de origen, Stone comenzó a plegar distraídamente las tiras de papel sobrantes de diversas formas y logró así una interesante figura plana en forma de hexágono regular que tenía una curiosa característica, ya que al unir tres de sus esquinas alternas, se podía volver a abrir, de manera similar a una flor, pero mostrando una nueva cara que antes no era visible y ocultando una de las que sí lo eran.
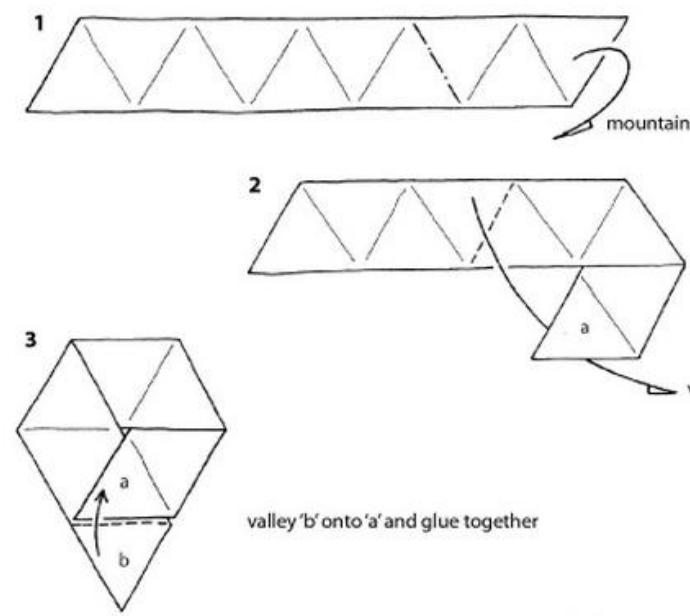

2

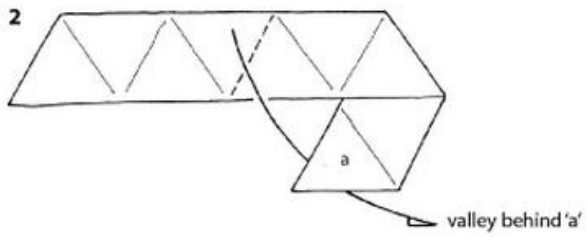

valley 'b' onto' $a$ ' and glue together

number as shown
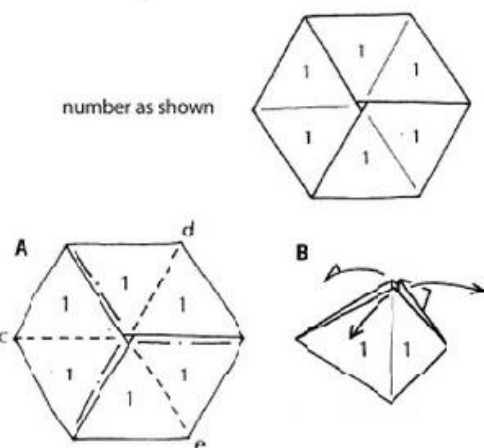

B

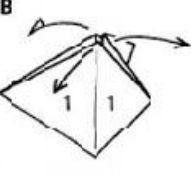

oren out a: the top
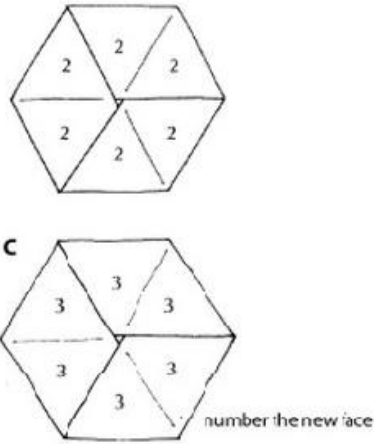

Face 2 has disappeared and 3 has taten its plsce. A further fex will make 1 diappear and bring 2 and 3 together.
90. Método de plegado de un trihexaflexagón. Fuente: Jackson, Paul. (2013, 1ª edición 1978) Flexagons: Origami flexagon paper folding. Editorial British Origami Society. pp 8 -9.

90 Jackson, Paul. (2013, $1^{a}$ edición 1978) Flexagons: Origami flexagon paper folding Editorial British Origami Society. p. 2. www.britishorigami.info ISBN 9781482569995 
A esta primera construcción se la conoce por el nombre de trihexaflexagón. Quizás el que Stone realizara su especialización en matemáticas topológicas le ayudara a darse cuenta de la especiales características de su casual descubrimiento. Al día siguiente consiguió construir un nuevo tipo de figura, esta vez con seis caras, dos visibles y cuatro ocultas, que posteriormente, y tras compartirlo con sus compañeros de la universidad, fue asignado con el complejo nombre de hexahexaflexágono.

El nombre de flexágono hace referencia a las características de la figura, ya que se trata de un polígono, flexible y transformable que ha sido realizado mediante procedimientos de pliegue de unas tiras de papel. Los flexágonos pronto se convirtieron en el pasatiempo más popular entre los matemáticos y científicos en general de la Universidad de Princeton, donde se fundó el Princeton Flexagon Committee (Comité de Flexágonos de Princeton) que agrupaba a destacados científicos como el matemático Bryant Tuckerman, que desarrollaría un método topológico, denominado "Tuckerman traverse", para descubrir todas las caras de un flexágono, el físico Richard P. Feynman (que sería posteriormente reconocido con el Nobel de Física en 1965) y el estadístico John W. Tukey.

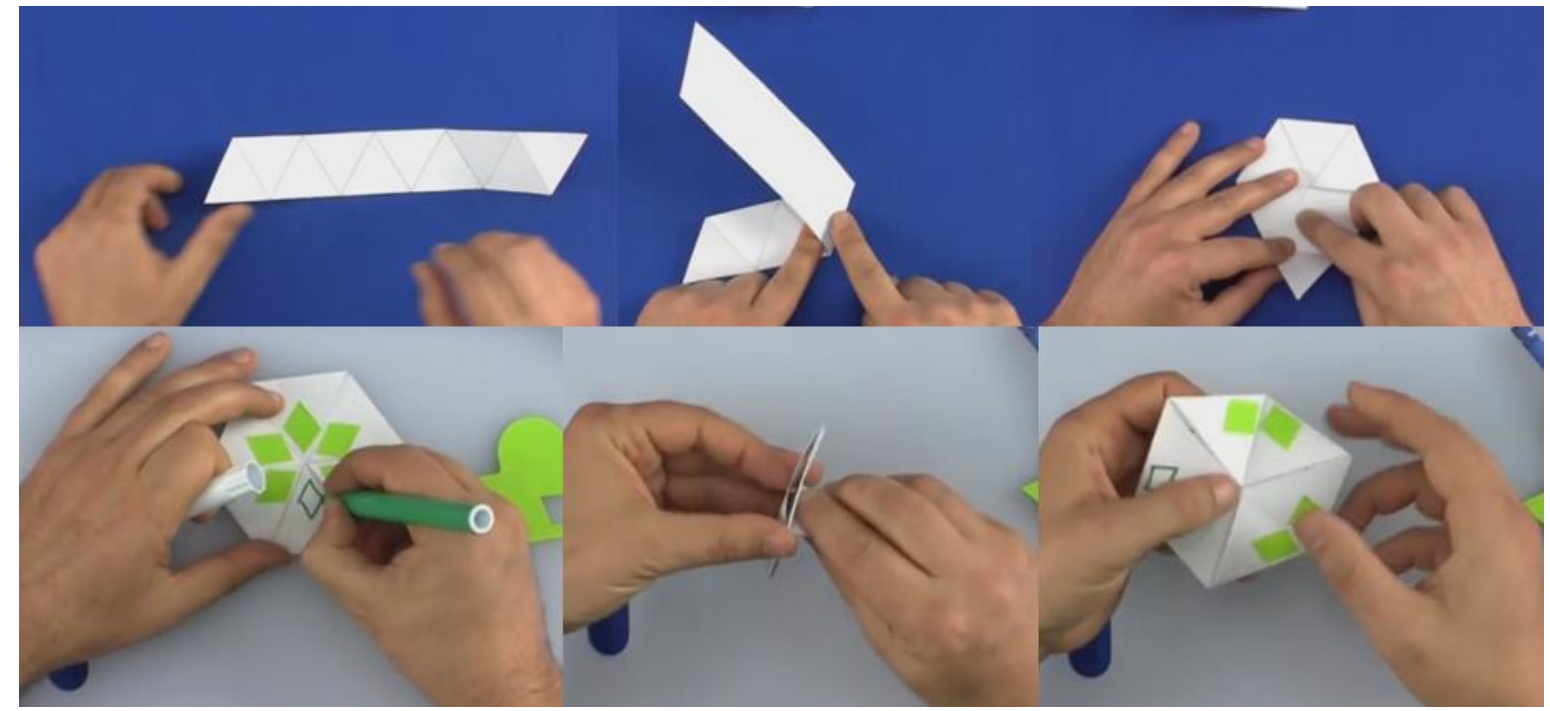

91. Secuencia de plegado de un Hexaflexágono.

Fuente: Gioco carta esagonale: How to make a flexagon. https://www.youtube.com/watch?v=zVGaiakMMS\&

Los flexágonos fueron dados a conocer entre la comunidad científica desde mediados de los años 50 gracias a la labor del filósofo y divulgador científico Martin Gardner, con la publicación de sus artículos de juegos matemáticos para la prestigiosa revista Scientific American. Precisamente la primera de estas columnas suyas, publicada en 1956, se llamaba "Flexágonos, en donde tiras de papel son usadas para hacer figuras hexagonales de inusuales propiedades" 91 . Posteriormente en 1959 publicaría el libro recopilatorio de sus exitosos artículos titulado "Hexaflexagonos y otras diversiones matemáticas" 92.

\footnotetext{
91 Gardner, Martin. (Diciembre de 1956) Flexagons. In which strips of paper are used to make hexagonal figures with unusual properties. Revista Scientific American.

Fuente: http://blogs.scientificamerican.com/guest-blog/the-top-10-martin-gardner-scientific-american-articles/

${ }^{92}$ Gardner, Martin (1988, Publicado originalmente en 1959 por Simon \& Schuster) Hexaflexagons and Other Mathematical Diversions: The First Scientific American Book of Puzzles and Games. University of Chicago Press.
} 
Como nos explican los matemáticos Pedro Alegría y Santiago Fernández ${ }^{93}$, la amplia difusión de sus artículos hacía que los más recientes trabajos de investigación fueran conocidos por un público más numeroso y despertaran el interés tanto de los especialistas como de la sociedad en general.
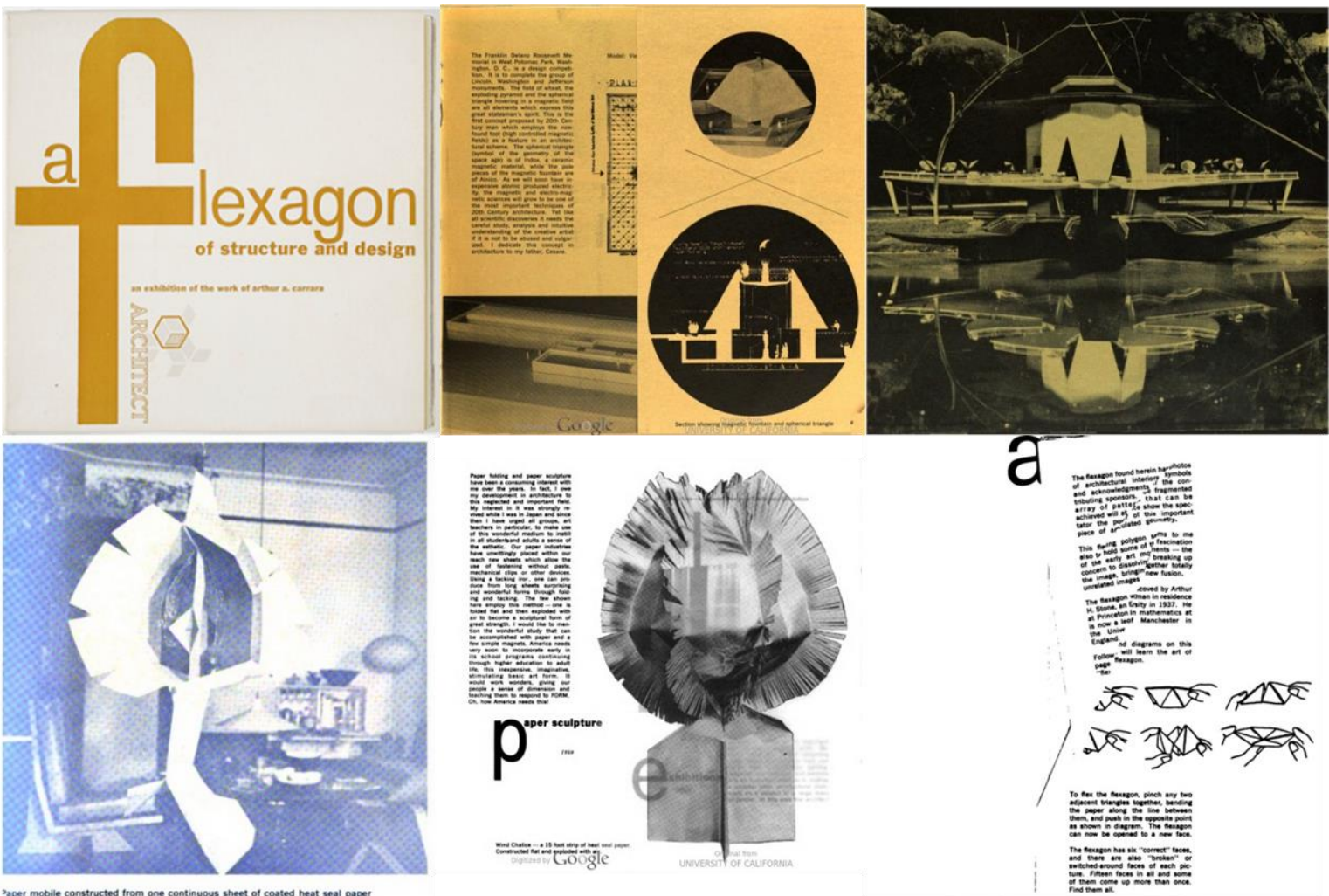

92. Catálogo exposición monográfica de A. Carrara. 1960.

Fuente: Carrara, Arthur Alfonso, 1914-: A flexagon of structure and design: an exhibition circulated by The Milwaukee Art Center ([Milwaukee: The Center, c1960]) Portada y páginas 33, 34, 52, 53759

http://hdl.handle.net/2027/uc1.31822034580019

Casi inmediatamente artistas y arquitectos como Arthur Alfonso Carrara se vieron inspirados por las cualidades multifacéticas de los flexágonos y desarrollaron proyectos que mostraban una clara influencia en los procesos de plegado y los trabajos en papel. Sobre estas líneas se muestra el catálogo de una exposición monográfica de la obra de Arthur Carrara en el Centro de Arte de Milwaukee realizada en 1960 donde se hace eco de la publicación de M. Gardner.

\footnotetext{
${ }^{93}$ Alegría, Pedro et Fernández, Santiago (2010) Martin Gardner, el mago de la divulgación. La Gaceta de la RSME, Vol. 13 (2010), Núm. 4, Págs. 671-704 Fuente: Automagia. La Magia de las Matemáticas.

http://www.automagia.com/archivos/martingardner.pdf

Como nos exponen Alegría y Fernández la importancia de M. Gardner fue ampliamente reconocida en Estados Unidos, como el caso de personalidades tan representativas como Douglas Hofstadter, el cual destacó que Gardner fue uno de los grandes intelectuales que ha producido Estados Unidos en el siglo XX. Igualmente, el lingüista Noam Chomsky mantuvo que "su contribución a la alta cultura contemporánea es única en su alcance, penetración y comprensión de las preguntas difíciles que realmente importan", mientras que el escritor de ciencia ficción Arthur C. Clarke creía que era "un tesoro nacional americano" y sus libros tenían que ser de lectura obligatoria en los institutos.
} 


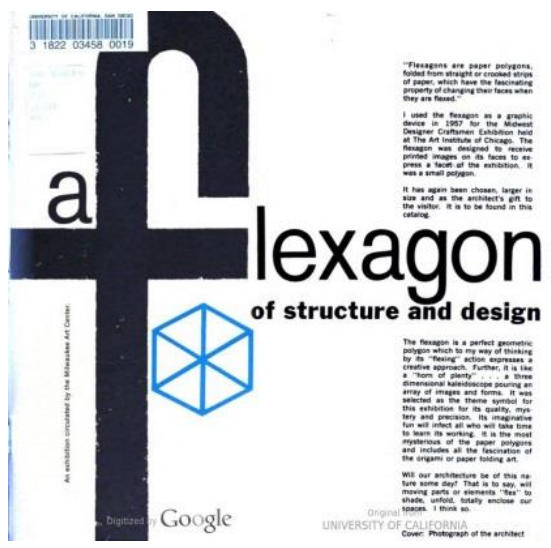

93. Contraportada del catálogo exposición monográfica de A. Carrara. 1960

En la contraportada Carrara expone que utilizó la figura descubierta por Arthur Harold Stone como un pequeño elemento gráfico en 1957 para mostrar imágenes impresas para una exhibición realizada en el Art Institute of Chicago y que en esta ocasión la ha vuelto a utilizar a mayor escala como un "regalo del arquitecto" para el visitante incluido en el catálogo.

Estima Carrara ${ }^{94}$ que el flexagón es un polígono de geometría perfecta que por su acción de "flexado" expresa un acercamiento a la creatividad, como un "cuerno de la abundancia", un caleidoscopio dimensional que vierte una cascada de imágenes y formas. Carrara continúa explicando que seleccionó esta figura como símbolo de la exhibición monográfica que sobre su obra realizó el Milwaukee Art Center por sus especiales cualidades, su misterio y precisión.

Para Carrara su diversión imaginativa contaminará a todo aquel que tome su tiempo en conocer cómo funciona. Considera que es el polígono plegado de papel más misterioso, el cual incluye toda la fascinación del origami y del arte del plegado de papel. $Y$ termina preguntándose: ¿Tendrá nuestra arquitectura esta naturaleza enigmática e inspiradora alguna vez? ¿Habrá elementos móviles y flexibles preparados para dar sombra, desplegarse y generar espacios? Para Arthur Carrara no hay duda de que sí.

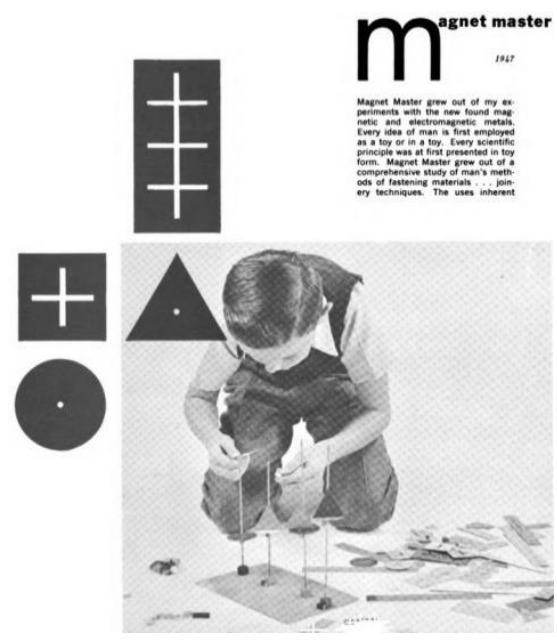

Arthur Carrara fue un prolífico arquitecto preocupado por la realización de viviendas de calidad a bajo coste y por la utilización de nuevos materiales en construcciones que recuperaran aspectos tradicionales por su funcionalidad, adaptación y austeridad. Carrara no solo proyectó edificios de muy diversa índole, realizó exposiciones de arte y diseño y fue el comisario de otras tantas, sino también diseñó luminarias inflables, mobiliario en madera laminada y juguetes de construcción como el "magnet master".

94. Juguete de construcción "magnet master" de A. Carrara. 1947 Fuente: Carrara, Arthur Alfonso (1960) A flexagon of structure and design. The Milwaukee Art Center. Página 45 del documento digitalizado.

\footnotetext{
${ }^{94}$ Carrara, Arthur Alfonso (1960) A flexagon of structure and design. The Milwaukee Art Center. Contraportada del catálogo de la exposición. Página 5 del documento digitalizado.

http://babel. hathitrust.org/cgi/pt?id=uc1.31822034580019;view=1up;seq=11;size=125

I used the flexagon as a graphic device in 1957 for the Midwest Designer Craftsmen Exhibition at The Art Institute of Chicago. The flexagon was designed to receive printed images on its faces to express a facet of the exhibition. It was a small polygon. ...It has again been chosen, larger in size and as the architect's gift to the visitor. It is to be found in this catalog. The flexagon is a perfect geometric polygon which to my way of thinking by its "flexing" action expresses a creative approach. Further, it is like a "horn of plenty" ... a three dimensional kaleidoscope pouring an array of images and forms. It was selected as the theme symbol for this exhibition for its quality, mystery and precision. Its imaginative fun will infect all who will take time to learn its working. It is the most mysterious of the paper polygons and includes all the fascination of the origami of paper folding art. Will our architecture be of this nature some day? That is to say, will moving parts or elements "flex" to shade, unfold, totaly enclose our spaces. I think so."
} 
Y volviendo otra vez a las publicaciones de Martin Gardner, Alegría y Fernández ${ }^{95}$ también destacan que, como consecuencia del artículo de Gardner de julio de 1975 titulado "On Tessellating the Plane with Convex Polygon Tiles" sobre el número de pentágonos congruentes con los que se puede teselar el plano, una sencilla ama de casa de San Diego, Marjorie Rice, se interesó por este campo de trabajo y consiguió desarrollar una notación y procedimientos únicos para el estudio sistemático de las posibles soluciones, encontrando incluso cuatro tipos adicionales y más de 60 diferentes teselaciones mediante pentágonos, lo cual llamó la atención de la matemática Doris Schattschneider que adaptó uno de sus trabajos para el diseño del tapiz del vestíbulo de la sede de la Mathematical Association of America.
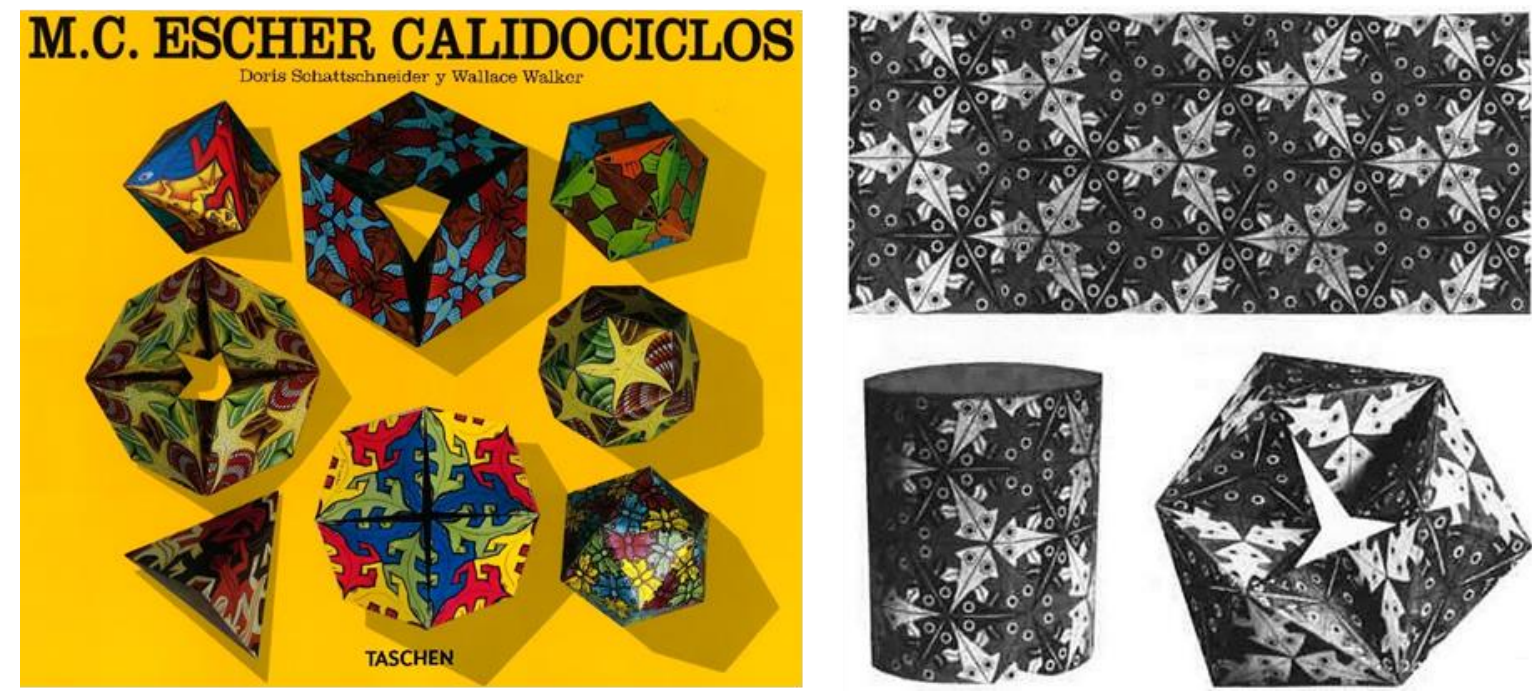

95. M. Escher Calidociclos. Portada y detalle página 17

Fuente: Schattschneider, D. et Walker, W. (2015 edición española, $1^{a}$ edición 1977) M.C. Escher Calidociclos. Editorial Taschen. Alemania. ISBN: 978-3-8228-0675-3

En 1977, Doris Schattschneider publicó, junto con el diseñador gráfico Wallace Walker, otra variante de los flexágonos, que vino a llamar calidociclos ${ }^{96}$. Los diseños de Schattschneider y Walker destacaban por la utilización de los patrones inspirados en las xilografías y litografías del artista neerlandés Maurits Cornelis Escher, más conocido por M. C. Escher, y que tratan sobre figuras imposibles, teselaciones y mundos imaginarios. Schattschneider y Walker exploraron las implicaciones tridimensionales de muchos de los característicos diseños periódicos bidimensionales de Escher.

Conocido por sus representaciones extrañamente realistas de visiones que desafían las leyes de la física, Escher se interesó en las composiciones por repetición y simetría que descubrió en un viaje a la Alhambra de Granada. Fascinado por los patrones periódicos de los mosaicos de sus estancias, comenzó a explorar la idea de la división y repetición de un módulo con intervalos fijos para formar un patrón que se expande teóricamente hasta el infinito.

\footnotetext{
${ }^{95}$ Alegría, Pedro et Fernández, Santiago (2010) Martin Gardner, el mago de la divulgación. La Gaceta de la RSME, Vol. 13 (2010), Núm. 4, Págs. 671-704 Fuente: Automagia. La Magia de las Matemáticas. p. 686.

http://www.automagia.com/archivos/martingardner.pdf

${ }^{96}$ Schattschneider, D. et Walker, W. (1994, $1^{\text {a }}$ Edición 1977) Escher Kaleidocycles. 17 models of Escher's graphics and the story of how they were devised. Editorial Taschen. Alemania. ISBN: 0-7649-3110-5
} 
Para Schattschneider la clave de los descubrimientos ópticos de Escher se fundamenta en las matemáticas hechas visuales en la geometría. En la introducción del libro sobre calidociclos Schattschneider dejó escrito sobre la obra de Escher unas descriptivas palabras: "Las sorpresas gustan a todo el mundo. Las hay de dos tipos: unas consisten en el accidente gozoso; las otras en aquél planteado minuciosamente, quizás incluso ejecutado con habilidad con el fin de que parezca ingénuo." ${ }^{97}$ Así, la obra de Escher se relaciona con los sorprendentes, mágicos y sutiles juegos de los calidociclos, que por medio del uso del pliegue de papel y el conocimiento de las leyes geométricas consiguen deslumbrarnos y maravillarnos.
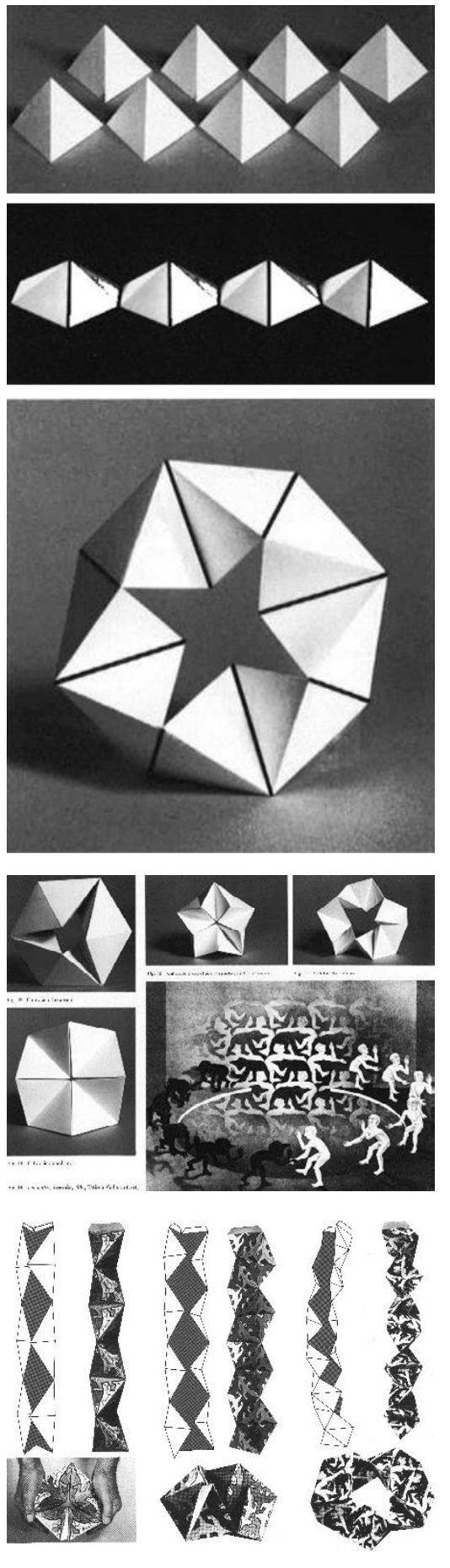

Bautizados así por la combinación de las palabras griegas

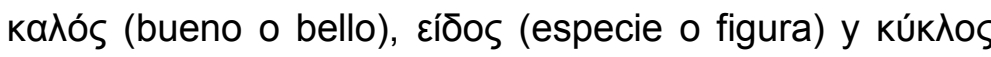
(ciclos o anillo). Los calidociclos se constituyen como una cadena cerrada de tetraedros que, unidos por una de las aristas, pueden girar sobre sí mismos completando un ciclo sin fin dejando siempre un espacio central. Para construirlo hay que partir de varios tetraedros idénticos aunque no tienen que ser necesariamente regulares, esto es, realizados con triángulos equiláteros. Uniendo de forma flexible cada dos por una arista, se obtiene una cadena de tetraedros. Cuando la cadena es suficientemente larga, puede ser ensamblada en forma de anillo cerrado. Dependiendo del número de tetraedros utilizados en la cadena y el tipo de triángulo se pueden realizar calidociclos hexagonales, octogonales, etc con triángulos equiláteros, rectángulos, isósceles genéricos e incluso con triángulos escalenos.

96. Calidociclo octogonal con triángulos equiláteros

Fuente: Schattschneider, D. et Walker, W. (2015) M.C. Escher Calidociclos Detalle página 9

Sobre estas líneas se puede observar un calidociclo octogonal con triángulos equiláteros y en la imagen izquierda un calidociclo hexagonal, estrellado realizado con diez caras, oblicuo (con triángulos escalenos) y cuadrado (octogonal con triángulos rectángulos).

97. Calidociclos hexagonal, estrellado, oblicuo y cuadrado

Fuente: Schattschneider, D. et Walker, W. (2015) M.C. Escher Calidociclos. Página 11

98. Ensambles del calidociclo hexagonal, cuadrado y oblicuo Fuente: Schattschneider, D. et Walker, W. (2015) M.C. Escher Calidociclos Página 36

${ }^{97}$ Schattschneider, D. et Walker, W. (2015 edición española, $1^{\text {a }}$ edición 1977) M.C. Escher Calidociclos. Editorial Taschen. Alemania. ISBN: 978-3-8228-0675-3 página 6 

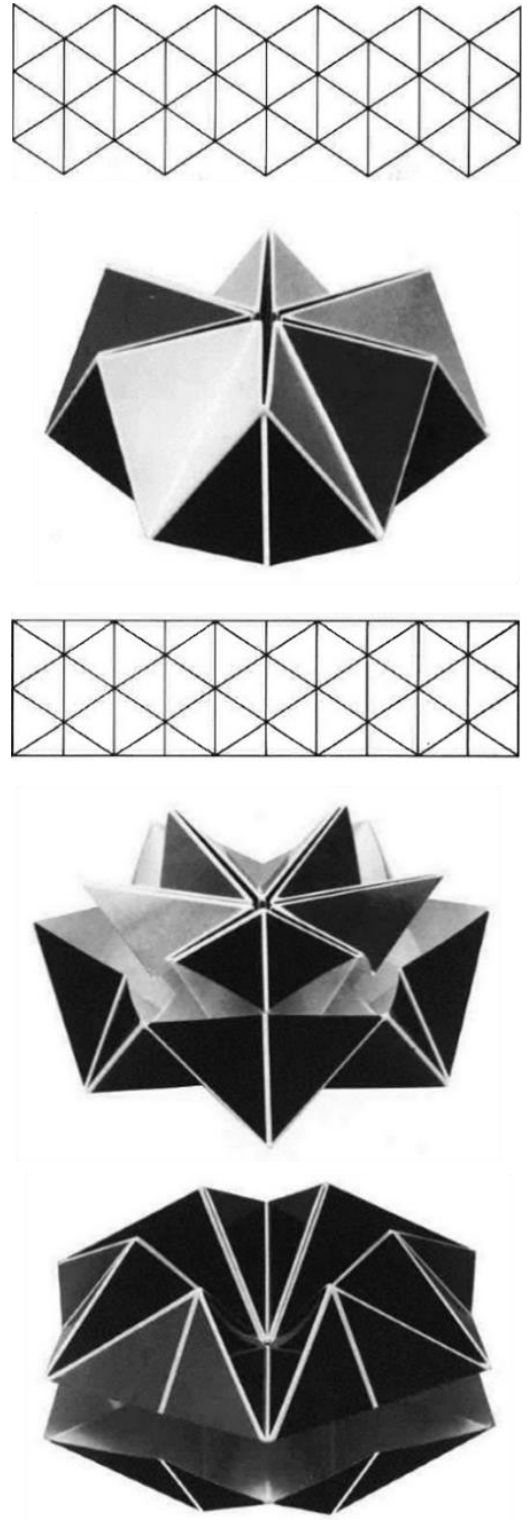

Los calidociclos tienen su origen en la patente llamada IsoAxis realizada por el diseñador gráfico Wallace Walker en 1958 cuando trabajaba, siendo estudiante en la Cranbrook Academy or Art de Michigan, en un proyecto cuyo objetivo consistía en lograr configuraciones estructurales en papel. Sobre este hecho aparentemente azaroso Schattschneider deja otra luminosa reflexión sobre las circunstancias de la creación artística: "Es frecuente que el descubrimiento de nuevas formas e ideas aparezca descrito en los libros de enseñanza como el resultado de desarrollos previsibles. La realidad es otra. Primero se realiza un descubrimiento inesperado $y$ únicamente mucho después se logra clasificar el nuevo conocimiento en su contexto natural." 98

Las IsoAxis se construyeron originariamente mediante una malla bidimensional de triángulos isósceles iguales entre sí dispuestos de tal modo que la altura de la malla sea dos hipotenusas, o en el caso de los triángulos equiláteros dos lados cualesquiera, para formar un calidociclo hexagonal es necesario que el número mínimo de triángulos dispuestos a lo largo de la malla sea de seis, aunque el diseño inicial realizado por Wallace fue de un calidociclo decagonal al realizar una malla con un largo de 10 triángulos.

99. IsoAxis en diente de sierra y truncada

Fuente: Schattschneider, D. et Walker, W. (2015) M.C. Escher Calidociclos. Detalle página 10

En el modelo plano de la IsoAxis no es posible apreciar ninguna de las sorprendentes formas tridimensionales en las que se puede convertir. Al doblarla plegando las verticales como valle y las diagonales como montañas y posteriormente uniendo los dos laterales de la malla, se convierte en un anillo tridimensional. Lo sorprendente es que, gracias a la flexibilidad de las aristas-bisagra, resulta posible girar en torno a su centro esta vistosa forma anular. Cada giro modifica su apariencia. Tras realizar 4 vueltas, vuelve a recobrar su forma originaria de partida, de modo que el ciclo de tranformación puede empezar de nuevo. Wallace introdujo además dos propuestas, una con la malla en diente de sierra, con los triángulos sin cortar en su parte superior e inferior, con lo que el ensamblado se realiza de forma sencilla y sin imperfecciones y otra donde las hipotenusas de los triángulos quedan cortadas y sin ensamblar finalmente, lo que deja mostrar el cambiante y sugerente espacio interior de los tetraedros.

${ }^{98}$ Schattschneider, D. et Walker, W. (2015 edición española, $1^{a}$ edición 1977) M.C. Escher Calidociclos. Editorial Taschen. Alemania. ISBN: 978-3-8228-0675-3 página 9 
Actualmente los calidociclos también se Ilaman Kaleidogamis o Kinetogamis ${ }^{99} \mathrm{y}$ abarcan una mucho más amplia gama de formas complejas en las que también se incluyen objetos prismáticos. Las capacidades del Kinetogami permiten construir mediante paneles de muy variados materiales, texturas y colores, múltiples diseños mecánicos de objetos en 3D que además pueden ser reconfigurables con sistemas electrónicos de control del movimiento.
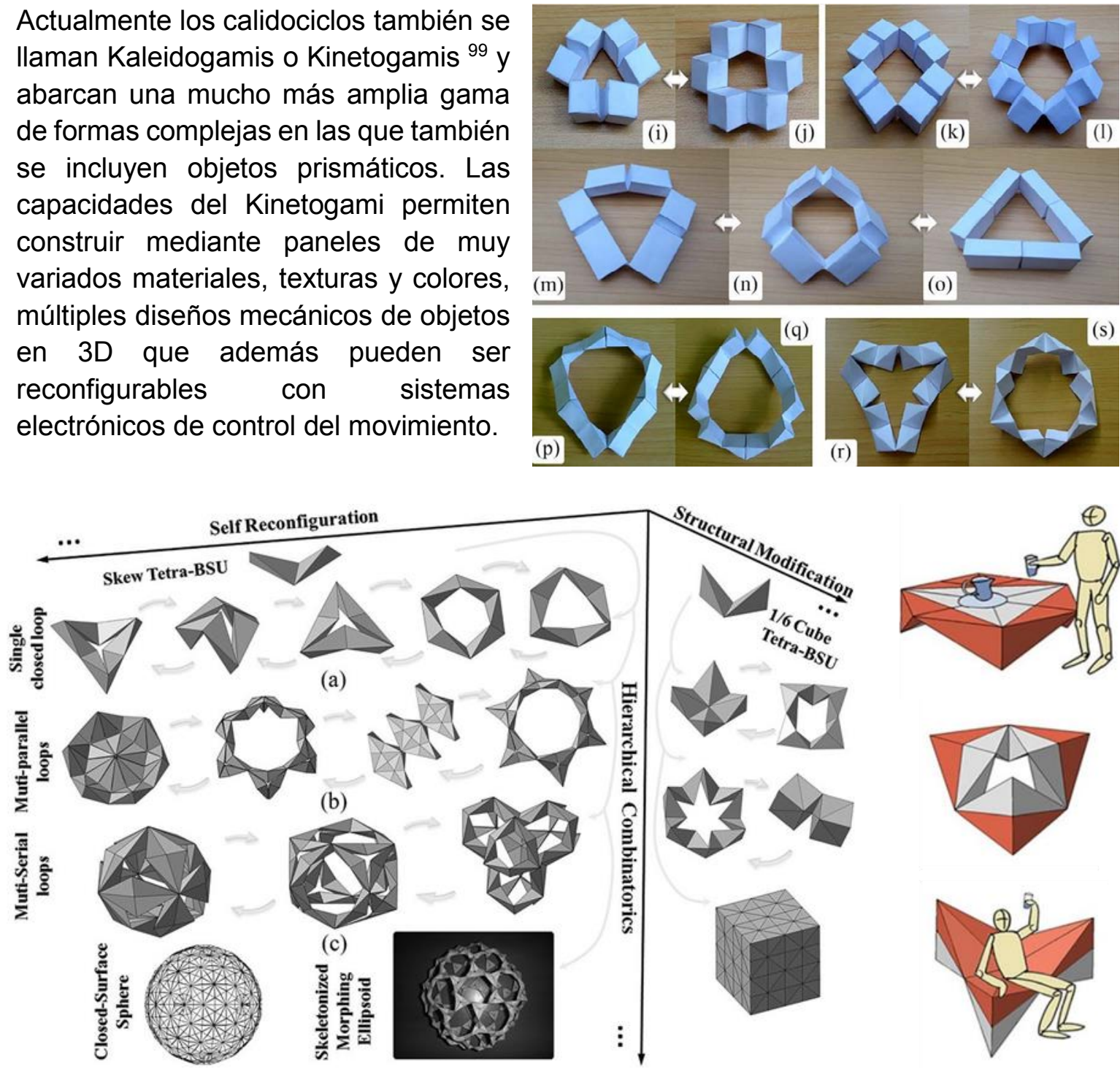

100. Kinetogami: A Reconfigurable, Combinatorial, and Printable Sheet Folding

Fuente: Gao, W. et all (Nov. 2013) Kinetogami: A Reconfigurable, Combinatorial, and Printable Sheet Folding.

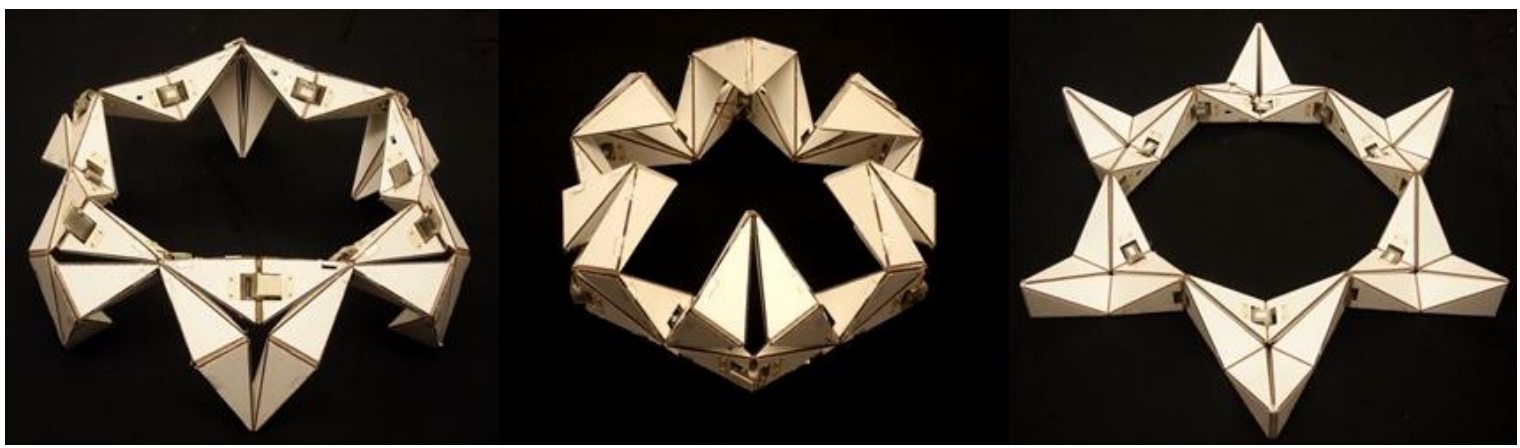

101. HexaMorph: A Reconfigurable and Foldable Hexapod Robot Inspired by Origami.

Fuente: Gao, W.; Huo, K.; Seehra, Jasjeet S.; Ramani, Karthik; Cipra, Raymond J.; (Sept. 2014) HexaMorph: A Reconfigurable and Foldable Hexapod Robot Inspired by Origami. IEEE/RSJ International Conference on Intelligent Robots and Systems (IROS'14), Chicago.

99 Gao, W.; Ramani, K.; Cipra, Raymond J.; Siegmund, Thomas (Nov. 2013) Kinetogami: A Reconfigurable, Combinatorial, and Printable Sheet Folding. Transactions of the ASME. 111009-10 / Vol. 135, School of Mechanical Engineering, Purdue University,West Lafayette, IN 47907 [DOI: 10.1115/1.4025506]

https://pdfs.semanticscholar.org/30f8/5725d4491074e824dbff1a810b563b0c6883.pdf 


\subsubsection{Las esculturas de papel plegado: Folded paper sculptures}

Tras intensas décadas de desarrollo, exploración y difusión del arte del origami a nivel internacional. En los años 80 del siglo XX se comenzó a gestar una nueva variante creativa que buscaba ir más allá del camino que se había tomado por conseguir mayor complejidad de los patrones, realizando los insectos y animales más complejos por su número de patas y alas, y de mayor literalidad en la representación. Como explica el origamista y divulgador de los patrones y técnicas del origami Paul Jackson en su web personal ${ }^{100}$, tras casi 20 años realizando figuras en origami, en los años 80 se sintió insatisfecho con los caminos recorridos por el origami tradicional, así que comenzó a experimentar ampliamente con alternativas técnicas y filosóficas al plegado de papel como una actividad de creación artística. Quería hacer que la gente se preguntara ¿por qué? en lugar de ¿cómo?, y realizar objetos que fueran estéticamente agradables, no sólo inteligentes.

A este camino creativo lo vino a llamar esculturas de papel plegado para acercarse a los caminos artísticos de la escultura occidental contemporánea. Jackson establece una clasificación de las obras que realizará en este nuevo camino creativo: Organic Abstracts (abstracciones orgánicas), One Crease (pliegues únicos), Crumpling (arrugados), Geometric (geométricos) y Crease Patterns (patrones de pliegue).
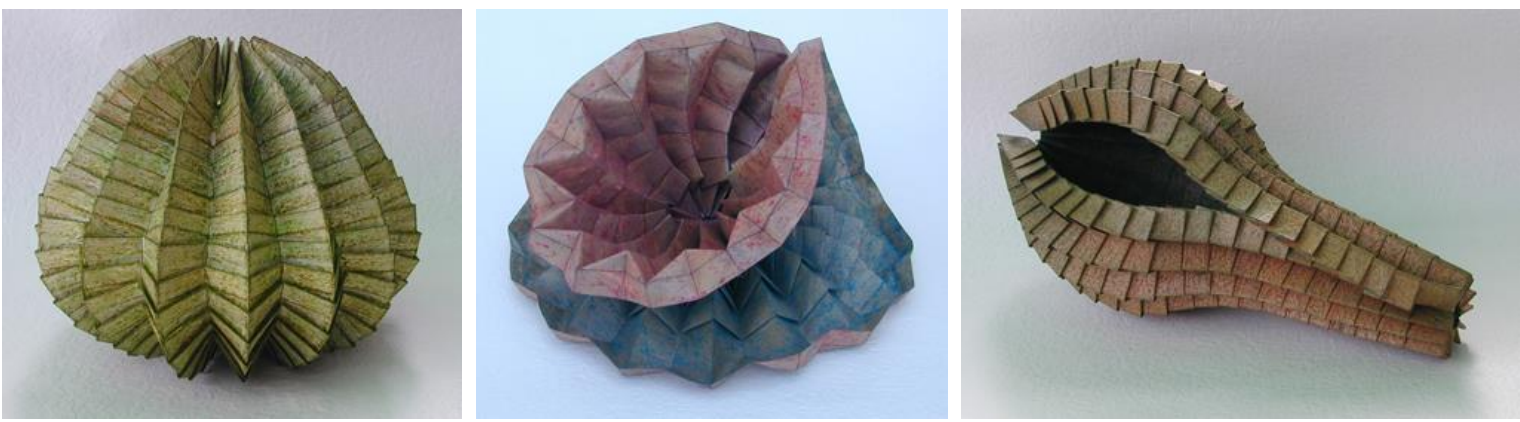

102. Organic Abstracts (abstracciones orgánicas) Paul Jackson

Papel coloreado con carbón, pastel y tratado con barniz mate. 20 cms de alto aprox.

Jackson empezó las series Organic Abstracts (abstracciones orgánicas) a principio de la década de los 90 y hasta la fecha ha realizado 250 piezas distintas realizadas mediante el pliegue de costilla ('rib' technique) con un patrón ortogonal curvado en papel coloreado con carbón o pastel seco y frotado sobre una superficie rugosa para crear un lustre mate personal. Para Jackson esta personalización de la superficie de alguna manera cambia un modelo o un objeto de artesanía en un objeto de arte. Inspirado en formas orgánicas como bacterias, cabezas de semilla y conchas, la realización de estas series técnicamente similares, cambia el enfoque creativo que se venía manteniendo en el origami, de una larga serie de modelos únicos hacia un enfoque de variaciones sobre el color, la forma y el significado. De esta manera, las piezas tienen un énfasis creativo diferente a casi todos los otros trabajos de origami tradicional basados en un concepto más técnico.

\footnotetext{
100 "In the mid 1980's, dissatisfied with the origami world's twin obsessions of complexity and literal representation, I began to experiment widely with technical and philosophical alternatives to folding paper as a model making activity. I wanted to make people ask 'why?' rather than 'how?', and to make objects that were aesthetically pleasing, not just clever." Fuente: http://www.origami-artist.com/folded_sculptures.htm

Paul Jackson ha publicado más de 20 libros de origami y de origami aplicado. Siendo el último libro:

Jackson, Paul (2015) Complete Pleats: Pleating Techniques for Fashion, Architecture and Design. Ed. Laurence King
} 
Consolidado como corriente artística a finales del siglo XX y principios del XXI, este camino emprendido por Jackson lo podríamos denominar origami abstracto, pues se aleja de los referentes figurativos del origami tradicional japonés y se desvincula de la perspectiva narrativa clásica de representación de objetos, animales y personas de la vida cotidiana y/o de mitologías reconocibles. Mediante la utilización de las técnicas y procedimientos básicos de pliegue o "bases" de las figuras tradicionales, el origami abstracto genera una serie de patrones generalmente regulares de pliegue de superficies de múltiples variantes geométricas y se acerca a expresiones propias del arte conceptual, donde el objeto creado es referente en sí mismo sin necesidad de parecerse o querer representar a ningún objeto o ser vivo reconocible.

De este modo, los artistas del origami abstracto exploran sobre las características expresivas propias del material plegado: su opacidad o traslucidez debida al grosor y componente del material o a la superposición de capas, sus posibilidades de ser plegado y la capacidad formal de cada pliegue para, de forma particular o seriada, acercarse a los conceptos y las relaciones formales vinculadas a la escultura y al dibujo, tales como ritmo, simetría, tensión, equilibrio, contrastes entre lleno y vacío, entre liso y rugoso, entre opaco y transparente o translúcido, capacidades cinéticas y estructurales del objeto plegado, etc.

103. Paul Jackson (sin título, principios del siglo XXI) Serie One Crease (pliegues únicos)

104. Giotto's Circle, Andrea Russo (Italia, 2011) Papel y pegamento.

105. 03M (Partial Shell), Richard Sweeney (UK, 2010) Pliegue húmedo sobre papel de acuarela.

Fuente: International Arts \& Artists (Agosto 2012) Folding Paper. The Infinite Possibilities of Origami. Japanese American National Museum. Los Angeles.
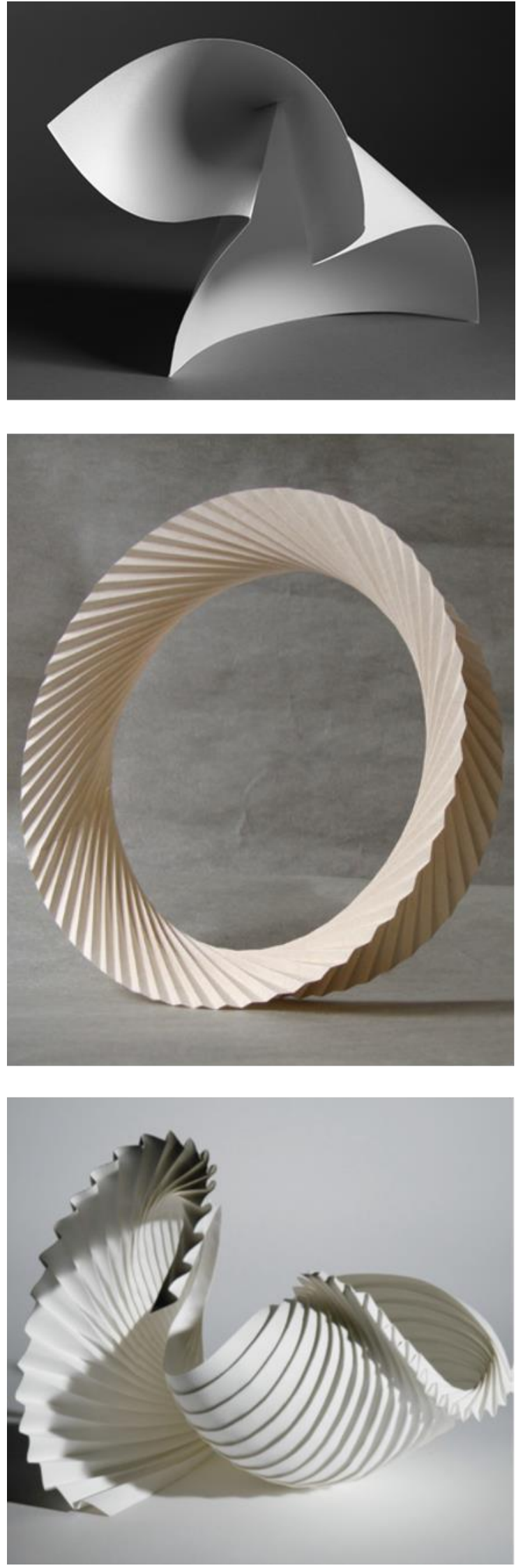


\subsubsection{El origami arquitectónico}

En la arquitectura se está desarrollando una amplia gama de patrones de pliegue vinculados con la tradición del origami y cercanos a la estrategia narrativa del origami abstracto. Estos patrones se utilizan para la ideación y creación de proyectos con elementos arquitectónicos estructurales, constructivos, de acabados superficiales, de envolventes, incluso de mobiliario y luminarias. A estas aplicaciones del origami en la arquitectura le damos el nombre de origami arquitectónico ${ }^{101}$ el cual fue enunciado inicialmente por el doctor arquitecto Tomohiro Tachi en una clase magistral ofrecida en el año 2010 en el Massachusetts Institute of Technology (MIT) donde expondría diferentes sistemas de diseño de formas arquitectónicas generadas en origami computacional. En ese curso Tachi mostraría los tres software específicos diseñados por él: el Rigid Origami Simulator ${ }^{102}$, el Free Form Origami ${ }^{103}$ y el Origamizer ${ }^{104}$, programas que calculan y realizan una simulación en 3D de procesos de plegado de superficies planas.

De los tres programas, el Rigid Origami Simulator destaca por ofrecer nuevas posibilidades para los proyectos de arquitectura cinéticos y plegables, publicada la primera versión en septiembre del 2007, su fácil manejo y necesidad de pocos recursos de hardware lo ha hecho muy popular entre los estudiantes. Hasta la fecha Tachi ha publicado de este exitoso programa nueve mejoras, siendo la última en septiembre del 2010. El Rigid Origami permite plegar patrones de superficies planas siguiendo unos sencillos códigos gráficos. El archivo original donde se realice el patrón de plegado deberá ser dibujado en autocad y guardado en $\mathrm{dxf}$, las líneas dibujadas en azul plegarán en forma de valle y las dibujadas en rojo en montaña. Además permite controlar de forma progresiva el proceso de plegado y desplegado y guardar cada fase como imagen y como objeto tridimensional que puede ser abierto y editado en programas de edición 3D como Rhinoceros y Sketchup, con estos programas se puede añadir grosor a la lámina plegada que en el Rigid Origami es solo una superficie matemática sin sección definida.

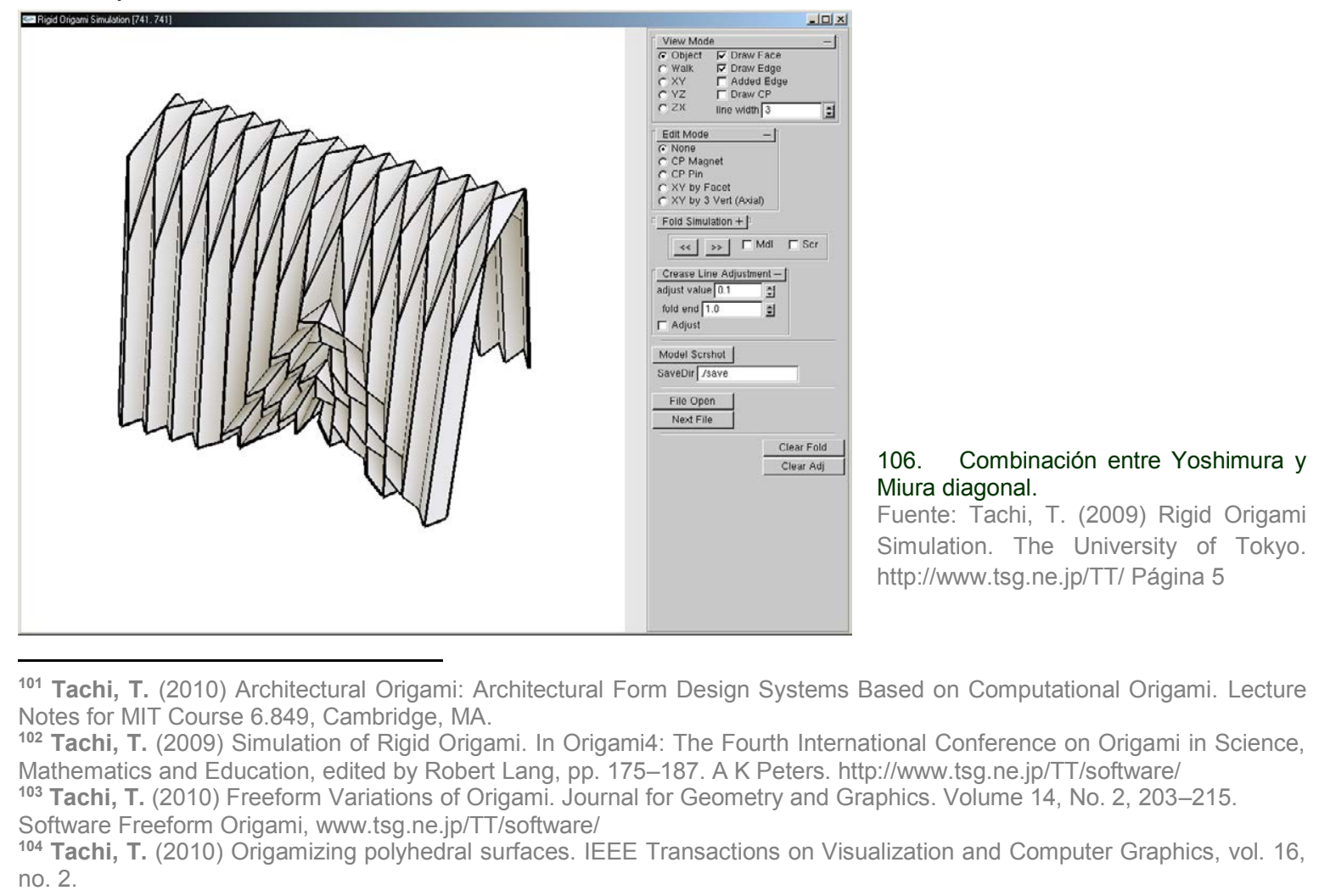


Tachi además ha programado el Free Form Origami que sigue unas directrices gráficas y de control del pliegue parecidas al Rigid Origami pero que, además, permite transformar y deformar la superficie plegada seleccionando puntos de agarre y desplazando éstos manualmente, con lo que se consigue mover y plegar la superficie, ya no de una forma progresiva y uniforme, sino de forma irregular y particular. Una vez realizada esta deformación en la superficie, en el Free Form Origami no es posible retroceder paso a paso el proceso de plegado, pues la superficie y el patrón inicial han sido alterados en sus dimensiones. Posteriormente también se puede exportar el diseño resultante en formato obj para ser abierto por programas de edición y diseño 3D como el Rhino. Bajo estas líneas se pueden ver dos ejemplos de transformaciones de los patrones de origami regular miura y yoshimura y como quedan los patrones una vez ha sido transformado y deformado. En rojo se señalan los puntos de control del movimiento que pueden ser manipulados y desplazados individualmente.
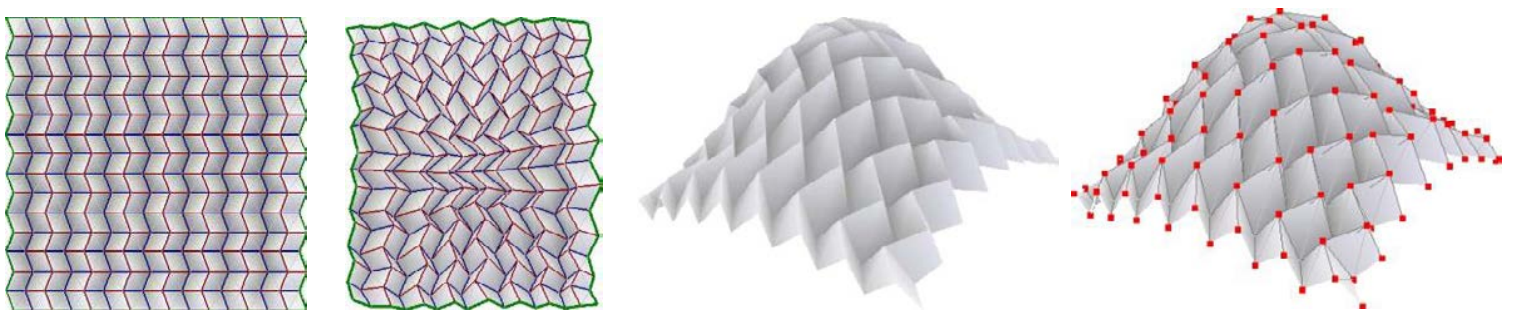

107. Patrón de origami regular Miura y deformación con Free Form Origami

Fuente: Tomohiro Tachi. (2010) Architectural Origami: Architectural Form Design Systems Based on Computational Origami. Lecture Notes for MIT Course 6.849, Cambridge, MA. Página 28
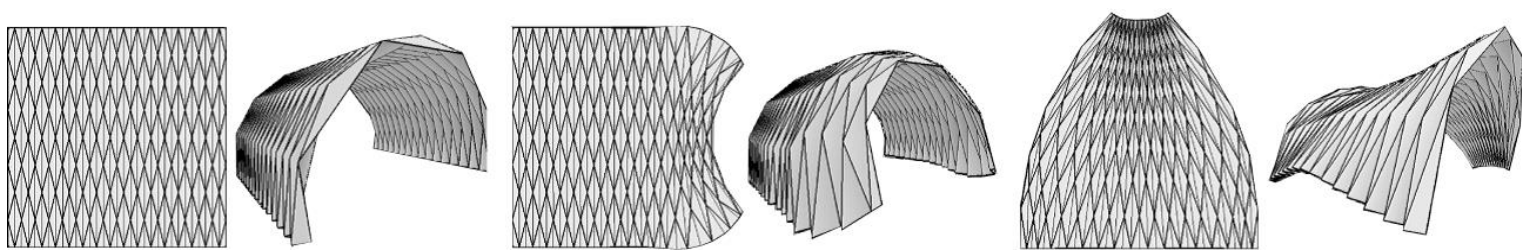

108. Patrón de origami regular Yoshimura y deformaciones con Free Form Origami

Fuente: Tomohiro Tachi. (2010) Architectural Origami: Architectural Form Design Systems Based on Computational Origami. Lecture Notes for MIT Course 6.849, Cambridge, MA. Página 28
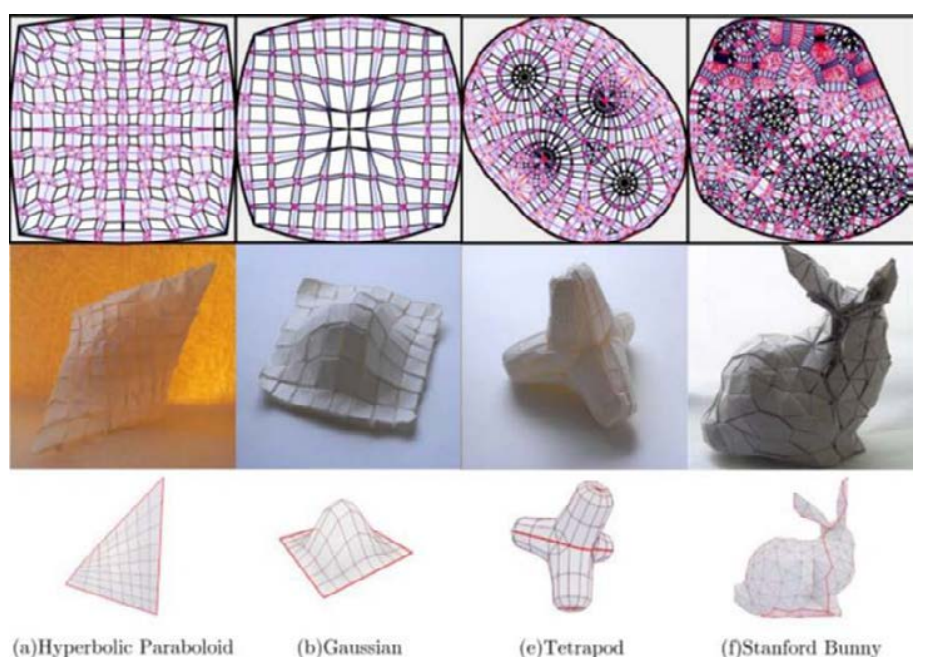

El tercer programa realizado por Tachi, el Origamizer, busca poder realizar cualquier forma tridimensional mediante el plegado de una superficie plana continua. Es capaz de, dada un objeto tridimensional, calcular la superficie y el patrón de plegado necesario para poder representarlo.

109. Ejemplos de trabajos en Origamizer Fuente: Tachi, T. (2010) Origamizing polyhedral surfaces. IEEE Transactions on Visualization and Computer Graphics, vol. 16, no. 2. p. 19 


\section{El "rigid origami"}

El origami rígido o rigid origami es llamado así porque se diseña y ejecuta manteniendo planas cada una de las múltiples caras del pliegue, sin alabeos ni curvaturas, en su versión regular se genera mediante diferentes patrones de superficies desarrollables o desplegables que se pliegan completamente cambiando de una superficie plana a un perfil de sección uniforme dependiente de cada patrón. Los patrones del origami rígido también han sido llamados pliegues corrugados ${ }^{105}$ o corrugaciones de forma genérica para referirse indistintamente a unos $u$ otros. Hasta la fecha no se ha establecido ninguna clasificación que relacione geométricamente a estos patrones entre sí, siendo la clasificación de Sophia Vyzoviti ${ }^{106}$ la que ha tratado de ordenarlos en relación a sus posibles aplicaciones en la arquitectura. En el origami rígido destacan cuatro patrones elementales regulares: plisado, yoshimura, miura y fishbone. Mostrados en la imagen inferior. El código de colores de las líneas dibujadas en cada patrón es el establecido por Tomohiro Tachi ${ }^{107}$ en su programa de simulación Rigid Origami Simulator: rojo para las limatesas (montaña) y azul para las limahoyas (valle).
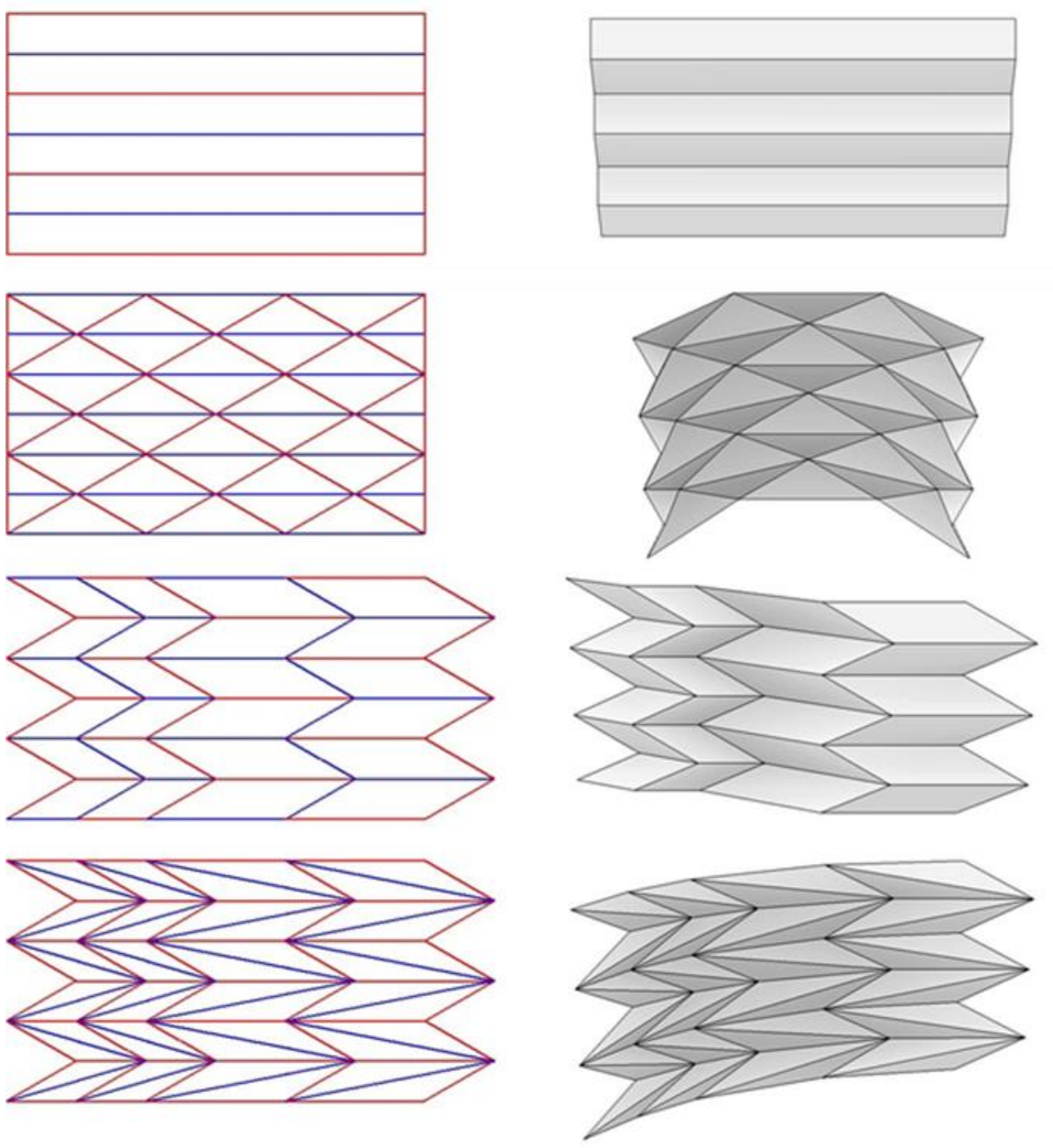

110. Patrones elementales regulares: Pleat, Yoshimura, Miura y Fishbone

Autor: Pablo De Souza, 2017. Simulaciones con Rigid Origami, software diseñado por Tomohiro Tachi.

\footnotetext{
105 Saito, Keiko E. et Röhmer Litzmann, Matias (2007) Plegado, simetria y software gráfico. Forma y Simetría: Arte y Ciencia. Congreso de Buenos Aires. Página 424

${ }^{106}$ Vyzoviti, Sophia (2011) Soft Shells: Porous and Deployable Architectural Screens. Amsterdam: BiS Publishers

107 Tachi, Tomohiro (5 de agosto de 2009) Simulation of Rigid Origami. Actas del congreso Origami 4: The Fourth International Conference on Origami in Science, Mathematics, and Education. J. A K Peters/CRC Press. pp. 175-187.

El software Rigid Origami Simulator está diseñado por T. Tachi y compartido en su web: http://www.tsg.ne.jp/TT/software/
} 
El Pleat, Plisado o Pliegue en Acordeón se forma partiendo de la subdivisión en facetas paralelas regulares de la superficie, éstas se pliegan alternando las limatesas (montañas) y limahoyas (valles). Este pliegue aumenta el canto ocupado por la lámina que al plegarse se dota de más rigidez.
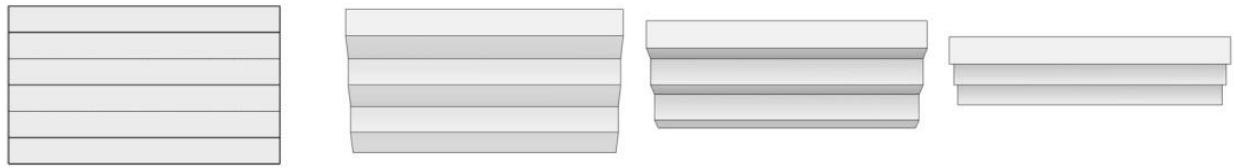

111. Pleat, Plisado o Pliegue en Acordeón

Autor: Pablo De Souza, 2017.

Simulaciones con Rigid Origami, software diseñado por Tomohiro Tachi.

Paul Jackson en su libro Técnicas de plegado para diseñadores y arquitectos ${ }^{108}$, muestra una extensa variedad de transformaciones y aplicaciones de este plegado, que llama "divisiones lineales", y que pueden ser transformadas como "variaciones rotatorias", plegados incrementales, plegados lineales en caja, etc. estas variaciones se pueden considerar pertenecientes a una misma familia de pliegue donde generalmente se irán alternando una, dos o tres limatesas con limahoyas y donde, y esta es la característica que mejor define a este patrón, las líneas de pliegue no son cruzadas por otras.
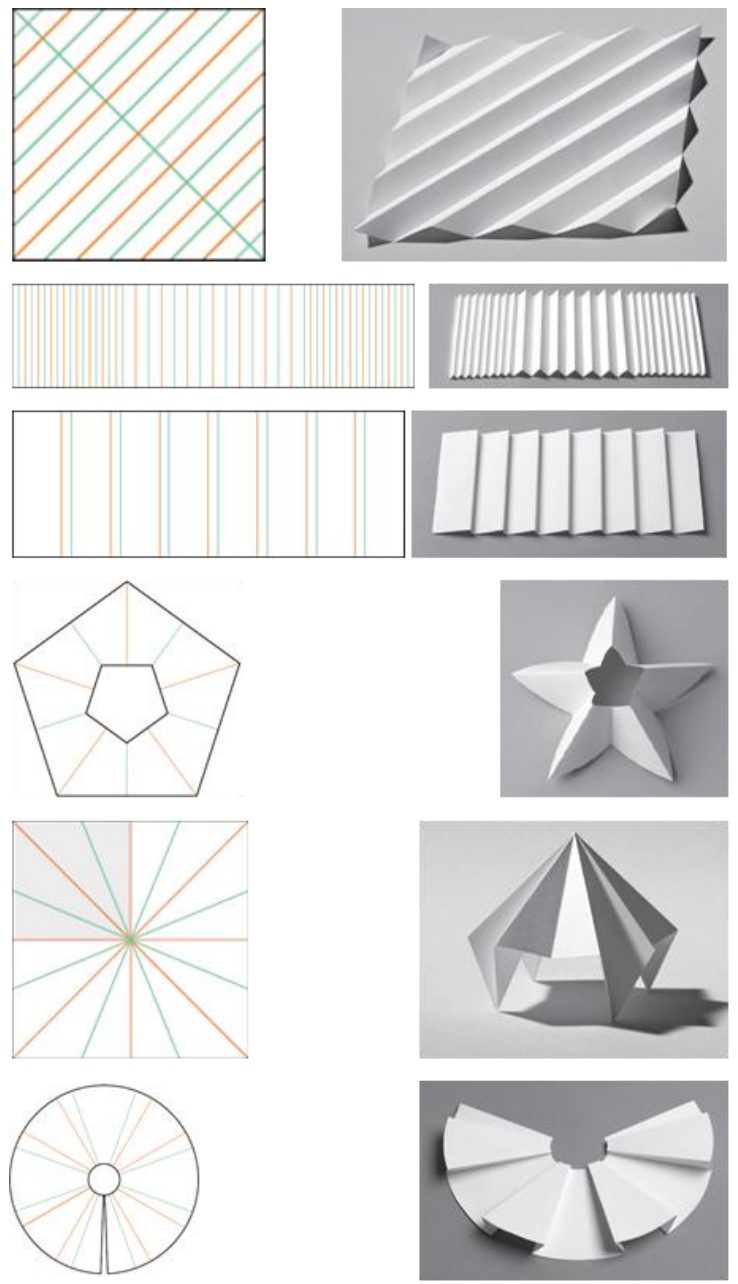

112. Variaciones de plisados

Diagonal (fotografías 1 y 2), escalado (3 y 4), asimétrico (5), polar (6, 7, 8 y 9) y de caja (11 y 12).

Fuente: Jackson, Paul (2011) Tecnicas de plegado para diseñadores y arquitectos. Ed. Promopress.

\footnotetext{
108 Jackson, Paul (2011) Tecnicas de plegado para diseñadores y arquitectos. Editorial Promopress. ISBN: 9788492810215
} 
El Yoshimura, pliegue en diamante o triángulo turco se construye al añadir un trazado diagonal sobre la base del plisado, de este modo se consigue cambiar la dirección de pliegue de las divisiones horizontales iniciales, de tal modo que la malla diagonal se convierte en valle y todas las trazas horizontales en montaña. El pliegue Yoshimura tiene la característica de generar superficies que al plegarse se "recogen" en bóvedas hasta formar, una vez plegada totalmente, polígonos regulares. La figura final vendrá marcada por el ángulo de plegado de la malla diagonal inicial, con lo que se pueden conseguir bóvedas de origen pentagonal, hexagonal, heptagonal...
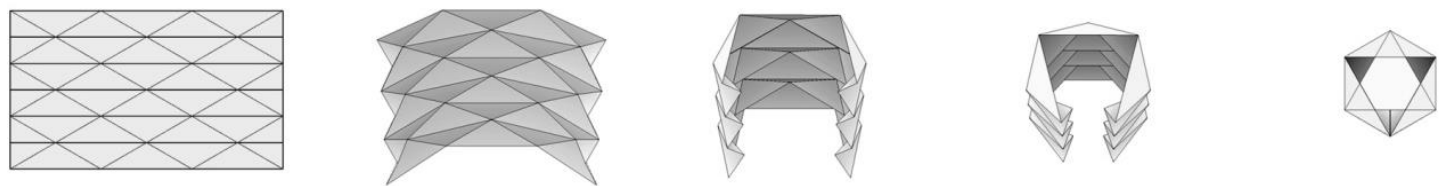

113. Yoshimura o pliegue en diamante

Autor: Pablo De Souza, 2017.

Simulaciones con Rigid Origami, software diseñado por Tomohiro Tachi.

Partiendo del cuadrado inscrito en una circunferencia y trazando sus diagonales se consigue el único pliegue yoshimura que al cerrar ocupa toda la superficie de la figura regular inicial, éste tiene un proceso de plegado y desplegado rápido y con gran canto. Cuanto más tendido sea el ángulo inicial del triángulo base el proceso de plegado será más lento y el canto ocupado por la lámina plegada será menor.
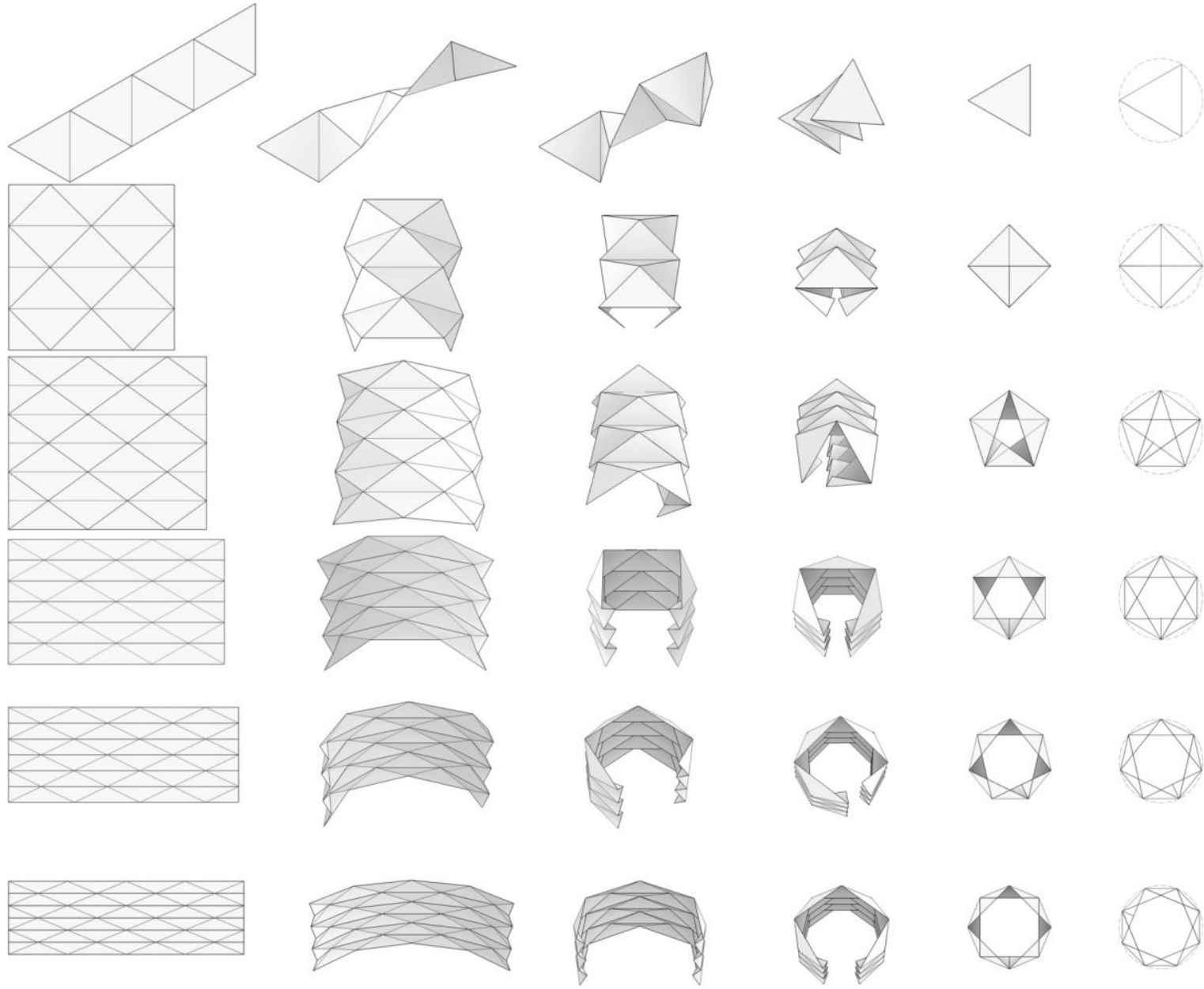

114. Desarrollos geométricos de patrones regulares Yoshimura

Autor: Pablo De Souza, 2012.

Simulaciones con Rigid Origami, software diseñado por Tomohiro Tachi. 

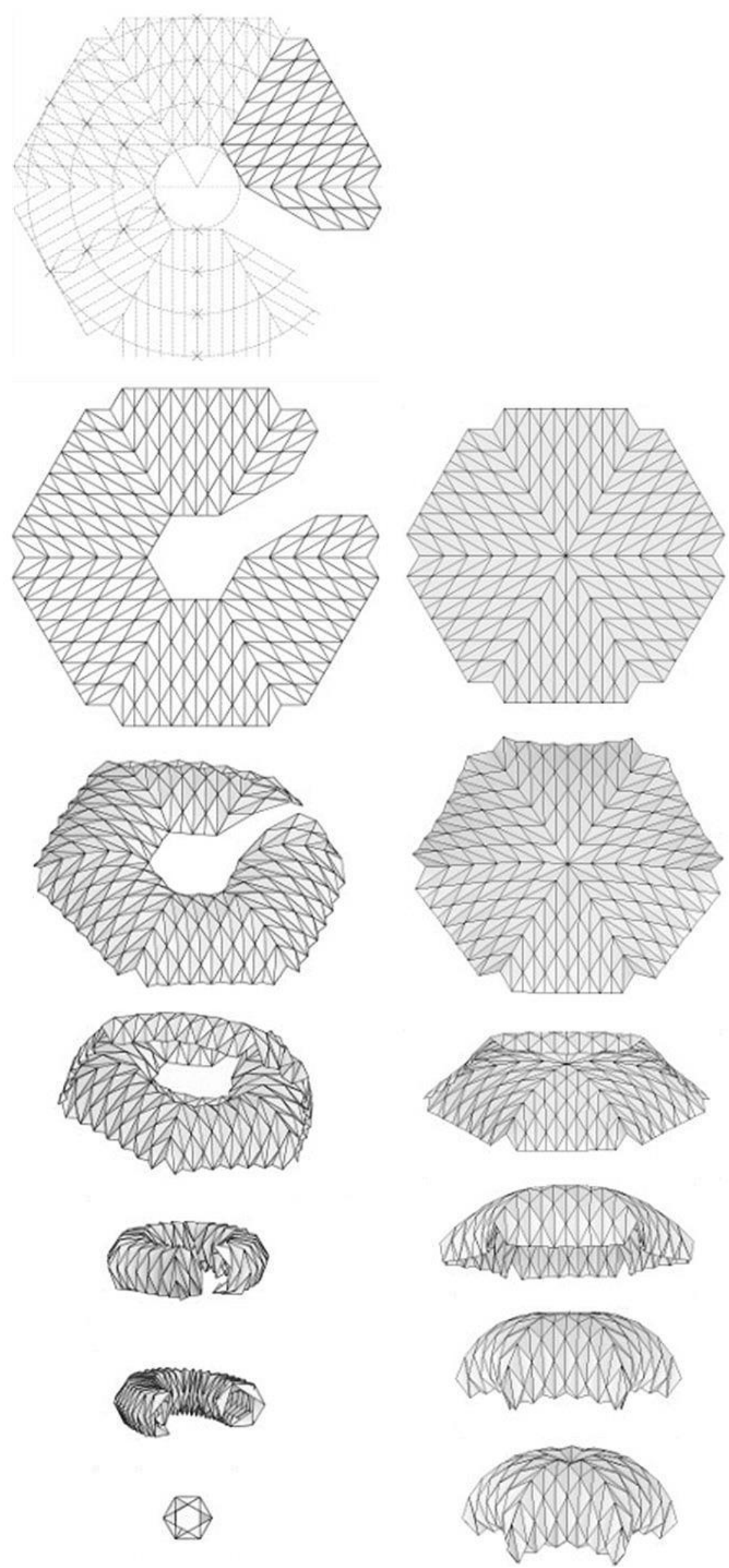

115. Yoshimura Hexagonal Polar

Autor Pablo de Souza, 2012. Simulaciones realizadas con el programa Rigid Origami de Tomohiro Tachi. 
El patrón de pliegue Yoshimura puede generar formas no solo abovedadas, como es el caso de la cúpula del ejemplo derecho de la pagina anterior, sino también cúpulas que tienen un desarrollo plegable completo si se parte de patrones regulares como el hexagonal distribuído en una circunferencia dividida en 6 partes y se mantiene abierta, ejemplo izquierdo.

116. Polar Yoshimura

Autor Pablo de Souza, 2012.

Simulaciones realizadas con el programa Rigid Origami de Tomohiro Tachi.
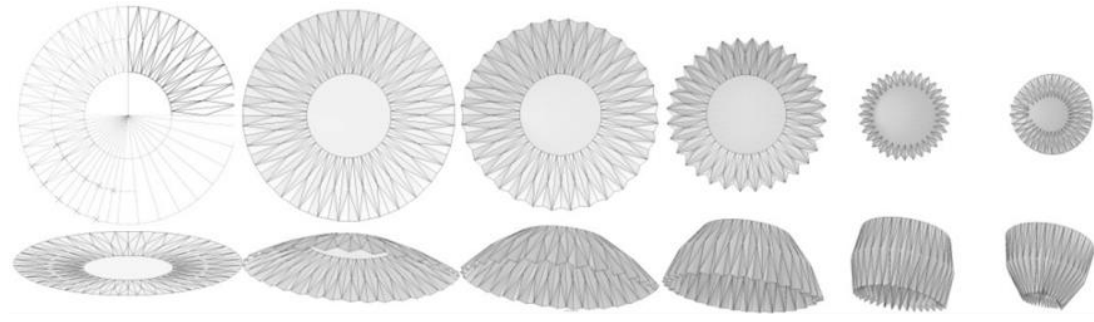

La transformación topológica radial o polar del patrón de plegado regular yoshimura se configura partiendo de arcos de circunferencia equidistantes, como es el caso de la imagen superior. Bajo estas líneas también se pueden ver las transformaciones topológicas radial, convexa, cóncava y la combinación entre ellas.

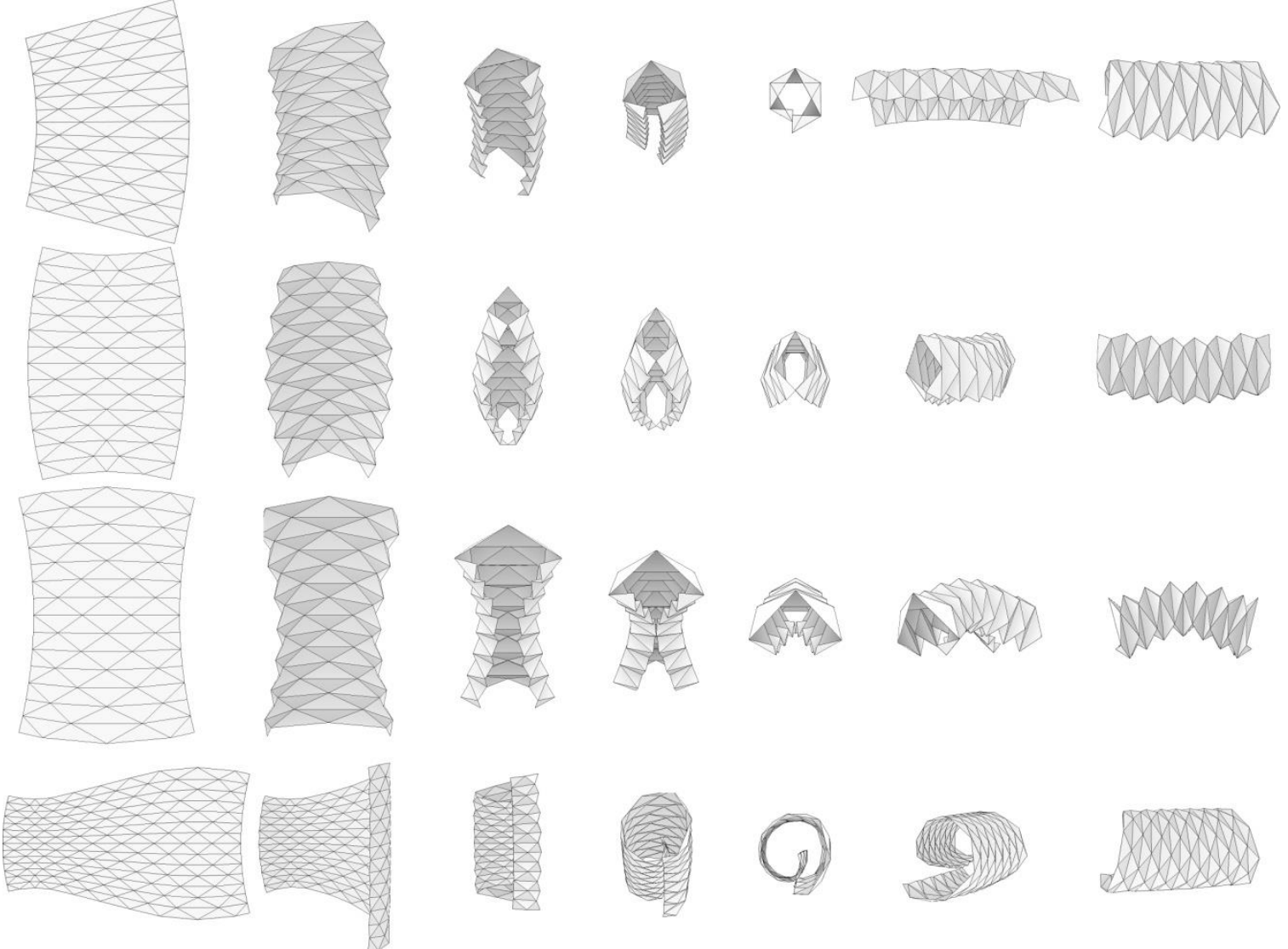

117. Transformaciones topológicas de patrón yoshimura: radial, convexa y cóncava.

Autor Pablo de Souza, 2012. Simulaciones realizadas con el programa Rigid Origami de Tomohiro Tachi.

Los desarrollos polares simétricos también tienen su correspondiente perfil plegado, dependiendo de la distancia entre los radios y el ángulo que forman entre ellos, definido por el radio de circunferencia, la dirección del perfil en espiral se formará de dentro hacia fuera o al revés. Son el caso de las variantes polares que dividen el radio en partes iguales, como se puede observar en el ejemplo de la izquierda de la página siguiente, o las que lo dividen siguiendo progresiones escalares como la Fibonacci, ejemplo derecho. 

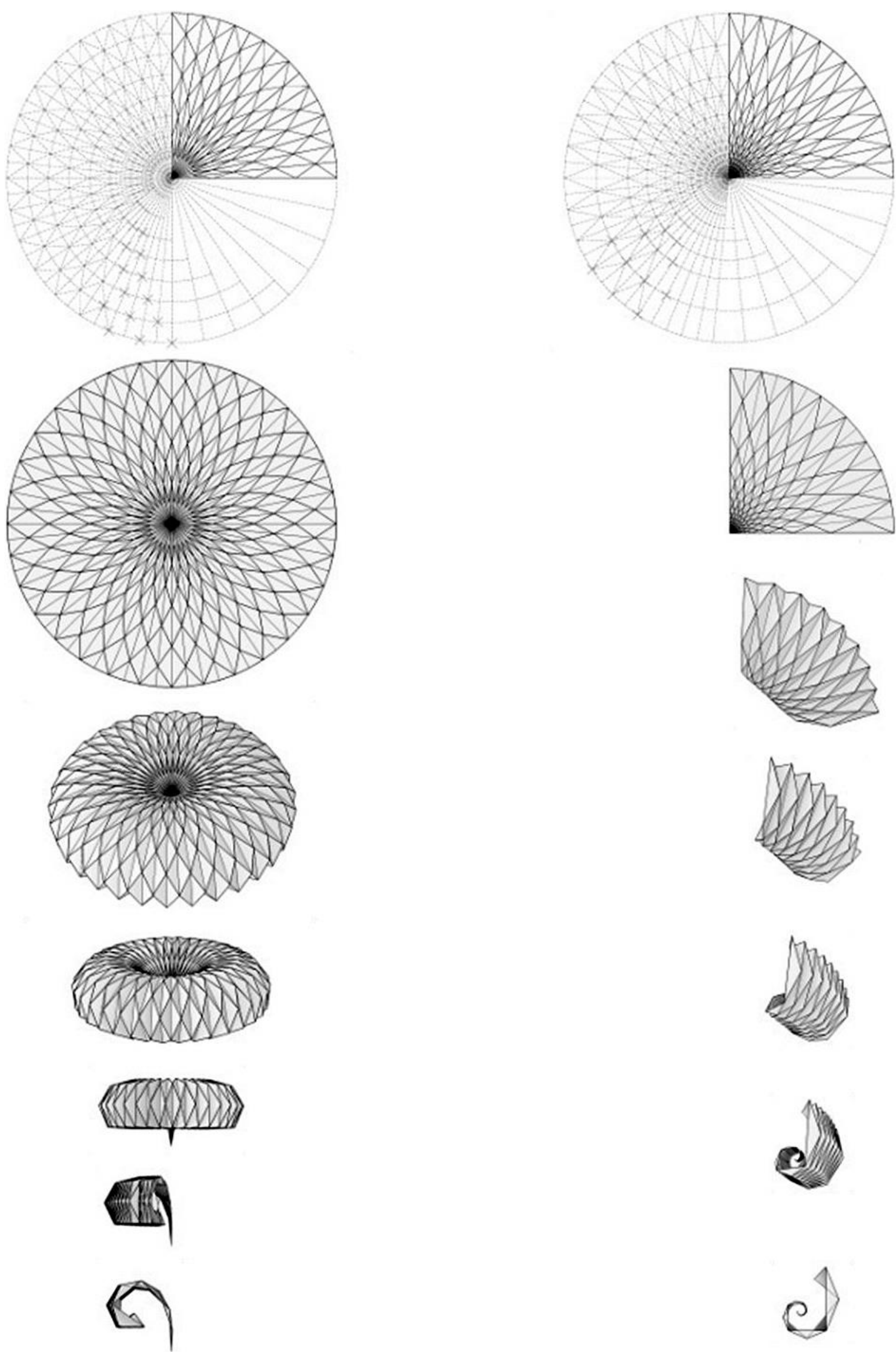

118. Yoshimuras polares de subdivisiones del radio iguales y en proporción Fibonacci.

Autor Pablo de Souza, 2012. Simulaciones realizadas con el programa Rigid Origami de Tomohiro Tachi. 
En la propuesta presentada bajo estas líneas se combinan pliegues polares y transformaciones topológicas del pliegue yoshimura con lo que se generan posibilidades infinitas a la hora de configurar espacios abovedados con capacidades cinéticas.

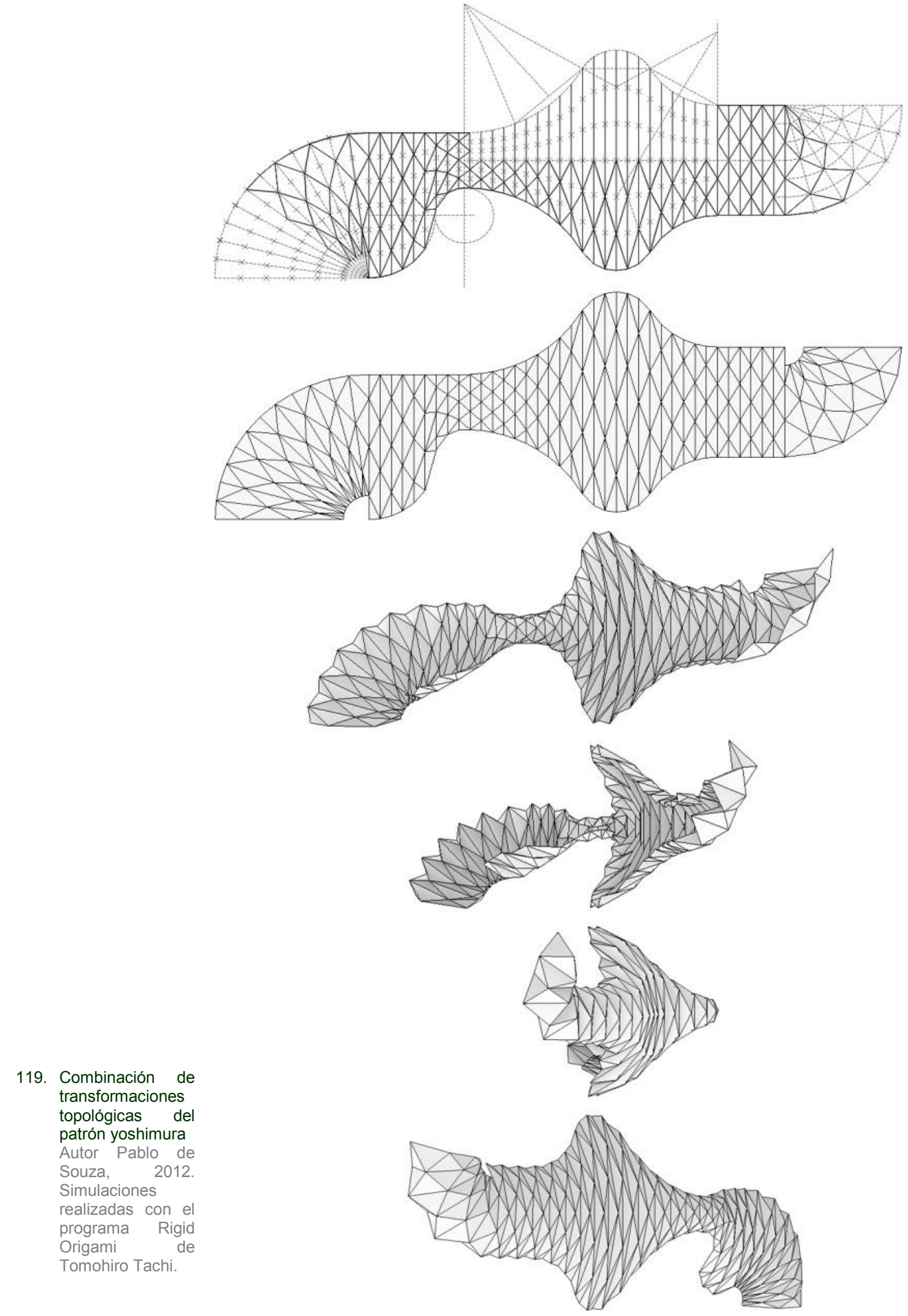


Bajo estas líneas se muestran otras variaciones del patrón yoshimura como son:

Yoshimura extendido: llamado así pues el triángulo inicial se estira por los vértices convirtiéndose en un trapecio sin afectar al proceso de pliegue del yoshimura.
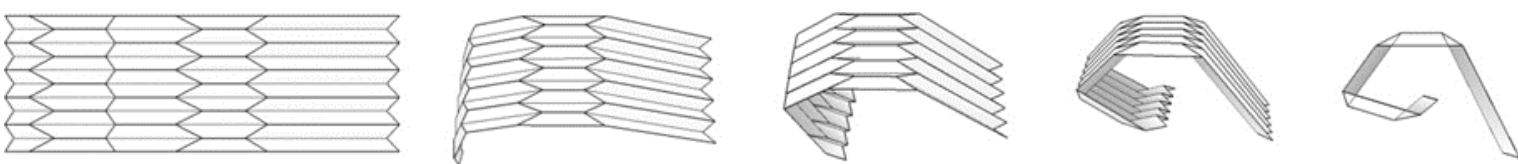

Yoshimura extendido diagonal: que es una derivación del extendido al que se le ha trazado una diagonal que cruza el trapecio.
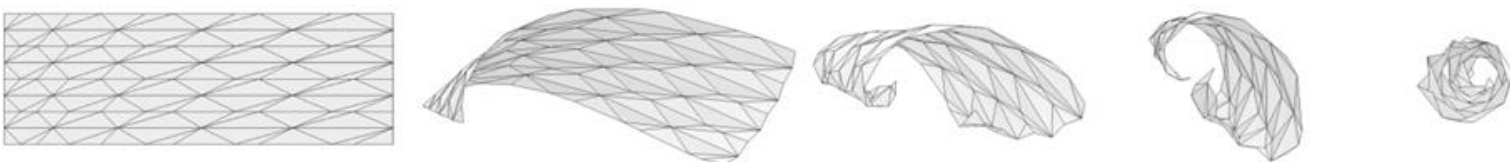

Yoshimura asimétrico: donde los triángulos del patrón no son isósceles, sino escalenos.
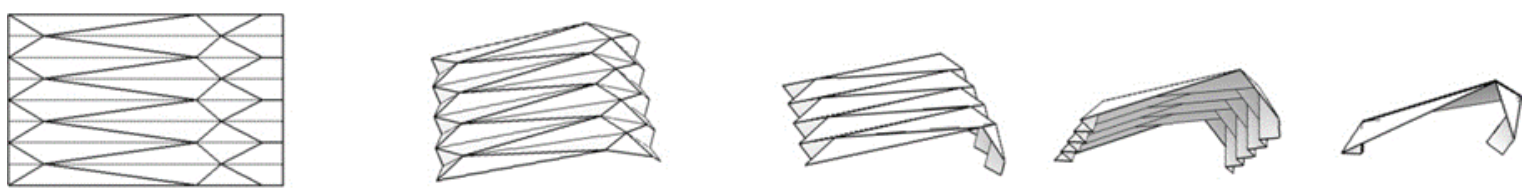

Variaciones escalares: Son variaciones por subdivisión de la distancia horizontal o de la vertical sin modificar el ángulo del patrón original. Bajo estas líneas se puede ver la variación escalar horizontal y la vertical del patrón yoshimura hexagonal.
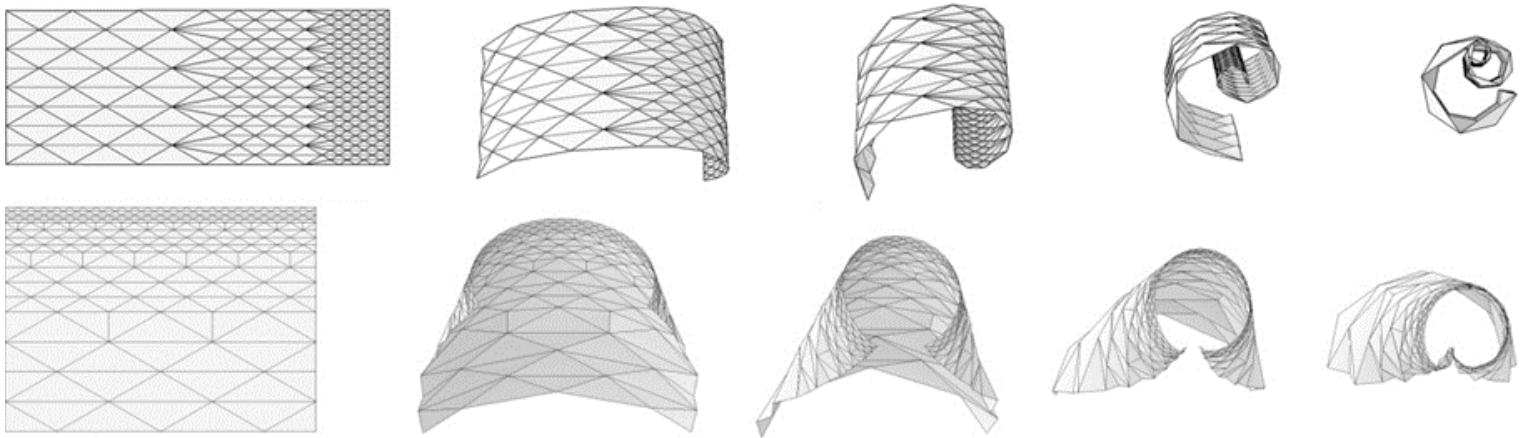

Transformación seriada: Donde se modifica el patrón reduciendo la hipotenusa del triángulo yoshimura de una forma progresiva y seriada. Bajo estas líneas la transformación seriada horizontal y la vertical con simetría invertida.
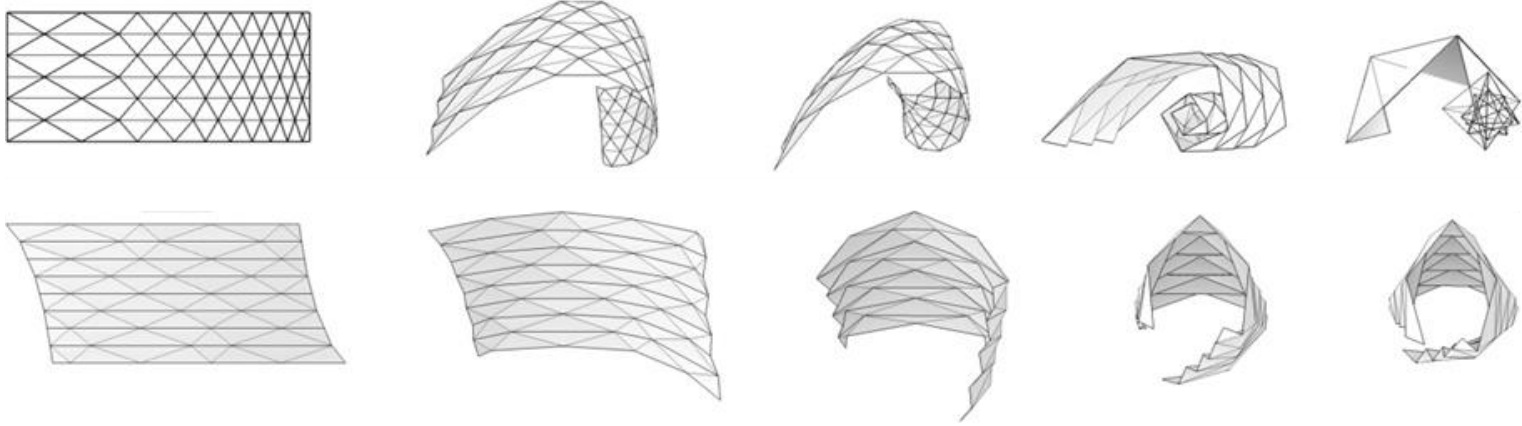

120. Variaciones generales del patrón yoshimura

Autor Pablo de Souza, 2013. Simulaciones realizadas con el programa Rigid Origami Simulator de Tomohiro Tachi. 
Miura-Ori: O comúnmente llamado Miura. Sobre la malla original del trazado yoshimura, se eliminan una de las líneas diagonales de los triángulos uniendo éstos y formando figuras romboidales, de este modo las divisiones horizontales paralelas vuelven a cambiar su pliegue alternando valle y montaña. Al contrario del pliegue yoshimura que pliega formando bóvedas, el pliegue miura pliega formando elementos lineales rectos.
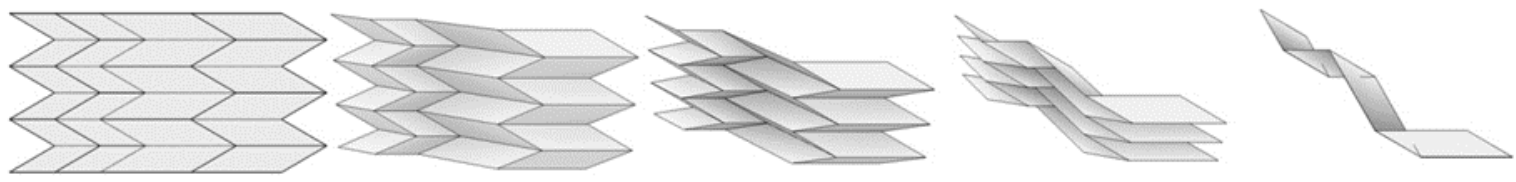

121. Pliegue Miura

Autor: Pablo De Souza, 2017.

Simulaciones con Rigid Origami, software diseñado por Tomohiro Tachi.

Fishbone: Al subdividir el rombo del pliegue miura mediante una diagonal que une sus vértices más alejados, se consigue anular la alternancia entre valles y montañas de las líneas horizontales del pliegue miura y generar bóvedas de curvas suaves y progresivas.
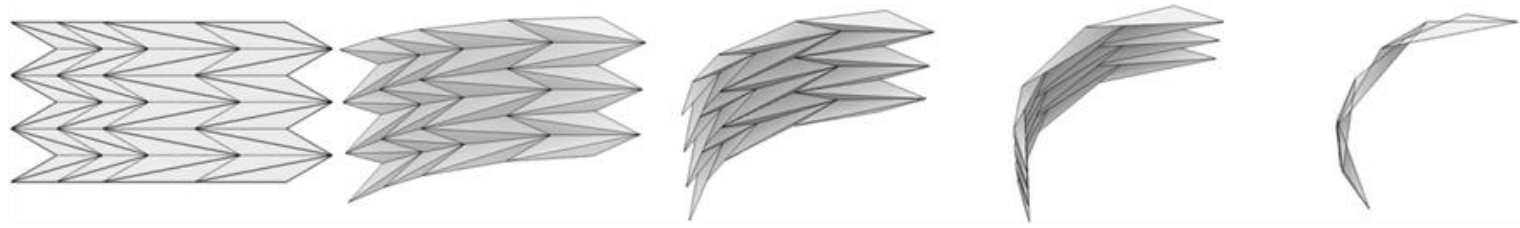

122. Fishbone o Espina de pez

Autor: Pablo De Souza, 2017

Simulaciones con Rigid Origami, software diseñado por Tomohiro Tachi.

Los patrones de pliegue elementales además pueden combinarse formando diferentes perfiles de pliegue más complejos. La adición de un pliegue miura a un pliegue yoshimura o a un fishbone cambia la dirección de plegado de éstos de cóncavo a convexo. La combinación de los cuatro patrones regulares (sin transformación topológica) elementales asegura un proceso de pliegue y despliegue completo con lo que se puede definir desde el inicio del proceso de diseño el perfil deseado en cualquiera de las fases de plegado.
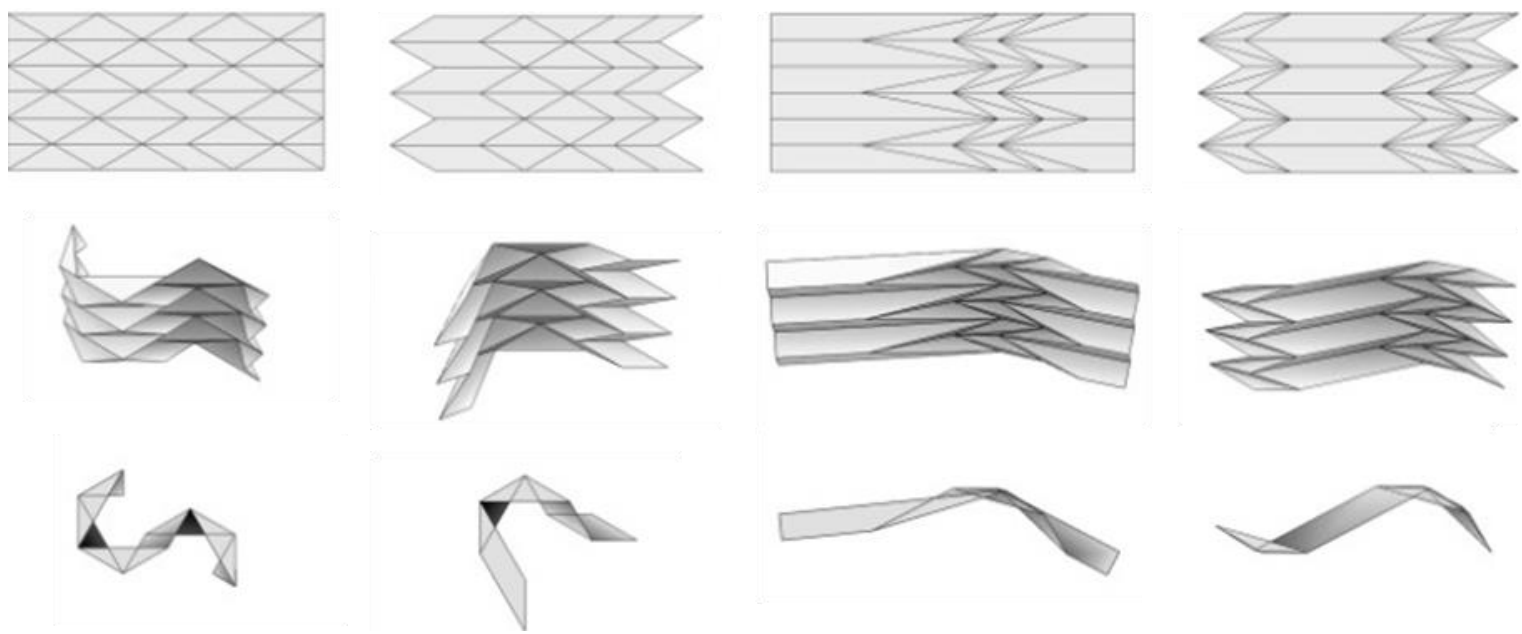

123. Combinaciones de los patrones de pliegue elementales.

Autor: Pablo De Souza, 2017.

Simulaciones con Rigid Origami, software diseñado por Tomohiro Tachi. 


\section{Curved Folding o pliegue curvo}
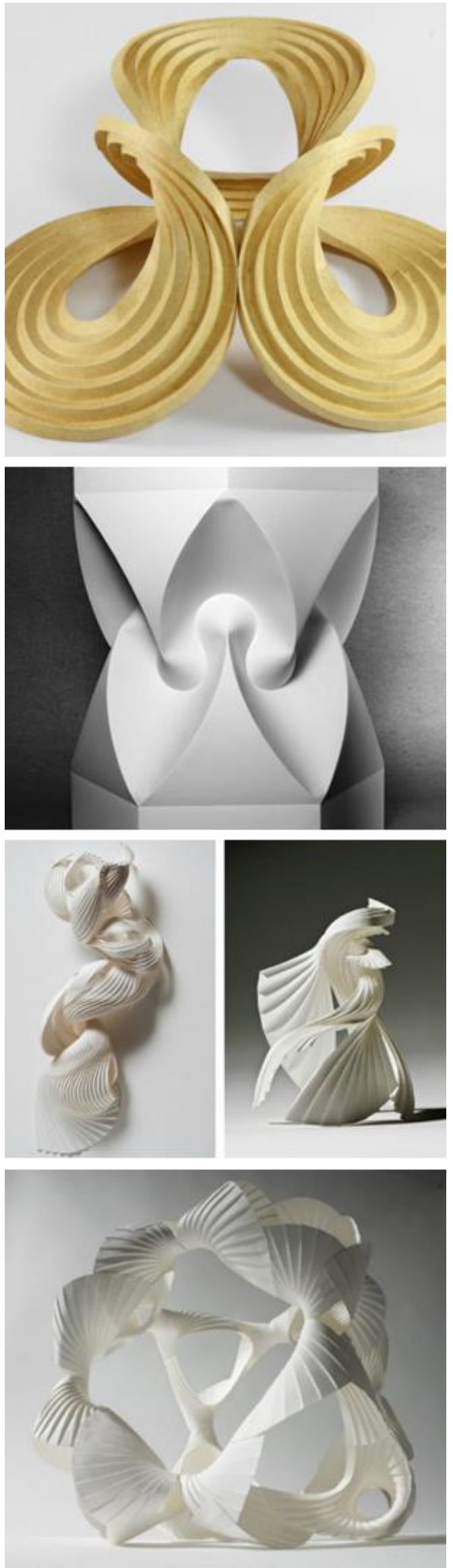

El primer ejemplo de pliegue curvo conocido lo tenemos en los cursos preliminares dirigidos por Josep Albers en la Escuela de la Bauhaus en la década de los 20. En nuestros días, artísticamente destacan los trabajos de Martin y Erik Demaine, padre e hijo son profesores doctores en informática en el Massachutes Institute of Technology y especialistas en origami matemático. El ejemplo es una evolución del plisado curvo de Albers.

\section{Splash II, Erik and Martin Demaine, USA, 2011}

Fuente: International Arts \& Artists (Agosto 2012) Folding Paper. The Infinite Possibilities of Origami. Japanese American National Museum. Los Angeles

También destacan las estructuras abstractas y geométricas de las obras de David Huffman, ingeniero y pionero en el desarrollo de las matemáticas de la papiroflexia, sus trabajos indagan en la relación entre diferentes trazados curvos para generar superficies alabeadas complejas.

125. Hexagonal Column with Cusps David Huffman (1925-1999)

Fuente: Demain, Erik D.; et al (2011) Reconstructing David Huffman's Legacy in Curved-rease Folding. Origami 5: Fifth International Meeting of Origami Science, Mathematics, and Education. A. K. Peters/CRC Press; pág. 48

Las obras de Richard Sweeney son una evolución del plisado realizado en papel y luego humedecido para darle curvatura. Éstas destacan también por el uso de varios módulos combinados que son pegados para configurar una sola pieza. Estas obras con curvas sinuosas se asemejan a los últimos proyectos de arquitecturas paramétricas del estudio Zaha Hadid arquitectos.

126. Pleated Works (2015), Embrace (2013) and Cube (2012) Fuente: http://www.richardsweeney.co.uk/works 

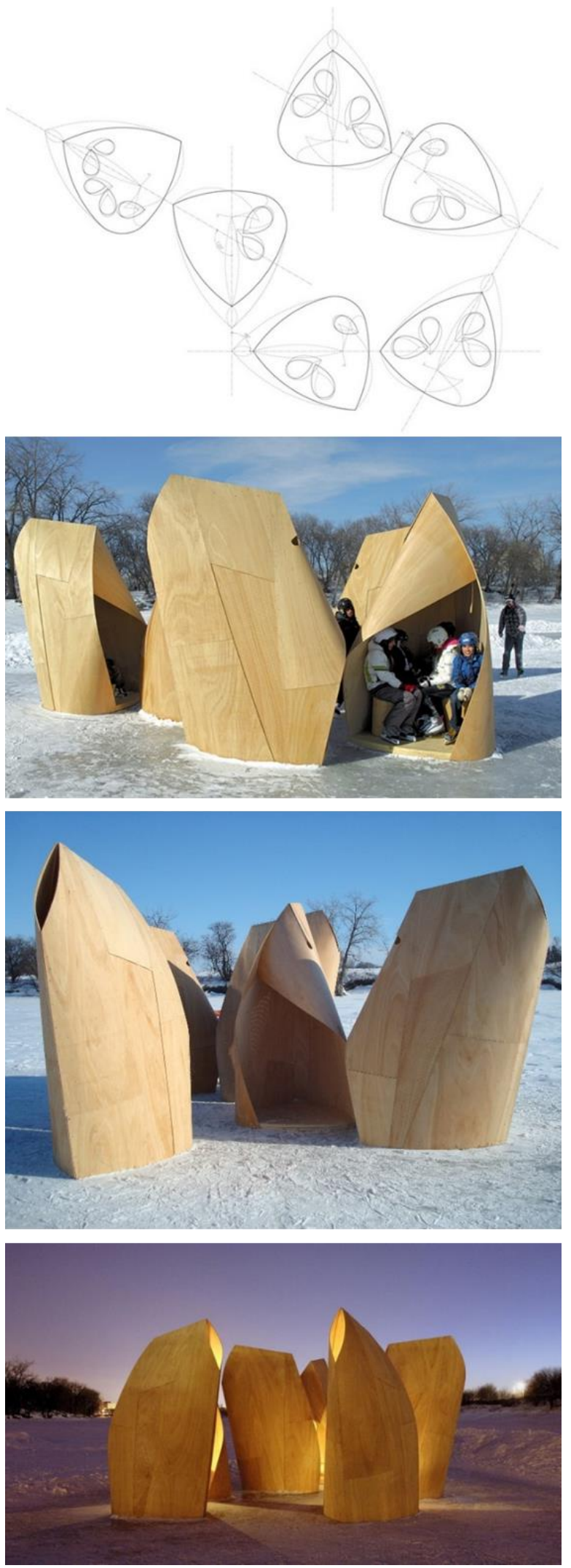

Muchas de las obras del estudio de arquitectura Patkau Architects ${ }^{109}$ están inspiradas en la papiroflexia curva. Con el título original de Jellyfish... wait for it! El estudio se presentó a la competición internacional Warming Huts organizada por el ayuntamiento de Winnipeg - Canada en el 2011. Dirigido a arquitectos, artistas y diseñadores con el objetivo de promover la construcción de cabañas o refugios que consoliden una ruta turística a lo largo del río "Assiniboine".

Ubicada en la pradera canadiense. Winnipeg es la ciudad más fría de su tamaño fuera de Siberia. Con temperaturas que llegan a alcanzar los 40 grados bajo cero, la creación de refugios frente al viento aumenta en gran medida la capacidad de utilizar las pistas de patinaje que se crean en los 6 meses de invierno sobre los dos ríos helados que rodean la ciudad. Para fomentar el uso de estas pistas, desde el año 2010 la ciudad ha desarrollado un programa anual para patrocinar el diseño y construcción de múltiples refugios temporales ubicados a lo largo de las pistas de patinaje que se han convertido en un importante atractivo turístico para la zona. 110

La propuesta de Patkau consiste en un grupo de cálidos e íntimos refugios, con una poética y serena solución, un conjunto de seis linternas con capacidad para unas pocas personas a la vez. Agrupados para formar un colectivo de algo, como si de un pequeño asentamiento indio $o$ de un rebaño se tratase. De espaldas al viento como búfalos, parecen tener vida $\mathrm{y}$ propósito mientras se amontonan protegiéndose mutuamente de los elementos.

127. Jellyfish Winnipeg Skating Shelters. Patkau Architects (2011)

Fuente: http://www.canadian-architects.com/en /projects/37236_Winnipeg_Skating_Shelters

\footnotetext{
109 Fuente: http://www. patkau.cal

${ }^{110}$ En la galería Warming Huts (refugios calientes) se muestran todos los proyectos realizados en los últimos 6 años Fuente: http://www.warminghuts.com/gallery
} 
La instalación esta compuesta por seis piezas diferentes, construidas con laminas de madera contrachapada de $5 \mathrm{~mm}$ de espesor, recortadas, dobladas y ensambladas con fijaciones mecánicas, formando una estructura cónica que, junto con los bancos instalados en el interior, definen un entorno donde descansar, estar y percibir la presencia del paisaje.
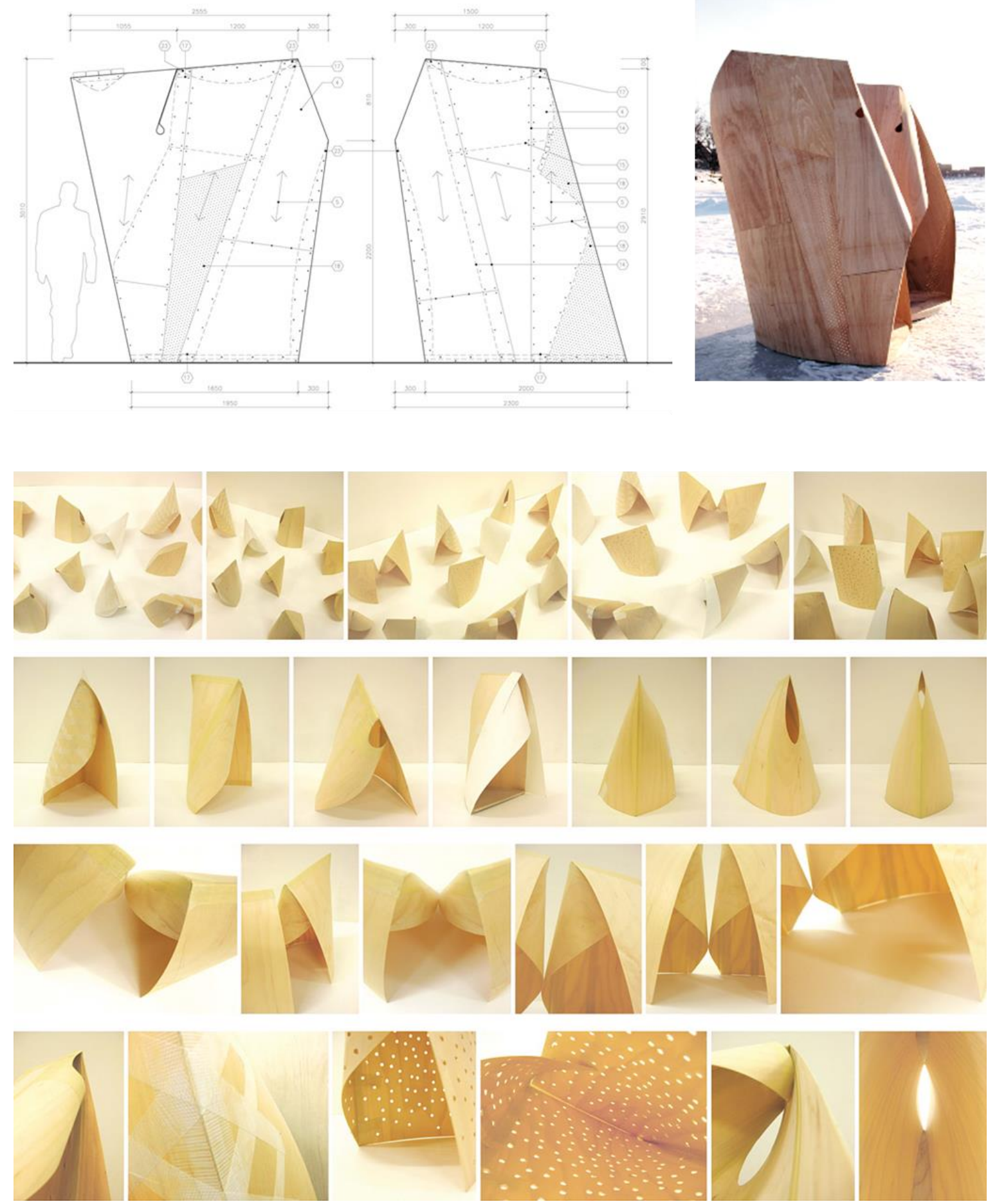

128. Jellyfish Winnipeg Skating Shelters. Patkau Architects (2011)

Fuentes:http://www.world-architects.com/en/projects/37236 Winnipeg_Skating_Shelters http://blog.bellostes.com/?p=14319 


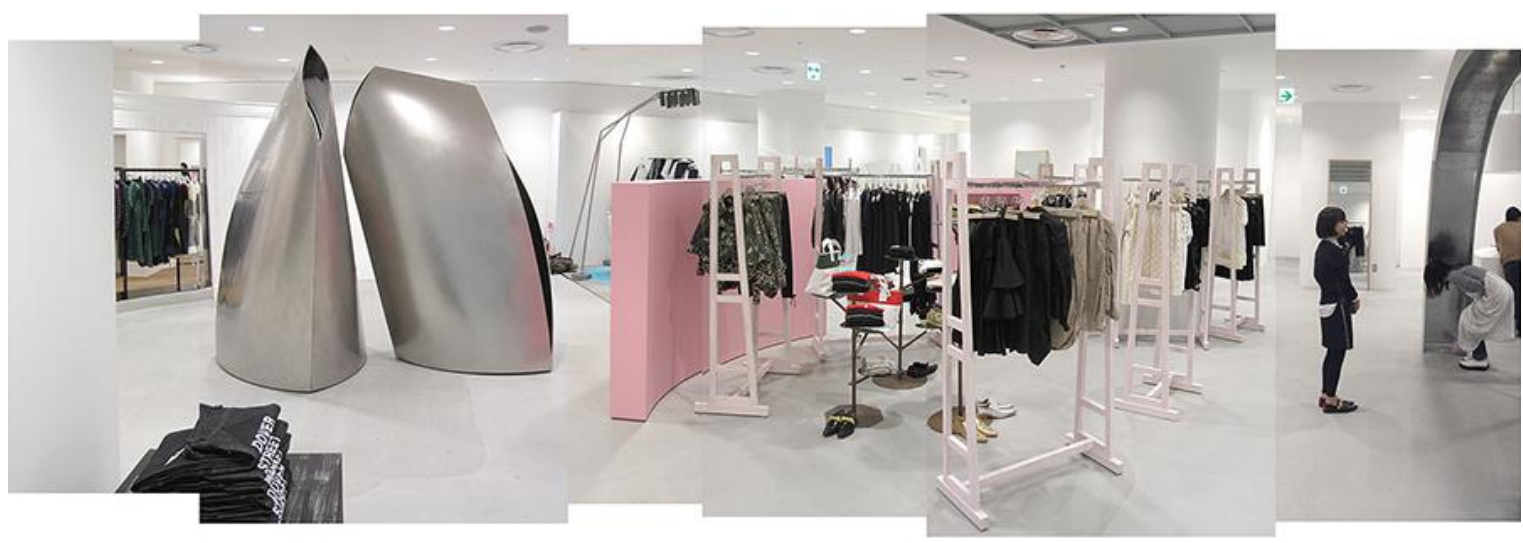

129. Cocoons, Tokyo, Japan, 2011-2012

Este proyecto tuvo su continuidad en la intervención llevada acabo por el mismo estudio en el Dover Street Market Ginza de Tokio, Japón en el año 2012. Diseñados no solo como elementos decorativos, sino también para poder ser utilizados como exhibidor de algunos de los productos de la colección de moda o como vestuarios. Encargo directo de la diseñadora de moda Rei Kawakubo y fundadora de la empresa Comme des Garçons. Kawakubo no sólo concibió todos los espacios para su marca, sino también seleccionó los artistas y arquitectos que participarían en el diseño interior de los 6 pisos de todo el centro comercial con el objetivo de crear un caos hermoso y coherente a la vez.

En este contexto, los caparazones se asemejan a unos capullos que, agrupados por parejas, ofrecen un silencioso y calmado momento de pausa entre el éxtasis de las compras. Cada elemento se construye a partir de tres hojas de acero inoxidable de $18 \mathrm{~mm}$ soldadas y fijadas a un marco de acero inoxidable con un piso de acrílico retroiluminado. Con su propia escala interna, son figuras animadas e íntimas, un par o pareja de "algo", una relación de dos, irreductible a una sola interpretación. Su papel es igualmente ambiguo, cambiar el recinto o la exhibición, ocupante u ocupado, afirmando la innegable presencia de sus «cuerpos» frente a los objetos efímeros que los rodean. Con su suave, fría y continua superficie exterior de acero inoxidable transforma la lámina en masa, construyendo un sentido de lo inmutable. Las reflexiones interiores multiplican las simetrías formales en una serie caleidoscópica vertiginosa. Se entra en un espacio enteramente otro, como una especie de cámara criogénica, y se emerge cambiado mientras los capullos mismos permanecen.
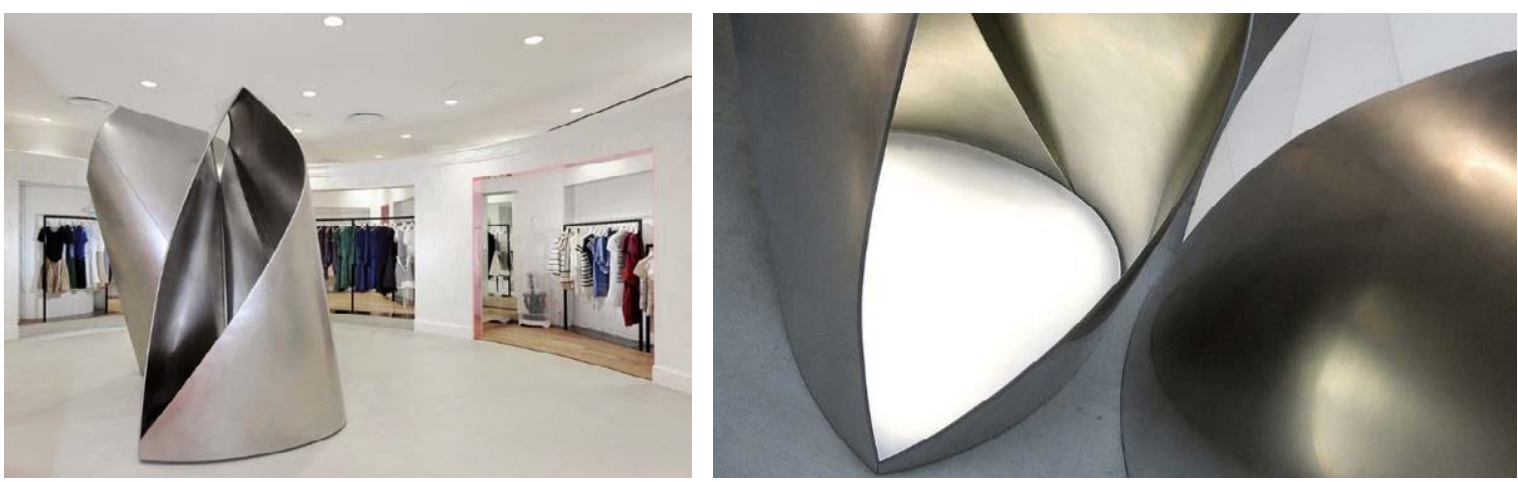

130. Cocoons, Tokyo, Japan, 2011-2012 

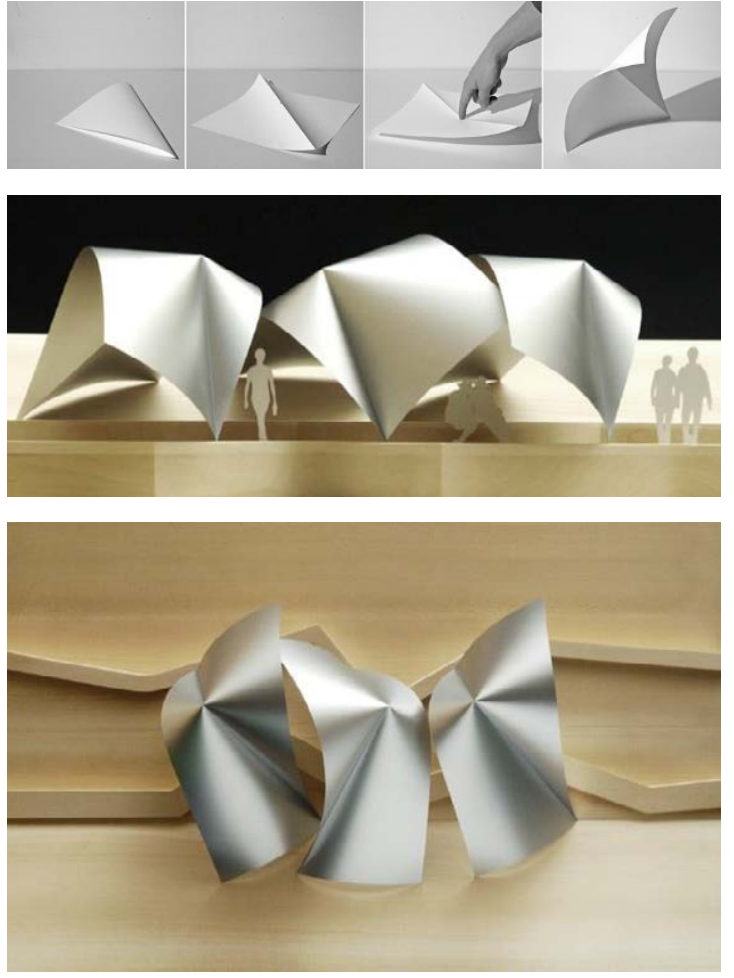

El proyecto One Fold realizado también por el estudio Patkau Architects es una exploración del potencial espacial y estructural resultante del simple plegado de una hoja de acero inoxidable. Inspirado en el origami abstracto de Paul Jackson debió resolver el problema de la extrema rigidez que alcanza una chapa de acero plegada. Para resolver este problema hicieron un agujero cerca del centro de la línea de pliegue con lo que pudieron forzar la chapa para plegarla en la dirección perpendicular al pliegue inicial. La solución al problema de aumento del tamaño y grosor de la chapa fué inventar una máquina que doblara simultáneamente una chapa de acero y rompiera la hoja a través del pliegue perpendicular. La simultaneidad de ambas operaciones ha hecho posible hacer en acero lo que es secuencialmente posible en papel. Las tensiones introducidas en la chapa de acero por la operación de plegado / rotura se liberan en superficies y bordes sin restricciones para formar curvas complejas de una impresionante belleza natural.

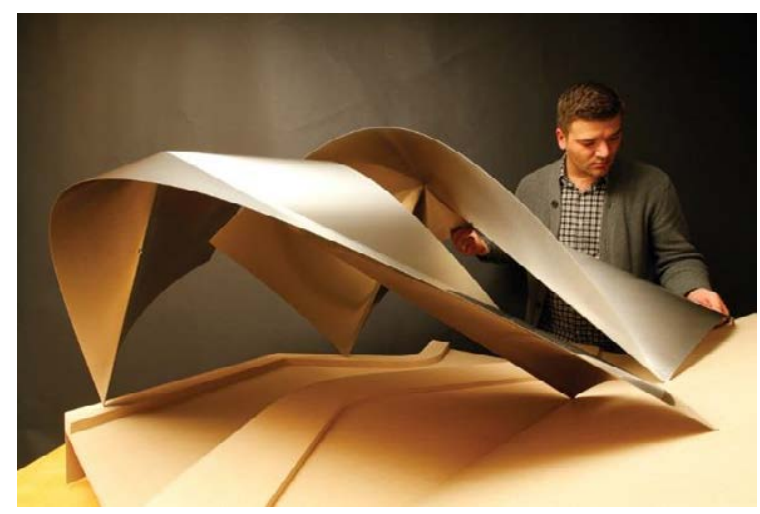

131. One Fold, Vancouver, British Columbia, 2011 Medidas: 152,4 × 365,76 cm (5 x 12 pulgadas) Fuentes:

http://www.patkau.ca/

http://www.detail-online.com/inspiration/technology-one-fold$\%$ E2\%80\%93-simply-folded-111724.html
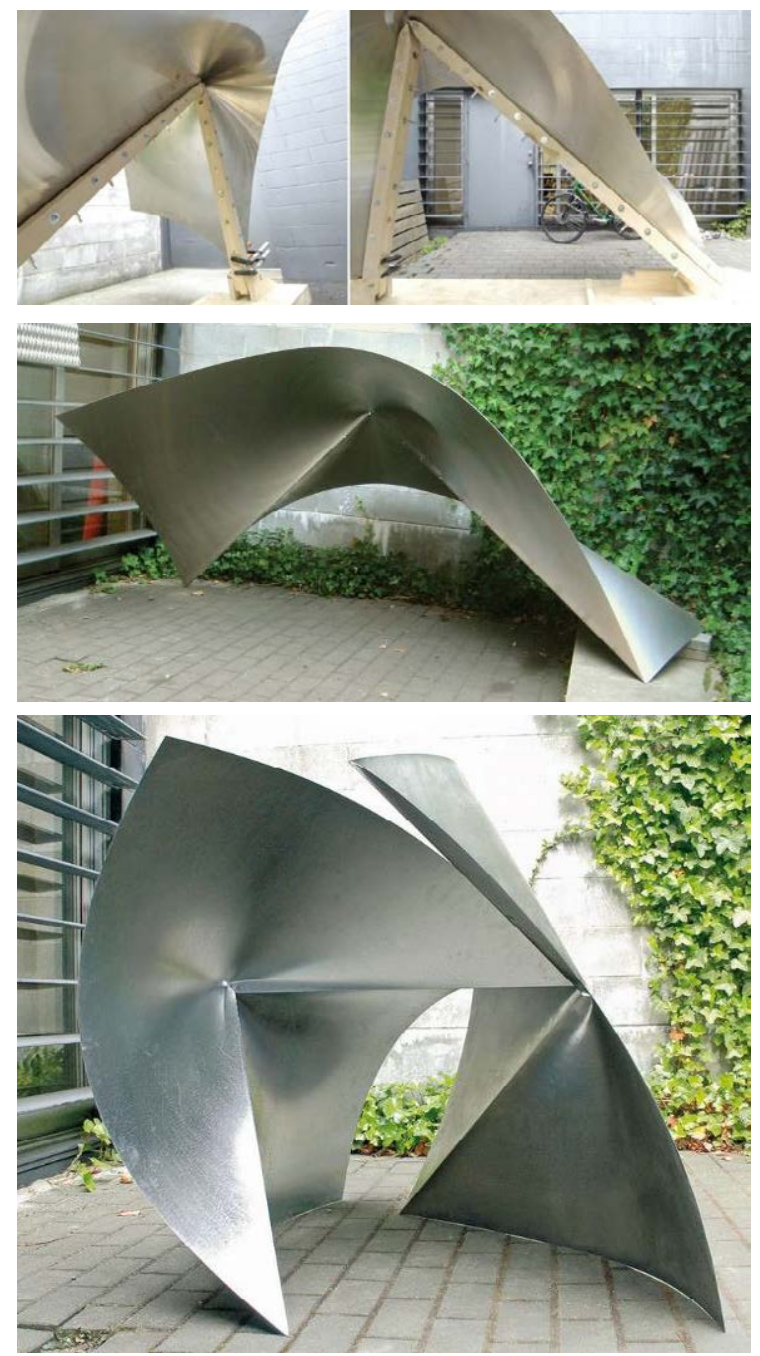
En la arquitectura, autores como los doctores arquitectos Gregory Epps y Tomohiro Tachi están investigando en el cálculo para la simulación y construcción de estructuras curvas cinéticas mediante pliegues de superficies rígidas de sección variable. Lo que han venido a llamar Rigid Curved Folding ${ }^{111}$. Otros programas para el diseño y edición de superficies plegadas son el plugin de Grasshopper para Rhino ${ }^{112} \mathrm{o}$ el Catia utilizado por F. Ghery.
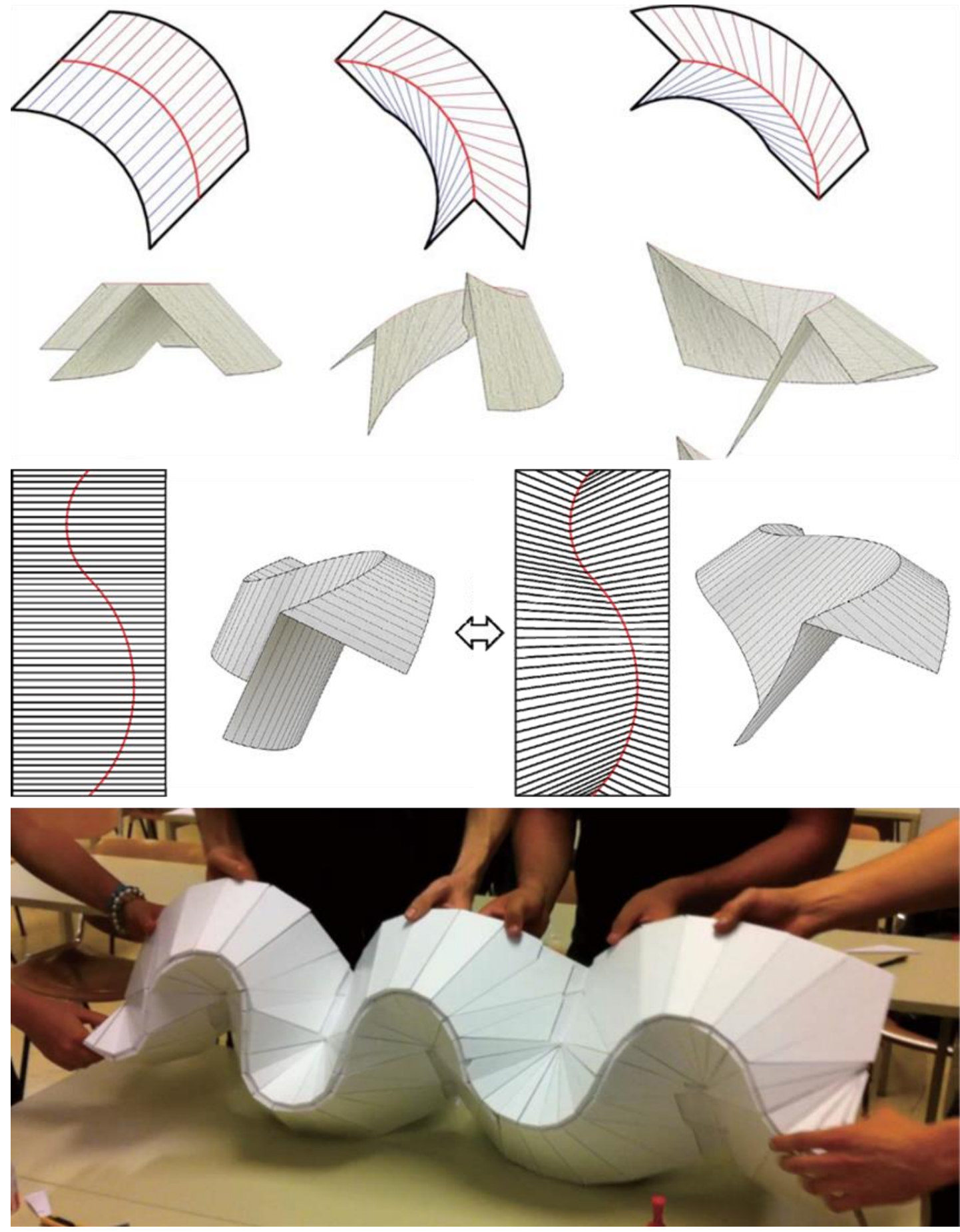

132. Pliegues curvos de superficies rígidas

Fuente: Tachi, T.; Epps, G. (2011) One-DOF. Designing Mechanisms for Architecture by Rationalizing Curved Folding. Proceedings of the I. S. A. D. for Architecture and Urban Design, ALGODE TOKYO 2011. Tokyo, Japan

\footnotetext{
111 Tachi, Tomohiro; Epps, Gregory (Marzo 14-16, 2011) One-DOF. Designing Mechanisms for Architecture by Rationalizing Curved Folding. Proceedings of the International Symposium on Algorithmic Design for Architecture and Urban Design, ALGODE TOKYO 2011. Tokyo, Japan

112 McNeel. Grasshopper - Generative Modeling for Rhino, http://grasshopper.rhino3d.com/./
} 


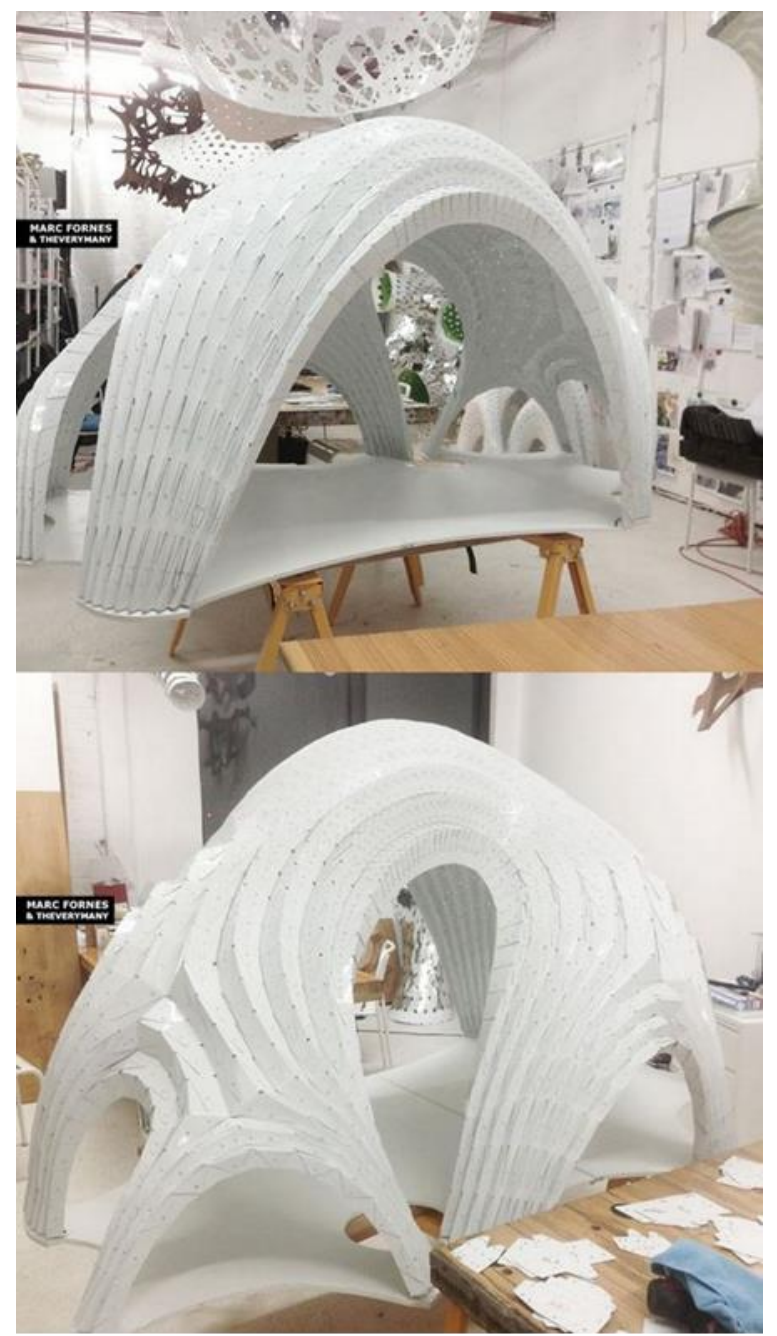

Otro buen ejemplo de la aplicación de los pliegues curvos en el diseño y construcción de arquitectura contemporánea es el proyecto de Marc Fornes Pleated Shell (concha plegada) también llamado Pleated Inflation / Informal amphitheater (Plisado Inflado / Anfiteatro informal) está diseñado partiendo del plisado curvo que se realizara en los cursos de Josep Albers y que han evolucionado los científicos, artistas y origamistas Erik y Martin Demaine. Construido mediante piezas plásticas engarzadas entre sí, conformando una superficie con la suficiente continuidad estructural, para aprovechar la geometría del plisado curvo y alcanzar una considerable luz gracias a la rigidez propia de esta configuración plegada.

\section{Pleated Shell. $1 / 15$ scale structural mode} Fuente: www.theverymany.com

134. Pleated Inflation | Informal amphitheater | ArgelesSur-Mer, France | 2013

Design \& computation: MARC FORNES / THEVERYMANY Location: Lycee Christian Bourquin, Argeles-Sur-Mer

Hypothesis of research: self-supported shell through pleated inflation + agents based porosity (implementing our Calder installation) Photos series: "end assembly" v.150828:

Fuente:https://theverymany.com/public-art/argeles-sur-mer/
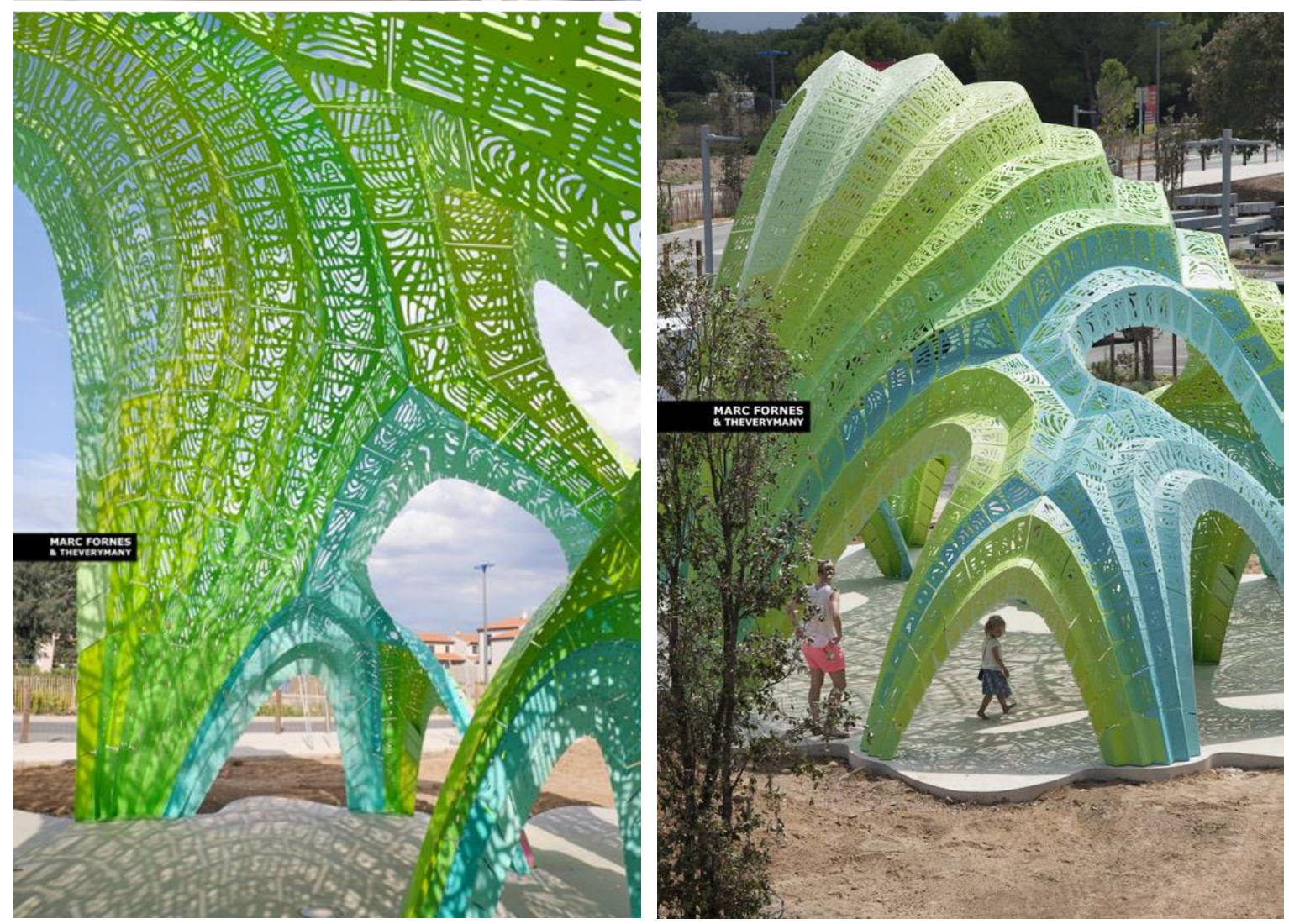


\section{El Origami Modular}
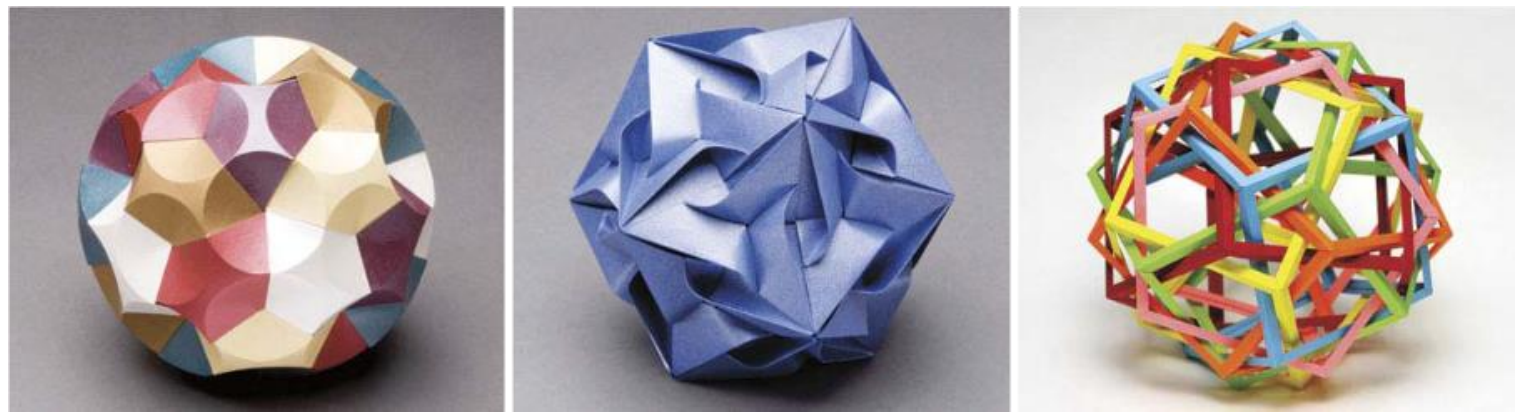

135. Tres ejemplos de Origami Modular

Six Interlocking Pentagonal Prisms, Daniel Kwan. USA, 2010

90 rectangles of paper. Miyuki Kawamura. Polyhedron Origami. 2002.

Fuente: International Arts \& Artists (Agosto 2012) Folding Paper. The Infinite Possibilities of Origami. Japanese American National Museum. Los Angeles

La papiroflexia u origami modular consiste en construir figuras generalmente geométricas mediante la unión de varias unidades o piezas sencillas plegadas previamente por separado, las cuales serán imbricadas sin pegamento. Cada uno de estos módulos posee solapas y bolsillos, que se usan para ensamblarlos entre sí.

Tanto en el diseño como en el plegado y ensamblaje de los módulos, se experimentan de forma sencilla las propiedades de los poliedros tales como el grado de un vértice, regularidad, simetría, entre otros.
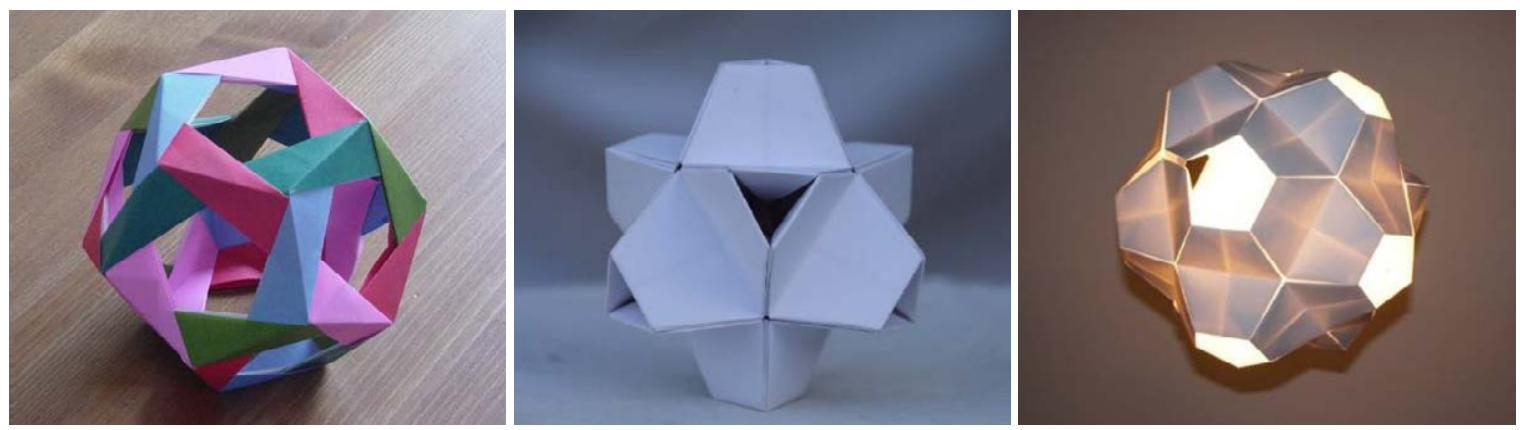

136. Tres ejemplos de origami modular

Dodécaèdre Lampe. 15 décembre 2014

Poliedros Regulares Polyèdres Réguliers Avec « Little Turtle »

Fuente: https://lespetitspapiersdemoise.wordpress.com/blog/

La primera referencia que tenemos de un elemento realizado en origami modular la encontramos en el libro Ranma Zushiki de Shunboku Ooka publicado en 1734 mostrado ya en esta tésis en el capítulo "De los pliegues ceremoniales al arte lúdico del origami japonés", en este libro se muestran diferentes diseños para paneles decorativos entre los que se encuentran varias láminas que representan objetos realizados en papel, sobre estos diseños llama la atención una serie de representaciones de un cubo y sus pliegues modulares conocido con el nombre de tamatebako o baúl mágico y que se construye con el módulo de plegado triangular Menko. 

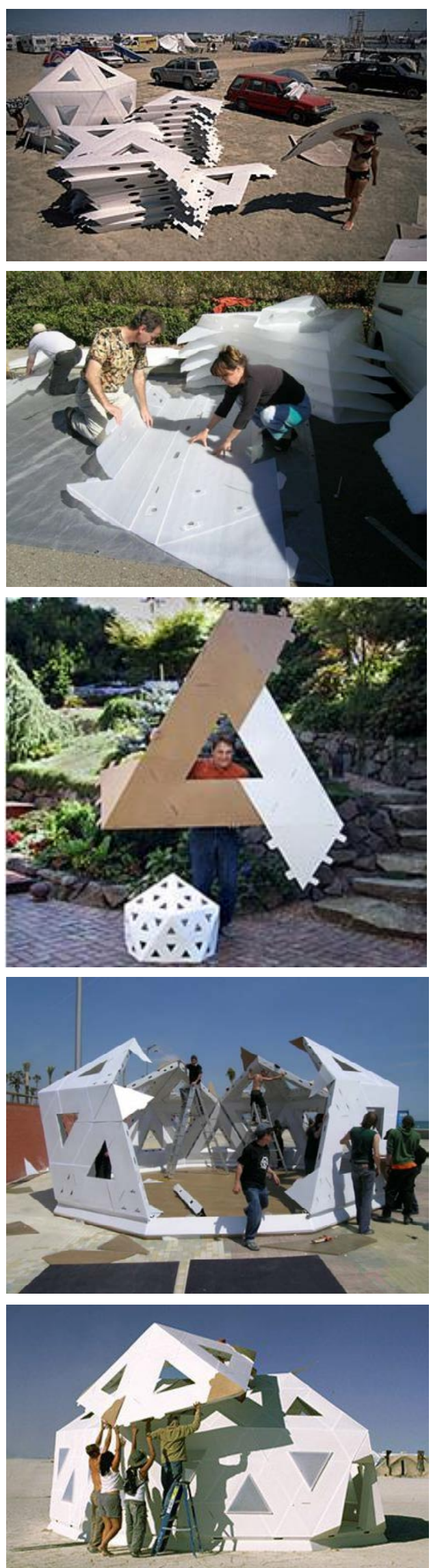
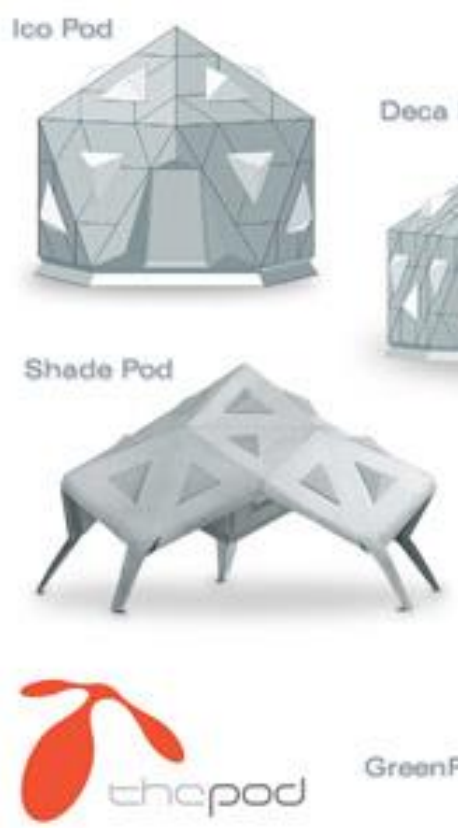

GreanPod

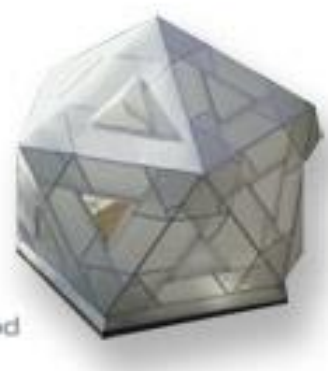

Desde la década de 1940, el diseñador, arquitecto, visionario e inventor estadounidense Richard Buckminster Fuller trabajó en el diseño de estructuras geodésicas que pudieran servir como una alternativa económica a los hogares tradicionales. Registrando la patente en 1954 en formato de cúpulas de cartón, el diseño de Fuller creaba una estructura autoportante sin refuerzos internos mediante la utilización de parte de una esfera geodésica, un poliedro generado a partir de un icosaedro o un dodecaedro. Defensor del modelo geodésico de Fuller y con la convicción de que sigue siendo la técnica de construcción más eficiente y rentable disponible, el inventor Sanford Ponder, patentó el diseño the Pod que evolucionaba la cúpula plegada de una sola lámina de Fuller hacia una estructura más rígida de doble pared. Como una obra de origami modular, the Pod se construye doblando láminas idénticas de material cortado previamente para formar cada una de las piezas en base de triángulo equilátero que van a formar una estructura en forma de icosaedro.

137. Ico, Deca, Shade y Green Pods.

Fuente: http://foldedhomes.com/pods.html 


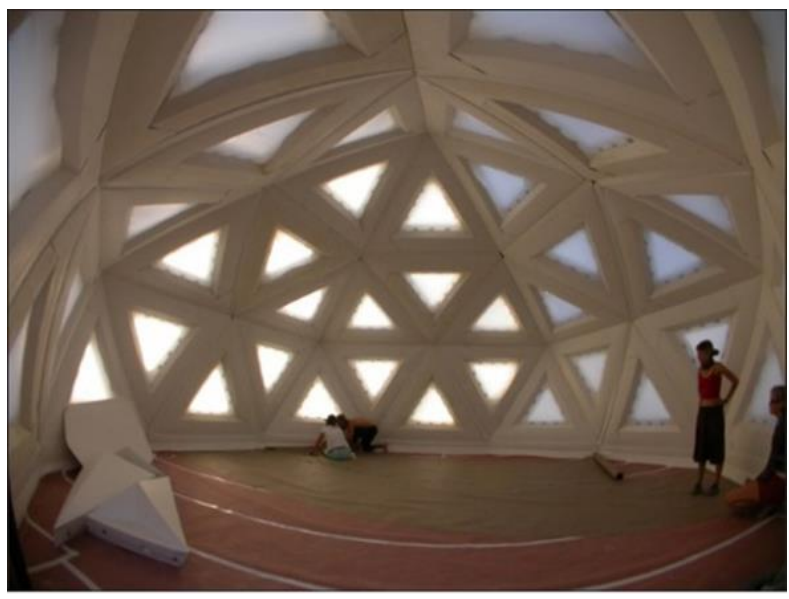

Los recintos habitables de la empresa Folded Homes (hogares/casas plegados) fundada por Sanford Ponder, buscan optimizar los recursos mediante construcciones sencillas, pues cada panel, unido al resto de los paneles, configura una lámina plegada continua que funciona como pared y cubierta. Diseñado como un triángulo equilátero de $244 \mathrm{cms}$ de lado y 16, $2 \mathrm{cms}$ de ancho, y realizado con tres hojas plegadas de polipropileno extruido, cada panel es una forma estructural y

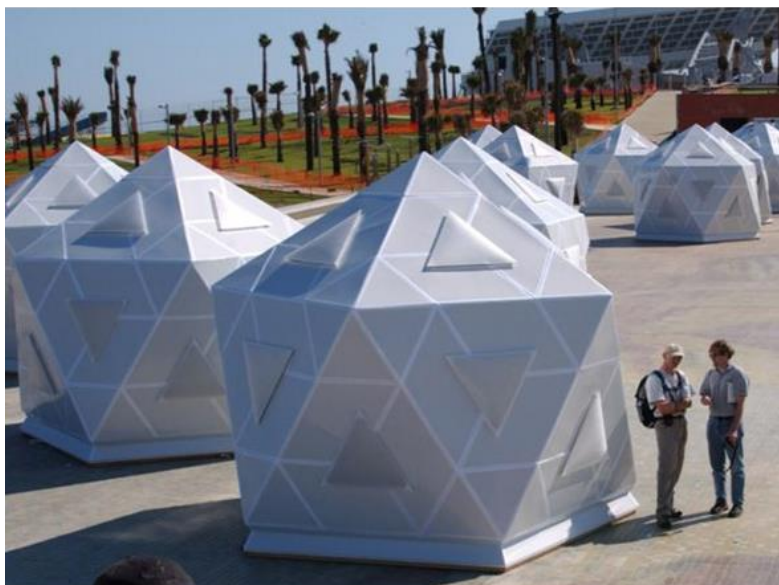
constructiva básica, hueca y ligera, que se puede levantar y ensamblar entre dos personas, ofreciendo la posibilidad de incluir aislamiento en el interior o de aprovechar la cualidad translúcida del material plástico para tamizar la luz interior creando espacios que pueden ser utilizados como invernaderos.

El primer diseño realizado por la empresa, el Ico Pod, es un icosaedro al que le falta la base, por lo que sus 20 caras iguales se reducen a 15. La construcción más grande realizada es el Deca Pod de 7'80 centímetros de luz, que se resuelve al construir cada cara triangular del nuevo icosaedro ampliado con cuatro triángulos base del Ico Pod, además este nuevo diseño solo representa la mitad geométrica de un icosaedro, por lo que se necesitarán en total 30 triángulos base. Estas estructuras han sido probadas como refugios de emergencia por MSF Médicos Sin Fronteras en la región afectada por el terremoto de Cachemira en $2010{ }^{113}$. También han sido expuestas en el Forum Barcelona 2004 y en la gran fiesta de la arquitectura y el arte efímeros que es el Festival Burning Man que se celebra cada año en verano en el Black Rock Desert de Nevada.

138. Ico, Deca y Shade Pods

Fuente: http://foldedhomes.com/pods.html

\footnotetext{
${ }^{113}$ Fuente: http://www.design4disaster.org/2011/02/12/icosa-village/
} 


\section{Las "Origami Tessellations"}
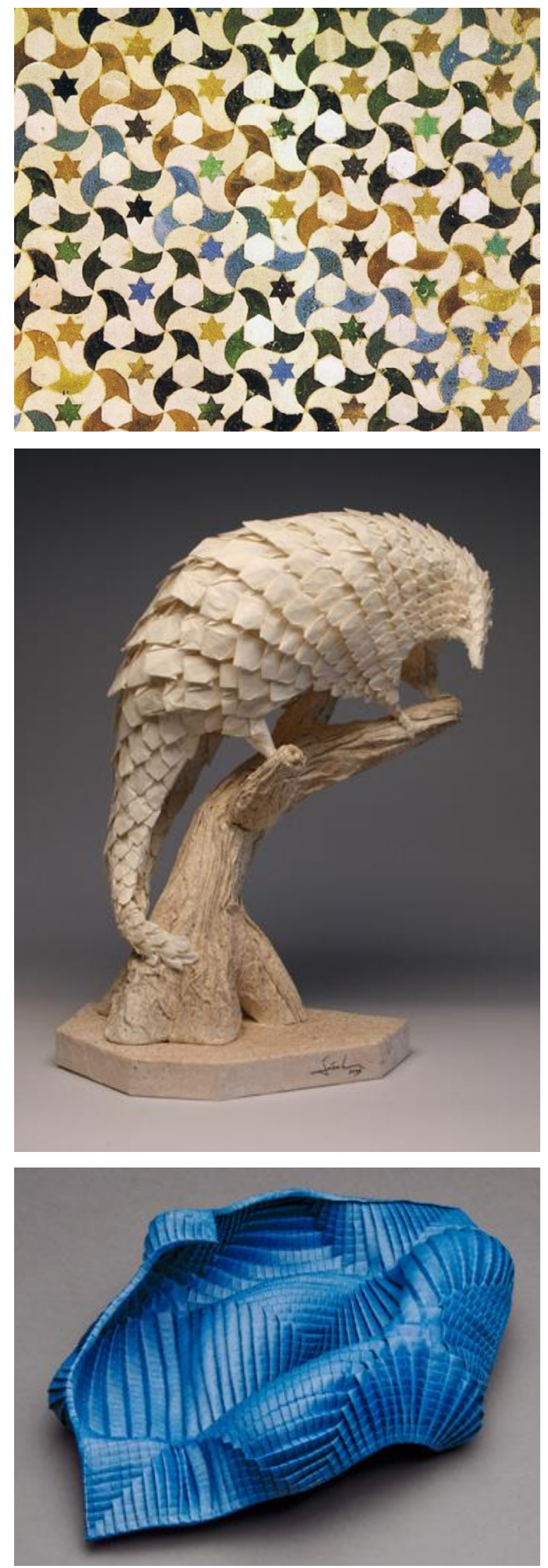

Las "origami tessellations" ${ }^{114}$, teselaciones - mosaicos de origami son diseños geométricos realizados mediante el doblado de una sola hoja de papel, creando un patrón complejo mediante la repetición en varias direcciones de uno o varios módulos, realizados mediante el pliegue y la superposición de una sola lámina sobre sí misma. El nombre viene de la palabra latina "tessella", tesela en español, que son las partes que forman un mosaico, en general realizado con pequeñas piedras, piezas cerámicas o maderas.

139. Mosaico de alicatado. Arte Nazarita, siglo XIV. Patio de los Arrayanes. Palacio de Comares. La Alhambra. Granada. Fuente: Hernández Rojo, Fernando (2010) Arte y Geometría. Editorial Universidad de Granada. ISBN 9788433851680 Pág. 59

Para hacer los mosaicos de origami, los origamistas se han inspirado generalmente en los complejos patrones geométricos del arte islámico, aunque algunos ejemplos destacan también porque buscan representar figuras y formas reconocidas como caras, peces, etc. Las obras del escultor Eric Joisel son un excelente ejemplo de unión entre calidad técnica y capacidad representativa.

\section{Pangolin, Eric Joisel, Francia, 2009}

Realizado en una sola pieza de papel sin cortar. Soporte y base en alambre y pintura. Fuente: International Arts \& Artists (2012) Folding Paper. The Infinite Possibilities of Origami Japanese American National Museum. Los Angeles. Pág. 5

Otras obras se vinculan a los procesos creativos contemporáneos del origami abstracto, donde los origamistas exploran cualidades como la textura, el volumen, la forma, etc.

\section{Double Wave, Goran Konjevod. USA 2007}

Realizado en un cuadrado de 24 pulgadas de papel "piel de elefante". Fuente: International Arts \& Artists (Agosto 2012) Folding Paper. The Infinite Possibilities of Origami. Japanese American National Museum. Los Angeles. Página 8

\footnotetext{
114 Gjerde, Eric (2008) Origami Tessellations: Awe-Inspiring Geometric Designs. A K Peters/CRC Press. ISBN-13: 978-
} 1568814513 

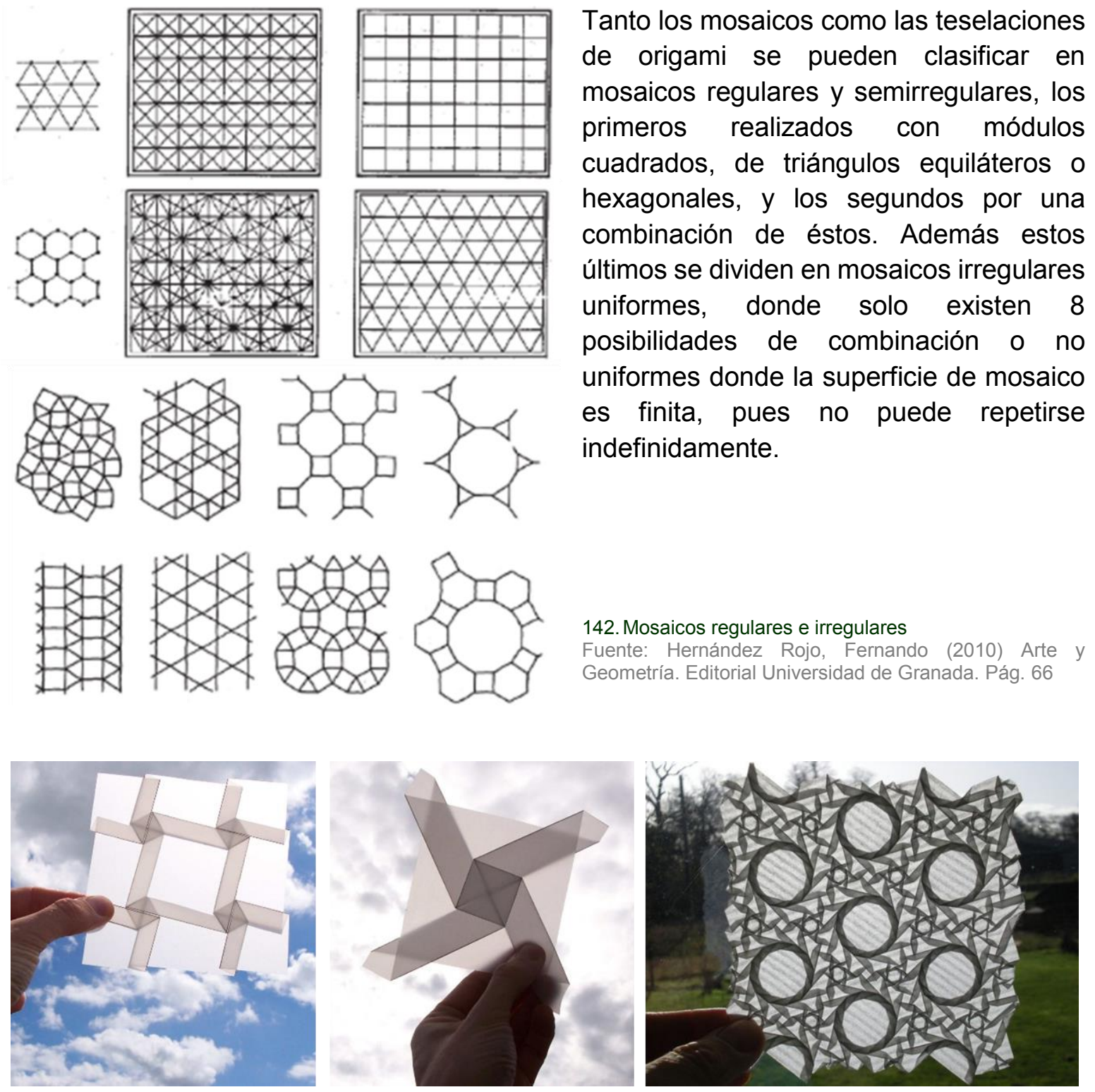

143. Origami Tessellations de Alex Bateman (2005)

Fuente: http://www.papermosaics.co.uk/

Una de las caracterísitas más comunes de las teselaciones de origami es el juego de matices tonales generado por la mayor o menor filtración de la luz que se consigue mediante la superposición del papel al ser plegado. Sobre estas líneas podemos ver algunas de las obras de Alex Bateman, quien ha diseñado un software específico para el plegado de teselaciones de origami. Este programa permite variar cada módulo, su número, ángulo de pliegue, etc. y finalmente exportar en pdf el patrón para ser plegado.

144. Tess: origami tessellation software

Fuente: http://www. papermosaics.co.uk/software.html

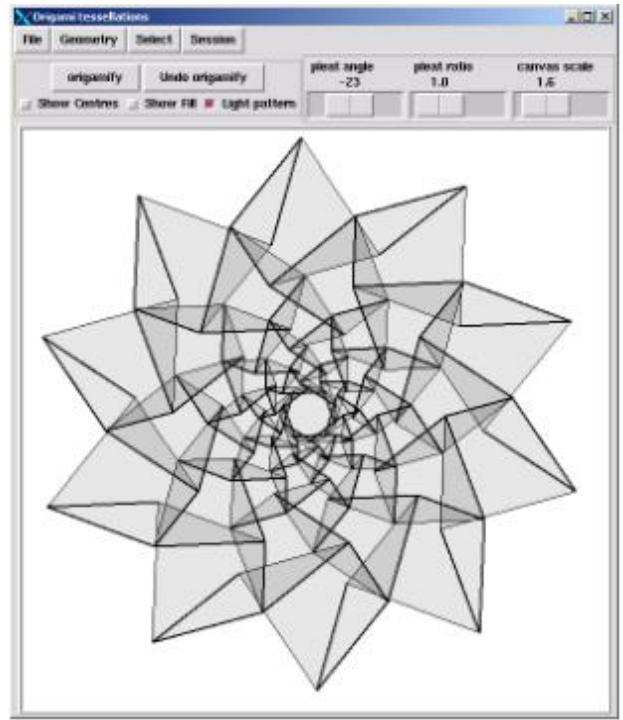


En la arquitectura las teselaciones de origami no solo se están desarrollando como planos superficiales dispuestos en fachada para tamizar la luz, sino también para diseñar superficies de complejas texturas que, sin usar la coloración de los originales mosaicos de la cultura árabe, exploran nuevos y complejos patrones geométricos vinculados a teorías matemáticas como las triangulaciones de Delaunay y los algoritmos de Voronoi representados bajo estas líneas.
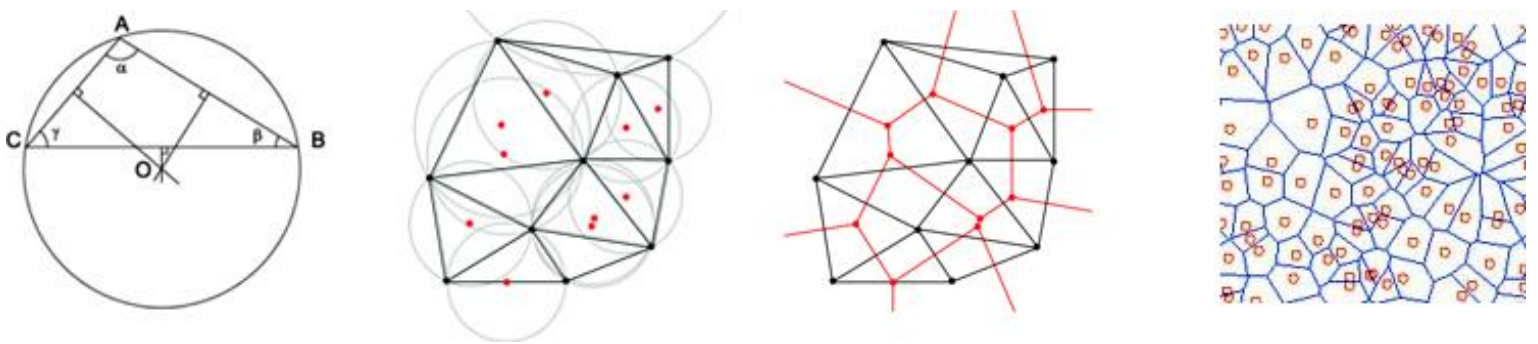

145. Triangulación de Delaunay, Algoritmo de Voronoi

En geometría computacional las regiones del Algoritmo de Voronoi (descrito por primera vez por Alfred H. Thiessen y Georgy Voronoi) son las zonas del plano más cercanas a un conjunto dado de puntos. Gracias a la triangulación de Delaunay (en honor al matemático ruso Boris Nikolaevich Delone) la circunferencia circunscrita es vacía, si no contiene otros vértices aparte de los tres que la definen. Esa condición asegura que los ángulos del interior de los triángulos son los más grandes posibles, es decir, maximiza la extensión del ángulo más pequeño de la red. Esta definición para espacios bidimensionales es posible ampliarla para espacios tridimensionales usando la esfera circunscrita.

Los teoremas matemáticos de Voronoi y Delaunay no solo han servido para el estudio, análisis y medición de intervenciones territoriales y urbanísticas en superficies irregulares, sino también para el diseño de sistemas y patrones irregulares y aleatorios de elementos dispersos en un plano de los que se puede extraer un orden. El origamista Eric Gjerde ha sabido aplicar estos teoremas en la creación de teselaciones de origami realizadas mediante la triangulación de Delaunay y los diagramas de Voronoi.
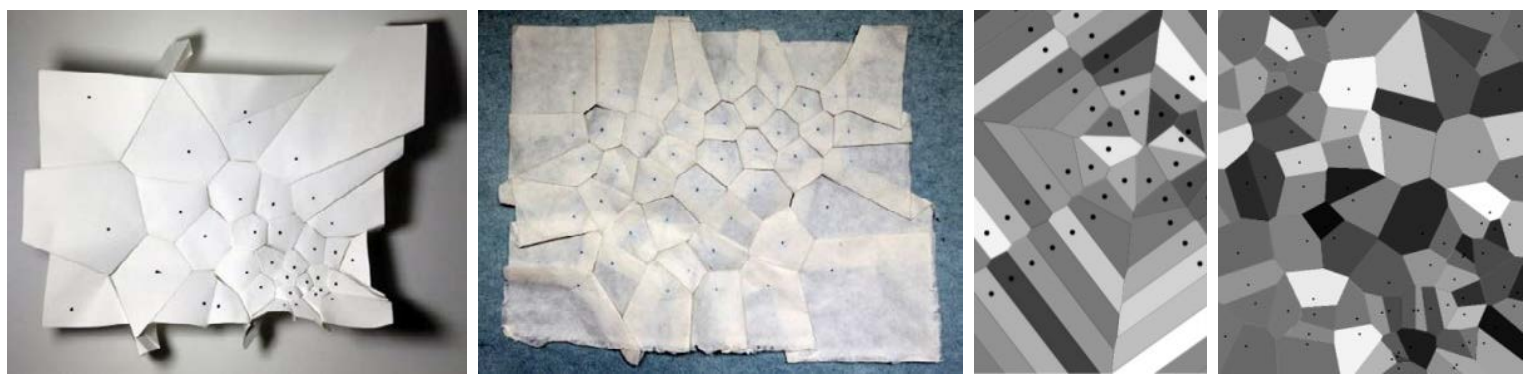

146. Teselaciones y Diagramas de Voronoi

Eric Gjerde. Agosto del 2012. Medidas del papel: 400x300 cms

Fuente: http://www.origamitessellations.com/2012/08/holland-paper-biennale-2012/voronoi-tessellation-detail/ 
Estos patrones pueden ser utilizados como una nueva materialidad exterior de los edificios o como nuevos elementos superficiales tanto exteriores como interiores. Pieles plegadas que muestran ricos ritmos de luces y sombras, nuevas texturas que quiebran la lisa planeidad de las paredes ofreciendo expresarse en múltiples y progresivos cambios en algunos casos vinculados a las modificaciones graduales de la arquitectura paramétrica y en otros a transformaciones aleatorias e incluso anárquicas.

Ejemplos de estas nuevas propuestas las podemos ver en los trabajos de pantallas y muros arquitectónicos del arquitecto Erwin Hauer ${ }^{115}$ y en los realizados en el curso Folded SKINS (pieles plegadas) realizado el 2015 por la profesora Milena Stavric en el Institut für Architektur und Medien de la universidad de TU Graz en Austria.

147. Folded [SKINS], Workshop I Stavric I Wiltsche I 16-20.2.2015 Institut für Architektur und Medien, TU Graz.

Fuente: https://iam.tugraz.at/milena/folded_skins/
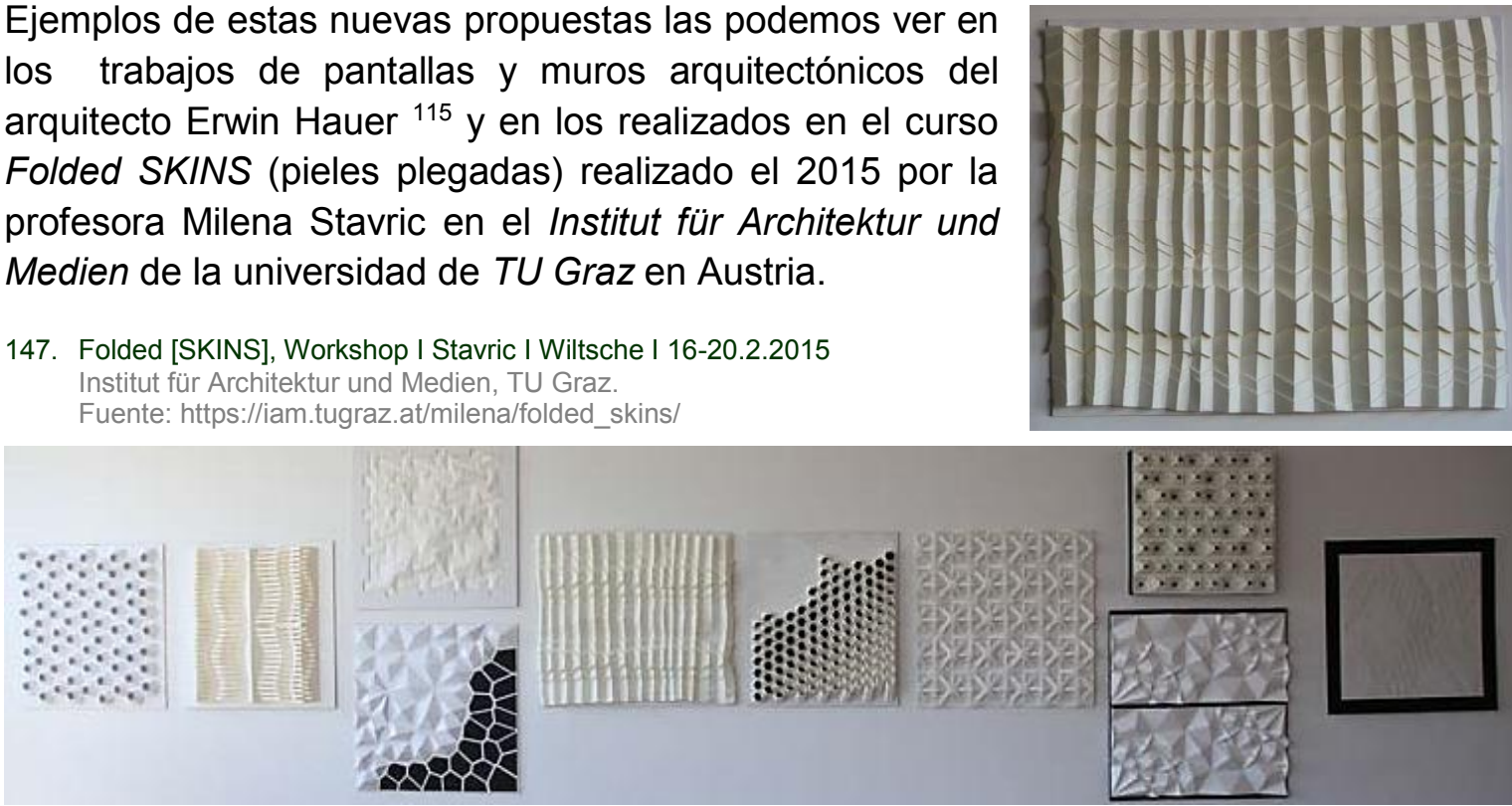

Una nueva variedad es el camino emprendido por Ron Resch en la creación de teselaciones dinámicas y tridimensionales. Artista pionero en el desarrollo de representaciones virtuales en $3 \mathrm{D}$ apoyadas en la programación matemática en medios informáticos, Ron Resch es conocido sobre todo por sus trabajos de origami modular y las teselaciones tridimensionales realizadas con el patrón que lleva su nombre. El patrón Ron Resch ${ }^{116}$ era el módulo básico con el que construia toda una gama de múltiples variaciones de teselaciones tridimensionales y fue presentado por el mismo en 1966 como parte de su tesina final de los estudios de arte. La tesina recopilaba en formato vídeo los trabajos realizados por Resch entre 1960 y 1966, y el vídeo fue reeditado y publicado posteriormente en 1992 con el nombre de The Ron Resch Paper \& Stick Film ${ }^{117}$.
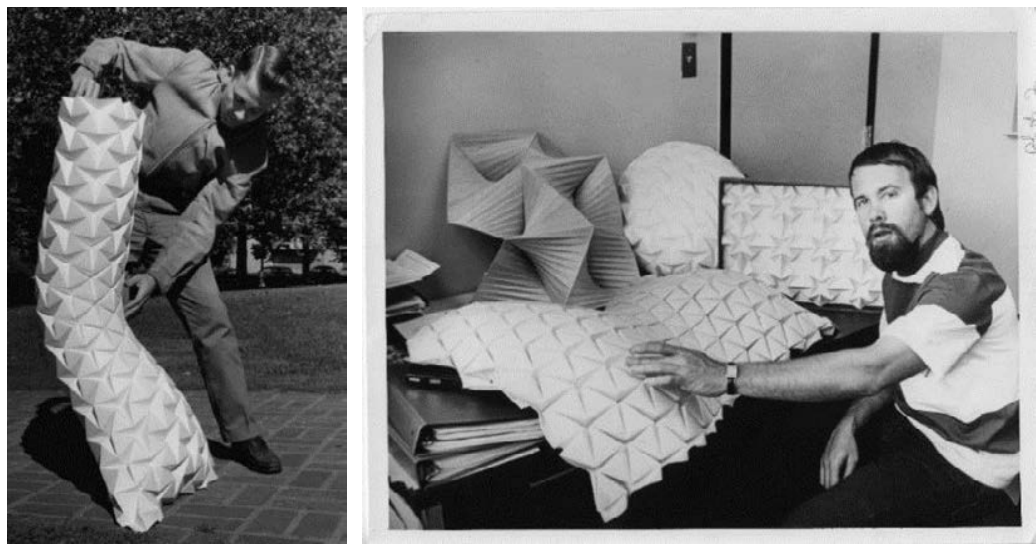

148

Imágenes de R. Resch

Izq. Ron Resch enseñando las diferentes posibilidades formales de su patrón de pliegue. (1960)

Dcha. Ron Resch en su oficina de la Universidad de Utah mostrando sus trabajos con pliegues. (1970)

Fuente:

http://www.ronresch.org/ronresch/ gallery/paper-folding-origami/

\footnotetext{
${ }^{115}$ Hauer, E. (2004) Architectural Screens and Walls, Princeton Arch. Press, New York.

116 Tachi, T. (Nov. 2013) Designing Freeform Origami Tessellations by Generalizing Resch's Patterns. Journal of Mechanical Design | Volume 135 | Issue 11 | ASME

117 Fuente: http://www.ronresch.org/ronresch/gallery/paper-and-stick-film/
} 
El arquitecto Tomohiro Tachi estudiará e implementará las teselaciones cinéticas tridimensionales de Resch en los softwares diseñados por él mismo. Planteando diferentes versiones y consideraciones estructurales para posibles aplicaciones arquitectónicas ajustadas a los parámetros de rigidez de las superficies tal como se estipula en el Rigid Origami ${ }^{118}$. Bajo estas líneas se pueden ver una evolución del patrón simple hexagonal de Resch hacia el patrón pentagonal y variantes donde se aplican patrones cuadrados y hexagonales en la superficie exterior. Además Tachi ha explorado como generar automáticamente patrones de plegado Resch sobre superficies curvas y cómo realizar distintos patrones que den como resultado una teselación frontal superficial triangular mientras en su cara posterior se generan complejas formas estrelladas y poligonales.
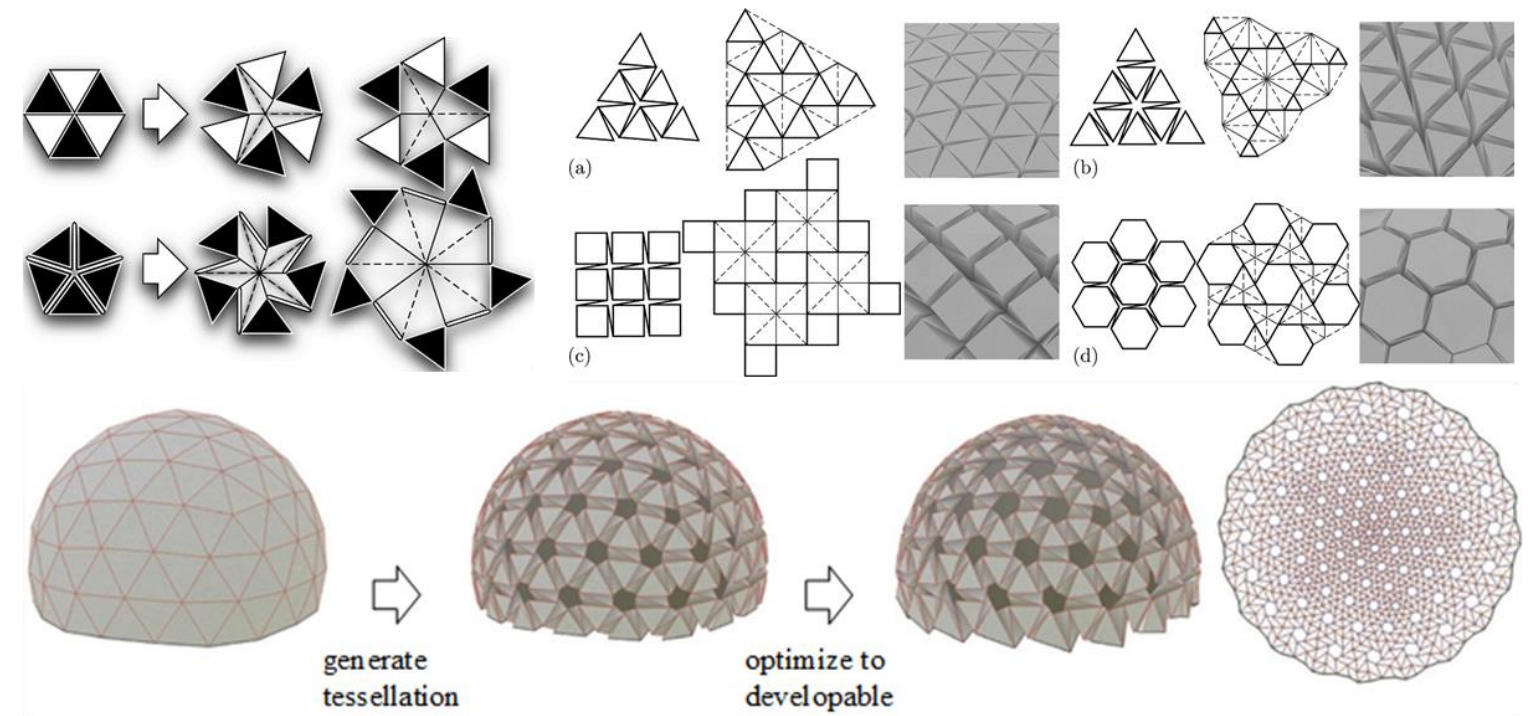

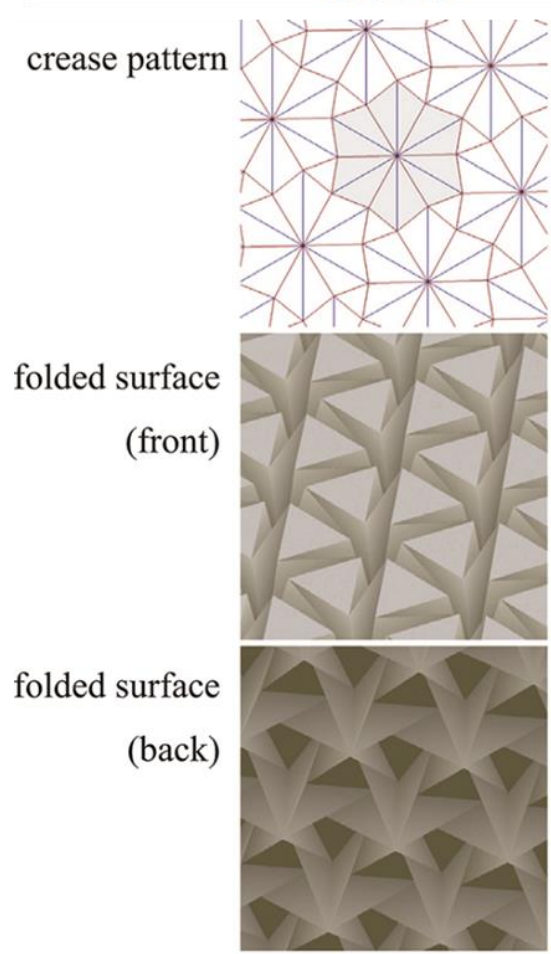

(a) star

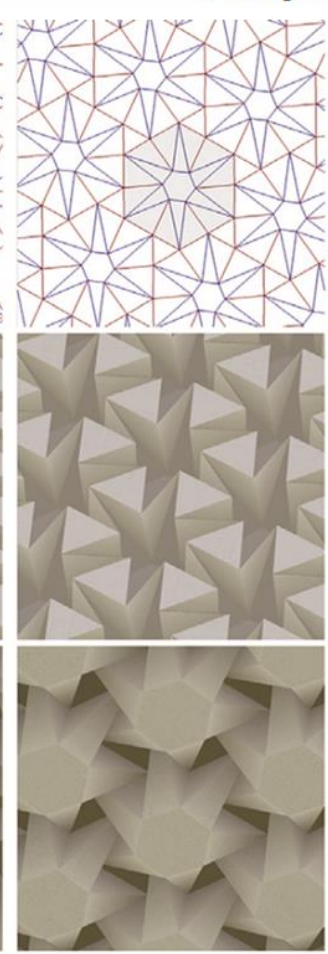

(b) truncated star

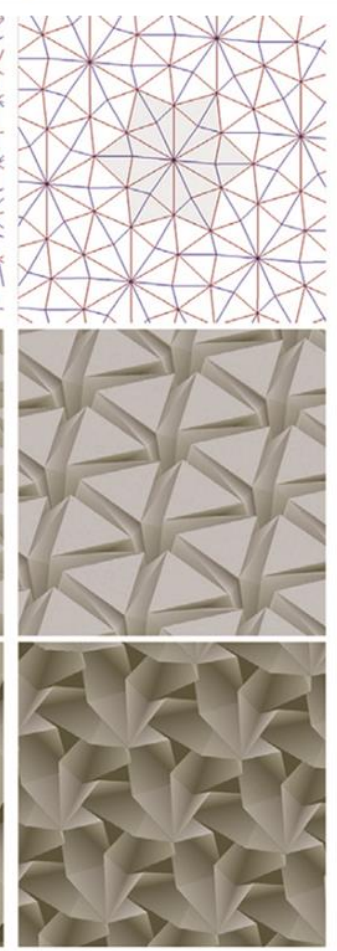

(c) curly star

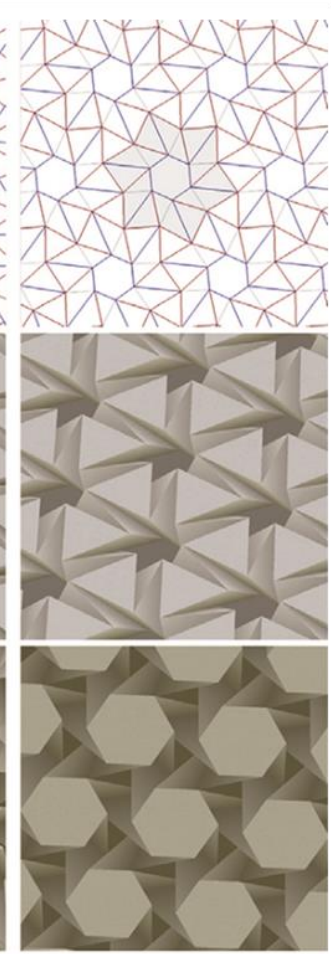

(d) twist fold

149. Variaciones de teselaciones de Resch realizadas por Tachi

\footnotetext{
118 Tachi, T. (8-12 de noviembre del 2010) Geometric Considerations for the Design of Rigid Origami Structures. Proceedings of the International Association for Shell and Spatial Structures (IASS) Symposium 2010, Shanghai Spatial Structures Permanent and Temporary. Shanghai, China
} 

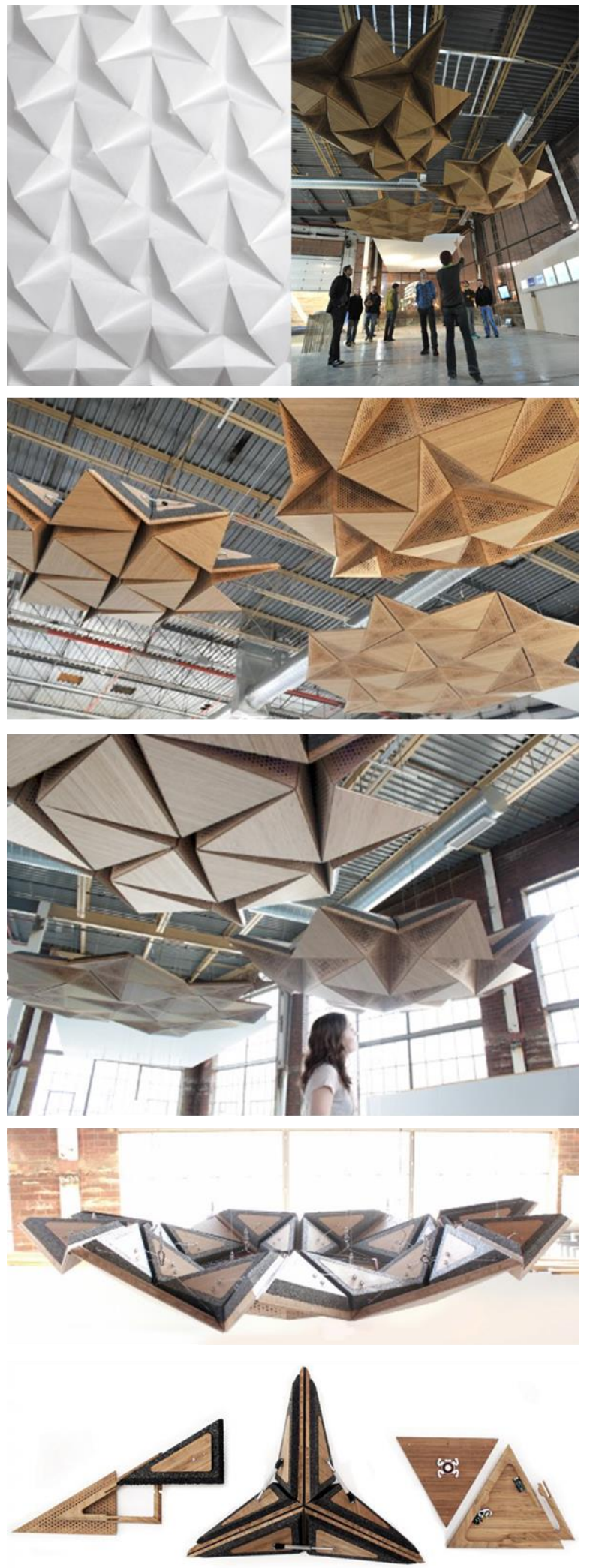

En el año 2012 el estudio norteamericano RVTR en colaboración con los consultores de ARUP Acoustics, presentaron un proyecto inspirado en la teselación de Resch, en el que habían estado investigando en el marco del programa Research Through Making (RTM), traducible como Investigación+Acción o investigación a través de la realización, un programa competitivo de donaciones para grupos de investigación de la Taubman College's de la University of Michigan, que proporciona financiación inicial de un año para el diseño, realización y aplicacion práctica de una investigación de arquitectura.

El proyecto Resonant Chamber (cámara o cubierta resonante) es un sistema de envolvente interior desplegable que utiliza los principios del origami rígido de Tachi y los estudios que éste ha realizado sobre pliegue de materiales con sección variable Rigid-foldable thick origami 119, para transformar el ambiente acústico a través de tecnologías dinámicas espaciales, materiales y electroacústicas. El objetivo es desarrollar una piel interna sonora capaz de ajustar sus propiedades en respuesta a las condiciones acústicas cambiantes, alterando el sonido de un espacio durante una actuación y creando un instrumento a la escala del espacio arquitectónico en el que se halle, tan flexible y ágil que pueda ser manipulado fácilmente.

150. Resonant Chamber, RVTR, 2012

Fuente: http://rvtr.com/research/resonant-chamber/

\footnotetext{
119 Tachi T. (2011) Rigid-foldable thick origami. In Origami 5: Fifth Int. Meeting of Origami Science Mathematics and Education, pp. 253-264. Fuente: http://www.tsg.ne.jp/TT/cg/ThickRigidOrigami_tachi_5OSME.pdf.
} 


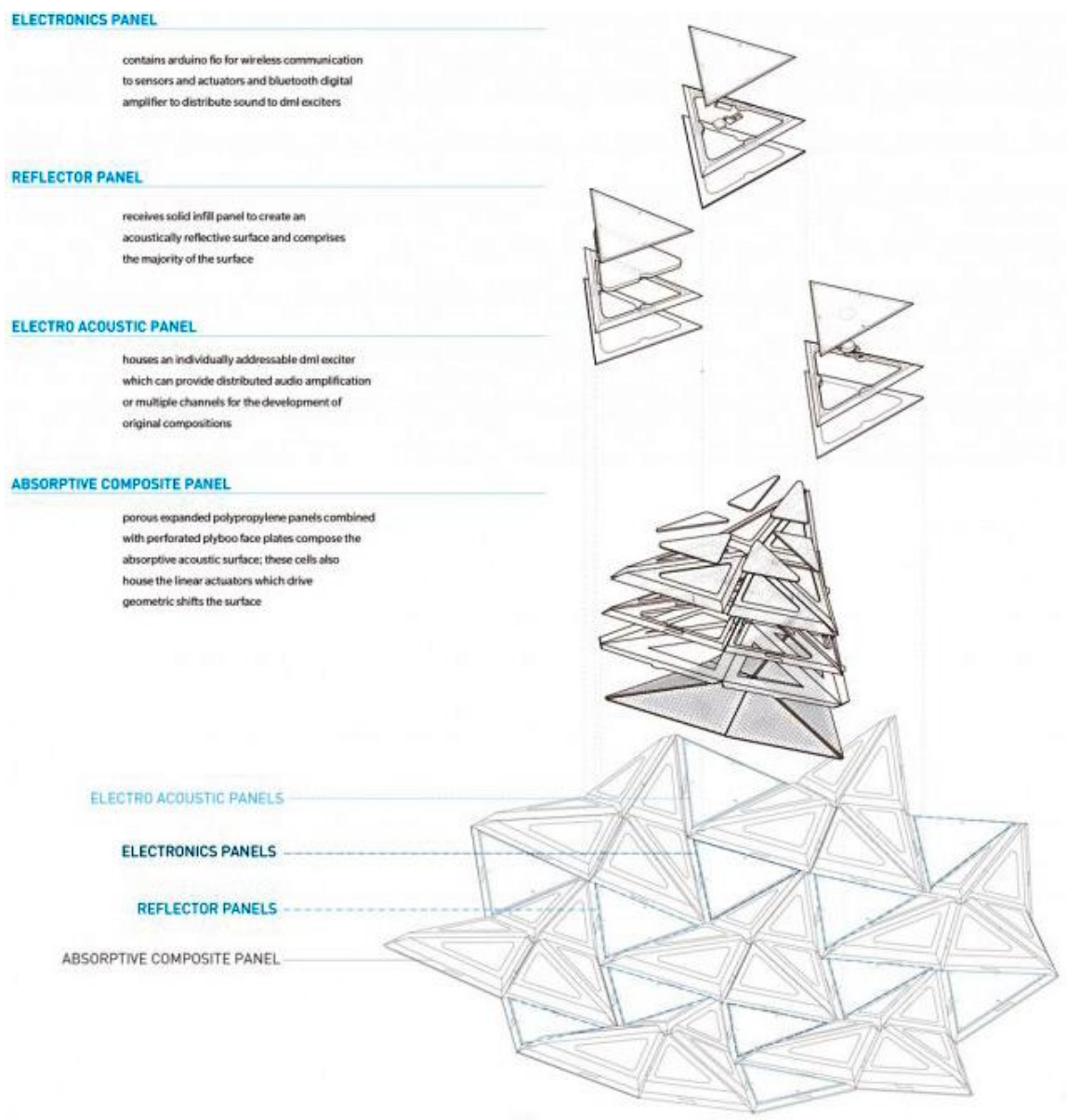

151. Axonométrica de los paneles sándwich del Resonant Chamber. RVTR, 2012.

Fuente: https://taubmancollege.umich.edu/research/research-through-making/2012/resonant-chamber

La superficie facetada se compone de paneles sándwich con diferentes propiedades reflectantes, de absorción y electroacústicas, conectados mediante un circuito electrónico a una interfaz desde la que se puede realizar el accionamiento lineal del movimiento de cada panel o hacer funcionar los altavoces integrados. Además en los paneles se han integrado sistemas de detección de humos y de ruidos, pudiéndose activar automáticamente el movimiento de apertura de los paneles si es necesario aumentar la absorción de ruido ambiental.

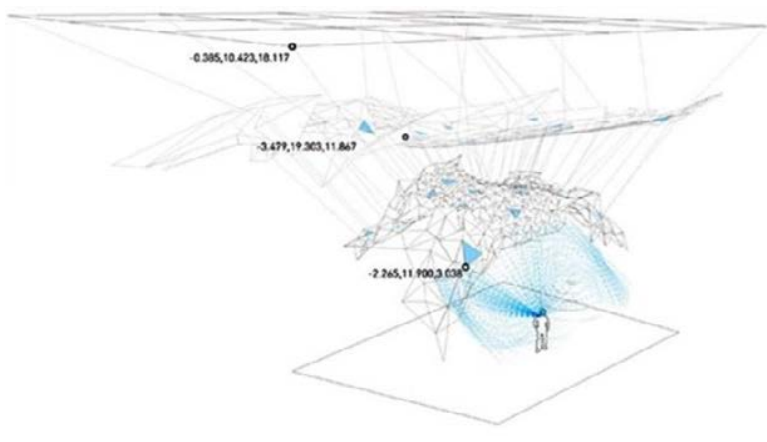

El proyecto de investigación se ha desarrollado a través de tres ámbitos de estudio tanto en pruebas computacionales como en la instalación de prototipos a gran escala: geometrías de superficies dinámicas, nuevos materiales $\mathrm{y}$ combinación entre ellos, y sistemas de diseño interactivos con actuación y respuesta variables.

152. Sistema de monitorización, Resonant Chamber, RVTR, 2012.

Fuente: http://www.rvtr.com/projects/research-through-making-iii 

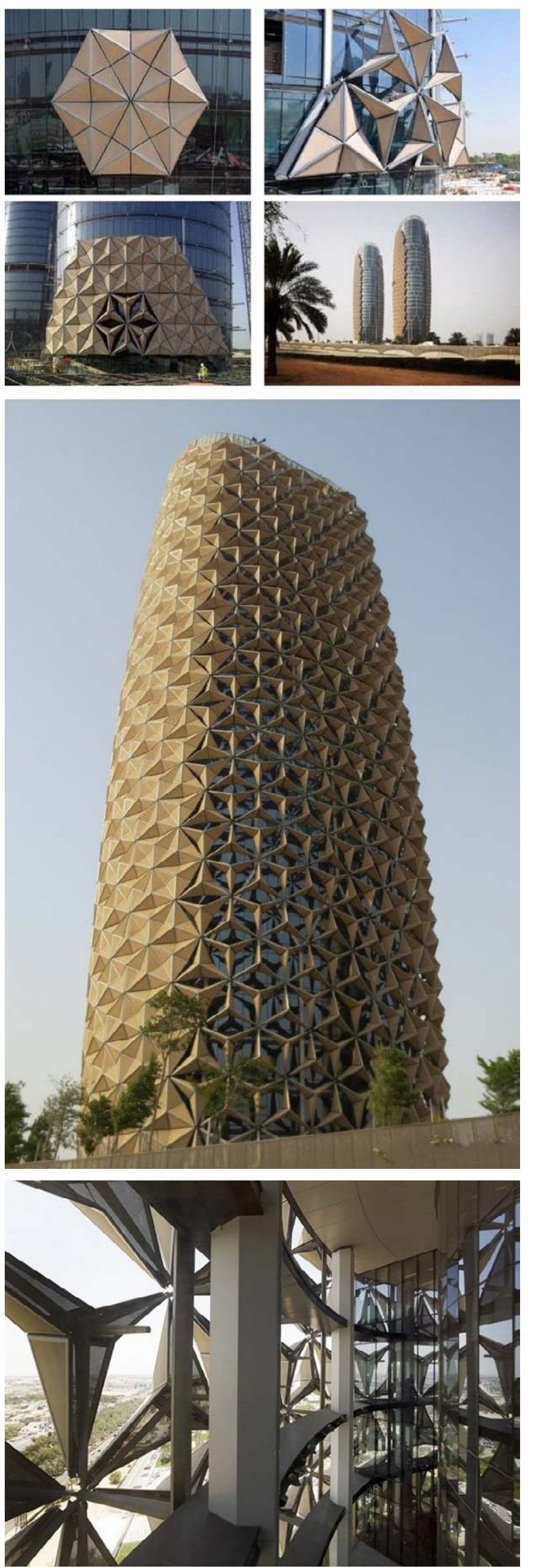

Utilizando el mismo patrón de plegado, llamado por Resch el pliegue básico de papel, en el año 2012, el estudio Aedas diseñó y construyó para la nueva sede del Abu Dhabi Investment Council dos torres gemelas con el nombre de Torres Al Bahar en Abu Dhabi. La utilización de la teselación con el patrón Resch fue justificada desde un punto de vista ambiental y a la vez cultural. El estudio encontró en las teselaciones un vínculo con la "mashrabiya", las celosías tradicionales del mundo árabe.

El sistema de fachada propuesto desafía la típica tipología de rascacielos de la zona inpirada en modelos de fachadas acristaladas de la cultura occidental, sugiriendo unas soluciones más acordes con las condiciones climáticas. De este modo, las Torres Al Bahar buscan proporcionar un diseño contextual y culturalmente sensible al lugar a la vez que implementan la utilización de tecnología moderna para cumplir con los estándares más altos de eficiencia en el consumo de energía eléctrica para acondicionamiento ambiental.

Los arquitectos e ingenieros del estudio trabajaron con la programación de sistemas paramétricos computerizados para encontrar la geometría y el movimiento de pliegue adecuado a los paneles movibles de la fachada, simulando su funcionamiento en respuesta a la mayor o menor exposición al sol y el consiguiente cambio de ángulos de incidencia durante los diferentes días del año. Los paneles triangulares metalizados están microperforados $y$, siendo capaces de tamizar la luz directa, también permiten ver el paisaje desde el interior.

153. Torres Al Bahar. Estudio Aedas 2012, Abu Dhabi Fuente: http://www.archdaily.com/270592/al-bahar-towersresponsive-facade-aedas 


\section{EL ORIGAMI ABSTRACTO}

Alegría, Pedro et Fernández, Santiago (2010) Martin Gardner, el mago de la divulgación. La Gaceta de la RSME, Vol. 13 (2010), Núm. 4. http://www.automagia.com/archivos/martingardner.pdf

Argán, Giulio Carlo (1998, $1^{\text {a }}$ ed. 1991) El Arte Moderno. Del iluminismo a los movimientos contemporáneos. Ediciones AKAL.

Bauhaus 1919-33: Workshops for modernity. (2009) Edit. David Frankel. MOMA, New York.

Beckmann, Hannes (1971) Bauhaus und Bauhäusler, ed. Eckhard Neumann. Bema.

Best, Alastair (01/03/1969) Imaginative toys. Design Journal. issue 243. Article 3. p. 36-39

Bordes Caballero, J. (2001) Historia de las Teorías de la Figura Humana. Ed. Cátedra. Madrid.

Bordes Caballero, J. (2007) La infancia de las vanguardias. Ed. Cátedra. Madrid.

Brosterman, Norman; fot. Kiyoshi Togashi. (1997, $1^{\text {a }}$ edición 1952) Inventing kindergarten. Ed. Harry N. Abrams, York University. New York.

Boyaki, Amanda (Mayo 2010) Ahna Buscher Siedhoff: An Examination of Children's Design and Gender at the Bauhaus during the Weimar Period. Capítulo: Paper Toys: Mechanical Crane and Sailboat [Bastelbogen] c. 1925, pág. 142. Texas Tech University, Estados Unidos.

Carrara, Arthur Alfonso (1960) A flexagon of structure and design. The Milwaukee Art Center.

Cohn, Jason et Jersey, Bill (2011) EAMES: The Architect and the Painter. Eames Office, LLC

Demain, Erik D.; et al (2011) Reconstructing David Huffman's Legacy in Curved-rease Folding. Origami 5: Fifth International Meeting of Origami Science, Mathematics, and Education. A. K. Peters/CRC Press;

Demetrios, Eames (2007) The design genius of Charles + Ray Eames. TED Talk 2007 • 15:08 • Filmed Feb 2007. Minuto. 8'14". https://www.youtube.com/watch?v=b0vDWqp6J7Y

Fiedler, Jeannine et Feierabend, Peter (2013) Bauhaus. Ullmann Publishing. Colonia.

Gao, W.; Ramani, K.; Cipra, Raymond J.; Siegmund, Thomas (Nov. 2013) Kinetogami: A Reconfigurable, Combinatorial, and Printable Sheet Folding. Transactions of the ASME. 111009-10 / Vol. 135, School of Mechanical Engineering, Purdue University,West Lafayette, IN 47907 [DOI: 10.1115/1.4025506]

Gao, W.; Huo, K.; Seehra, Jasjeet S.; Ramani, Karthik; Cipra, Raymond J.; (Sept. 2014) HexaMorph: A Reconfigurable and Foldable Hexapod Robot Inspired by Origami. IEEE/RSJ International Conference on Intelligent Robots and Systems (IROS'14), Chicago.

Gardner, Martin (Diciembre de 1956) Flexagons. In which strips of paper are used to make hexagonal figures with unusual properties. Revista Scientific American.

Gardner, Martin (1988, Publicado originalmente en 1959 por Simon \& Schuster) Hexaflexagons and Other Mathematical Diversions: The First Scientific American Book of Puzzles and Games. University of Chicago Press. 
Gjerde, Eric (2008) Origami Tessellations: Awe-Inspiring Geometric Designs. A K Peters/CRC Press. ISBN-13: 978-1568814513

Hauer, E. (2004) Architectural Screens and Walls, Princeton Arch. Press, New York.

Heinrich Blasche, Bernhard. Boileau, Daniel. (1825, 1830, 1834 y 1836) Papyro-plastics. The art of modelling in paper: Being an Instructive Amusement for Young Persons of Both Sexes. Editorial Boosey and Sons. Londres. Segunda Edición 1825.

Hernández Rojo, Fernando (2010) Arte y Geometría. Editorial Universidad de Granada. ISBN 9788433851680

Jackson, Paul (2015) Complete Pleats: Pleating Techniques for Fashion, Architecture and Design. Ed. Laurence King

Jackson, Paul (2013, $1^{\text {a }}$ edición 1978) Flexagons: Origami flexagon paper folding. Editorial British Origami Society.

Jackson, Paul (2011) Tecnicas de plegado para diseñadores y arquitectos. Editorial Promopress. ISBN: 9788492810215

Kinchin, Juliet et O'Connor, Aidan (2012) Century of the Child: Growing by Design, 1900-2000

Lichtenstein, Claude et W. Härberli, Alfredo (2000) Far vedere l'aria/ Air Made Visible: A Visual Reader on Bruno Munari. Ed. Lars Müller. Zurich.

McArthur, M.; Lang. R. J. (2013) Folding Paper. The Infinite Possibilities of Origami. Ed. Tuttle

Saito, Keiko E. et Röhmer Litzmann, Matias (2007) Plegado, simetria y software gráfico. Forma y Simetría: Arte y Ciencia. Congreso de Buenos Aires. Página 424

Siebenbrodt, Michael, et all (2009) Bauhaus: A Conceptual Model. Edit. Hatje Cantz

Schattschneider, D. et Walker, W. (1994, $1^{\text {a }}$ Edición 1977) Escher Kaleidocycles. 17 models of Escher's graphics and the story of how they were devised. Editorial Taschen. Alemania. ISBN: 07649-3110-5

Tachi, T. (2010) Architectural Origami: Architectural Form Design Systems Based on Computational Origami. Lecture Notes for MIT Course 6.849, Cambridge, MA.

Tachi, T. (Nov. 2013) Designing Freeform Origami Tessellations by Generalizing Resch's Patterns. Journal of Mechanical Design | Volume 135 | Issue 11 | ASME

Tachi, T. (2010) Freeform Variations of Origami. Journal for Geometry and Graphics. Volume 14, No. 2, 203-215.

Tachi, T. (8-12 de noviembre del 2010) Geometric Considerations for the Design of Rigid Origami Structures. Proceedings of the International Association for Shell and Spatial Structures (IASS) Symposium 2010, Shanghai Spatial Structures - Permanent and Temporary. Shanghai, China

Tachi T. (2011) Rigid-foldable thick origami. In Origami 5: Fifth Int. Meeting of Origami Science Mathematics and Education, pp. 253-264. http://www.tsg.ne.jp/TT/cg/ThickRigidOrigami_tachi_5OSME.pdf.

Tachi, T. (2009) Rigid Origami Simulation. The University of Tokyo. 
Tachi, T. (5 de agosto de 2009) Simulation of Rigid Origami. Actas del congreso Origami 4: The Fourth International Conference on Origami in Science, Mathematics, and Education. J. A K Peters/CRC Press. pp. 175-187.

Tachi, T. (2010) Origamizing polyhedral surfaces. IEEE Transactions on Visualization and Computer Graphics, vol. 16, no. 2.

Tachi, Tomohiro; Epps, Gregory (Marzo 14-16, 2011) One-DOF. Designing Mechanisms for Architecture by Rationalizing Curved Folding. Proceedings of the International Symposium on Algorithmic Design for Architecture and Urban Design, ALGODE TOKYO 2011. Tokyo, Japan

Vyzoviti, Sophia (2011) Soft Shells: Porous and Deployable Architectural Screens. Amsterdam: BiS Publishers

Wiebé, Edward (1869) The paradise of childhood: a manual for self-instruction in Friedrich Froebel's educational principles, and a practical guide to kinder-gartners. Publisher Springfield, Mass.: M. Bradley \& Company. Book contributor University of California Libraries.

Wingler, Hans M. et Wingler, Hedwig (1991, $1^{a}$ ed. 1969) Bauhaus: Weimar, Dessau, Berlin, Chicago. Edit. MIT Press. 


\subsection{EL PLIEGUE EN LAS PUBLICACIONES DEL $S . X X Y X X I$}

Encontrar la clave de los documentos originales, de las revistas -más que de los libros que suelen escribirse a posteriori y tratan de reinterpretar la realidad, ajustándola a parámetros contemporáneos al autor- ha sido la intención de este apartado de la investigación que se centra en las publicaciones periódicas de arquitectura que, como un papel de calco que muestra sus huellas, se presentan como una excepcional fuente documental, primordial para entender, en su tiempo y lugar, la importancia que tienen y tuvieron las diferentes manifestaciones arquitectónicas derivadas directamente de geometrías plegadas inspiradas en las técnicas del origami.

El número de marzo de 2011 de la revista del American Institute of Architecture, AIA (Instituto Americano de Arquitectura) dedicó su portada a la nueva generación de estudiantes, de los que escribe serán el futuro de la arquitectura americana. Presenta en portada una fotografía retrato de un estudiante sentado sobre su cama y en la que se pueden ver bajo sus pies diversas maquetas con papeles plegados en diferentes configuraciones.

154. ARCHITECT. The Magazine of the American Institute of Architecture. Marzo 2011.

In the Majority, Joseph Aguilar and his classmates are the future of amerian architecture. Portada y detalles de la portada de la revista. Editada por el Instituto Americano de Arquitectura.
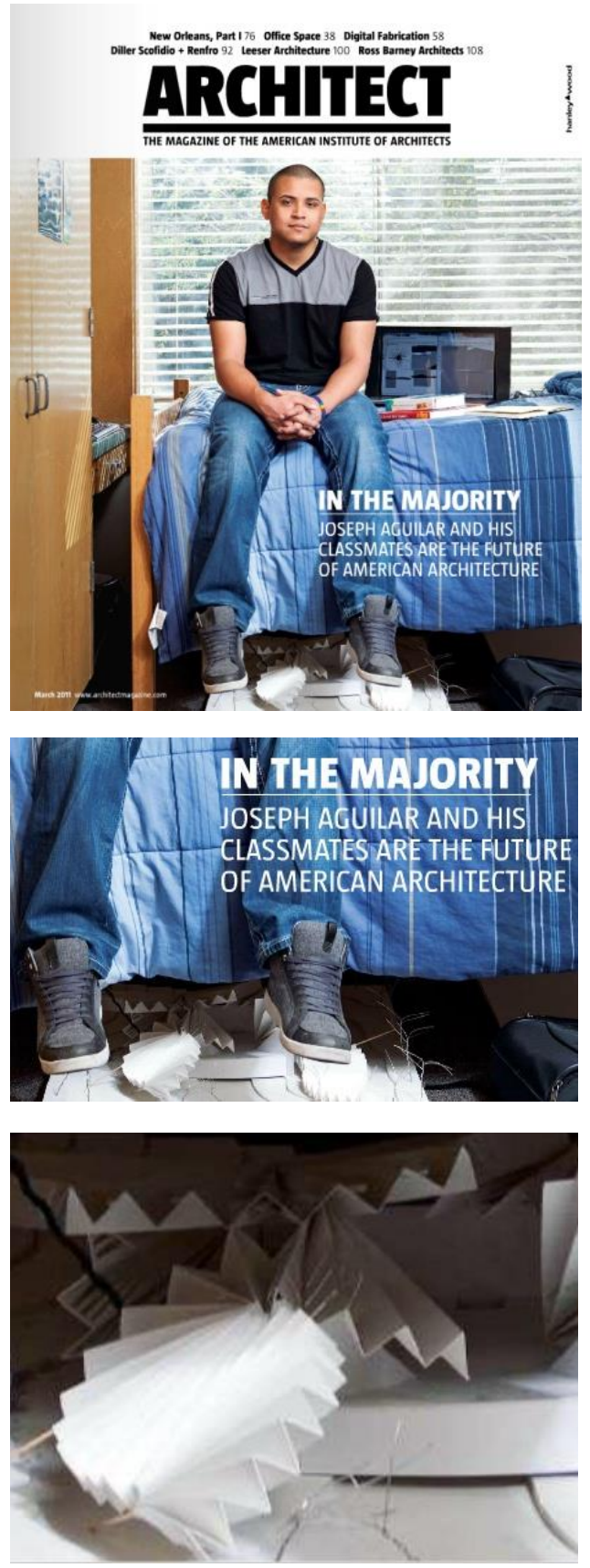

Que en revistas actuales de arquitectura aparezcan referencias gráficas constantes al origami y/o papiroflexia abstracta, pero de las que no se profundiza en sus intenciones conceptuales o estrategias creativas, no hace más que advertir la necesidad de clarificar los orígenes de esta práctica, de la que, como en el ejemplo de la revista Architect, en la que se usa como reclamo gráfico sin abordar palabra alguna en los artículos del interior, es necesario clasificar caminos y evoluciones y concretar conceptos para potenciar todas sus capacidades creativas. 


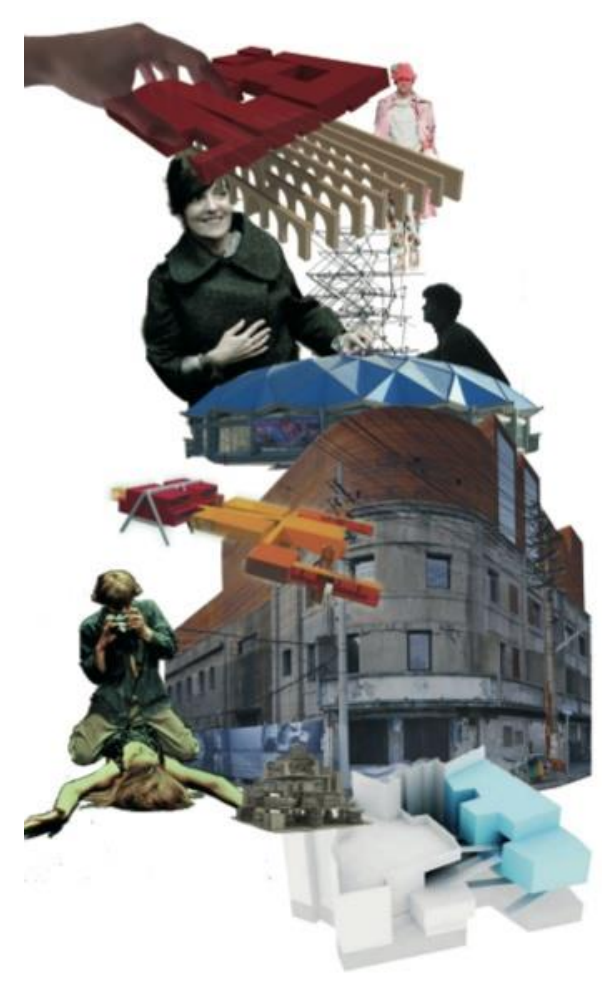

155. Indice-Collage de la revista Márgenes Arquitectura "Reciclaje Urbano" n¹ del año 2010.

Otro ejemplo actual que podemos encontrar es el artículo "Ulán Bator (Ulaan Baatar)" de la revista Márgenes Arquitectura del año 2010_n ${ }^{01}$ "Reciclaje Urbano" en la que se presenta a toda página el circo de la ciudad con una cubierta azul construida en metal y configurada por los pliegues Yoshimura en su patrón circular, pero de la que no se escribe ni una sola palabra, aún siendo utilizada esta imagen como reclamo central del collage que se muestra junto a éstas líneas y que representa la portada interior de la revista que acompaña gráficamente al índice.

Quizás el más paradigmático de los ejemplos, es el presentado en la revista Glaströsch $n^{\circ} 2$ bajo estas líneas, en el que en palabras del propio jurado: "el conocimiento y comprensión de la historia de las estructuras unido a las posibilidades expresivas de las superficies plegadas son aplicadas aquí en una

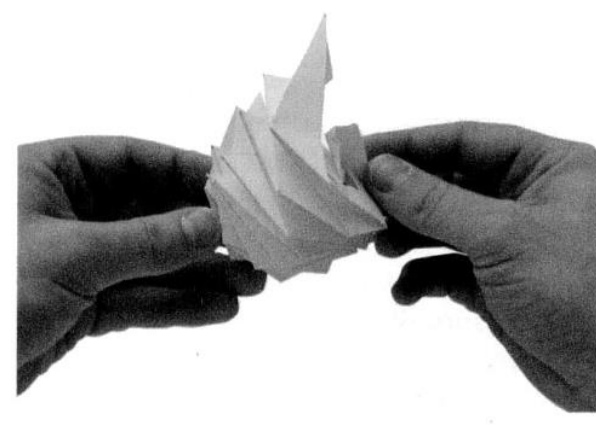
-nueva configuración- ampliando la base creativa con nuevas variaciones formales. El trabajo es un próspero ejemplo para el potencial constructivo del vidrio". ${ }^{120}$

Resulta sorprendente que, pasados más de cien años desde que estos pliegues llegaran a Occidente, la importación directa del patrón yoshimura simple regular como propuesta para un
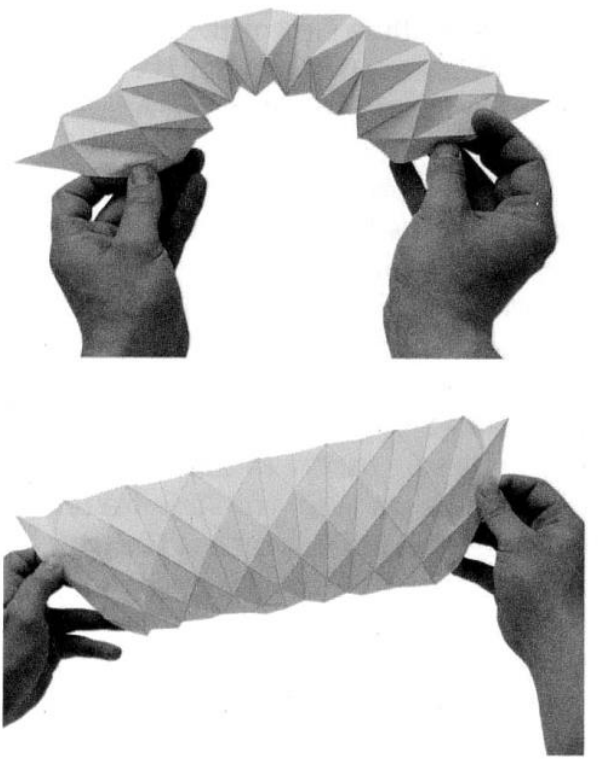
proyecto de arquitectura siga sorprendiendo por su originalidad, cabe entonces preguntarse por la necesidad de profundizar en este campo y establecer de la manera más precisa posible el origen y los ejemplos de este arte y determinar los artículos clave que participaron de un contexto general en torno al conocimiento de los patrones de pliegue basados en el Origami exportables al área de la Arquitectura.

\section{Faltwerke 2007.}

Proyecto ganador para el concurso Glas Trósch Prix 2007 de cubiertas de cristal del grupo empresarial Glas Trösch Holding AG. -SwitzerlandProyecto de Mathias Krupna y Stefan Trometer, München Fachhochschule, (Escuela Técnica Superior de Munich); Prof. Richter, Prof. Höhmeier, Prof. Bucal.

Fuente: Artículo "Faltwerke 2007" Revista Glaströsch n² / 2007

\footnotetext{
${ }^{120}$ Traducción del autor del artículo de la Revista Glaströsch n² / 2007. Edit. Glas Trösch Holding AG. "Beurteilung der Jury: Die historische Erkenntnis der Stabilisierungsmöglichkeiten ebener Flächen durch Faltungen wird hier in einer neuartigen Geometrie angewandt. Linear gefasste VSG-Scheiben ermöglichen interessante Strukturen bei grosser Varianz der Grundflächen. Die Arbeit ist ein gelungenes Beispiel für das konstruktive Potential von Glas."
} 


\section{Las primeras reseñas históricas.}

John S. Smith seleccionó en 2005 para la British Origami Society 301 artículos y publicaciones bibliográficas especializadas en Origami educativo, halladas en sus fondos y de las colecciones privadas de destacados miembros de la sociedad, como los fondos de su director David Lister o la biblioteca personal del origamista Gershon Legman. La mayoría de estas publicaciones han sido realizadas a partir de 1950 en congresos de la propia sociedad, exposiciones artísticas e investigaciones sobre matemática aplicada llevadas a cabo en Universidades de EEUU, Inglaterra y Japón. Esta nueva eclosión occidental de interés por el arte del origami se debe en gran parte a la publicación y exposición de la obra escultórica del gran maestro Akira Yoshizawa, que revitalizó el antiguo entretenimiento del origami para convertirlo en un arte, gracias a su capacidad de generar figuras inspiradas en la naturaleza de gran expresividad y originalidad formal.

De esta ingente selección, a priori parecen más interesantes para abordar el origen y evolución de este conocimiento las 27 publicaciones editadas antes de 1914 que abordan temas de geometría aplicada, papiroflexia y origami. Pero el acceso limitado a estos documentos hace escribir en la columna de futuros la investigación de su posible importancia en el bagaje histórico y conceptual.

Para una necesaria acotación de la investigación a las publicaciones que hubieran podido tener presencia en nuestro ámbito nacional, en el presente capítulo se reseñan los primeros artículos por orden cronológico de diferentes revistas de arquitectura nacionales e internacionales, que pudieran haber tenido relevancia entre los arquitectos españoles del S. XX, en los que aparecen recogidos de una forma clara y explícita elementos plegados inspirados directamente en las técnicas del origami.

Javier Sáenz Guerra, hijo del afamado arquitecto Francisco Javier Sáenz de Oíza nos deja el camino abierto al estudiar en su tesis y posterior publicación bibliográfica: "Un mito moderno. Una capilla en el Camino de Santiago" ${ }^{121}$, las diferentes publicaciones que influyeron en la generación de la cubierta plegada en base triangular del proyecto de la Capilla, ganador del premio Nacional de Arquitectura en 1954 por los arquitectos Sáenz de Oíza y José Luis Romaní y el escultor Jorge Oteiza.

J. Sáenz Guerra nos cita el número 6 de la revista Spazio de 1952, pero también nos reseña la revista L'architettura y la Revista Nacional de Arquitectura (RNA) en su número 173 de mayo de 1956 que, aunque posterior a la fecha del concurso debió ser importante por quizás ser la primera publicación en España de geometrías plegadas aplicadas a objetos de diseño en los que, según nos cuenta Sáenz Guerra ${ }^{122}$ los autores debieron hacerse eco de lo aparecido en la revista Spazio.

\footnotetext{
121 Sáenz Guerra, Javier. "Un mito moderno. Una Capilla en el Camino de Santiago. Sáenz de Oíza, Oteiza y Romaní, 1954". Fundación Museo Oteiza Fundaziao Museoa, 2007. ISBN 978-84-922768-6-2.

122 Ibidem. p. 250.

$\mathrm{Ni}$ en los fondos bibliográficos de la Escuela Técnica Superior de Arquitectura de Madrid (ETSAM), ni en los del COAM, ni siquiera en los del Reina Sofía se hayan números de esa revista, lo que hace poner en duda la relevancia real que tuvo en España, aunque tanto Romaní como Oíza si cuentan con la revista entre sus fondos.
} 


\subsubsection{Modelos y casos en las publicaciones periódicas de arquitectura}

Yoshimuras y pleats regulares para luminarias. 1950

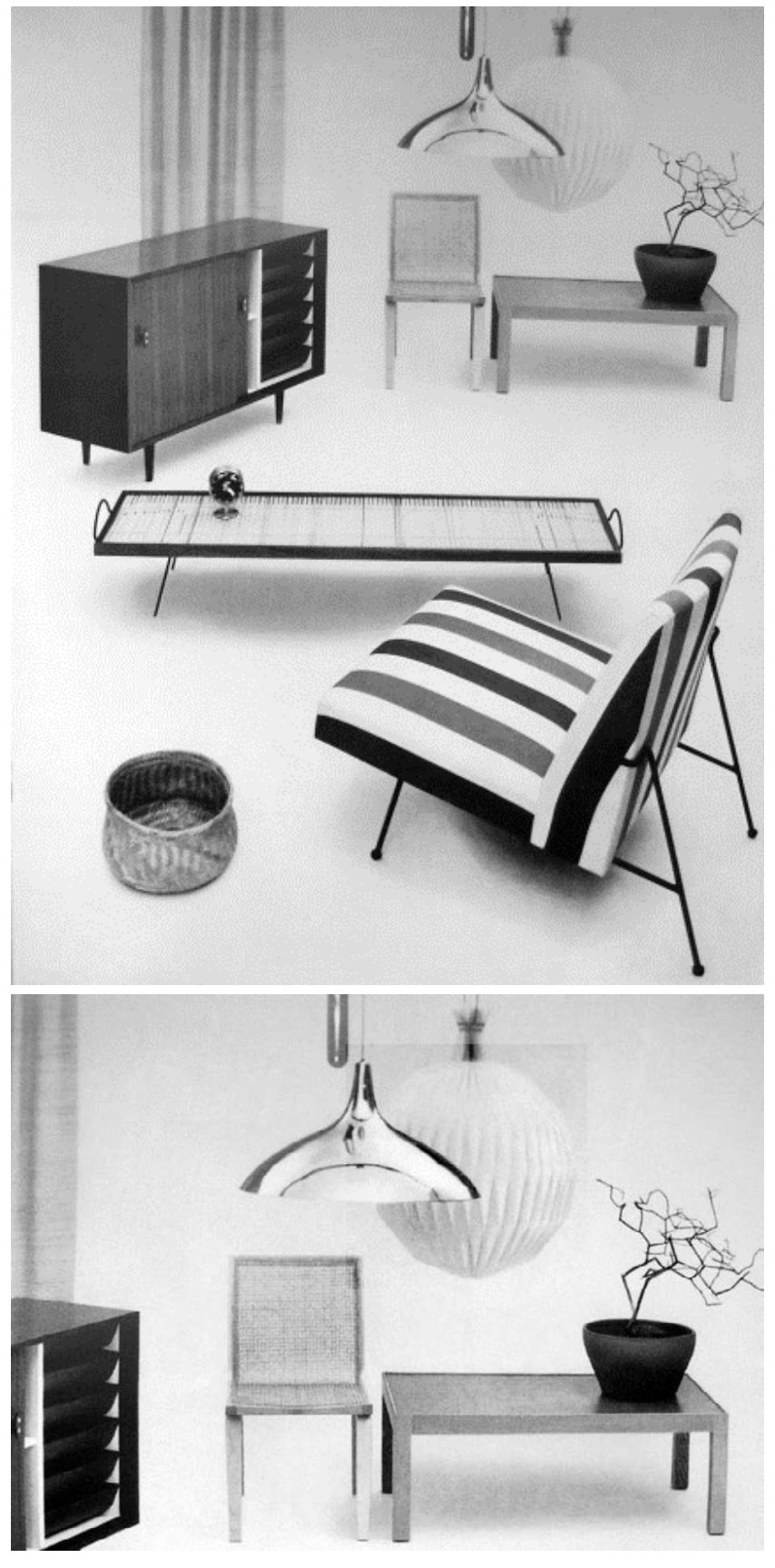

En el año 1950 la revista californiana Arts and Architecture se hizo eco de uno de los diseños de luminarias más exitosos de la empresa danesa Le Klint. La luminaria LK 101 (Frugtlygten - The fruit lamp) se realizó mediante un patrón regular yoshimura plegado en sus lados para formar una esfera.

Fundada en 1943 tras una larga tradición de arquitectos y diseñadores, hoy en día Le Klint es una de las empresas más internacionales de Dinamarca.

Plegando láminas de papel y de plástico translúcido, la familia Klint y sus colaboradores han diseñado una amplia y cuidada serie de luminarias de interior.

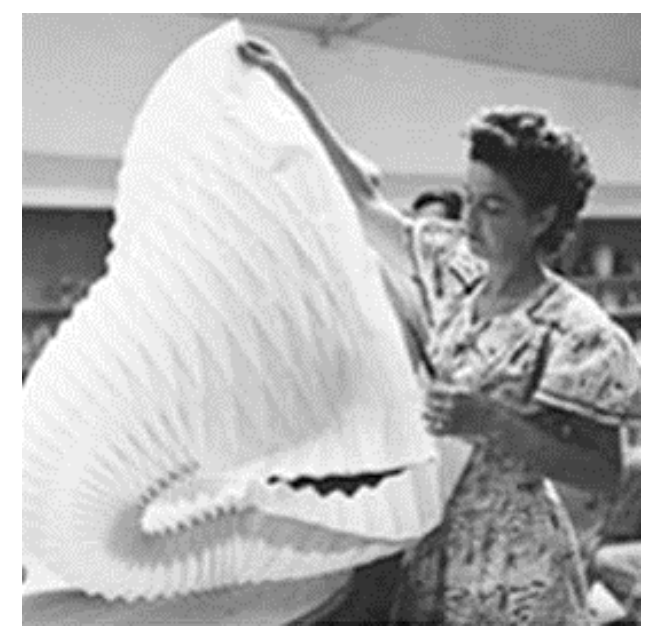

157. Arts and Architecture. Paper Shade from Denmark. Detalle fotografía de la página 4.

Con inscripción: Paper Shade from Denmark. 9,75 \$

Fuentes: http://www.danish-design.com/designers/pvk/timeline/

http://www.leklint.com/en-GB/Designers/Designere-Kaare-Klint.aspx

158. Fotografía del proceso de plegado de las luminarias. Fuentes: http://www.danish-design.com/designers/pvk Le Klint: https://www.youtube.com/watch?v=_lyS_RPZ93A 

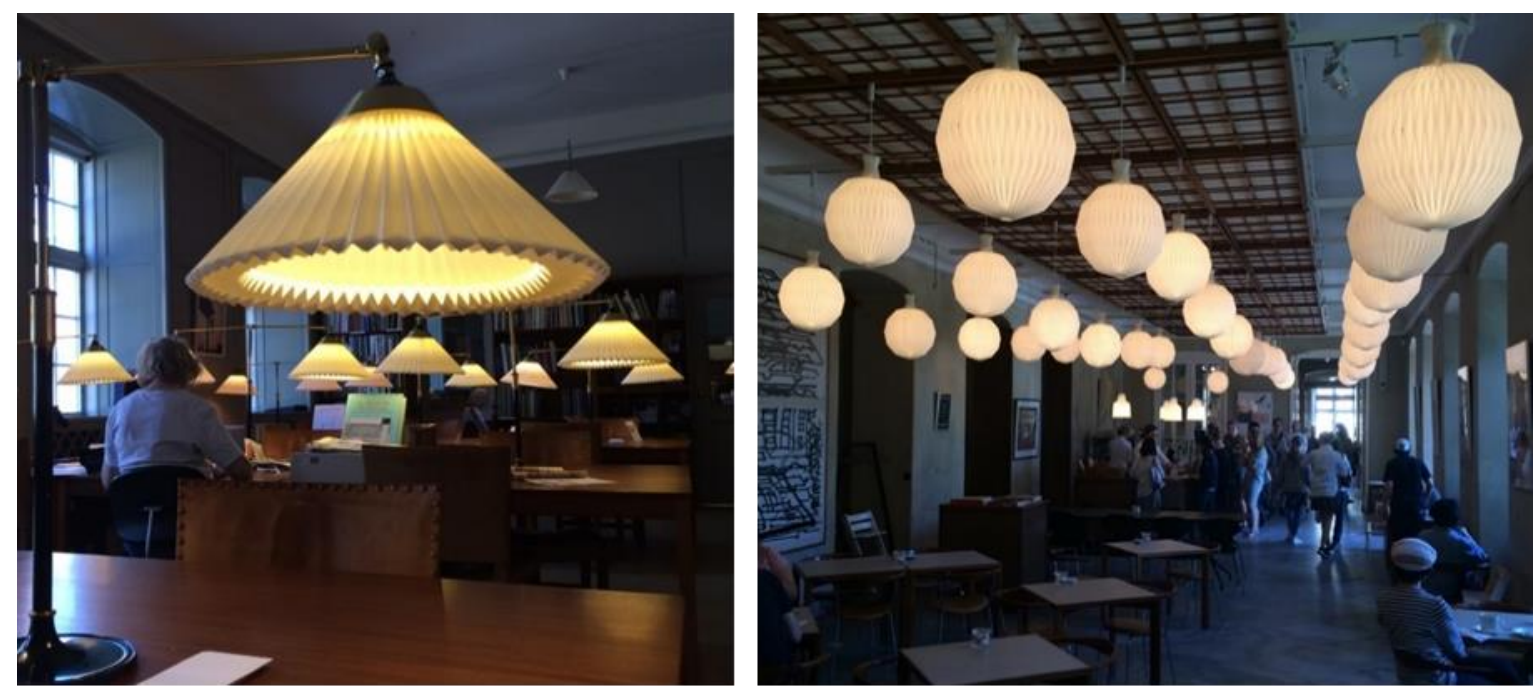

159. Luminarias Modelos LC 306, LK 101 (Frugtlygten The fruit lamp) 1944 y LK 145

Museo del Diseño de Dinamarca. Copenhague. Kaare Klint. Architecto, 1888 - 1954

Fotografías: Pablo De Souza 19/08/2015.

El autor de los primeros diseños de luminarias plegadas fue el arquitecto Kaare Klint, profesor en la Real Academia Danesa de Bellas Artes de Copenhague, donde fundó la escuela de diseño de muebles. Entre sus obras destaca la decoración del Museo Danés de arte y diseño en Copenhague (en colaboración con Ivar Bentsen) entre los años 1921 y 1926 donde se dispusieron las luminarias reseñadas. También fue el encargado del diseño del interior de la tienda central de LE KLINT en Kirkestræde en Copenhague para la que diseñó los modelos de luminarias LK 101 (conocida como la lámpara fruta) y LC 306 (una versátil lámpara de techo y mesa), estas luminarias y sus variantes siguen siendo las lámparas más destacadas de la gama que hoy día se ha ampliado con el uso combinado de patrones regulares de origami pleat, yoshimura, miura y fishbone, además del uso de patrones curvos.
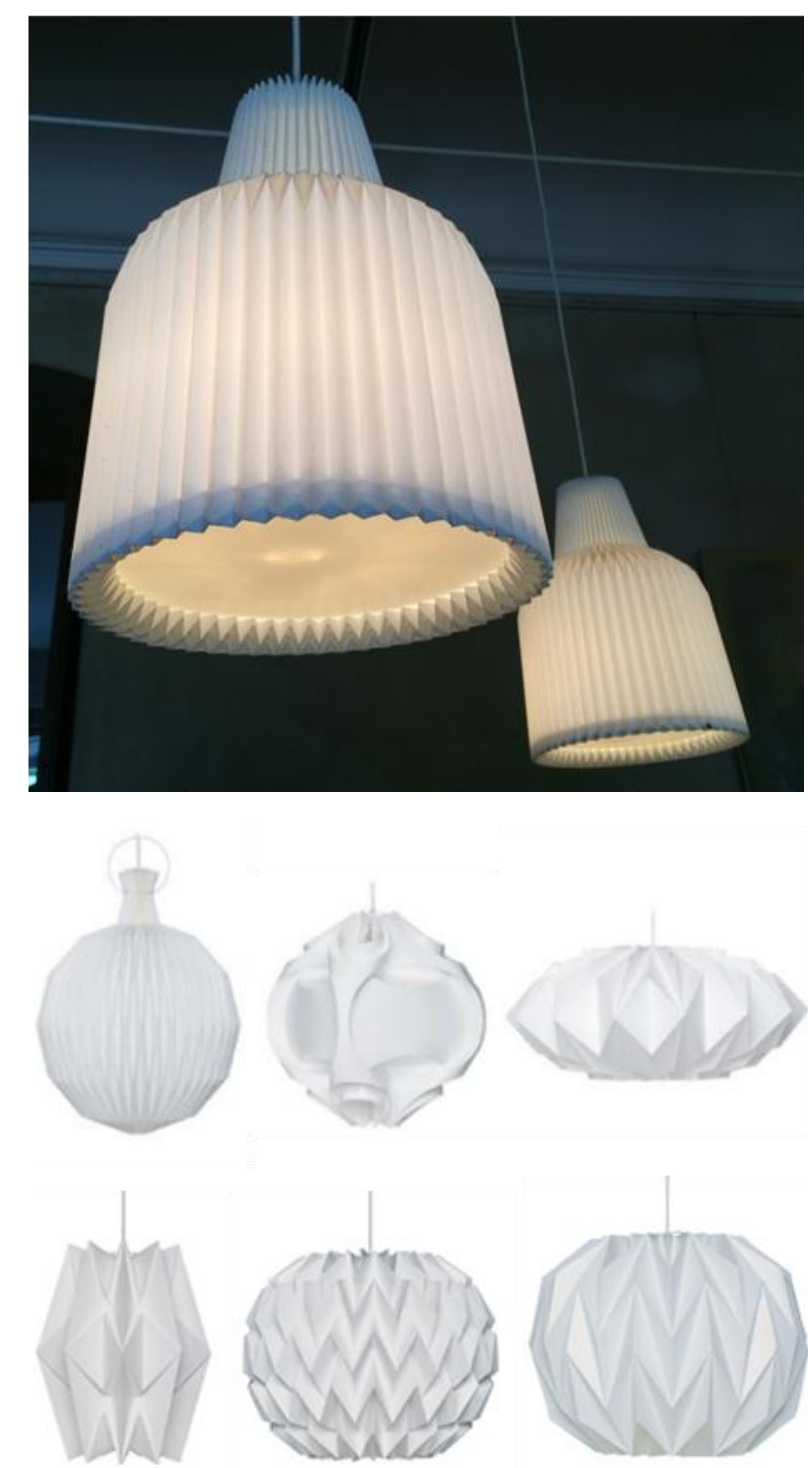

160. Luminarias Modelos LK 101, 167, 161, 152, 153, 157

Fuente: http://www.leklint.com/en-GB/Products/Categories-Pendants.aspx 
Digno contrapeso de las luminarias de Le Klint es la In-Ei collection de Issey Miyake para Artemide presentada en el año 2010 con su equipo de I+D el Reality Lab. Frente a los patrones regulares, continuos y simétricos Miyake explora, transforma y deforma los patrones regulares de origami en patrones pleat, yoshimura y fishbone diagonales, con el objetivo de realizar unos diseños dinámicos de simetrías diagonales invertidas.

"IN-El", que en japonés quiere decir "sombra, oscuridad y matiz", define las características de la colección de moda "132 5. ISSEY MIYAKE" que será también ampliada a la colección de luminarias. Es significativo el código utilizado para la colección: el 1 se refiere al único corte de tela que se usa en cada producto; el 2 indica el proceso de plegado inicial en 2D; el 3 evoca el 3D y el 5, tras un espacio vacío, se refiere a la metamorfosis de las formas, que se convierten en ropa o en objetos. Además, el 5 es un número que da buena suerte en la cultura oriental y representa el deseo de que el traje o el objeto sigan adoptando nuevas formas en el futuro.

En colaboración con Artemide, el Reality Lab de Issey Miyake ha desarrollado un textil de materiales reciclados cien por cien, a fin de propagar la luz de una manera sutilmente irregular. A tal efecto, se emplea una fibra tratada que se obtiene de botellas de PET. Las botellas se procesan mediante una tecnología innovadora que disminuye hasta un $40 \%$ el consumo de energía y las emisiones de $\mathrm{CO} 2$, en comparación con la producción de materiales nuevos.
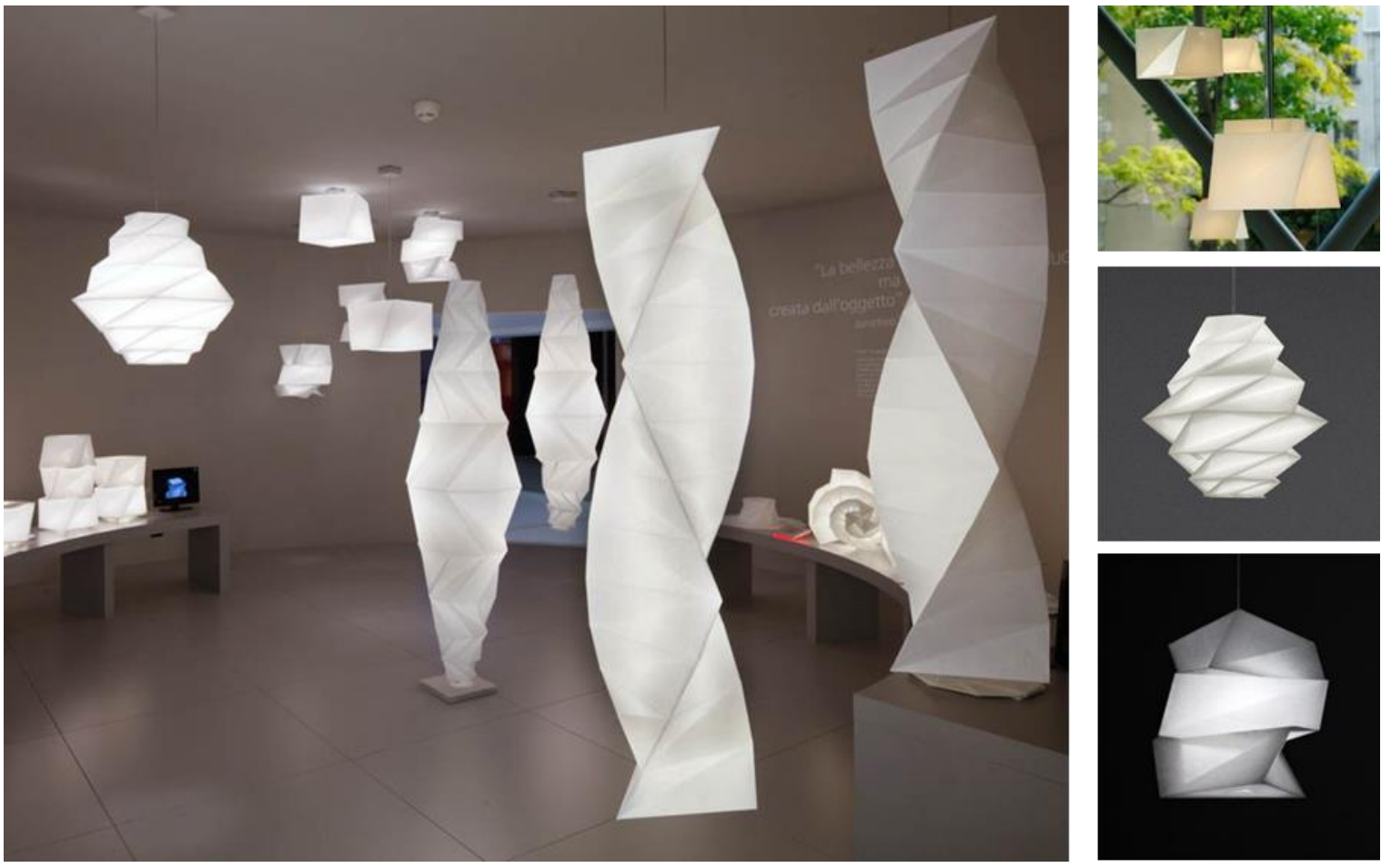

161. In-Ei collection. 132 5. ISSEY MIYAKE

Fotografías de Elodie Dupuis. Artemide 01-06-2012

Fuente: http://www.artemide.com/search/firstSearch.action;jsessionid=8A540DFF172D0212F824839C9171372B 
El patrón de plegado espina de pez. 1952

La revista Spazio, fundada y dirigida por el arquitecto italiano Luigi Moretti en 1950, llegaría a publicar siete números hasta 1953. En el n 6 de abril de 1952 Moretti firma un extenso artículo titulado "Struttura come Forma" (La estructura como forma) ${ }^{123}$ que recoge diferentes soluciones de cubiertas abovedadas para la cubrición de grandes espacios escénicos del arquitecto Guido Figus que, como nos cuenta J. Sáenz Guerra, son "claves para entender esa tela plegada en zigzag" ${ }^{124}$ de la cubierta del proyecto de la Capilla en el Camino de Santiago de Sáenz de Oíza, Oteiza y Romaní.

En este artículo sorprende la ausencia de opiniones o escritos por parte de Guido Figus 125, centrándose su participación estrictamente en ofrecer una extensa gama de variaciones geométricas sobre patrones de plegado yoshimura y en espina de pez ${ }^{126}$ relacionando estas geometrías con diferentes bóvedas nervadas del medievo que podemos ver en las páginas 23 y 29 en donde se muestran los techos de la Santísima Trinidad en Norwich y del cuerpo central de la nave de la Catedral de la Santísima Trinidad de Gloucester.

L. Moretti destaca a G. Figus como ejemplo de metodología de investigación para lograr estructuras vivas que sean capaces de transmitir su expresividad formal tanto al exterior como al interior, estructuras que lleven implícito el acabado formal final de la obra de arquitectura y que ofrecen un buen comportamiento acústico para la función requerida. De este modo y poniendo de ejemplo la investigación con estas geometrías plegadas, Moretti defiende una arquitectura paramétrica en donde los valores plásticos, constructivos y funcionales se integren y equilibren, adelantándose en cincuenta años al actual concepto de arquitecturas paramétricas ${ }^{32}$ que buscan dar respuesta global al hecho arquitectónico.
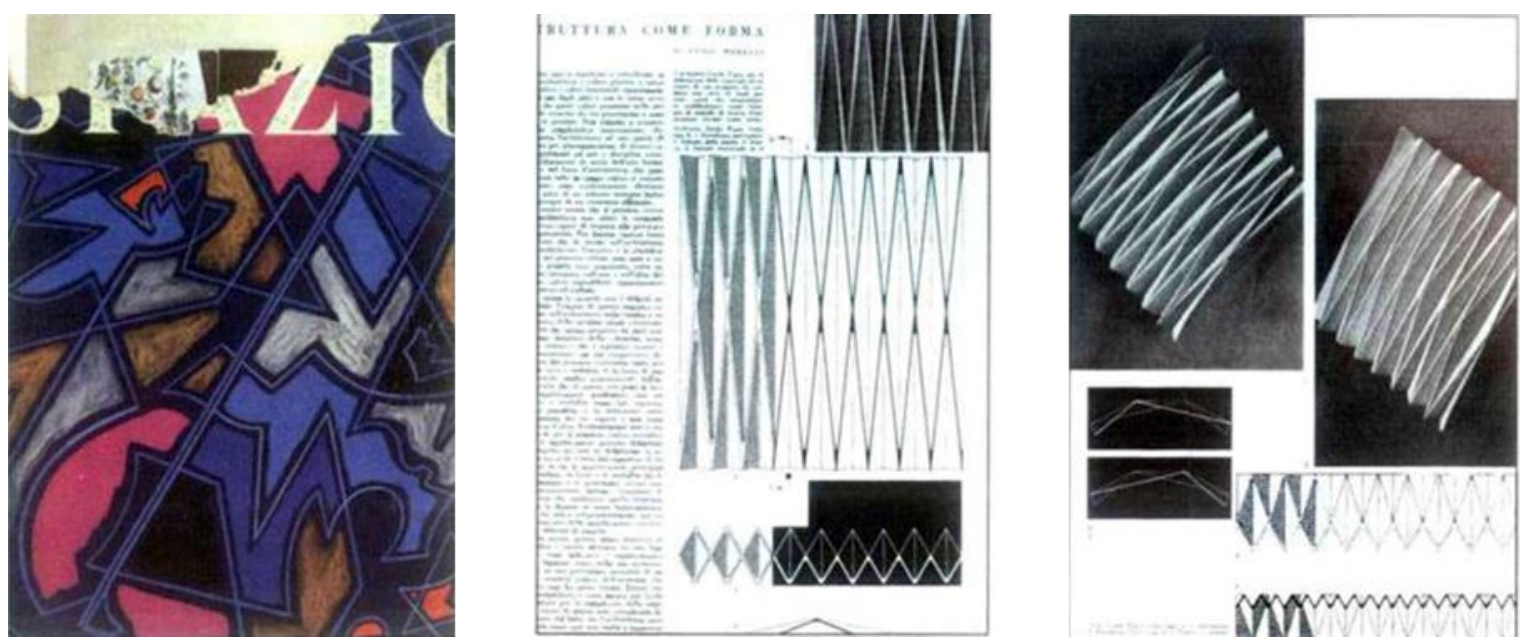

162. Spazio, n6, diciembre 1951 - abril 1952, portada y pp. $21-22$.

\footnotetext{
${ }^{123}$ Este texto también se encuentra en las páginas 175 a 177 del libro: "Luigi Moretti: works and writings" Escrito en inglés por Luigi Moretti, Federico Bucci y Marco Mulazzani. Edit. Princeton Architectural Press, 2002.

${ }^{124}$ Sáenz Guerra, Javier. “Un mito moderno. Una Capilla en el Camino de Santiago. Sáenz de Oíza, Oteiza y Romaní, 1954”. Fundación Museo Oteiza Fundaziao Museoa, 2007. ISBN 978-84-922768-6-2. (pág. 248)

${ }_{125} \mathrm{De} \mathrm{G}$. Figus existe constancia de ocho obras significativas en las que no llegó a aplicarse ninguna de estas investigaciones, así pues, quedaron como mero catálogo de posibilidades geométricas para futuras aplicaciones. Sus obras seleccionadas se pueden ver en la página www.casadellarchitettura.it

126 "spina di pesce" (pág. 31) "...esempio di metodo di recerca d'una struttura vivente... avesse un buon comportamento acústico e che si rivelasse sia all'esterno che all'interno dell'edificio, con forma piú viva e sinsibile... architettura parametrica o quiesti parametri sono numerosi e poco definibili e allora la funzione non puó che indicare una forma approssimata, una pre-forma latísima....architetura e struttura di densitá di energie. Nelle densitá di energie intendo impliciti gli spazi".
} 

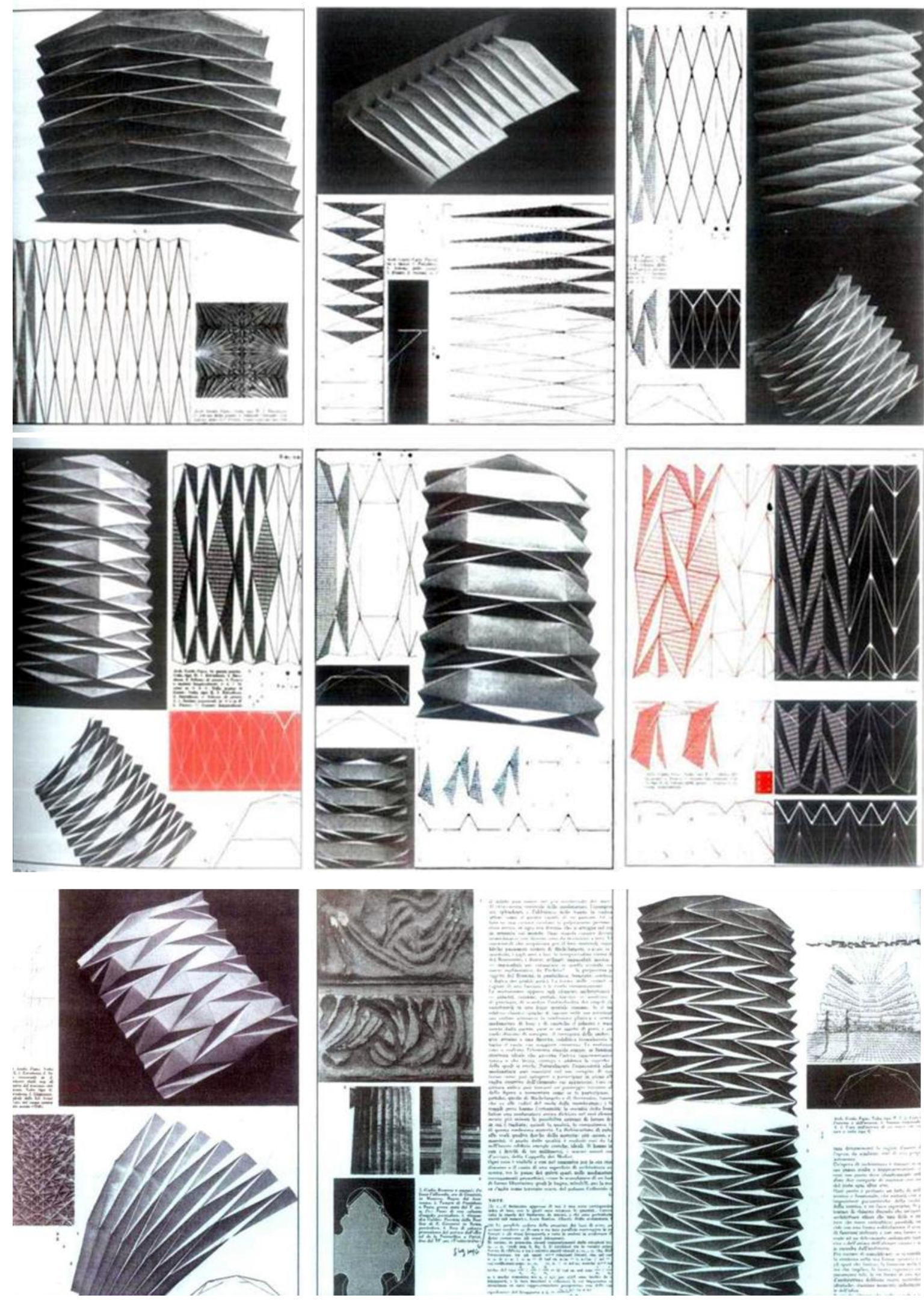

163. Spazio, n6, diciembre 1951 - abril 1952, páginas $23-31$. 
La interesección entre dos láminas plegadas. 1954
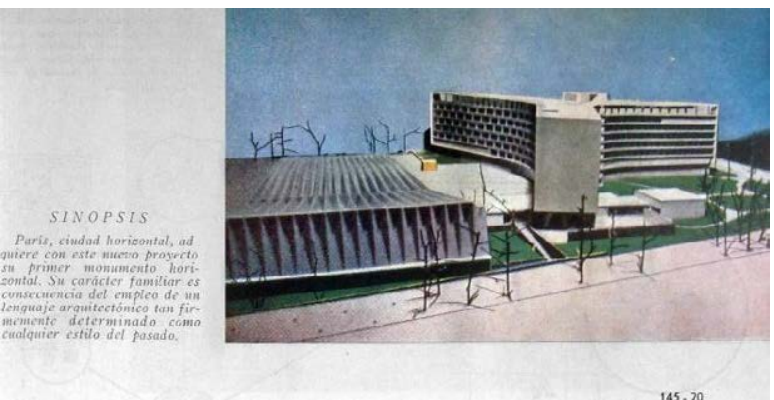

NUEVA SEDE DE LA UNESCO EN PARIS

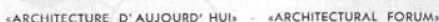

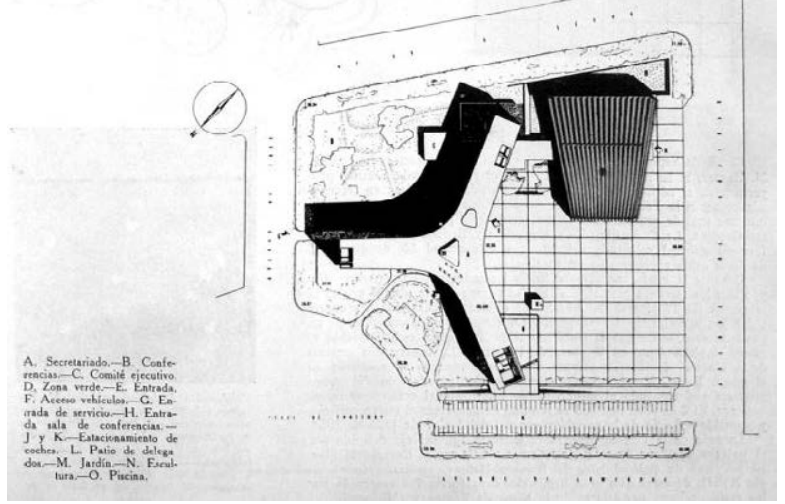

El artículo dedicado a la nueva sede de la Unesco en París proyectada por el arquitecto Marcel Breuer es un compendio de la información de las revistas internacionales: Architecture D'aujourd'hui y Architectural Forum. ${ }^{127}$ Aunque en años anteriores ya se habían tratado por parte de la revista Informes temas de cubiertas onduladas, láminas plegadas de hormigón armado y de espacios arquitectónicos con geometrías facetadas, incluso resaltando la conveniencia de estos pliegues ya sea por condicionamientos estructurales, acústicos o de confort visual. Por primera vez en la revista Informes de la Construcción queda constancia de un proyecto arquitectónico que se inspira claramente en geometrías plegadas que tienen su razón de ser en la papiroflexia abstracta.

164. Portada del artículo: Nueva sede de la Unesco en París. Informes de la Construcción, n 58, enero-febrero de 1954.

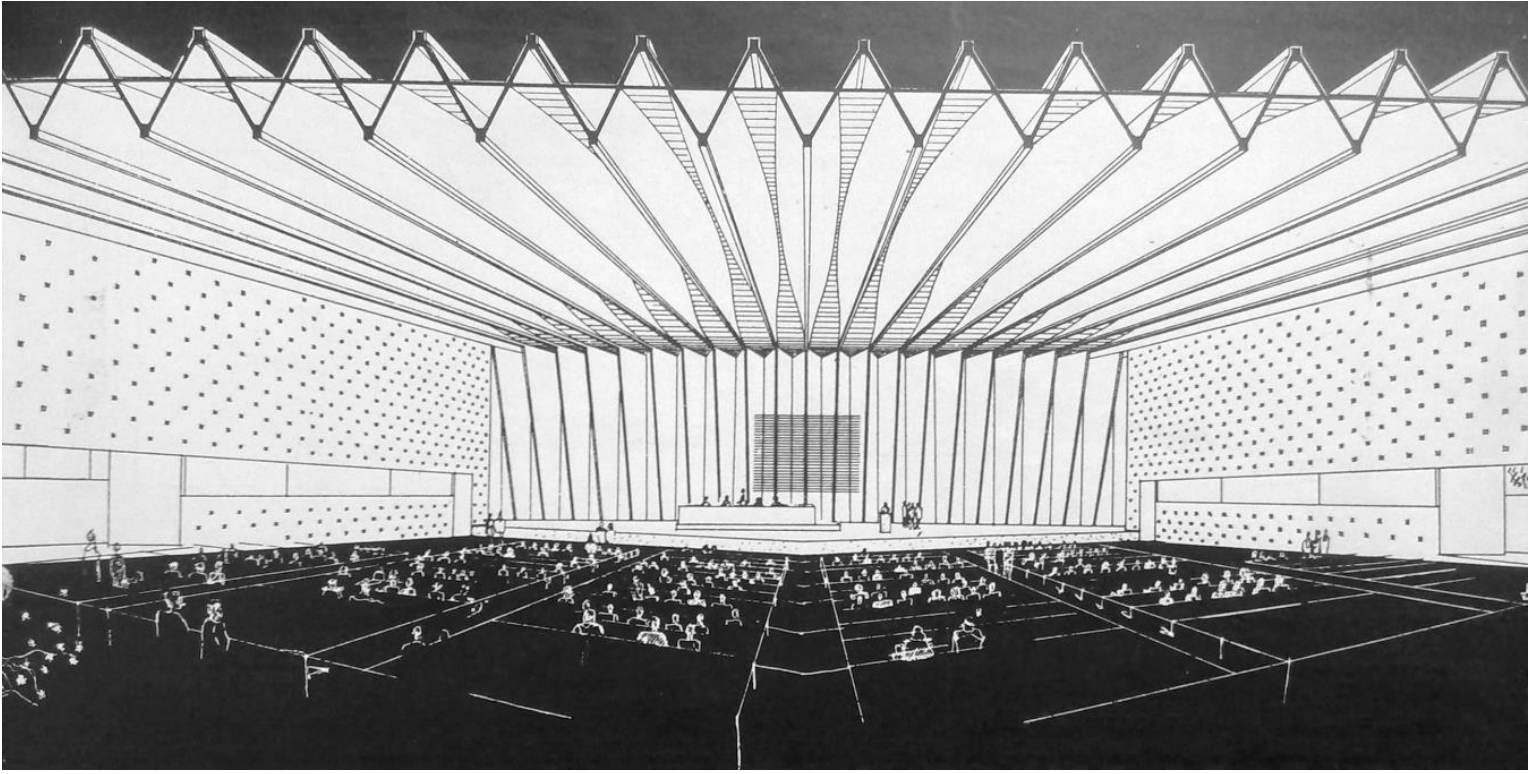

165. Sección fugada interior de la sala de conferencias de la sede de la Unesco en París.

Proyecto de Marcel Breuer junto a Pier Luigi Nervi y Bernard Zehrfuss, 1952-58. Fuente: Detalle artículo:

"Nueva sede de la Unesco en París". Informes de la Construcción, n 58, enero - febrero de 1954.

127 Como es habitual en los primeros años de la revista, en los artículos que resumen informaciones de revistas internacionales no se citan los números y títulos de los artículos de donde se ha extraído esta información. Tampoco es posible conocer la página en la que está insertado el artículo ya que vienen identificados por un complejo código numérico que los clasifica según los bloques temáticos tratados a nivel global por la revista. 


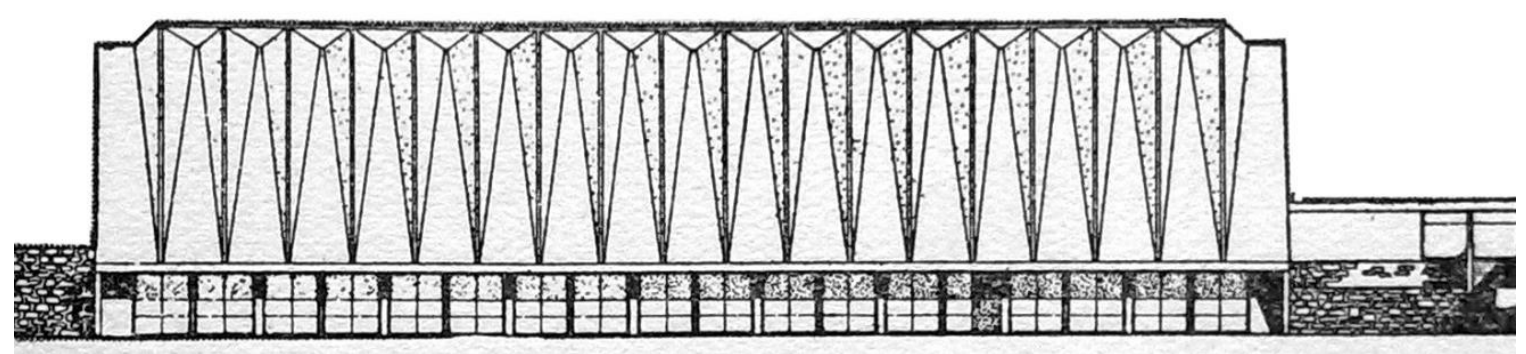

166. Fachada Este de la Sala de Conferencias de la Sede de la Unesco en París.

Proyecto de Marcel Breuer junto a Pier Luigi Nervi y Bernard Zehrfuss, 1952-58. Fuente: Detalle artículo:

"Nueva sede de la Unesco en París". Informes de la Construcción, n 58, enero - Feb. 1954.
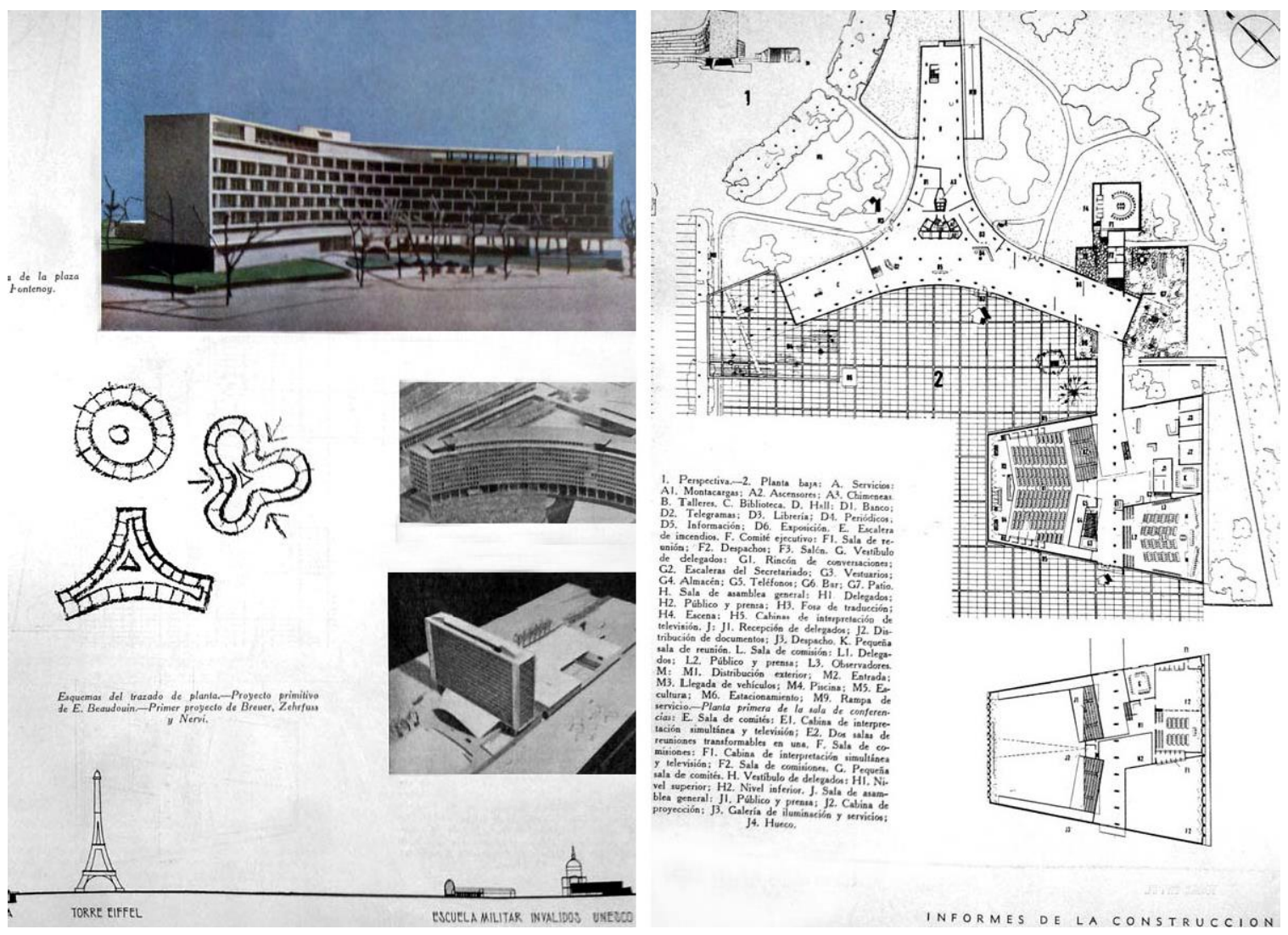

167. Páginas 3 y 4 del artículo: "Nueva sede de la Unesco en París".

Informes de la Construcción, nº 58, enero - febrero de 1954.

Marcel Breuer fue un arquitecto de origen húngaro que se formó en la Bauhaus de Weimar asistiendo a los cursos "preliminares" en los que, como hemos resaltado en capítulos anteriores, se recurría a las capacidades didácticas del trabajo en papel para dar una formación espacial y creativa que habilitara a los alumnos a proponer y explorar nuevos caminos arquitectónicos. Aunque en proyectos anteriores ya había explorado las posibilidades expresivas de láminas plegadas formando ligeras y dinámicas cubiertas ${ }^{128}$, es aquí donde más claramente recurre al pliegue como fenómeno conceptual que implica una nueva solución estructural de gran potencia espacial y al uso de geometrías triangulares claramente influenciadas por patrones de origami modular ${ }^{129}$.

\footnotetext{
${ }^{128}$ Ver por ejemplo el proyecto de casas para los jóvenes maestros de la Bauhaus "BAMBOS", Dessau, Alemania. 1927. ${ }^{129}$ Un año después, en 1953 Breuer inicia el proyecto de su primera construcción de un monasterio, la Abadía de St. John, y el complejo universitario anexo en Collegeville, Minnesota, que acabaría en 1968.
} 

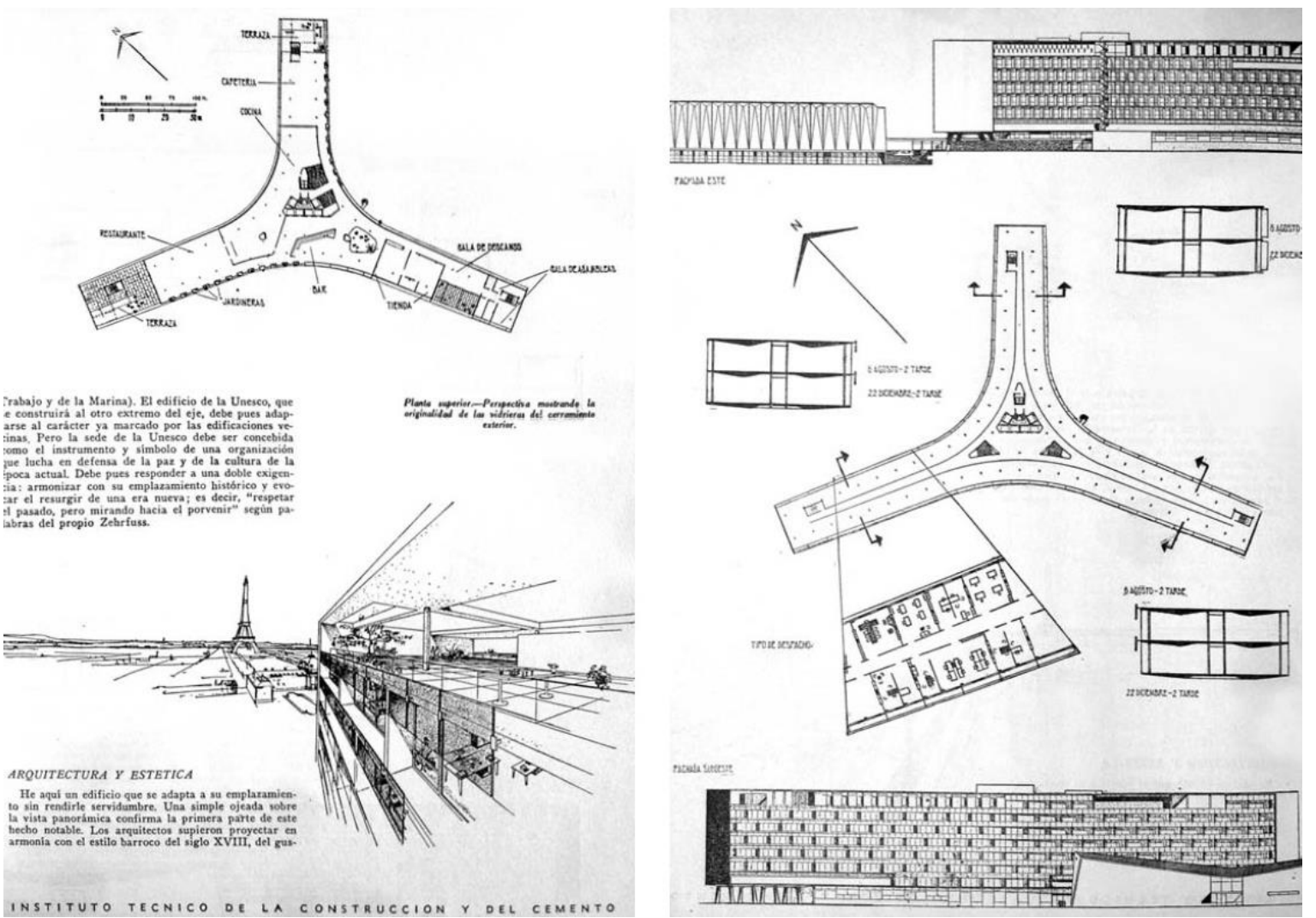

168. Páginas 7 y 8 del artículo: "Nueva sede de la Unesco en París". Informes de la Construcción, n 58, Enero - Feb. de 1954.

Concluido el proyecto el 18 de septiembre de 1952, tras la supervisión del comité asesor formado por Lucio Costa, Walter Gropius, Le Corbusier, Sven Markelius y Ernesto Rogers, no es hasta el 2 de abril de 1953 cuando, tras la modificación del emplazamiento, se termina el proyecto para someterlo a la aprobación de la Asamblea General de la Unesco. El texto del artículo hace referencia explícita a esta adecuación: "He aquí un edificio que se adapta a su emplazamiento sin rendirle servidumbre (p. 7) Paris, ciudad horizontal adquiere con este proyecto su primer monumento horizontal". (p. 1) "Hay siempre algo misterioso en este arte, hasta para sus creadores, pero pudiera ser instructivo saber que en este caso, los arquitectos no empezaron acampando formas funcionales abstractas al emplazamiento en cuestión. Su búsqueda inicial fue la solución práctica para un edificio de función bien determinada". (p.8a)

Nada se dice del uso de geometrías derivadas de la papiroflexia, aunque de su imagen global se escribe: "Su carácter familiar es consecuencia del empleo de un lenguaje arquitectónico tan firmemente determinado como cualquier estilo del pasado" (p. 1). "Las esencias de función y estética no solo se presentan sin doblegarse entre sí, y armonizando la una con la otra, sino que ambas se estimulan y dan alas". (p.8a). Conceptos por otra parte parejos a los descritos por L. Moretti en el artículo "La Struttura come Forma". ${ }^{130}$

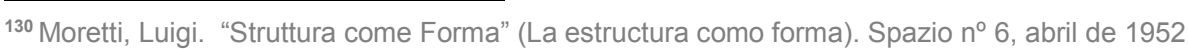


De las distintas fachadas nos describen: "sus pantallas verticales al tresbolillo, no son tan sencillas como a primera vista parecen. Sus tres fachadas curvas responden a cuatro tipos diferentes como consecuencia de su diferente orientación en torno a la rosa de los vientos". (p.8b) sin llegar a citar las geometrías triangulares de la fachada Este de la Sala de Conferencias. Aunque sí hacen una sentida reseña a la compleja estructura de la sala de conferencias y de su vestíbulo formada por plegaduras de hormigón armado: "alcanza la elevada meta de Nervi: demostrar las posibilidades de la construcción pura, la sencillez de proyecto y de la poesía inherente a una estructura transparente hecha por el hombre... Así se consigue una creación honrada y poética, una exquisita fusión de lo noble y lo sutil" (p.8b)

"Ambas zonas están cubiertas con una estructura ondulada de hormigón armado, que descansa en los muros igualmente ondulados de fachada y en una sola fila de pilares centrales. En el tramo de más luz, la cubierta se adapta a la forma de la gráfica de momentos. Los nervios exteriores, se estrechan y se ensanchan suavemente para ganar en profundidad... La inclinación de los muros y las sinuosidades de la cubierta proporcionan una acústica óptima". (p.8b) El artículo termina con una profunda reflexión que se hace eco del auge de estas estructuras plegadas de hormigón armado que durará hasta los años 60: "Hay una triste ironía en este audaz y poético logro arquitectónico: su ejecución es sólo posible en un país de mano de obra barata; su aplicación sólo es racional en países de escasez de materiales. Desde el punto de vista americano, éstos son los fallos de Europa; pero, ¿se ha mostrado jamás prosperidad tan afirmativamente o con tanto orgullo e imaginación como en éste proyecto?". (p.8b)
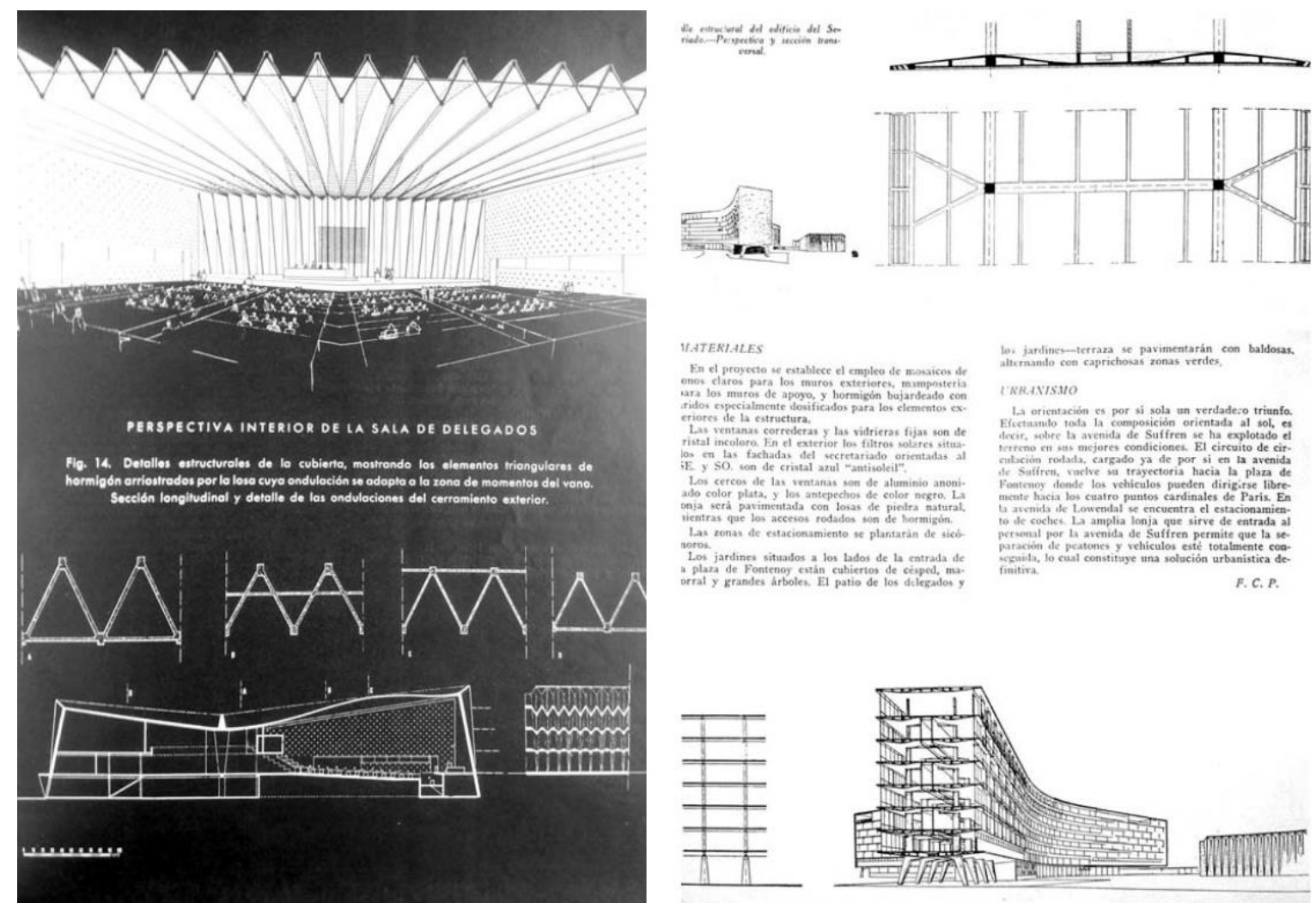

169. Páginas 9 y 10 del artículo: "Nueva sede de la Unesco en París". Informes de la Construcción, nº 58, enero - feb. de 1954. 


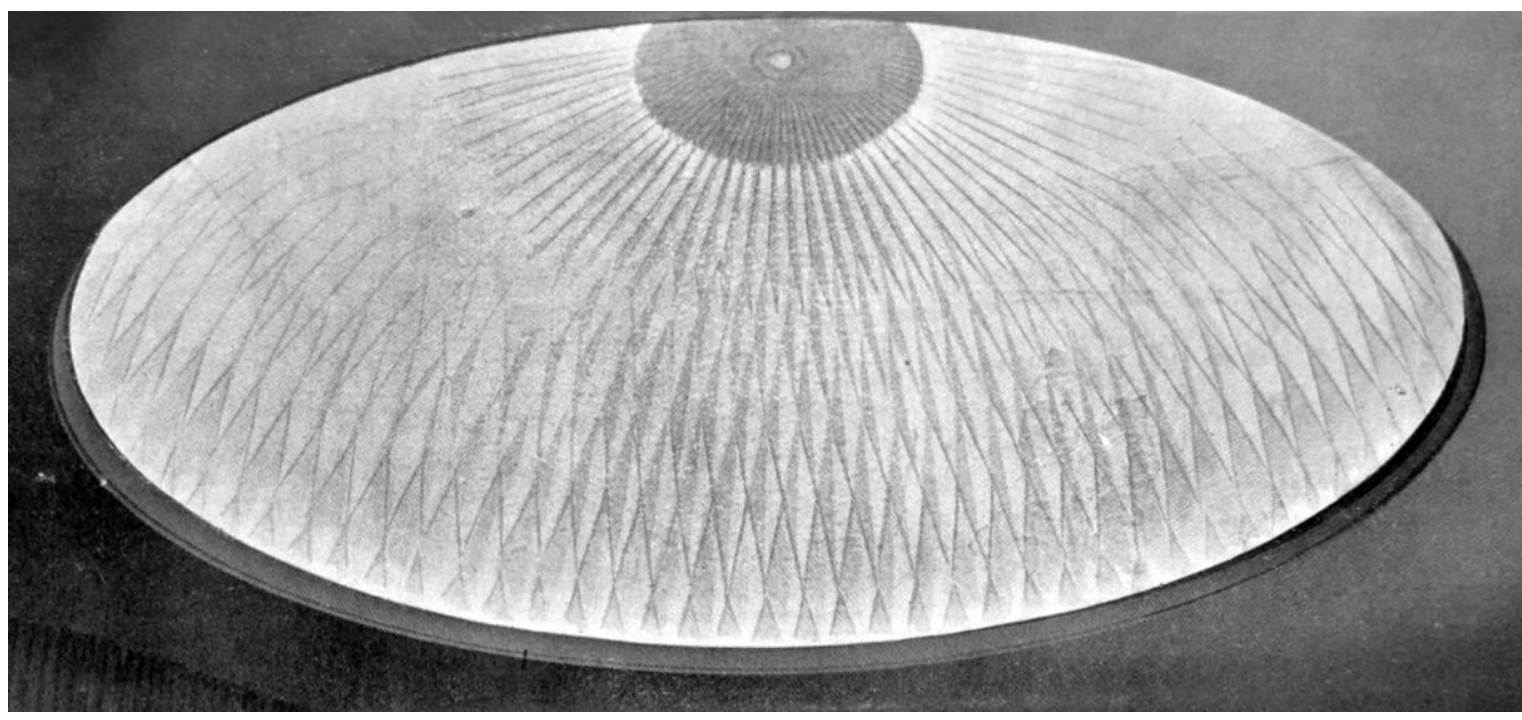

170. Cúpula del salón comedor del Restaurante "El Coto" en Madrid.

Detalle p. 6 del artículo: Restaurante "El Coto" en Madrid. Informes de la Construcción, nº 63, ag. - sept. 1954.

J. Sáenz Guerra había reseñado el artículo publicado en el nº 173 de mayo de 1956 de la Revista Nacional de Arquitectura (RNA), como la primera publicación española en la que aparecían obras de arquitectos inspiradas en el arte del origami ${ }^{131}$. Sin embargo, en su investigación faltaba por analizar la revista Informes de la Construcción, y es en ella donde encontramos el artículo -Restaurante "El Coto" en Madrid, L. Gutiérrez Soto-, publicado con dos años de antelación, que contiene la primera referencia fotográfica a geometrías inspiradas en el arte del origami aplicadas directamente en una obra de arte y / o arquitectura de un autor español. Luis Gutiérrez Soto destacó por su capacidad de adaptarse a los requerimientos programáticos y culturales proponiendo un amplio abanico de arquitecturas, desde posturas racionalistas de principios de siglo hasta el eclecticismo histórico imperante en la España de los años 50.

De este modo podemos entender la inclusión de esta cúpula de nervaduras romboidales plegadas de alto valor abstracto que derivan directamente de los pliegues del maestro Yoshimura en un restaurante de dudoso gusto burgués cargado de referencias pastoriles. Posiblemente realizada en escayola debía alojar la iluminación indirecta del comedor en su base circular perimetral, y sus múltiples pliegues ayudarían a una mejor difusión de la luz y absorción de los generalmente molestos ruidos del salón.

131 Sáenz Guerra, Javier. "Un mito moderno. Una Capilla en el Camino de Santiago. Sáenz de Oíza, Oteiza y Romaní, 1954”. Fundación Museo Oteiza Fundaziao Museoa, 2007. ISBN 978-84-922768-6-2. (pág. 251). 

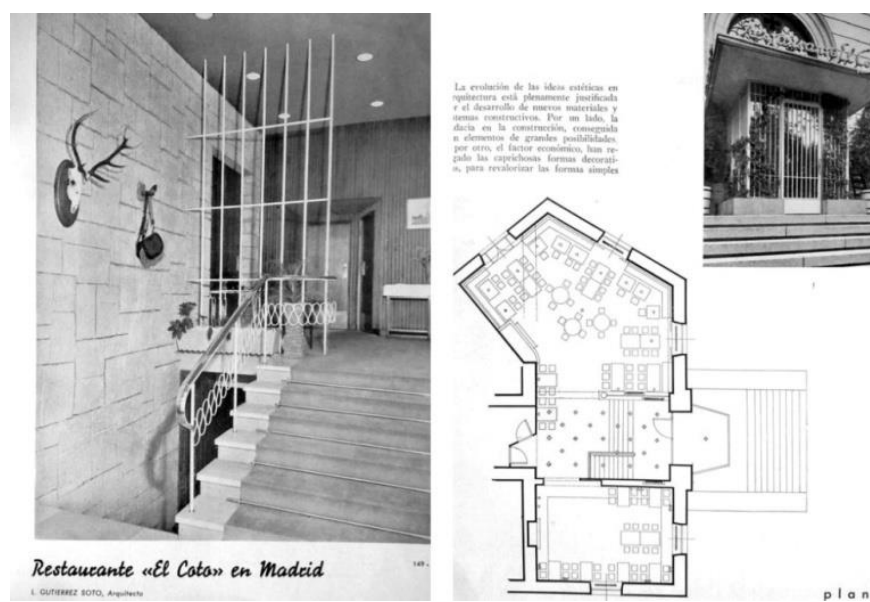

Con un total de seis páginas, el artículo cierra con la cúpula en todo su esplendor ocupando a toda página la parte superior de la lámina, acompañada por unas ilustraciones pastoriles que recuerdan vagamente a los grabados japoneses tradicionales. ¿Se buscaba algún diálogo entre estos elementos teniendo en cuenta su mismo origen cultural?

171. Restaurante "El Coto" en Madrid. Informes de la Construcción, n 63 , agosto - septiembre de 1954

Páginas 1, 2 y 6 del artículo.

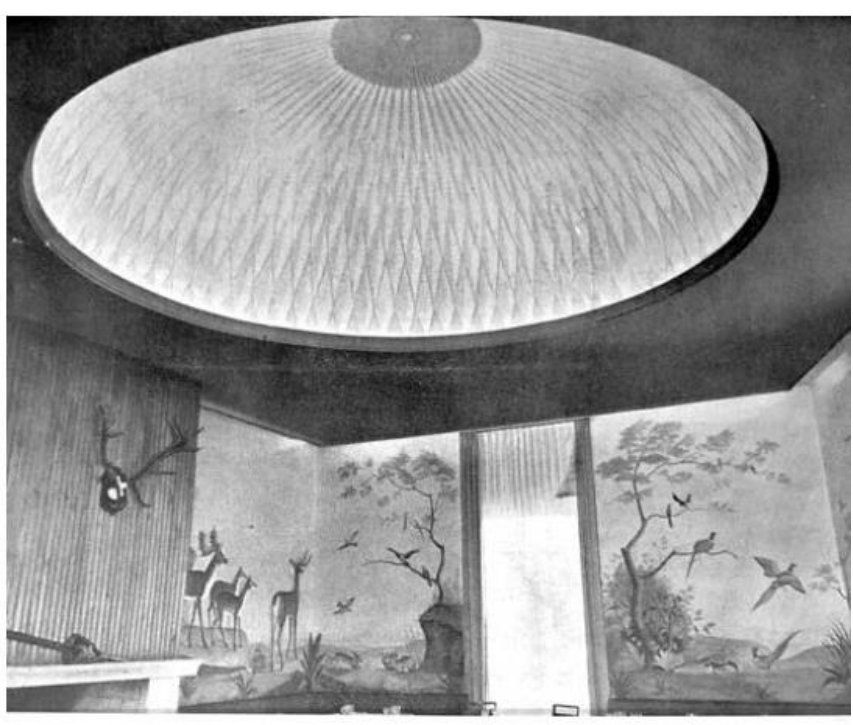

La escasa relevancia en conjunto del proyecto del restaurante hace preguntarnos por su inclusión en la revista de Informes, parece que sólo la originalidad geométrica de la cúpula pudo ser determinante para hacer reseñable este proyecto arquitectónico. ${ }^{132}$

Aunque en el texto del artículo no se hace referencia directa a esta cúpula, podemos subrayar algunas líneas que veladamente valoran su importancia: "La evolución de las ideas estéticas en Arquitectura está plenamente justificada por el desarrollo de nuevos materiales y sistemas constructivos. ...la audacia en la construcción, conseguida con elementos de grandes

unto de vista arquitectónico. Sencillez, ausencia de molduración, cuilosa ejecución, contrastes, armonías y ambiente grato y luminoso stituyen sus mís señaladas caracteristicas.

La pintura, pese a su falta de audacia y modernidad, juega un imtante papel en la decoración del conjunto, resultando equilibrada. paramentos de mamposteria se combinan con los de corcho rizaso, un inmejorable fort. fectamente con los motivos decorativos de caza, que ambientan la

posibilidades...han relegado las caprichosas formas decorativas, para revalorizar las formas simples y armoniosas conseguidas con la proporción de masas y juego de líneas y planos". ${ }^{133}$

\footnotetext{
132 Miguel Ángel Baldellou citó este proyecto en sus clases del programa de doctorado: "Arquitectura y Arquitectos Españoles Contemporáneos, Historia y Crítica" en el curso 2009-2010 como ejemplo del eclecticismo y libertad creativa de Gutiérrez Soto y del que recordó su "cúpula nervada" como posible referencia a arquitectura inspirada en el origami.

${ }^{133}$ Restaurante "El Coto" en Madrid. pp 2-3. Informes de la Construcción, n 63, agosto - septiembre de 1954.
} 
Variantes del yoshimura cilíndrico y polar. 1956

J. Sáenz ${ }^{134}$ destaca la revista L'architettura y la Revista Nacional de Arquitectura (RNA) como fuente documental que remarcan lo extendido de estas geometrías en la década de los 50. Sobre estas líneas, la RNA en su número 173 de mayo de 1956 recoge el Primer Concurso de Diseño Industrial patrocinado por el Colegio Oficial de Arquitectos de Madrid, en donde el primer premio por un juego de café, bandeja, panera y frutero lo obtuvo el equipo formado por Luis M. Feduchi, Jesús Bosch, Ramiro Tapia y Javier Feduchi aplicando directamente las geometrías del pliegue Yoshimura en sus versiones esférica y cilíndrica.
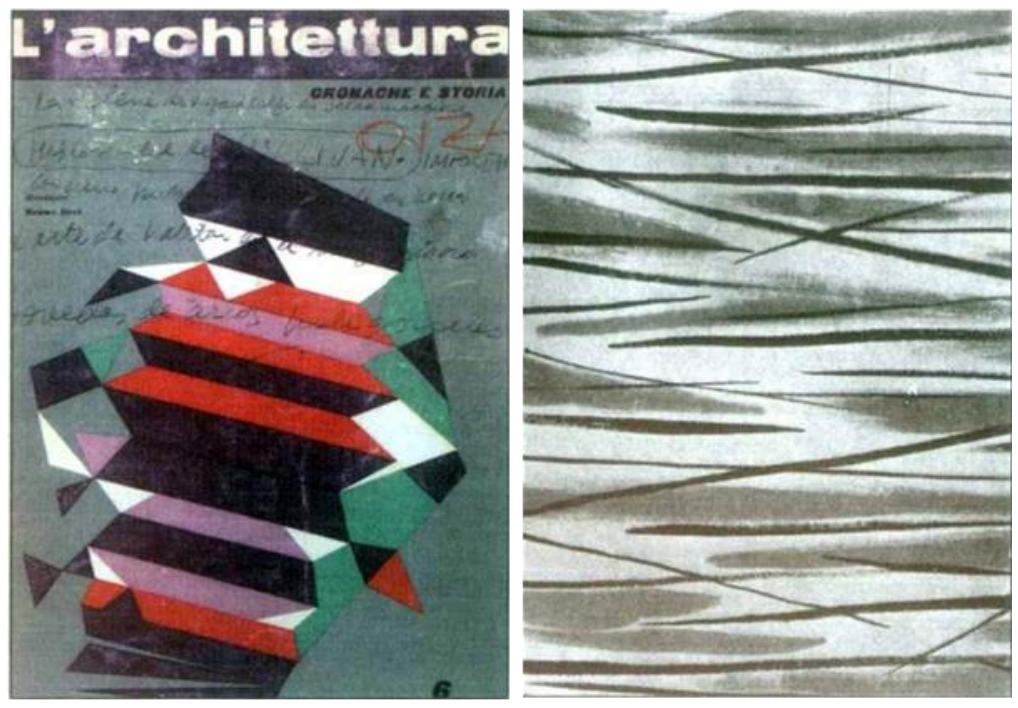

172. L'architettura, $n^{\circ} 6$, marzo - abril de 1956. Portada y Contraportada.
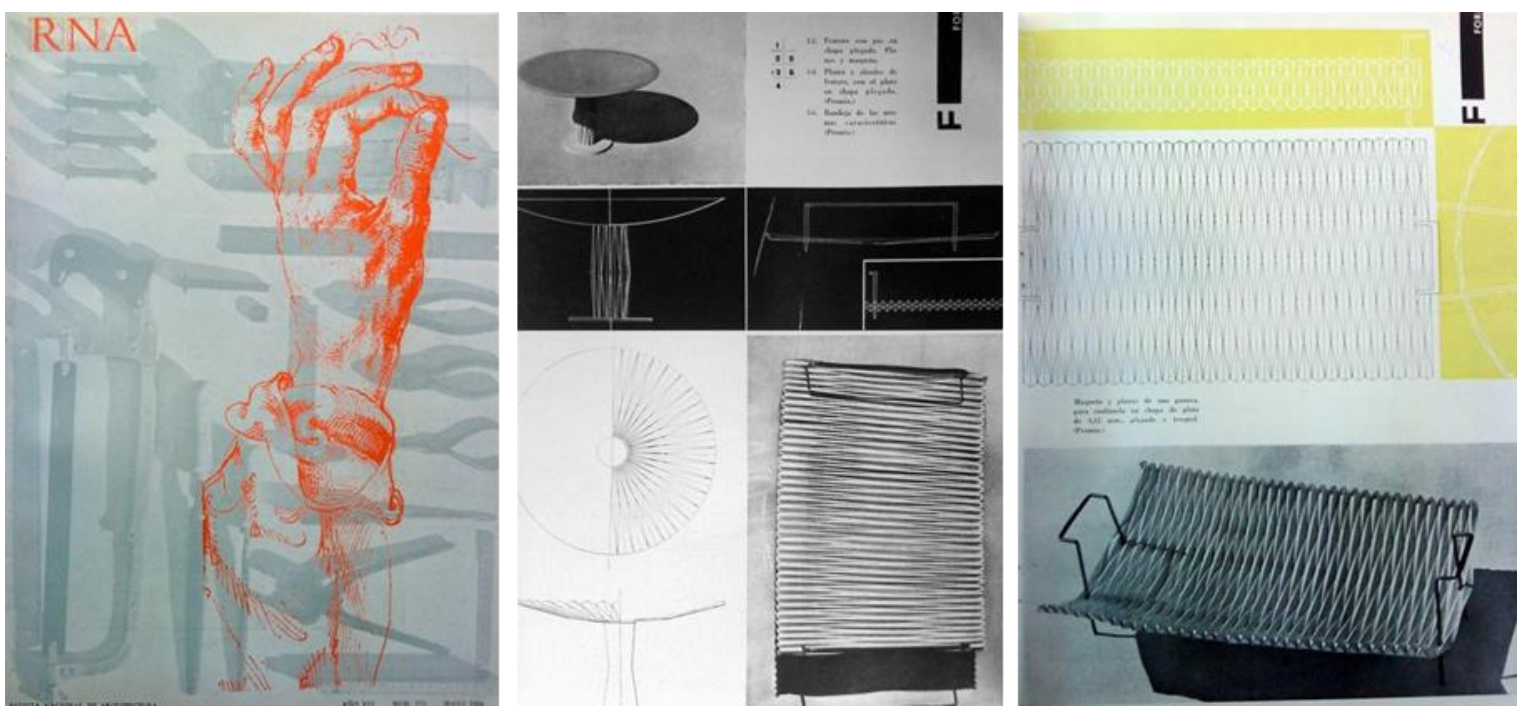

173. Revista Nacional de Arquitectura, $n^{\circ} 173$, mayo 1956, portada y páginas 6 y 7 .

\footnotetext{
${ }^{134}$ Sáenz Guerra, Javier. (2007) Un mito moderno. Una Capilla en el Camino de Santiago. Sáenz de Oíza, Oteiza y Romaní, 1954. Fundación Museo Oteiza Fundaziao Museoa. ISBN 978-84-922768-6-2. (pág. 251)
} 
Estructuras Plegadas. 1961
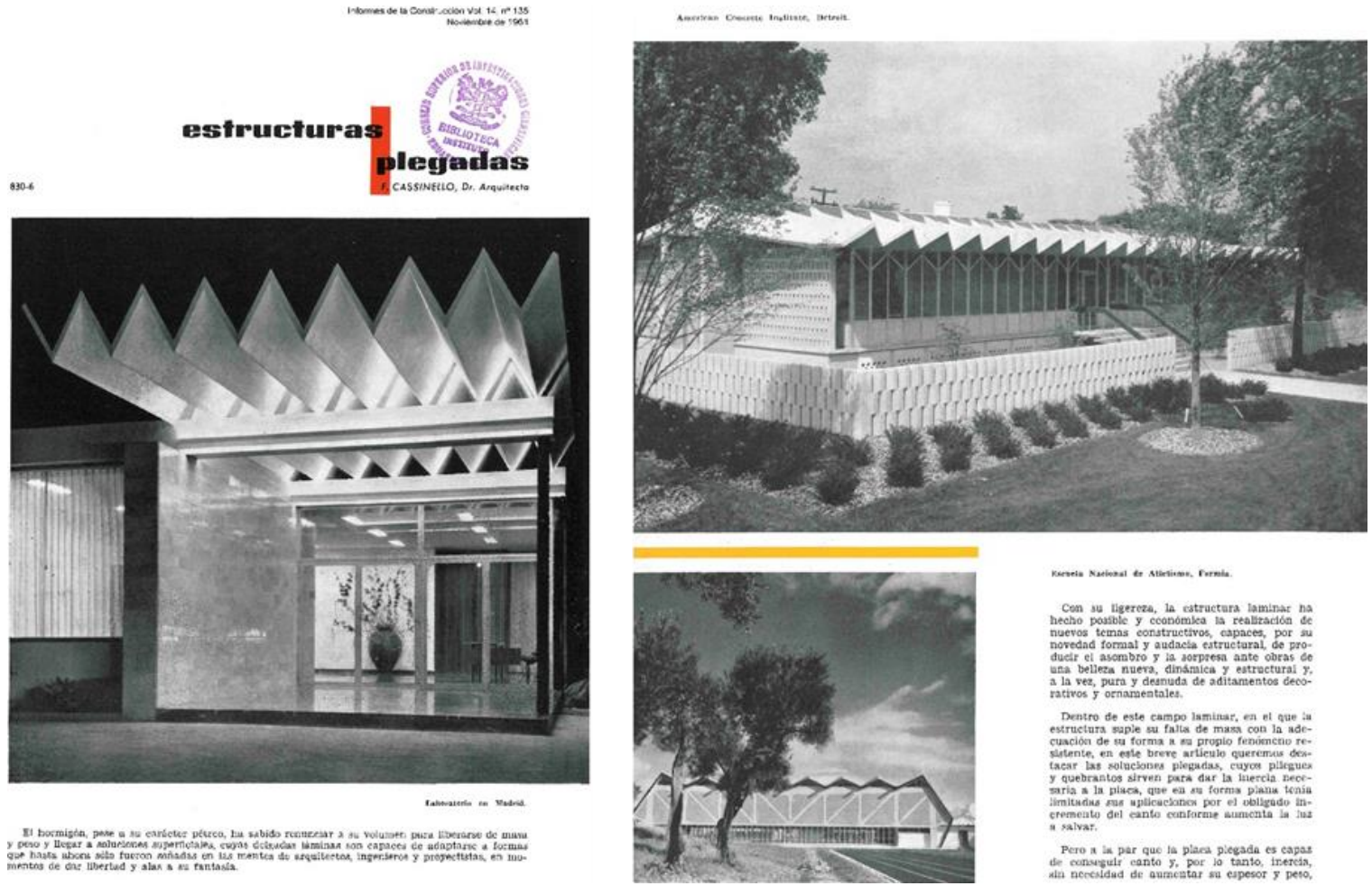

174. Portada del artículo Estructuras Plegadas. 1961 Informes de la Construcción. Vol. 14, n 135, Páginas 1 y 2 del artículo.

Izq. Entrada al Pabellón de Dirección de los Laboratorios Alter. Autor Miguel Fisac. 1960

Fuente: http://www.docomomoiberico.com/index.php?option=com_k2\&view=item\&id=186:laboratorios-alter\&lang=es Drcha. Nueva Sede del American Concrete Institute. Este edificio también se muestra en un artículo de Informes de la Construcción, Año XII, nº 107, Enero 1959.

En noviembre de 1961 el arquitecto Fernando Cassinello ${ }^{135}$ firmó un corto artículo de 6 páginas titulado Estructuras Plegadas, en el número 137 de la revista Informes de la Construcción, dedicado a las construcciones laminares de hormigón armado que estaban siendo ejecutadas con gran profusión durante la última década. Cassinello hace un repaso de algunas de las obras más significativas tanto a nivel nacional como internacional, entre las que destaca -en portada ver imagen superior izquierda- la cubierta de hormigón laminar con un pliegue en plisado o acordeón para la entrada al pabellón de dirección de los laboratorios Alter, construidos en Madrid en 1960 bajo la dirección del arquitecto español Miguel Fisac, y el Canódromo madrileño sito en el barrio de Carabanchel, que se muestra en la página siguiente, realizado por los arquitectos José Ramón Azpiazu y Pedro Pinto, inaugurado un año después en 1961. Como su concuñado Fisac (se casaron con dos hermanas), Azpiazu también emplea el hormigón como un argumento proyectual más que como un medio constructivo. Sin embargo entre la obra de ambos existe una gran distancia: la que separa una estructura con dos apoyos y comportamiento unidireccional, como es la estructura adintelada del arquitecto manchego, del trabajo en dos direcciones de las estructuras laminares de la obra del arquitecto cántabro.

135 Cassinello, Fernando (Noviembre de 1961) Estructuras plegadas. Informes de la Construcción. Vol. 14, nº 135 (sin paginación). 
La cubierta de la tribuna de espectadores está definida por una lámina plegada de hormigón armado de tan solo $6 \mathrm{~cm}$ de espesor, con nervios superiores de rigidización en la dirección contraria a los pliegues, y apoyada articuladamente sobre un pilar y posteriormente anclada mediante tirantes en V. Con una geometría no desarrollable, pero de caras planas, esta losa de perfil quebrado batió en su día el récord mundial con sus 18,5 metros de vuelo, una osadía estructural que, tal como posteriormente explicaran sus autores en el artículo publicado en marzo de $1962^{136}$ en la misma revista, estudiaron previamente con un modelo a escala $1 / 25$ de Plexiglas, en el Laboratorio Central Laboratorio de Ensayo de Materiales de Construcción, de Madrid, dependiente del Ministerio de Obras Públicas.

Basculando sobre el pilar central, la cubierta se equilibra mediante los tirantes en $\mathrm{V}$ de anclaje al graderio que actúa de contrapeso, sin poder evitar una flecha de $5 \mathrm{~cm}$ al desencofrar el extremo libre. En el citado artículo los autores concluyen: "La unidad del conjunto se basa en la sinceridad constructiva, dejando que cada material luzca su propia textura, y haciendo que los paramentos de hormigón armado, a cara vista, acusen la huella de su encofrado y dominen por su prodigalidad y audacia estructural."

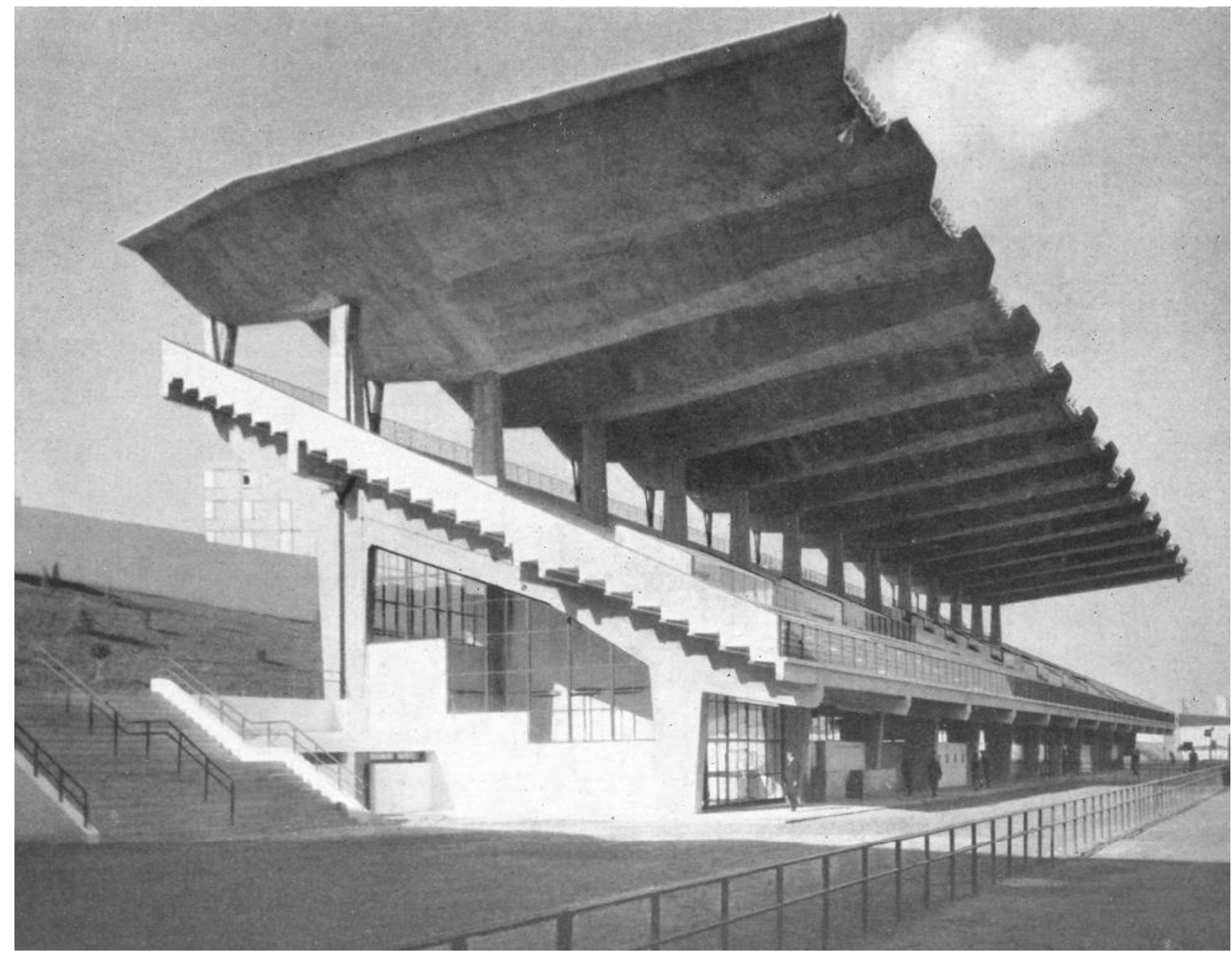

175. Canódromo madrileño. Azpiazu y Pinto, Estructuras Plegadas. 1961 Detalle pág 5

Fuente: Cassinello, F. (Nov. de 1961) Estructuras plegadas. Informes de la Construcción. Vol. 14, nº 135 Detalle página 5 del artículo.

${ }^{136}$ Azpiazu, J. R.; Pinto, P. (Marzo de 1962) Canódromo madrileño. Informes de la Construcción. Vol. 14, nº 138 


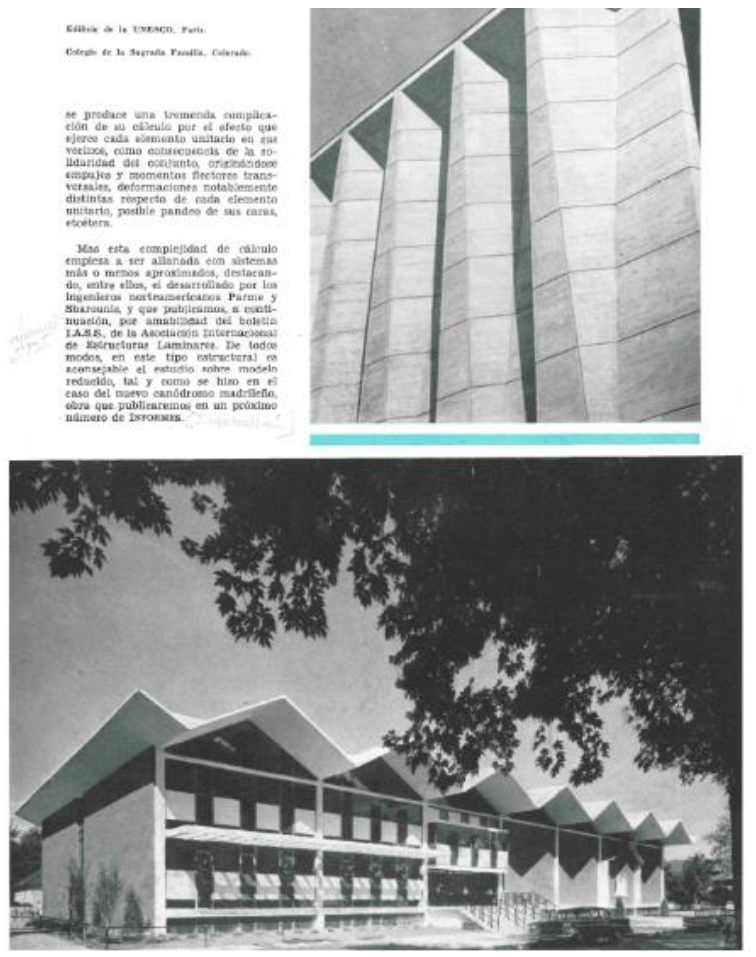

En el artículo Estructuras Plegadas, Fernando Cassinello hace una abierta defensa de la libertad creativa que confieren las delgadas láminas plegadas de hormigón armado, las cuales "son capaces de adaptarse a formas que hasta ahora sólo fueron soñadas en las mentes de arquitectos, ingenieros y proyectistas". Gracias a su ligereza y capacidades estructurales, podían salvar grandes luces y vuelos, y de producir además "el asombro y la sorpresa ante obras de una belleza nueva, dinámica y estructural $y$, a la vez, pura y desnuda de aditamentos decorativos y ornamentales". ${ }^{137}$

176. Estructuras Plegadas. 1961. Pág. 3

Cassinello destaca que la complejidad del cálculo estructural no parece ser un impedimento a su uso, sino más bien "los prejuicios estéticos ante una nueva forma que iba a romper con las doctrinas y moldes en boga". Y es aquí donde debemos detenernos en la cita para resaltar una sorprendente mención que realiza Cassinello al "triunfo espectacular de la arquitectura agresiva, personal y dinámica de Wright" pues sin mostrar ejemplo alguno en el artículo, el autor reconoce en Wright algunos méritos que plantean una revisión de la obra de Wright para descubrir nuevos matices expresivos. Como veremos en un capítulo de la presente tesis, los pliegues de pequeña escala del mobiliario y luminarias diseñados por Wright, como los proyectos con patrones triangulares y delgadas láminas plegadas, forman una característica destacada de algunas de las obras del maestro.

El autor también ve una referencia a la "estética lineal y geométrica de las grecas griegas" y los mosaicos y atauriques árabes, destacando que esta nueva estética "ha venido a dar nueva expresión y movimiento a los limpios y puros volúmenes racionalistas, puristas y neoplásticos, en los que el ángulo agudo y la línea inclinada no tenía lugar en su invariable credo de paralelismo y ortogonalidad. La lámina plegada se impone y marca la transición de la ortogonalidad a la curva; de la placa a la bóveda; del estatismo al dinamismo propio de una estética estructuralista y sincera."Para Cassinello, que incluirá en 1974 un capítulo titulado Láminas Plegadas ${ }^{138}$ en el libro Construcción. Hormigonería, "la aplicación de estructuras plegadas en cubiertas, marquesinas, voladizos, muros, etc., ha permitido ya la realización de múltiples ejemplos, en los que se evidencia la idoneidad del sistema desde el punto de vista constructivo, estructural y plástico, a la vez que, al cumplir satisfactoriamente las exigencias funcionales y económicas de cada obra, marcan un nuevo camino de sugestivas metas."

\footnotetext{
${ }^{137}$ Cassinello, F. (Noviembre de 1961) Estructuras plegadas. Informes de la Construcción. Vol. 14, n 135 (sin paginación) ${ }^{138}$ Cassinello, Fernando (1974) Láminas plegadas. En Construcción. Hormigonería, 537-542. Ed. Rueda. Madrid.
} 
Arquitecturas fantásticas, visionarias y prototipos. 1962
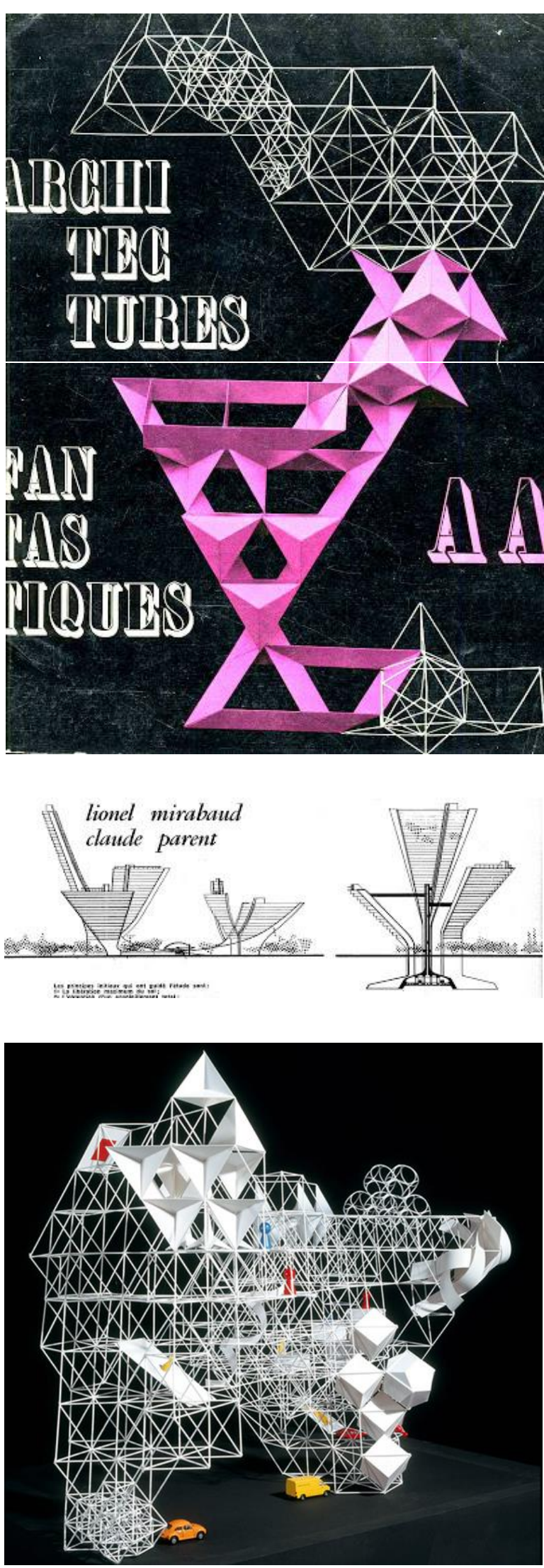

La revista mensual francesa AA L'Architecture D'Aujourd'Hui ${ }^{139}$ publicó en 1962, el número 102 especial dedicado a las Arquitecturas Fantásticas. La revista estaba dirigida en ese momento por André Bloc y destacaba su prestigioso consejo editorial entre los que se incluían Jean Prouvé, Edouard Albert y Claude Parent. Entre los proyectos publicados se incluían obras visionarias de arquitectos como Antonio Gaudí, Frei Otto, Pascal Haüsermann, Yona Friedman, Constant Niuwenhuys y Paul Maymont. Arquitecturas colonizantes, conectoras entre edificios preexistentes. Arquitecturas cinéticas con estructuras móviles, transportables y multiusos. Arquitecturas efímeras inflables, neumáticas y de pvc.

177. Portada de la revista Architecture D'Aujorud'Hui n¹02. 1962.

178. Principios de Urbanismo de Claude Parent y Lionel Mirabaud

En la revista también se habla del concepto Raumstadt de "ciudad espacial", un sistema de empleo de estructuras espaciales por el que pueden prácticamente continuarse indefinidamente en todas las direcciones. Un montaje de enrejados tridimensionales, formado por tetraedros y por octaedros, dividirá el espacio. Los ensamblajes, flexibles, se adaptarán al lugar y a la función y los espacios serán modulables y subdivisibles gracias a las posibilidades de las láminas plegadas.

179. Raumstadt, 1959

Autor: Eckard Schulze-Fielitz

Construido: no

Fuente: http://www.efimeras.com/wordpress/?p=260

${ }^{139}$ Fuente: http://www.larchitecturedaujourdhui.fr/aa-retro-2/ 
Como ejemplo de publicaciones de arquitecturas fantásticas, visionarias y prototipos también podemos destacar el número 300 de la revista Casabella ${ }^{140}$ de diciembre de 1965, el cual dedica la portada al proyecto "The Universal House" diseñado por los arquitectos McHale y Sadao. La casa universal es un estudio preliminar de casa prefabricada para la industria americana inspirado en los requerimientos necesarios para una vivienda universal establecidos por R. Buckminster Fuller.
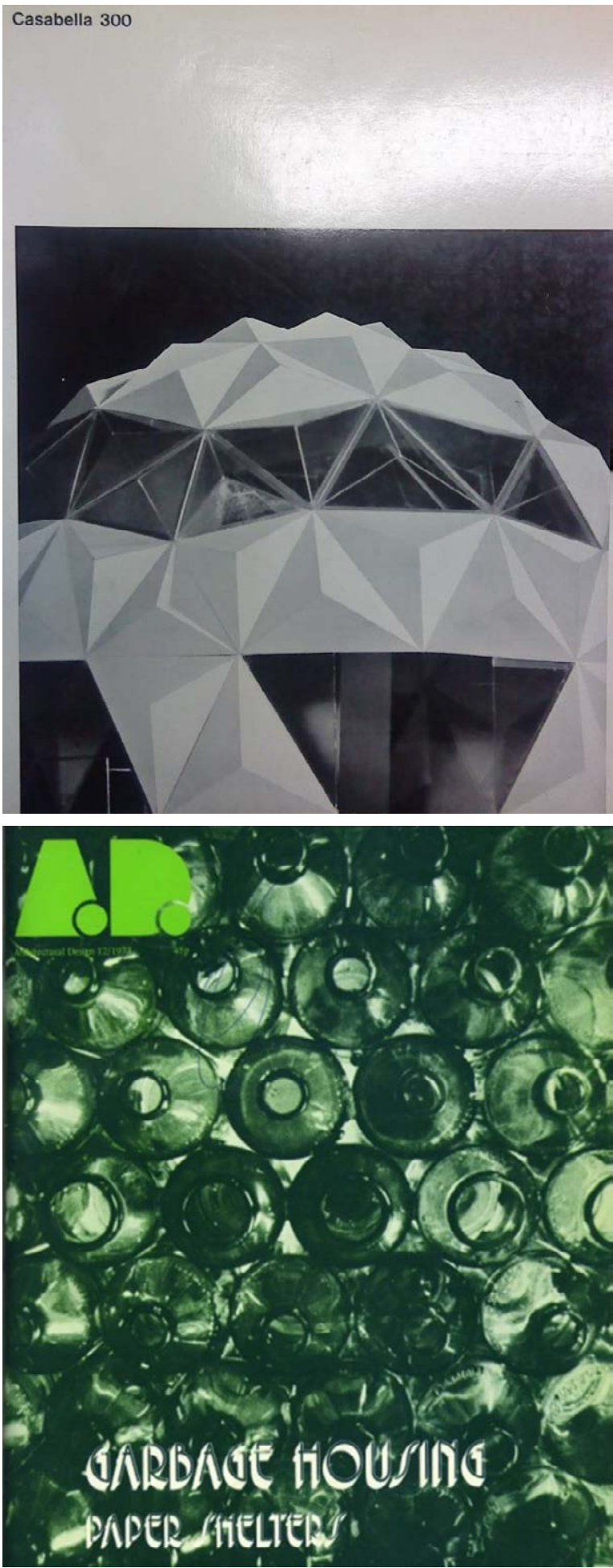

Entre las páginas 36 y 50 de la revista se presenta un artículo titulado Industrializzazione degli edifici (literalmente industrialización de los edificios) firmado por G.M Oliveri, que reflexiona acerca de la industrialización en la construcción analizando el estado actual y el camino recorrido con varios ejemplos. Atendiendo a los errores que se cometen, indica el camino a seguir para evolucionar en el mundo de la construcción industrializada y conseguir la "arquitectura de catálogo". Mostrando ejemplos de obras de B. Fuller y Le Corbusier.

180. La casa universal. 1965

Arquitectos McHale y Sadao. Prototipo. Fotografía: Marco Covi/Electa/Mondadori Portada de la revista Casabella $n^{\circ} 300$

Dando un salto en el tiempo, nos debemos situar en la década siguiente para señalar la publicación Paper Shelters (refugios de papel) de 1973 del número 12 titulado Garbage Housing (viviendas de basura o con basura) de la revista Architectural Design para mostrar unos extraordinarios prototipos diseñados por el arquitecto Vinzenz Sedlak de viviendas de emergencia ligeras y modulares realizadas en cartón.

181. Architectural Design $n^{\circ}$ 12. 1973.

Portada. Garbage Housing. Paper Shelters.

${ }^{140}$ Aa.Vv. (Dic. 1965) 'Casabella, No. 300. 20th century, Arnoldo Mondadori Editore, Milan, 28 x $31 \mathrm{~cm}$ Fuentes: http://www.aiap.it/cdpg?ID=7720\&IDsubarea=169\&IDsez=185\#top http://casabellaweb.eu/wp/the-magazine/yearannata-1965-xix/ 
La revista ${ }^{141}$ está dedicada a viviendas experimentales y alternativas, destacando el artículo Paper Shelters, donde V. Sedlak explora profundamente las posibilidades formales de láminas de cartón en configuración de patrones de pliegue yoshimura inicialmente, a los que irá añadiendo variaciones del patrón fishbone y cartelas de rigidización que impedirán el movimiento y las posibilidades desarrollables finales de la figura. El proyecto de Sedlak destacará también por proponer diferentes posibilidades de combinación de módulos mediante transformaciones del patrón en las intersecciones entre estos.
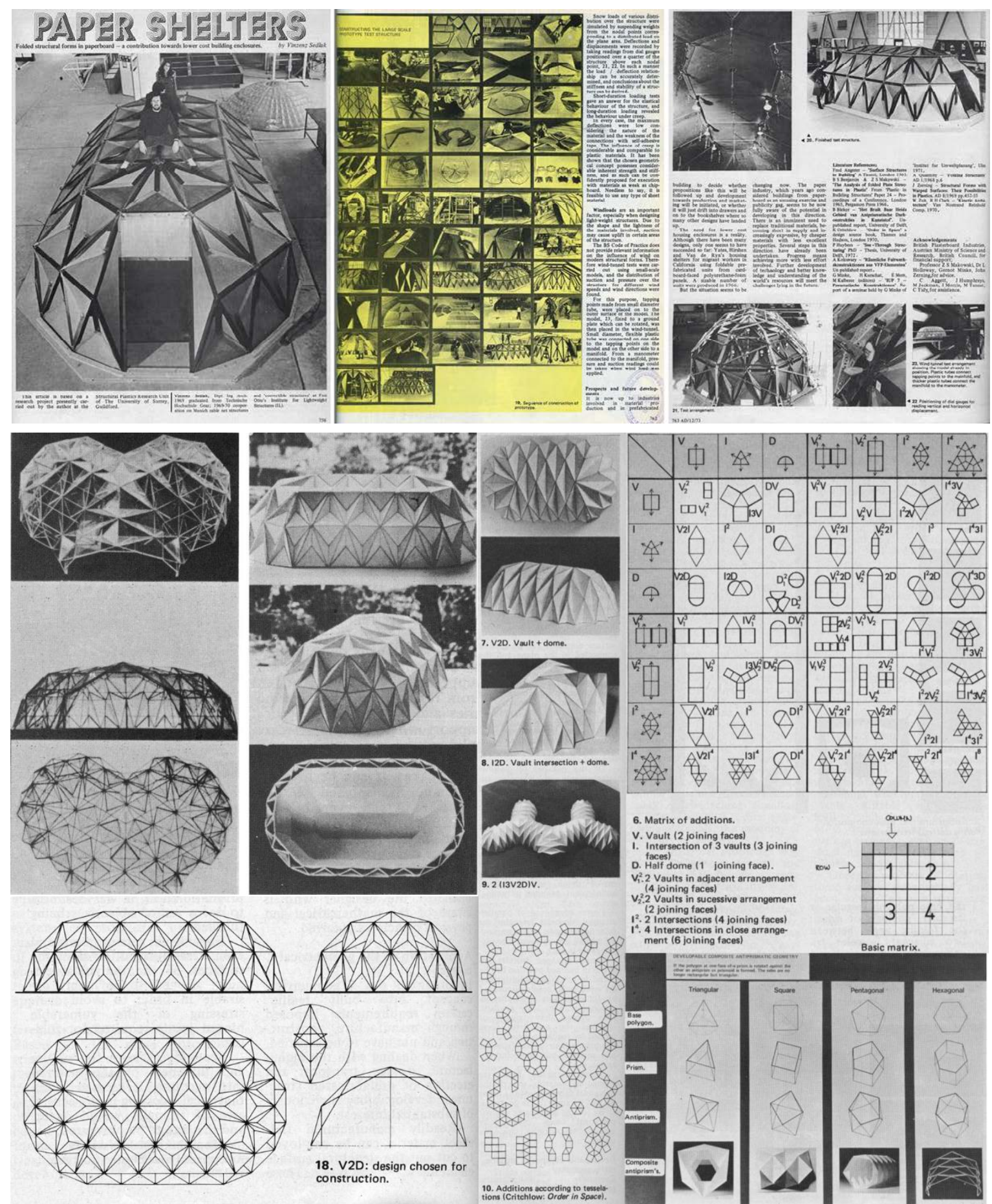

182. Paper Shelters. Architectural Design n¹2. 1973.

Páginas interiores y detalles del artículo.

\footnotetext{
${ }^{141}$ Sedlak, Vinzenz (1973) Paper Shelters. Architectural Design n¹2. Garbage Housing.
} 


\subsubsection{El pliegue moderno y su divulgación en textos didácticos.}

Construcción Laminar. Fred Angerer. 1960

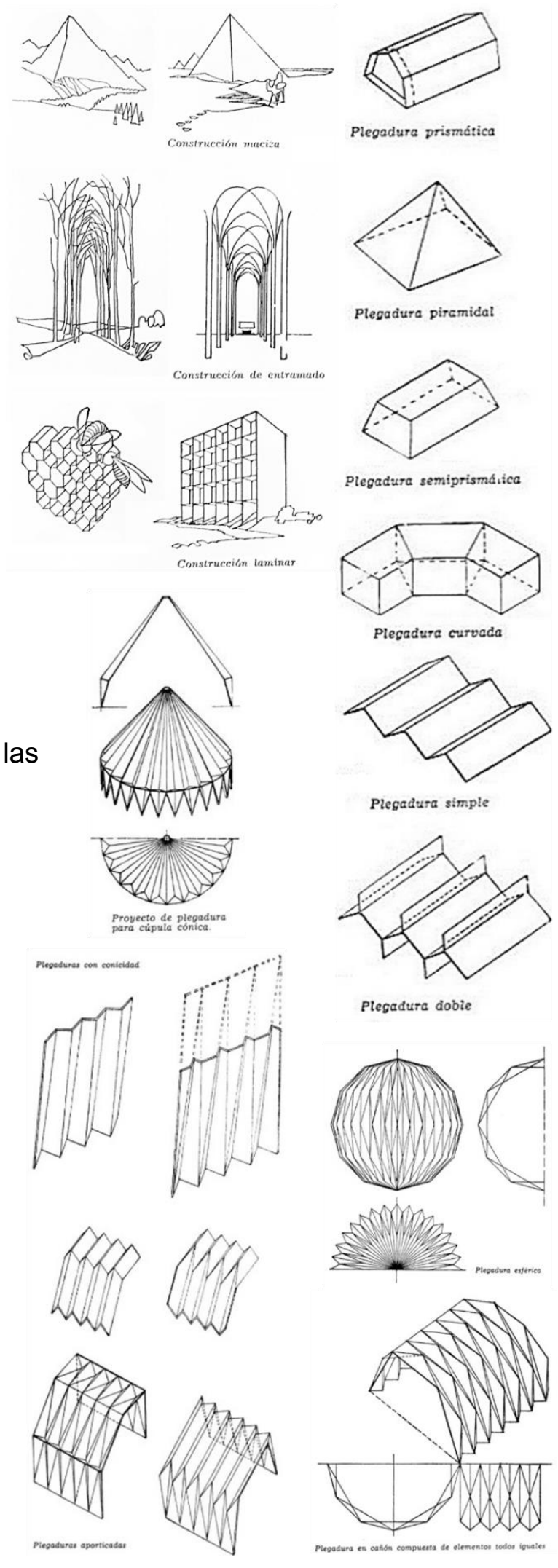

Publicada por primera vez en alemán en 1960 y en español en 1972, la publicación de Fred Angerer ${ }^{142}$ arrojaba luz sobre un concepto, el de las láminas de hormigón armado, que requería ser definido en profundidad dado el amplio desarrollo que había tenido en la década de los 50 y el previsible éxito que mantendría en la siguiente década. Angerer distinguirá entre construcciones macizas, de entramado y laminares. Destacando que, al contrario de las construcciones macizas donde no existe relación entre el aspecto exterior y el espacio interior, las construcciones laminares expresan en su espacio interior el orden exterior que las conforma. Además establecerá una clasificación de las plegaduras en prismáticas, piramidales, semipiramidales, curvadas, simples y dobles. También incluirá en otro capítulo plegaduras derivadas de poliedros regulares y las de cáscaras y superficies curvas. De estas plegaduras la única desarrollable (desplegable en una sola superficie continua) es la que considera plegadura simple, que también llamará en zig-zag, y que no es más que el pliegue en acordeón o plisado. El resto se construirán geométricamente mediante el pliegue $y$ unión de diferentes superficies planas.

Angerer llamará también plegaduras en cañón y esféricas a las realizadas con el patrón yoshimura, definiendo variaciones de este patrón como plegadura para cúpula cónica, plegaduras con conicidad y plegaduras aporticadas entre las que se encuentran los patrones yoshimura extendido y acordeón.

183. Construcción Laminar. Fred Ángerer. 1960 Detalle de las páginas 1, 42, 75, 76, 77

142 Angerer, Fred, (1972. $1^{\text {a }}$ Ed. Bauten mit tragenden flächen konstruktion und gestaltung, 1960). Construcción laminar. Elementos y estructuración. Edit. Gustavo Gili. Barcelona. 
Sistema de estructuras. Heino Engel. 1964

Sistemas de estructuras Heino Engel

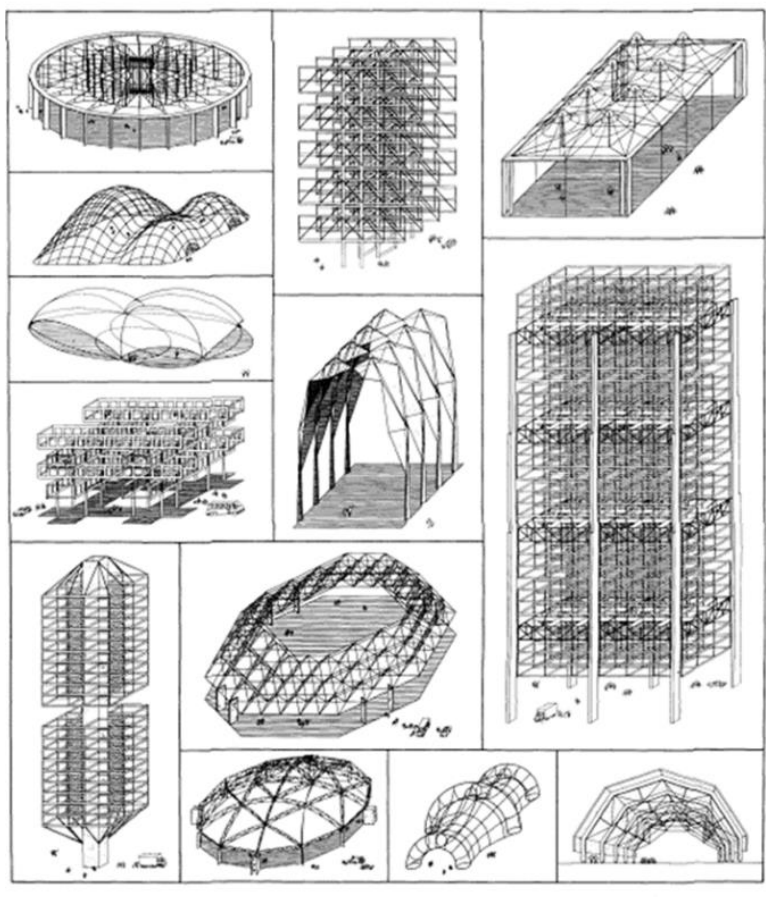

GG
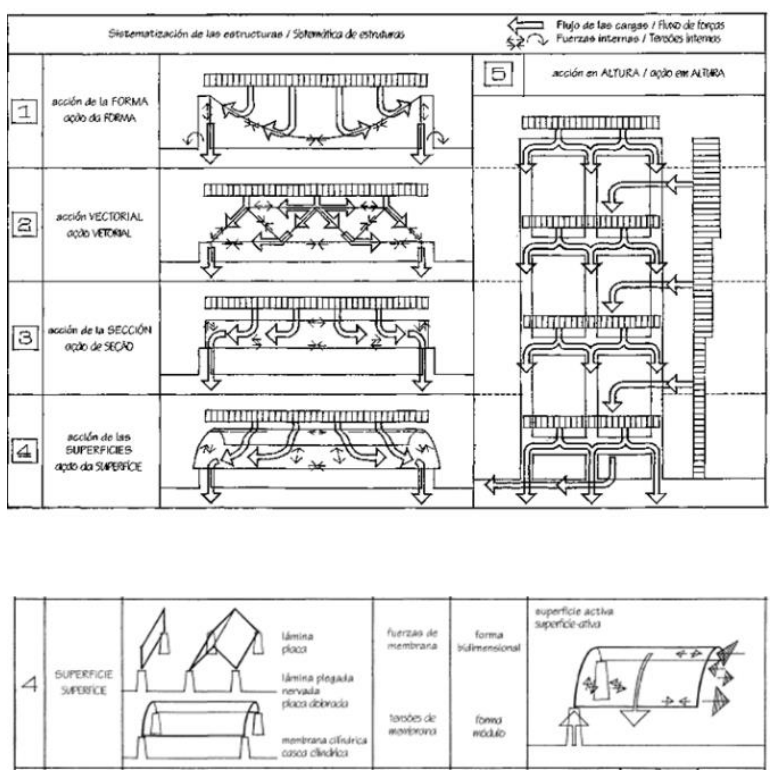

Rigurosamente ordenado y articulado en fichas y secciones, el libro Sistemas de estructuras $^{143}$ de Heino Engel recoge las conferencias, lecciones e investigaciones que sobre estructuras Engel había estado impartiendo en EEUU durante la década precedente. Presenta los diferentes sistemas de estructuras mediante series de dibujos y pequeñas descripciones que permiten comprender, sin entrar en cálculos numéricos y de forma rápida $\mathrm{e}$ intuitiva, cómo funcionan las estructuras, a qué esfuerzos se ven sometidas y cómo definen $y$ se relacionan con la forma arquitectónica.

Engel expone una serie de criterios para la elaboración de una sistematización de las estructuras según su función de transmisión de cargas o fuerzas y según las estrategias que adoptan. De este modo establece una clasificación según las estructuras que: (1) se adaptan a las fuerzas con una acción de la forma como las estructuras de cables, neumáticas y arcos, (2) subdividen las fuerzas con acción vectorial como las cerchas y las mallas, (3) confinan las fuerzas con una acción de la sección de forma transversal como las vigas y pórticos (4) buscan la dispersión de las fuerzas mediante una acción de las superficies como las estructuras laminares y (5) recogen y transmiten las cargas al suelo en forma de acción en altura como los pilares y rascacielos.

184. Sistemas de Estructuras. Engels 1964

Portada y diagramas de cargas o fuerzas sobre el sistema de clasificación y sistematización de las estructuras

\footnotetext{
${ }^{143}$ Engel, Heino (2015, $1^{\text {a }}$ edición 1964, Tragsysteme) Sistemas de estructuras. Trad. Fernando de Aguirre e Yraola, Juan Batanero García/Geraldo. Edit. Gustavo Gili. ISBN: 9788425218002
} 


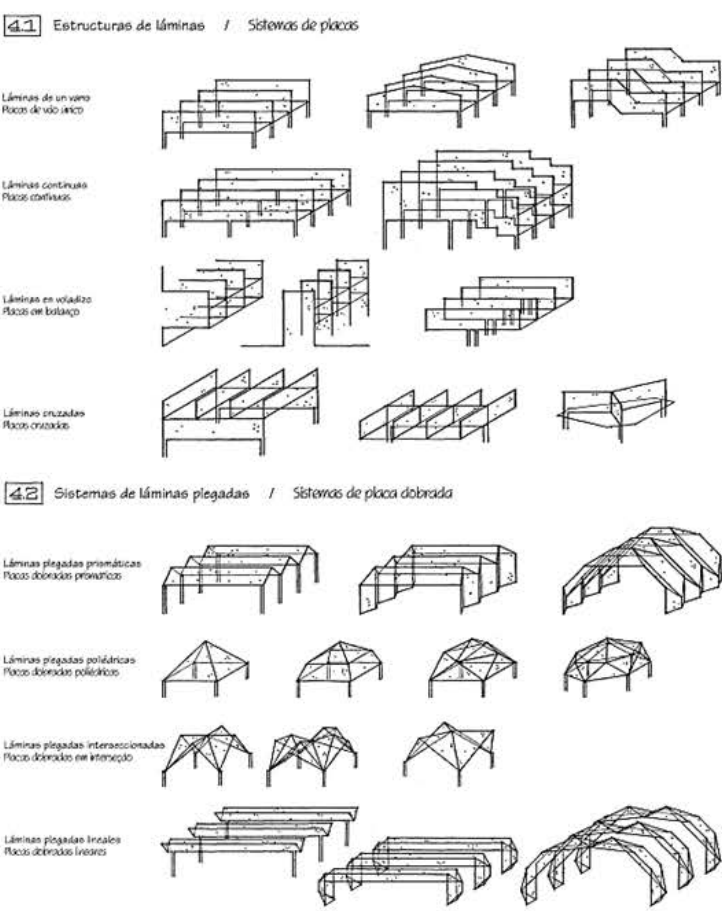

43 Estructuras de membrana I Ststewos de cosca
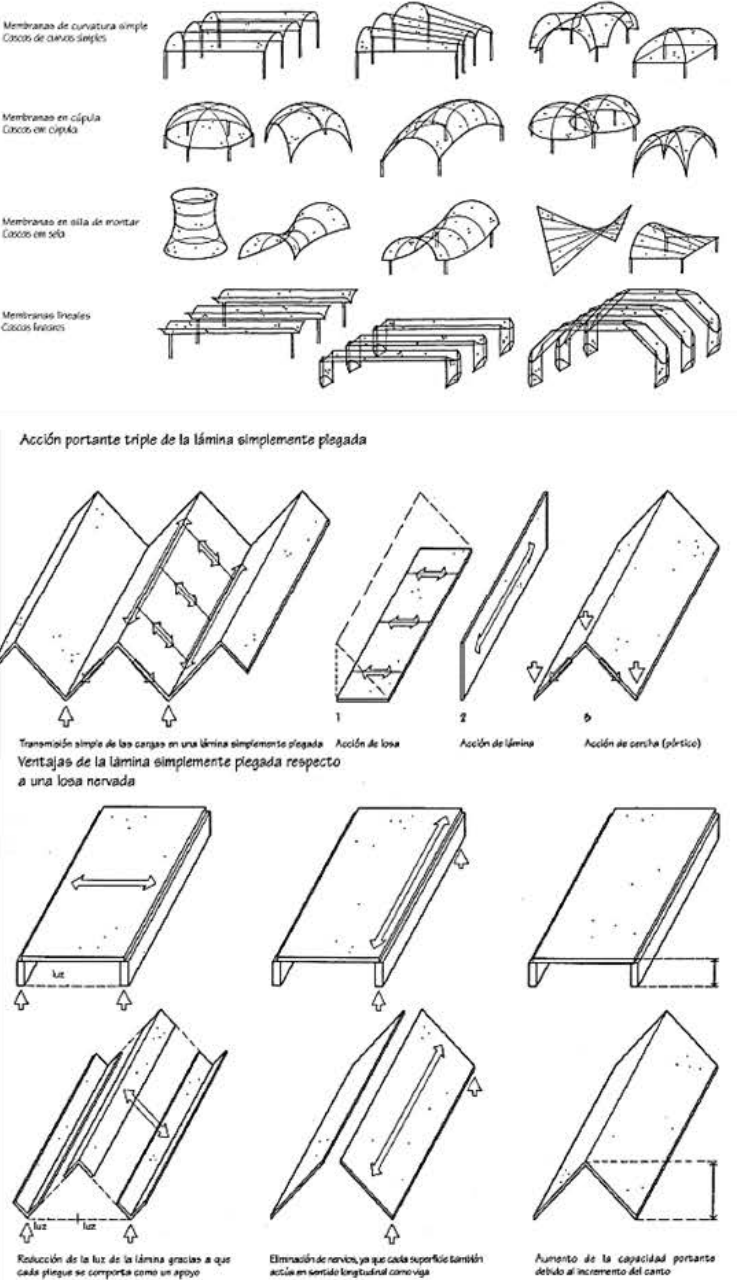

Las superficies "activas" son sistemas de superficies flexibles, pero resistentes a tracciones, compresiones y esfuerzos cortantes, en los que la transmisión de fuerzas se realiza a través de la resistencia de las superficies y una determinada forma de éstas. Engel a su vez las divide entre estructuras de láminas, estructuras de láminas plegadas 0 plegaduras $y$ estructuras de membranas que comprenden las superficies de curvatura simple, en silla de montar y las lineales que serán una variante de las de curvatura simple pero en disposición cóncava en vez de convexa. Las láminas plegadas las subdividirá también en prismáticas, poliédricas, interseccionadas y nuevamente lineales. (p.52)

Aunque se aprecia en estas nomenclaturas un cierto afán organizador, es posible afinar la clasificación, pues en el propio desarrollo de los ejemplos del libro, Engel no distinguirá entre prismáticas y lineales. Al igual que pasará con la división hecha con las superficies curvas, donde parece haber una cierta confusión entre la curvatura simple y la lineal. Quizás una clasificación más adecuada sería la que utilizara los términos y definiciones de la geometría. Distinguiendo entre láminas curvas cilíndricas, cónicas, esféricas, alabeadas y regladas, a las que habría que añadir las intersecciones y combinaciones entre éstas que darían lugar a algunos patrones conocidos del origami curvo. También esta clasificación podría realizarse entre las superficies planas plegadas, donde cabría distinguir entre los diferentes patrones de origami, las formas prismáticas, las poliédricas y las múltiples intersecciones entre ellas.

\section{Superficies activas}

Estructuras de Láminas, Láminas plegadas (plegaduras) y estructuras de membrana o de superficies curvas, alabeadas y regladas. 
Engel define las tres acciones portantes combinadas que realiza una lámina plegada: Acción de losa, acción de viga o lámina en posición vertical y acción de cercha. Además expone las ventajas que a su juicio tiene una lámina con un plegado simple respecto a una losa nervada: reducción de la luz de la lámina gracias a que cada pliegue se comporta como un apoyo, eliminación de nervios, ya que cada superficie también actúa en sentido longitudinal como viga, y aumento de la capacidad portante debido al incremento del canto.

Con 30 patrones de estructuras de láminas plegadas, descritos en planta, alzado, perfil y perspectiva caballera, la publicación de Engel supone la primera catalogación y exploración rigurosa y detallada de las posibilidades formales y estructurales en torno a las geometrías derivadas del pliegue de superficies planas y su aplicación en la arquitectura.
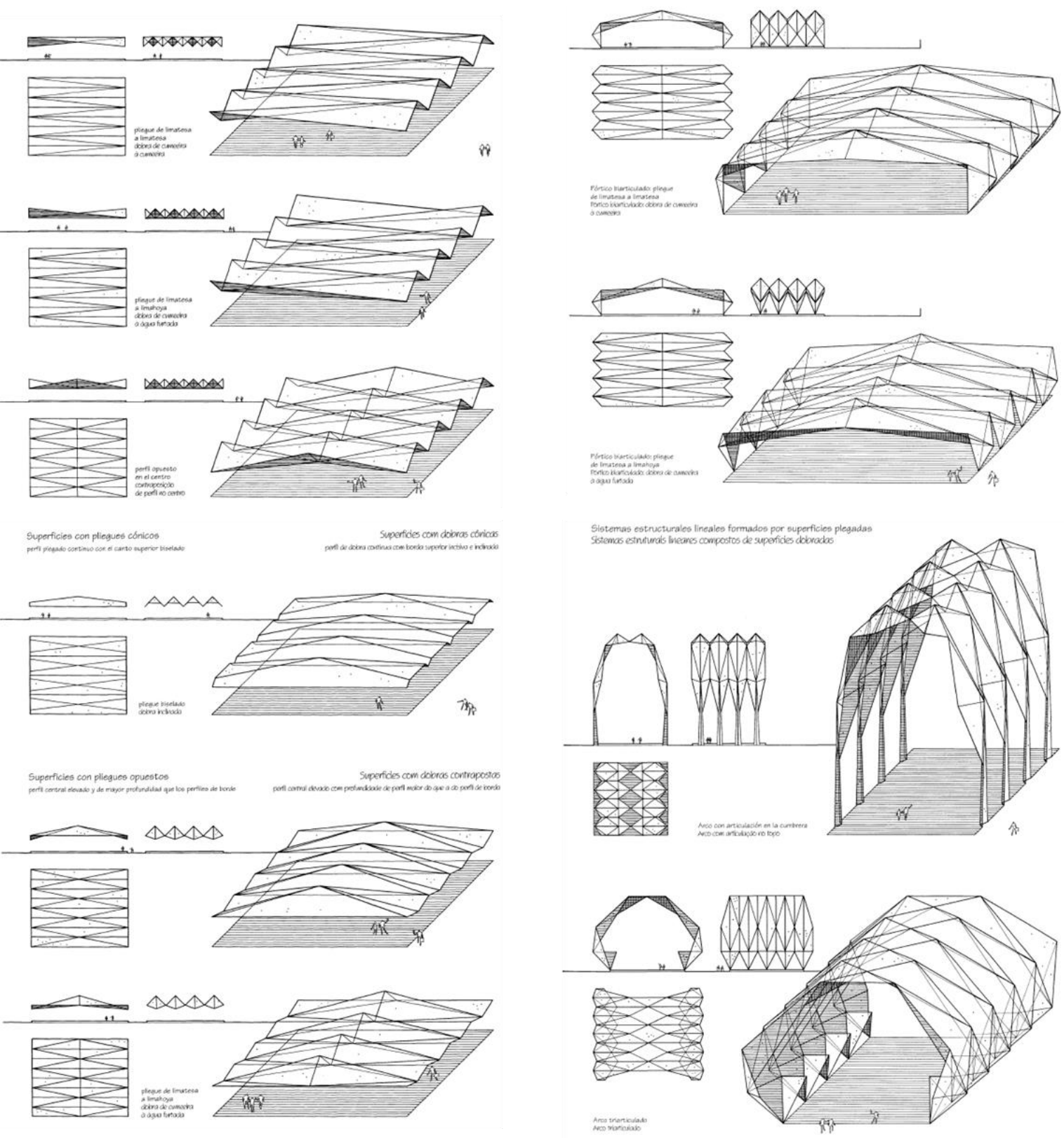

186. Superficies plegadas.

Engel, H. (2015) Sistemas de estructuras. Ed. Gustavo Gili. páginas 222, 223, 225, 227 
Why Buildings stand up. Mario Salvadori. 1980

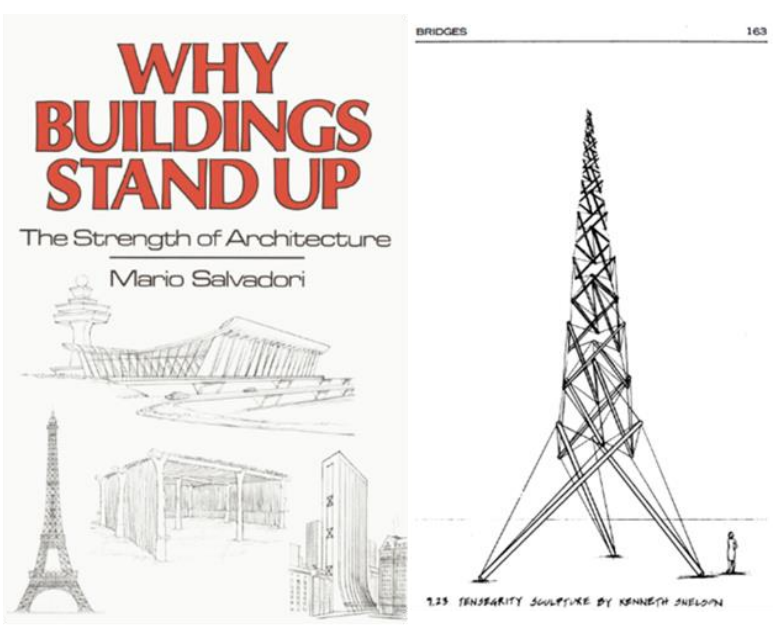

Mario G. Salvadori (1907-1997) fue profesor emérito de Arquitectura de Columbia University, miembro honorario del American Institute of Architects y profesor de Estructuras Arquitectónicas en Princeton y Columbia. Como nos cuenta su amigo Umberto Eco en el artículo "Recuerdos de un hombre recto", durante los dos o tres últimos decenios de su existencia se dedicó a enseñar a los niños de los barrios pobres de Nueva York enseñanzas introductorias que les ayudaran a entender, sin necesidad de

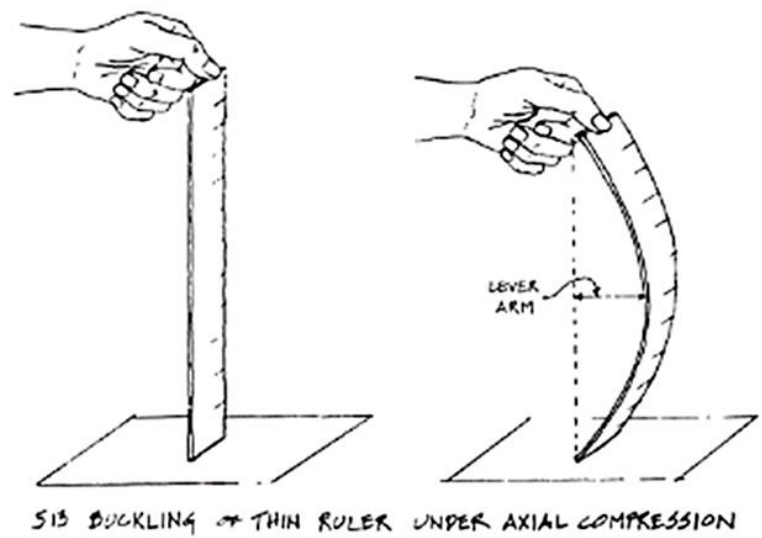
fórmulas complejas, el mecanismo estructural básico de los edificios: "Mostrando a los alumnos una hoja de papel, la sostenía por un extremo de tal modo que esta se doblaba, luego al encorvarla un poco, no sólo se mantenía, sino que podía sostener cualquier cosa más pesada. Para explicar por qué se mantienen los balcones, utilizaba una caja de fósforos vacía, demostrando hasta qué punto podía abrirse antes de que se derrumbara el balconcito así creado" ${ }^{144}$.

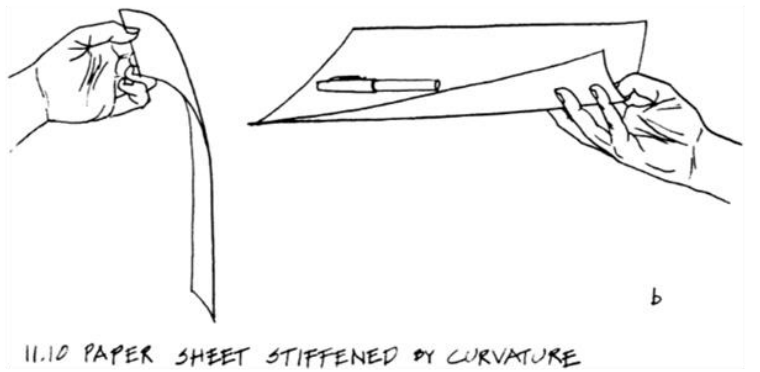

A partir de estos ejemplos gestó un discurso pedagógico que dio a luz en el libro Why buildings stand up: the strength of architecture, que podríamos traducir por: Por qué los edificios se sostienen: la fuerza de la arquitectura, en este libro Salvadori trazó la evolución histórica de las estructuras arquitectónicas, desde simples tiendas de campaña de los nómadas a la Torre Sears. Explicando de
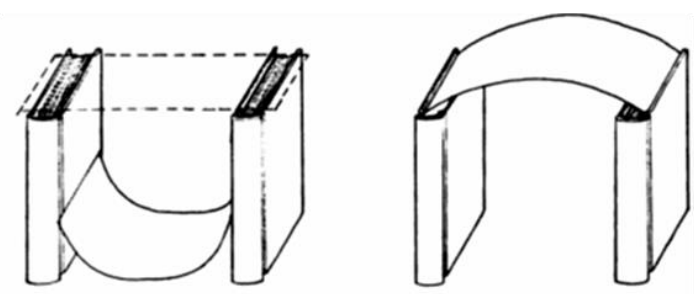

11.12 PAPER SHEET STIFFENED OY CYLINDRICAL SHAPE forma directa y sencilla las relaciones entre forma, estructura y capacidad resistente.

187. Why buildings stand up

Portada, página 163 e ilustraciones de detalle de las páginas 86,187 y 183

${ }^{144}$ Eco, Umberto. (1997-10-5). Recuerdos de un hombre recto. Revista La Nación. 

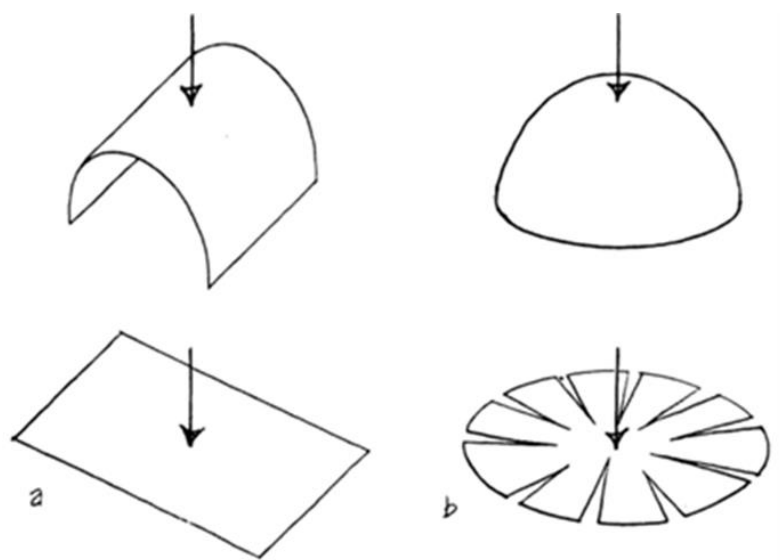

11.5

DEVELOPABLE (a) AND NON-DEVELPPABLE (b)SURFACES

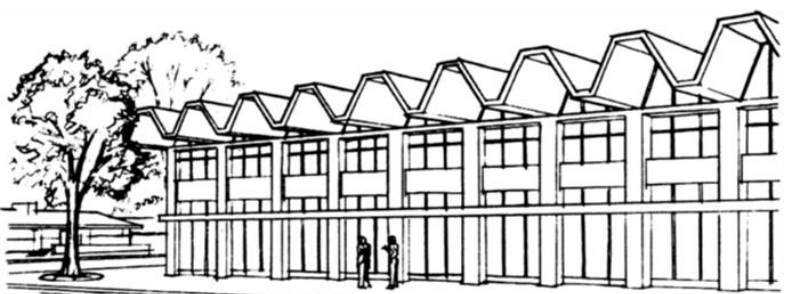

188. Why buildings stand up

Ilustraciones detalle de las Páginas 188 y 192, y páginas completas 193 y 194.

También dedica varias páginas a explicar las estructuras laminares y las estructuras plegadas, definiendo gráficamente de forma muy clara la diferencia entre estructura desarrollable y no desarrollable. Para Salvadori una de las ventajas de la construcción de cubiertas laminares plegadas es que no requieren prácticamente ningún encofrado, ya que las losas planas pueden ser vertidas en el suelo y articuladas en los valles $\mathrm{y}$ crestas de la cubierta, conectando la armadura de las losas transversalmente y utilizando un mortero o lechada de cemento de calidad para dar continuidad a las losas. ${ }^{145}$

II. 16 FOLDED-PLATE ROOF

FORM-RESISTANT STRUCTURES

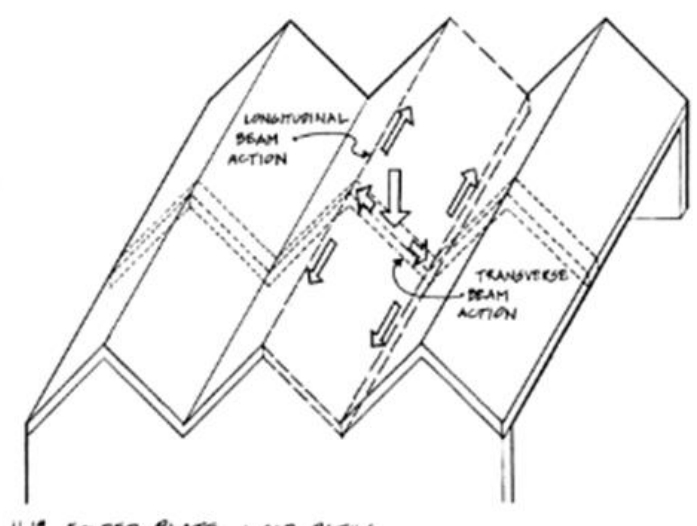

11.19 FOLDD-PLATE LOAD PATHS

Folded plates carry loads to the supports along a twofold path. Because of the stiffness achieved by the folds, any load acting on a slab travels first up the nearest nidge or down the nearest valley, and then is carried to the end supports longitudinally by the slabs acting as beams (Fig. 11.19). Folded plates must be supported at their ends. Since they consist of flat surfaces and folds they act like an accordion that can be pushed in or pulled out with little effort, and do not develop out-pushing thrusts.

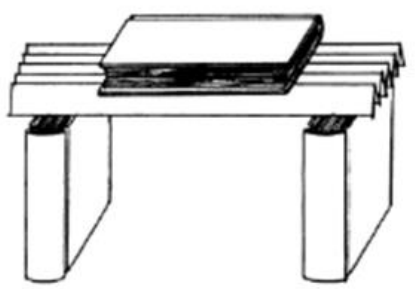

1.20 FOLDED-PLATE PAPLR MODEL
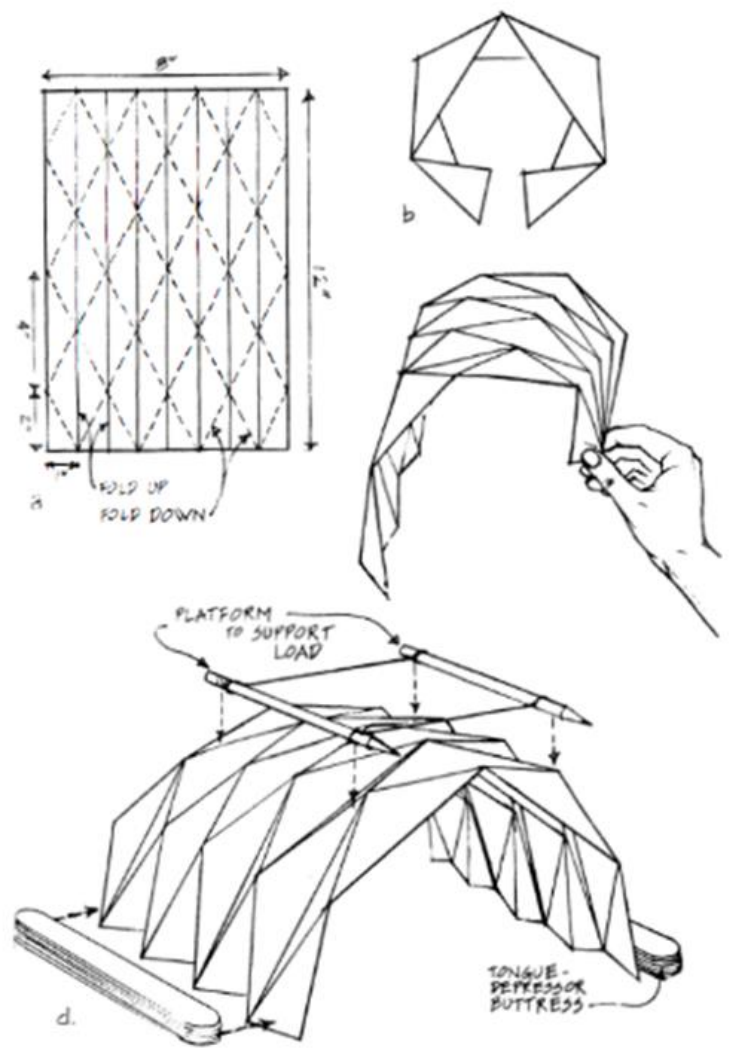

11.21 CREABED PAPER BARKEL

\footnotetext{
${ }^{145}$ Salvadori, Mario (1980) Why buildings stand up: the strength of architecture. W. W. Norton. New York. p.193
} 
Folding Architecture; Spatial, Structural and Organizational Diagrams. 2003

Desde que la autora Sophia Vyzoviti publicara en el 2003 la primera edición hasta el año 2009 se han publicado 10 ediciones de este libro que se ha convertido en un verdadero éxito de ventas en el segmento de las publicaciones relacionadas con el pliegue arquitectónico. El libro Folding Architecture; Spatial, Structural and Organizational Diagrams ${ }^{146}$ hace referencia a la arquitectura plegada, y a los diagramas espaciales, estructurales y organizativos que le dan forma, y recoge los trabajos realizados por ella y sus alumnos en los talleres que realizó, como docente invitada al curso de diseño arquitectónico D10 del profesor Hans Cornelissen, en la Escuela de Arquitectura de la Universidad Técnica de Delft - TU Delft-.
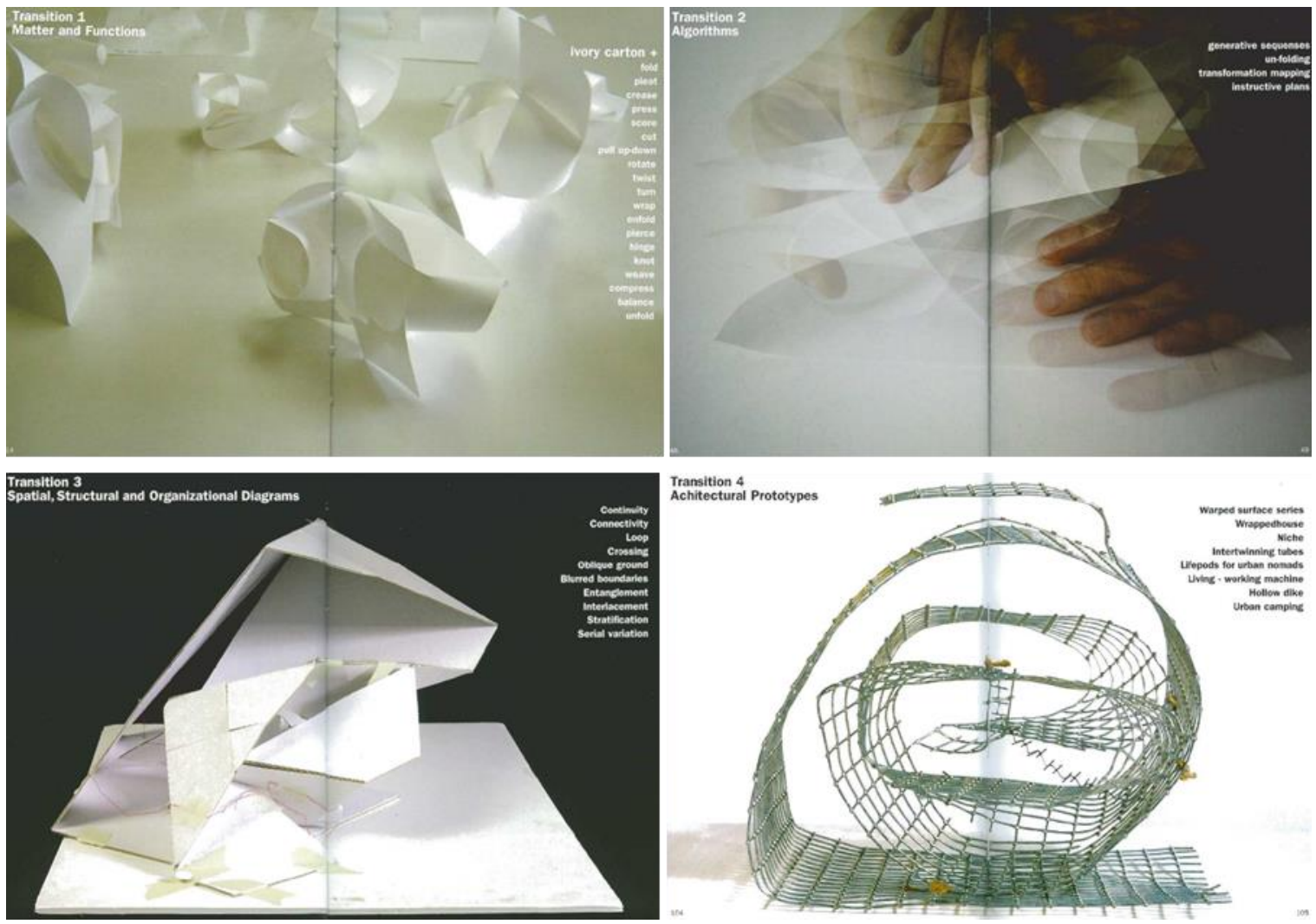

189. Folding Architecture. Transitions

Vyzoviti entiende el plegado como un proceso de generación de diseños arquitectónicos esencialmente experimental: agnóstico, pues no se vincula a ningún estilo y no lineal, pues no sigue un desarrollo racional ordenado y previsible. El documento trata de mostrar el proceso de génesis de la forma y la secuencia de transformaciones que afectan al diseño del objeto. Considerando esto como un desarrollo abierto y dinámico en el que el diseño evoluciona alternando periodos de desequilibrio, podemos apreciar la función del plegado como un generador de diseño con varias fases de transición, esto es, puntos críticos donde las transformaciones de calidad ocurren. Dando varios cortes al proceso continuo de creación del estudio-taller, Vyzoviti presenta cuatro fases de transición en el proceso de diseño y exploración formal: materia y funciones, algoritmos, diagramas espacialesestructurales-organizativos y prototipos arquitectónicos.

\footnotetext{
${ }^{146}$ Vyzoviti, Sophia (2003) Folding Architecture. Spatial, Structural and Organisational Diagrams. BIS Publishers.
} 
La transición 1: Materia y Funciones, se presenta en formato de trabajos realizados con cartulina, para la autora, la quintaesencia del material plegable, pues tiene capacidad resistente y estructural a la vez que flexibilidad y facilidad para el pliegue. La tarea de esta primera transición era explorar todas las transformaciones posibles que se le podrían producir a una simple hoja de papel para crear volumen con una sola limitación, mantener la continuidad del material. Las acciones descritas son sencillas y cercanas a respuestas intuitivas: plegar, comprimir, arrugar, plisar, arañar, marcar, cortar, tirar, rotar, retorcer, revolver, estrujar, agujerear, articular, anudar, tramar, entrelazar, serpentear, apretar, desplegar. Una vez realizadas las acciones el papel plegado se convierte en un diagrama de acciones, se constituye como una nueva realidad que introduce la investigación arquitectónica en un nuevo campo de estudio.

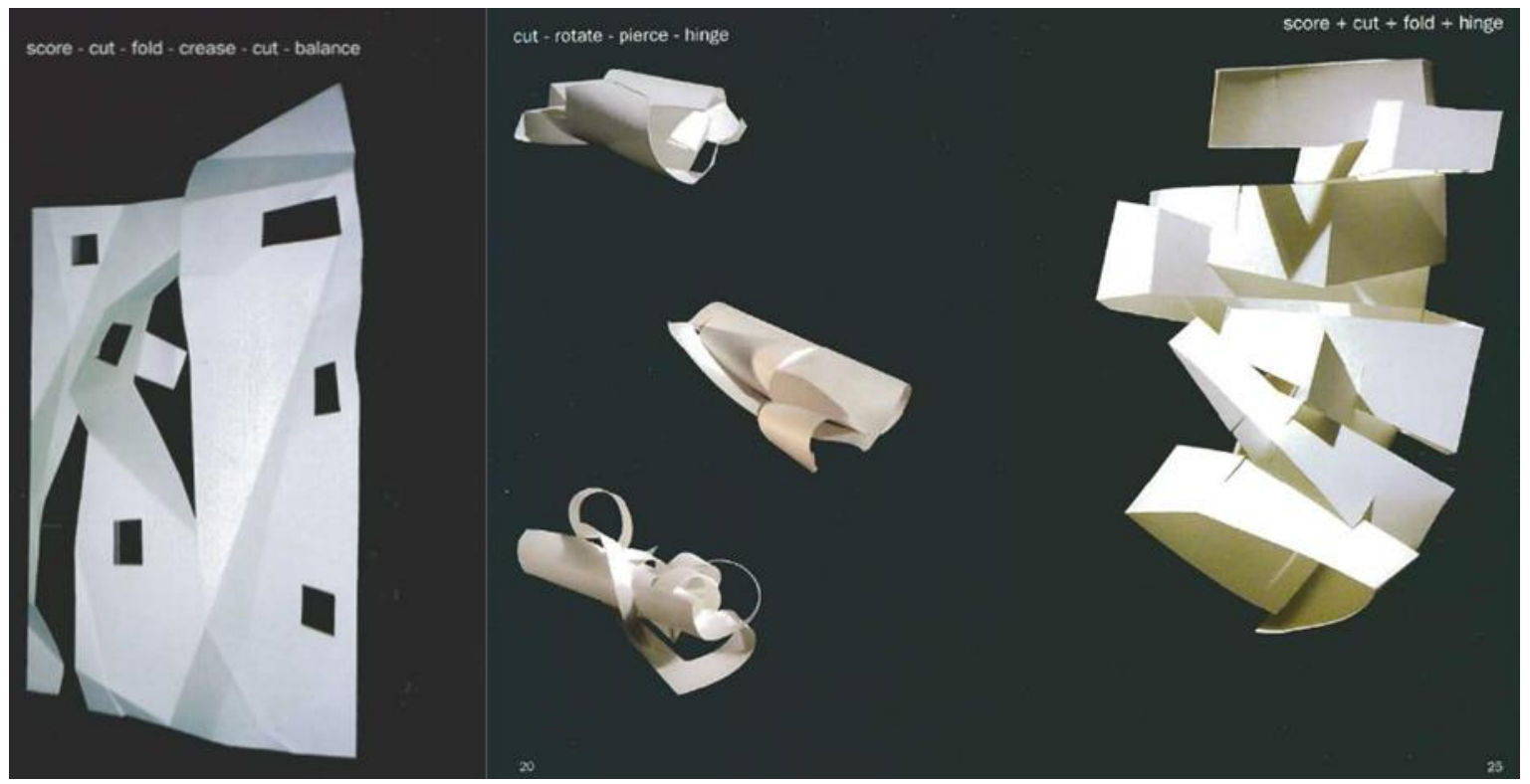

190. Folding Architecture. Primera transición: funciones

La transición 2: Algoritmos, muestra el papel plegado como un artefacto dinámico, inestable y en evolución. Desnuda los trazos de la actividad que lo ha creado: marcas, pliegues e incisiones que se dibujan en la superficie del papel. Desplegado, se convierte en un mapa de su proceso de creación. Con repetidas acciones de plegado se evoluciona de las iniciales respuestas intuitivas hacia técnicas primarias: triangulaciones, refuerzos, pliegues estratificados, pliegues entre pliegues, patrones de tiras, curvas, espirales o meandros. La manipulación de la superficie de papel para producir volumen constituye un enunciado de actividad, un programa que para ser realizado ha necesitado de una secuencia de acciones, técnicas, despliegues, mapas de transformación, que son codificados aquí como un algoritmo que debe ser documentado.

La transición 3: Diagramas espaciales, estructurales y organizativos, requiere de la necesaria labor de mapear la superficie trabajada, de explorar y definir sus diagramas del programa de necesidades y de relaciones topológicas entre los espacios: proximidad, separación, sucesión y continuidad espacial exterior e interior.

La transición 4: Prototipos arquitectónicos, busca atribuir propiedades arquitectónicas introduciendo parámetros de materialidad, programa y contexto. Vyzoviti lo definirá como los diagramas espaciales, estructurales y organizativos que han adquirido "sustancia arquitectónica". 
The Function of Form and Ornament. Farshid Moussavi. 2009
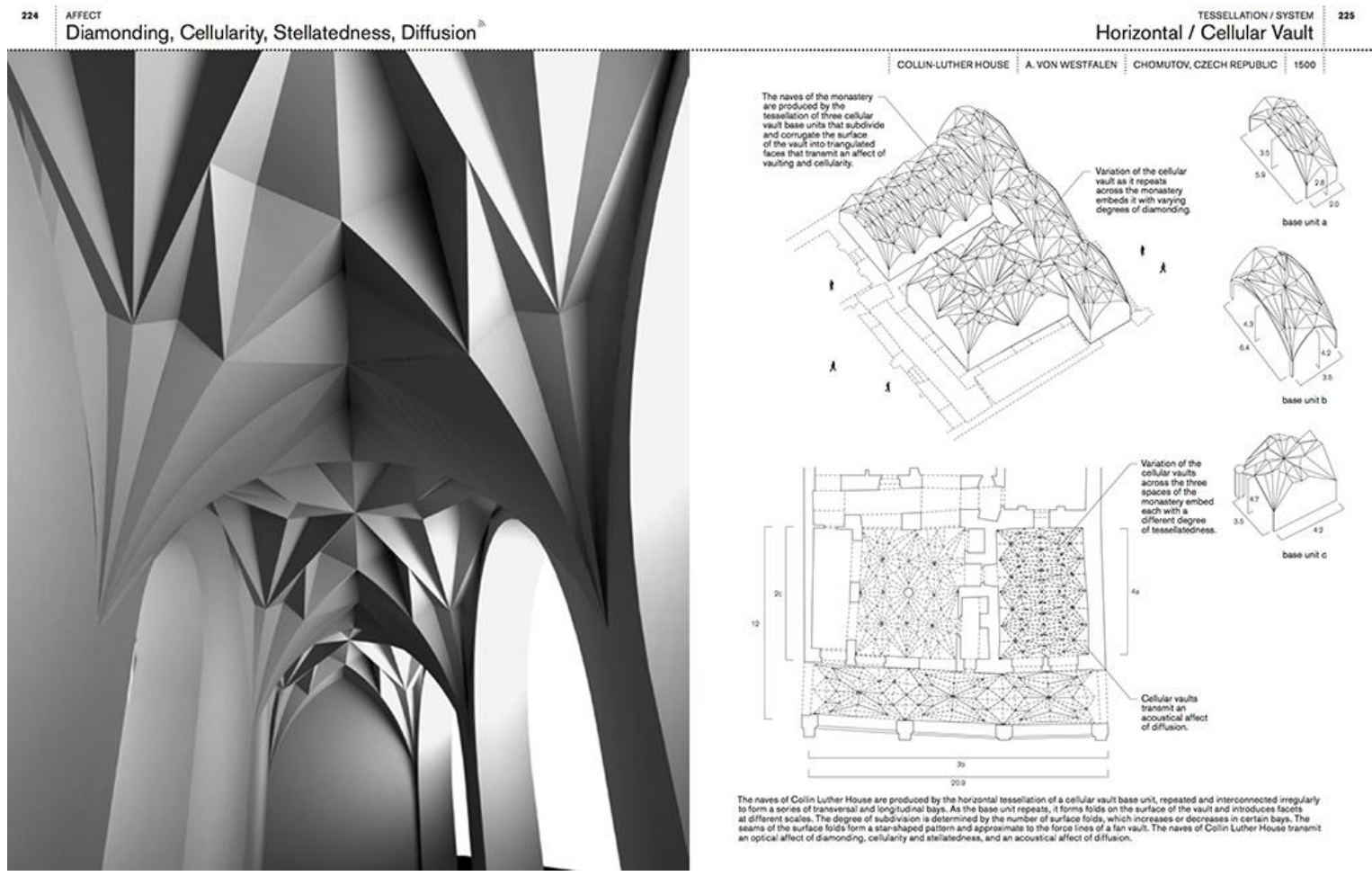

191. Moussavi, Farshid (2009) The Function of Form. p 224

En los libros La Función de la Forma y La Función del Ornamento, la arquitecta Farshid Moussavi, resalta la función sensorial y significante de la forma y el ornamento arquitectónico, apostando por las amplias posibilidades significantes de la forma arquitectónica. En la Función de la Forma ${ }^{147}$ Moussavi proporciona una crítica provocativa de la relación, históricamente opuesta, entre la función y la forma para revelar la contradicción en el corazón del movimiento moderno. Debemos alejarnos de la definición de función como utilidad, argumenta, para alinearla con la función que se define en las matemáticas, la biología o la música. La forma, por otra parte, debe considerarse no sólo en la manera en que se producen los edificios, sino también en la experiencia sensorial que proveen al usuario. La función y la forma, consideradas conjuntamente en arquitectura, se oponen al dualismo que definió nuestro acercamiento, enfoque y clasificación del entorno construido a lo largo del siglo XX.

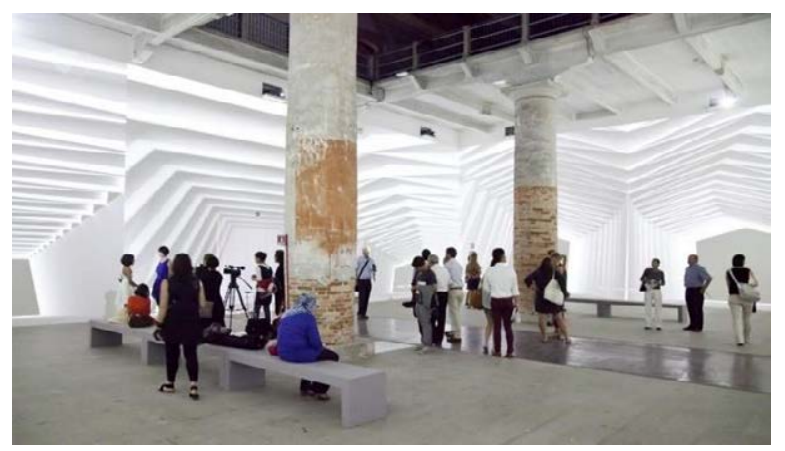

Moussavi dedicará un capítulo a los patrones de pliegue en diamante y plisados (diamonding), los sistemas de composición en mosaico (tessellations) y los plisados (pleats) Utilizando éstos últimos en la instalación "Architecture and Its Affects realizada en el Arsenale en la $13^{\mathrm{a}}$ Bienal de Venecia.

192. Architecture and Its Affects. F. Moussavi. Arsenale 2012

${ }^{147}$ Moussavi, Farshid (2009) The Function of Form. ACTAR, Harvard Graduate School of Design. ISBN13 : 9788496954731 


\subsection{EL PLIEGUE Y SUS SIGNIFICADOS}

\section{Hacia una semántica del pliegue.}

La semántica es la disciplina que estudia e interpreta el significado o el sentido de signos lingüísticos como símbolos, palabras, expresiones o representaciones formales. Buscar un significado conceptual y metafórica a un objeto físico, a una variable formal, a una cualidad estética más allá de su mera descripción, encontrar la idea que subyace detrás de una estrategia creativa, de un proyecto arquitectónico, es siempre una aventura incierta y arriesgada. Pero existen algunos cabos a los que nos podemos agarrar. Pequeñas certezas que paso a paso pueden ayudarnos a construir un pequeño castillo de ideas, de influencias, de intenciones, de inspiraciones.

El Diccionario de la Real Academia Española de la Lengua define pliegue como doblez, especie de surco o desigualdad, doblez hecho artificialmente en cualquier cosa flexible. Plegar es doblar, ceder, someter... doblar es torcer algo encorvándolo, volver una cosa sobre otra. Interesante también la definición que hace en relación al pliegue en el arte de la seda, "revolver la urdimbre en el plegador para ponerla en el telar" pura metáfora de algunas de las acciones realizadas en los cursos de Sophia Vyzoviti expuestos en el libro Folding Architecture. Spatial, Structural and Organisational Diagrams. Una doblez es la parte que se dobla o pliega de una cosa y al mismo tiempo la señal que queda de la parte por donde ha sido doblada.

Buscada además la palabra Origami nos encontramos que no está en el diccionario, pero sí papiroflexia, de papiro, papel y del latín "flexus", flectar, que es el "arte y habilidad de dar a un trozo de papel, doblándolo convenientemente, la forma de determinados seres u objetos" ${ }^{148}$, esta definición obvia claramente las experiencias creativas de los origamistas contemporáneos que han encontrado en la papiroflexia un arte con múltiples capacidades expresivas y narrativas más allá de la reproducción más o menos detalla y realista de seres y objetos, tal como se ha podido apreciar en el capítulo de esta tesis, el "origami abstracto" y "las esculturas de papel plegado".

Por su parte en el Diccionario Metápolis de Arquitectura Avanzada ${ }^{149}$ se nos muestran múltiples entradas de conceptos afines: enrollamientos, enroscamientos, bucles, contorsionismos, dobleces, estrategia, geometría, nudos, repliegue, despliegue, topología, trayectoria, vector, superposición, manipulación, tangente... En palabras de Manuel Gausa "hablamos de pliegues, despliegues y repliegues como posibles trayectorias dinámicas. Trayectorias a-escalares entre estructuras y organizaciones, entre dispositivos y ciudades, entre escenarios y proyectos, referidas a geometrías evolutivas (formaciones rizomáticas, despuntes y estirones, arracinamientos, entramados y enroscamientos, fluctuaciones, revesas y quiebros)".

${ }^{148}$ Real Academia Española, www.rae.es

149 Manuel Gausa, Vicente Guallart, Willy Müller et all. (2002) Diccionario Metápolis de Arquitectura Avanzada. Actar Editorial, Barcelona., ISBN: 8495273934. Página 472 


\subsubsection{Vivir en lo oblícuo}
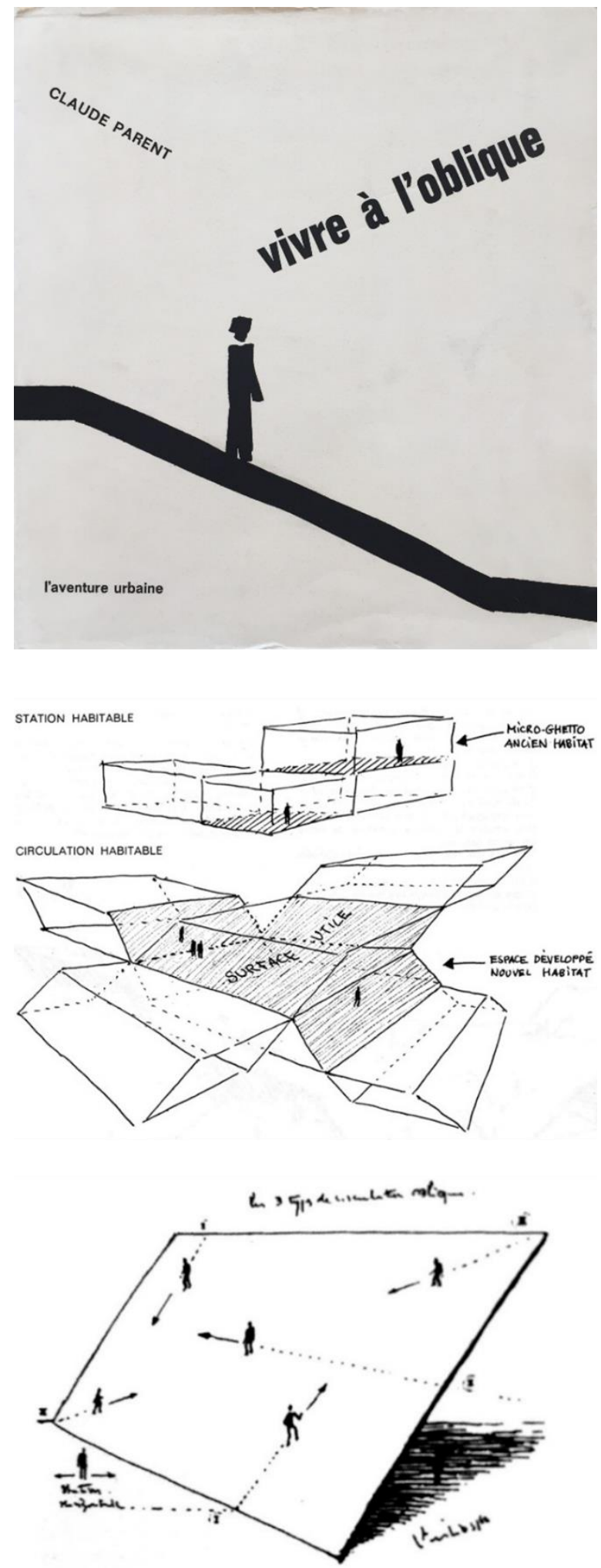

En los años sesenta, y tras una intensa década de auge de las láminas plegadas de hormigón armado, Claude Parent y Paul Virilio, arquitecto y urbanista respectivamente, fundarán el grupo Architecture Principe entre los que se encontrarán los arquitectos François Seigneur y Jean Nouvel. El grupo enunciará en 1964 la hipótesis de la arquitectura oblícua o función oblícua ${ }^{150}$ como un nuevo movimiento arquitectónico, que promulgará el fin de la vertical como eje de elevación y el fin de la horizontal como superficie de permanencia para avanzar los beneficios del eje oblícuo y de las superficies inclinadas que serán capaces tanto de conectar como de dinamizar las relaciones y la vida humanas.

Publicado por la editorial l'aventure urbaine en 1970 y firmado solamente por el arquitecto Claude Parent, el libro Vivre à l'oblique ${ }^{151}$, Vivir de forma oblícua, recoge este manifiesto y trata de ofrecer una idea de conjunto de ciertas soluciones para la habitabilidad y concentración urbana. Para Parent y Virilio es necesario recuperar los espacios intersticiales de circulación como espacios habitables y de comunicación vital, "asistimos desarmados al crecimiento incontrolado de los espacios de circulación comunitarios (un no man's land no utilizable) que crece a costa del interior del espacio (útil) de vivienda" y que está cambiando la forma de repartir el territorio, "el suelo ya no se utiliza para su función básica, habitar-vivir, sino para responder a una idea que nace por constricción: circular, ser canalizado." 152

193. Vivre a l'oblique. Portada y bocetos interiores

\footnotetext{
${ }^{150}$ Elliott, Anthony (2001) Profiles in contemporary social theory, Londres, SAGE. ISBN 978-0-7619-6589-3 pp217

${ }^{151}$ Parent, Claude (2009, $1^{\text {a }}$ edición 1970, Vivre à l'oblique) Vivir en lo oblicuo. Colección GGmínima. ISBN: 9788425222771

152 Ibidem página 14
} 


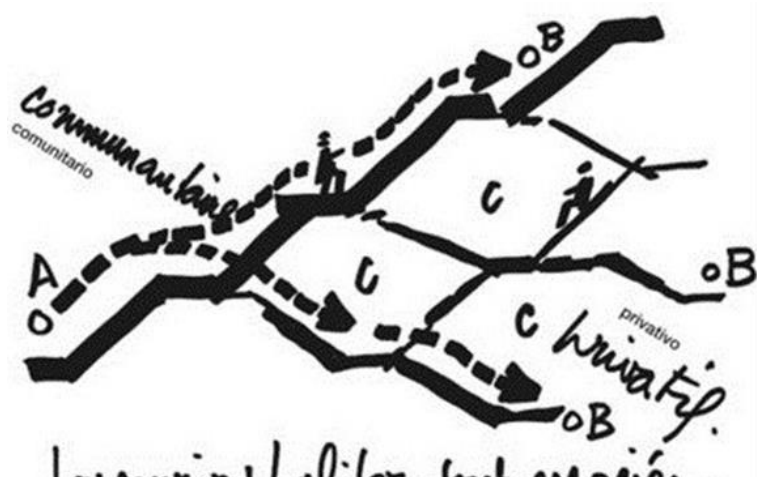

harcowrinthabiter tont associés.
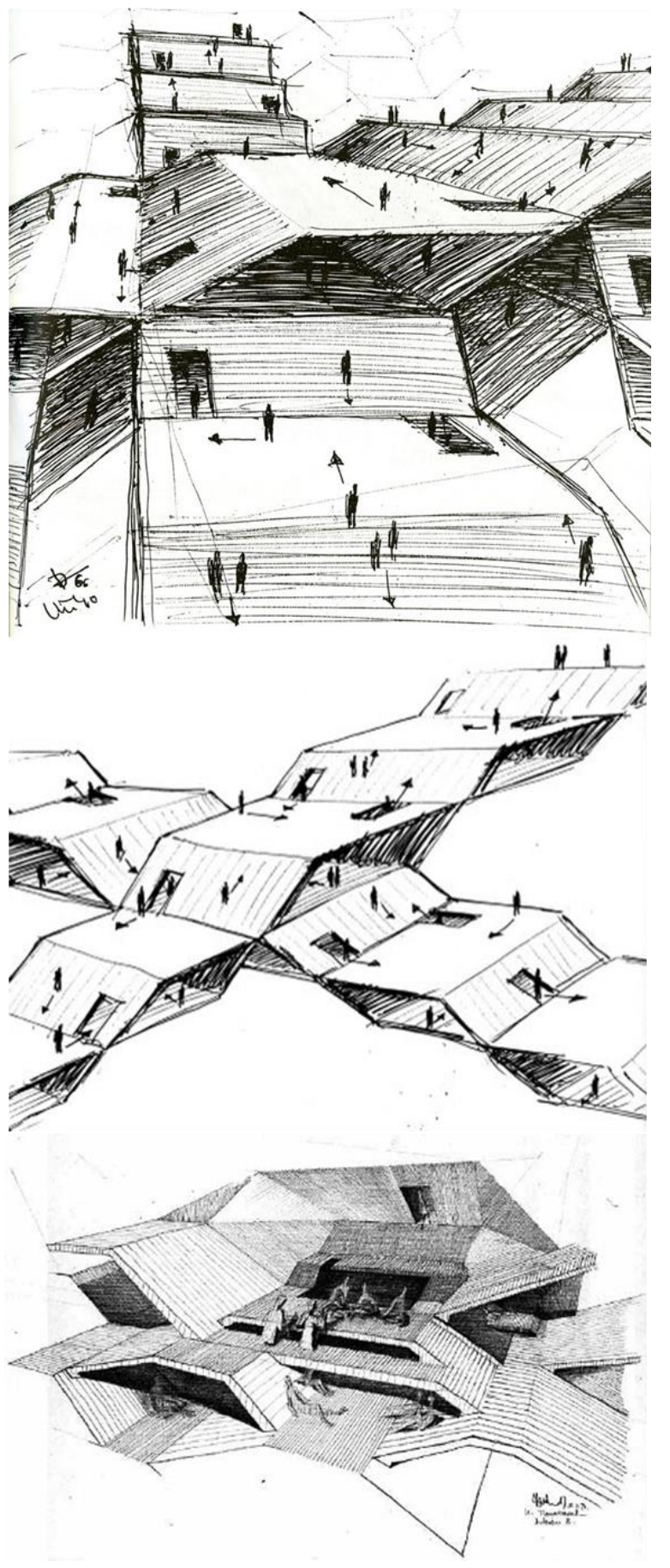

Frente a los conocidos ejemplos de cubiertas plegadas con tratamientos formalistas y estructurales, Parent y Virilio tratan de proponer una arquitectura pensada desde la transformación del plano horizontal, que se pliega manifestando funciones y que, teniendo un gran valor plástico, trata de ofrecer nuevas situaciones fisiológicas espaciales y físicas cercanas a la experiencia vital del habitante. Para Parent el plano inclinado es la mejor estructura soporte para la configuración de los asentamientos humanos, en contraposición a la horizontalidad de los desplazamientos en las ciudades actuales y a la disposición vertical de nuestros espacios privativos.

El texto se acompaña además de numerosos dibujos que ilustran las diversas posibilidades de esta nueva forma de ocupar el espacio y de concepción urbana, materializada en una superficie del suelo que puede albergar espacios cerrados o ser recorrida de forma continua. Esta superficie se pliega sobre sí misma formando arrugas que, no solo originan y contienen las rutas que circulan a través del edificio, con lo que crean las condiciones diferenciales para el programa, sino que también proporcionan fuerza estructural. De esta manera desaparece la separación tradicional entre el edificio envoltura y la estructura que soporta las cargas y se evita el uso de elementos segmentados como columnas, paredes o suelos en favor de la tendencia hacia una materialidad en que la diferenciación de las tensiones estructurales no esté determinada por elementos codificados, sino por singularidades dentro de un material continuo.

194. Vivre a l'oblique. Los espacios exteriores 


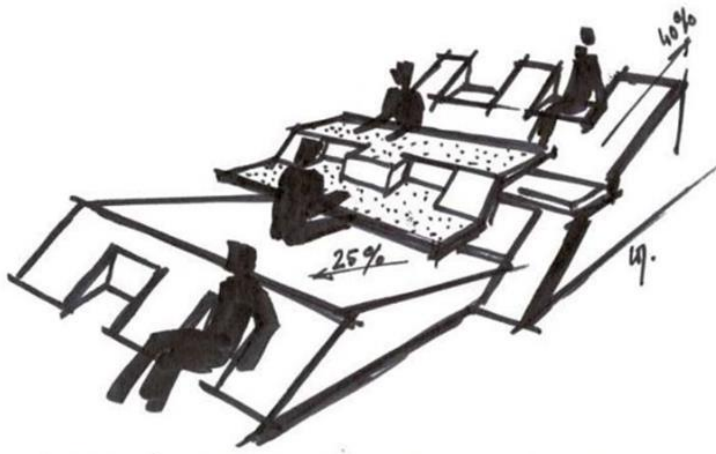

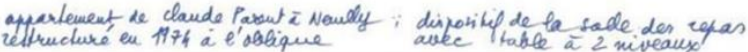
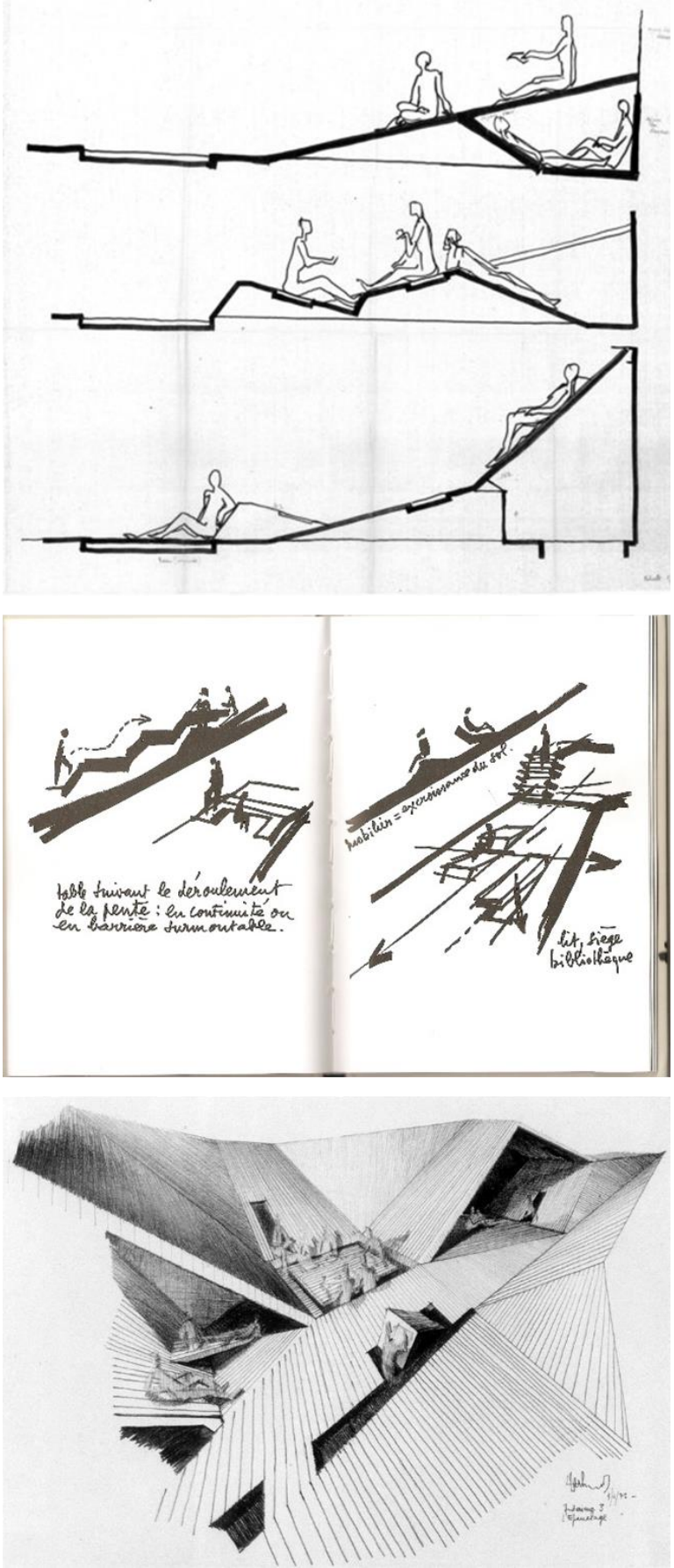

Parent incluso llega a definir las posibilidades de la función oblícua convertida en lámina continua que se pliega para la pequeña escala del mobiliario convertido en una excrecencia de la rampa, es el mismo suelo que, al levantarse, enderezarse, ahuecarse, y modelarse, forma los planos horizontales y necesarios para la actividad cotidiana, en definitiva, un suelo vivible que da continuidad entre mobiliario y soporte. Un mobiliario que puede ser recorrido, que no entorpece los trayectos del usuario, como una mesa escalonada que sigue la pendiente de la rampa, una puerta que no es más que una parte escamoteada al forjado (como ocurre con las puertas de un avión), o una biblioteca por la que podamos trepar. ${ }^{153}$

La función oblícua o estructura oblícua será definida finalmente por dos grandes principios:

1. La función oblicua es el obstáculo salvable. El hecho de convertir el espacio $\mathrm{C}$ en privativo no supone la imposición de un obstáculo. Pues puede recorrerse inclinado o sea, "trepable", sin obstaculizar ya el recorrido directo entre $\mathrm{A}$ y $\mathrm{B}$.

2. La función oblicua es el de la integración del circular en el habitar. Esta proposición permite distribuir los diferentes espacios privativos por la superficie exterior, pudiéndose utilizar con completa libertad para circular. El espacio comunitario de los accesos, hasta ahora reservado a la circulación, ya no está canalizado por los diferentes espacios privativos, pasa a ser parte integrante de la estructura que constituye estos espacios -vemos así cómo la circulación es asociada al habitar, y ya no algo disociado como ocurría en la estructural horizontal-.

195. Vivre a l'oblique. Un nuevo sistema de mobiliario

\footnotetext{
${ }^{153}$ Parent, Claude (2009, $1^{\text {a }}$ edición 1970, Vivre à l'oblique) Vivir en lo oblicuo. Colección GGmínima. Página 32
} 

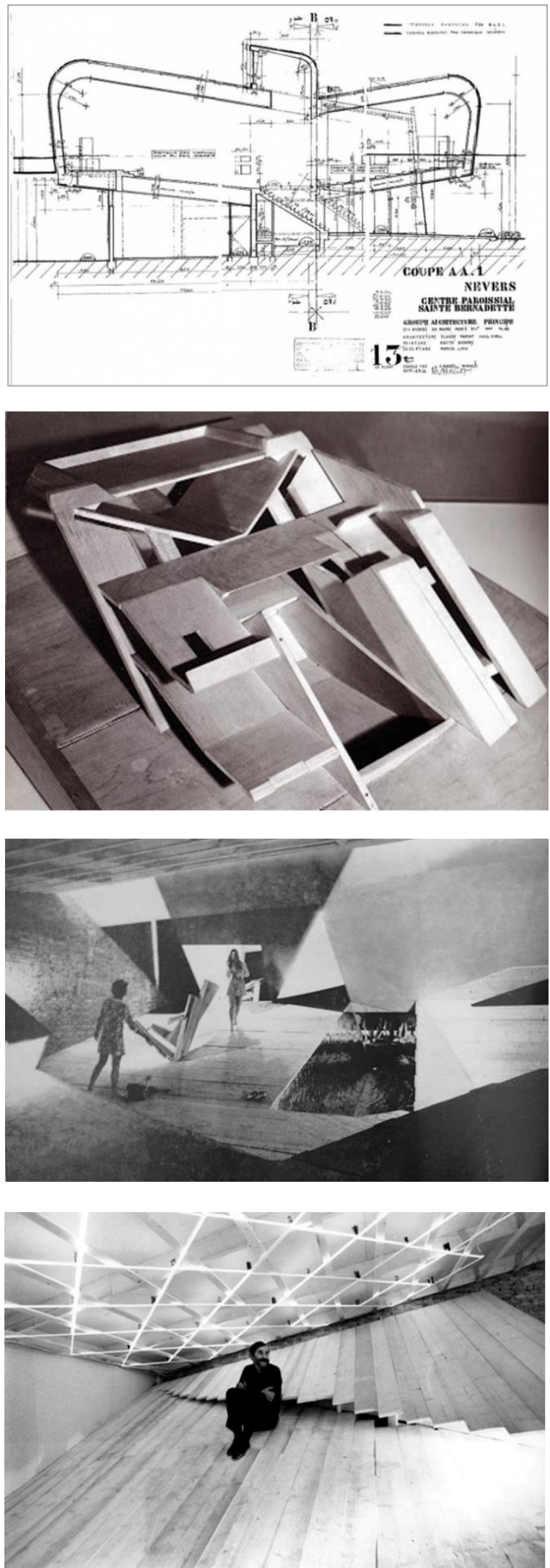

Los principios de la función oblícua se pusieron en práctica en muchos de los proyectos de Parent, quien proyectó y construyó obras como la Iglesia de Santa Bernadette Nevers Banlay, dibujo superior izquierdo, construida en 1966. También proyectó sin construir viviendas unifamiliares como la Casa Mariotti, maqueta de la imagen izquierda, y algunas casas de la cultura en Le Havre (1969), en Nevers (1971), Amiens (1972), etc. que se convirtieron en prototipos experimentales de las posibilidades reales de los "espacios" oblicuos.

La realización del pabellón francés para la exposición de la Bienal de Venecia del año 1970 funcionó como una pequeña parte habitable a escala real de las posibilidades de la ciudad oblícua en la que las paredes pueden alojar el cuerpo en diferentes posiciones dependiendo del grado de inclinación. Parent no solo fue un reconocido arquitecto, sino también un gran pensador. Sus teorías han inspirado no sólo a compatriotas como Jean Nouvel, sino también a Frank $O$. Gehry, Zaha Hadid, Odile Decq, François Roche, Bernard Tschumi y Coop Himmelb (I) au. Podemos ver su influencia en referencias como la transformación del suelo de la terminal de pasajeros del puerto de Yokohama.

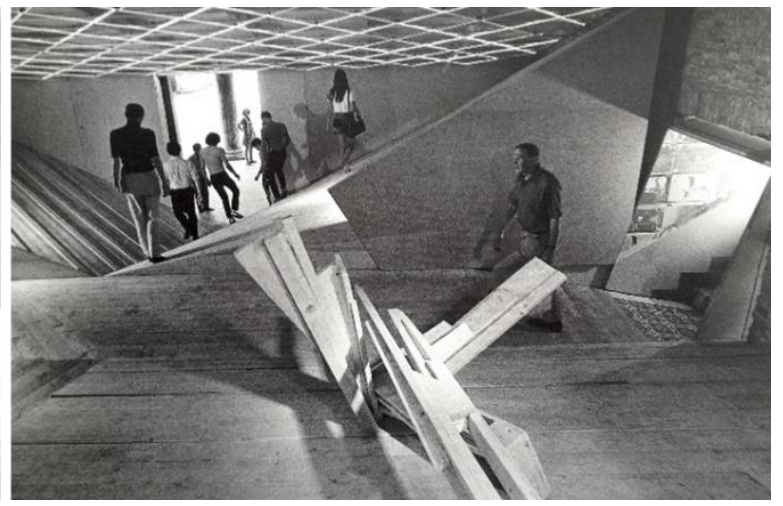

196. Planos, maquetas y fotografías de obras de C. Parent. 1964-70 


\subsubsection{El pliegue y el barroco. Hacia la autonomía del espacio interior.}

En 1988 el filósofo francés Gilles Deleuze escribirá el libro El pliegue. Leibniz y el Barroco 154 , un libro capital para entender la visión barroca de Gottfried Wilhelm Leibniz, filósofo racionalista del siglo XVIII y uno de los grandes genios universales de la historia, Para Deleuze, Leibniz es el creador de conceptos por autonomasia, pues a sus contribuciones al pensamiento filosófico hay que añadir las áreas de metafísica, epistemología, lógica, filosofía de la religión, así como en la matemática, física, geología, jurisprudencia e historia. El libro trata de desentrañar la filosofía barroca de Leibniz y su visión del pliegue desde una perspectiva contemporánea, con múltiples referencias de todas las artes, desde la poesía de Mallarmé, la novela de Proust, la música de Boulez y hasta la pintura de Hantaï. Encontrará en la geometría natural los pliegues de los vientos de las aguas, del fuego y de la tierra, que remiten a un sistema de interacciones complejas, para Deleuze "la ciencia de la materia tiene por modelo el origami, o el arte del pliegue de papel." 155

Deleuze además distingirá entre el pliegue inorgánico de la materia, simple y directo que se acercará a la cultura oriental frente al pliegue orgánico, compuesto, cruzado, indirecto, mediatizado por medio interno que tendrá su origen en la cultura griega y que podemos apreciar en la estatuaria helénica. Esta distinción de doble plegado de Gilles Deleuze resulta esencial y esclarecedora a la hora de intentar acercarnos a un nuevo entendimiento dentro del complejo sistema de los pliegues, y a su posible acepción dentro del ámbito arquitectónico. "...la búsqueda de un modelo del pliegue pasa por la elección de una materia. ¿Es el pliegue de papel, como sugiere el Oriente, o el pliegue de tela que parece dominar Occidente? Todo el problema radica en que los componentes materiales del pliegue (la textura) no deben ocultar el elemento formal o la forma de expresión." 156

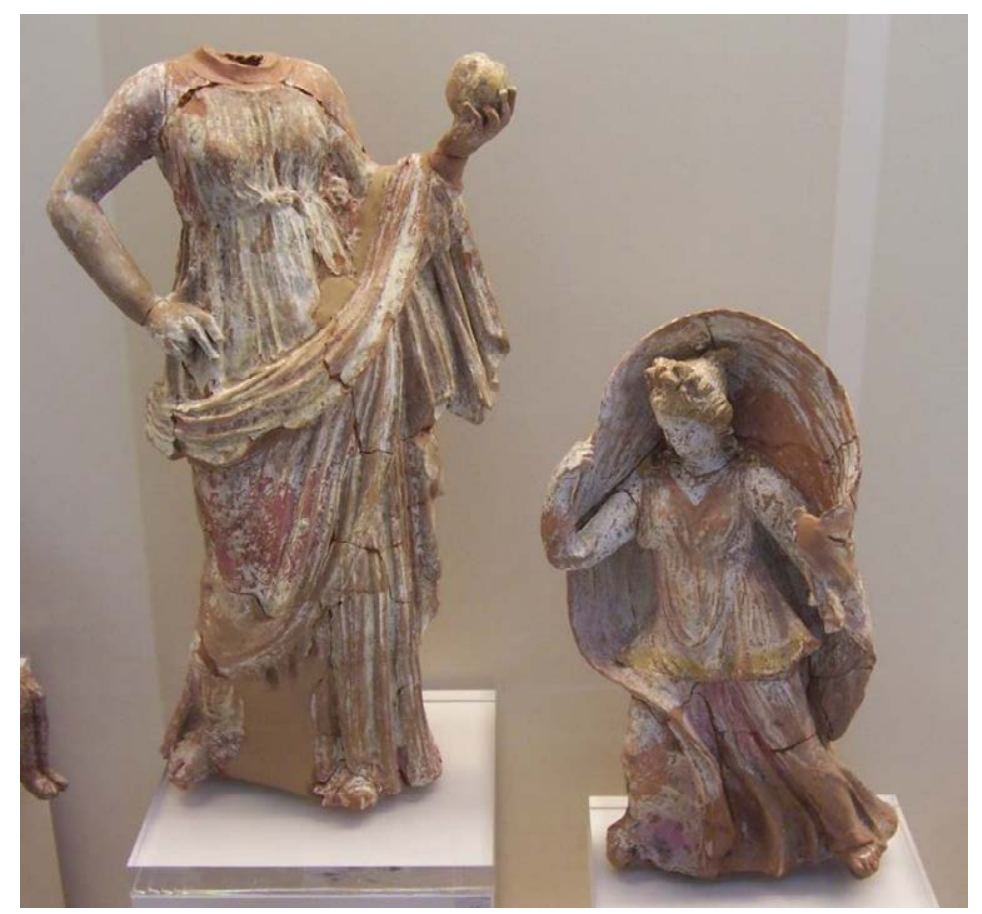

197. Estatuillas de dos Korés, S. III a.C.

Koré: escultura de mujer joven vestida característica del arte griego arcaico.

Museo Arqueológico de Náfplio (NaúTiıo). Fotografía de Pablo De Souza. 25/05/2013

\footnotetext{
${ }^{154}$ Deleuze, Gilles. (1989) El pliegue. Leibniz y el Barroco, Edit. Paidós Básica, España.

${ }^{155} \mathrm{Ibídem} \mathrm{página} 15$

156 Ibídem página 54
} 

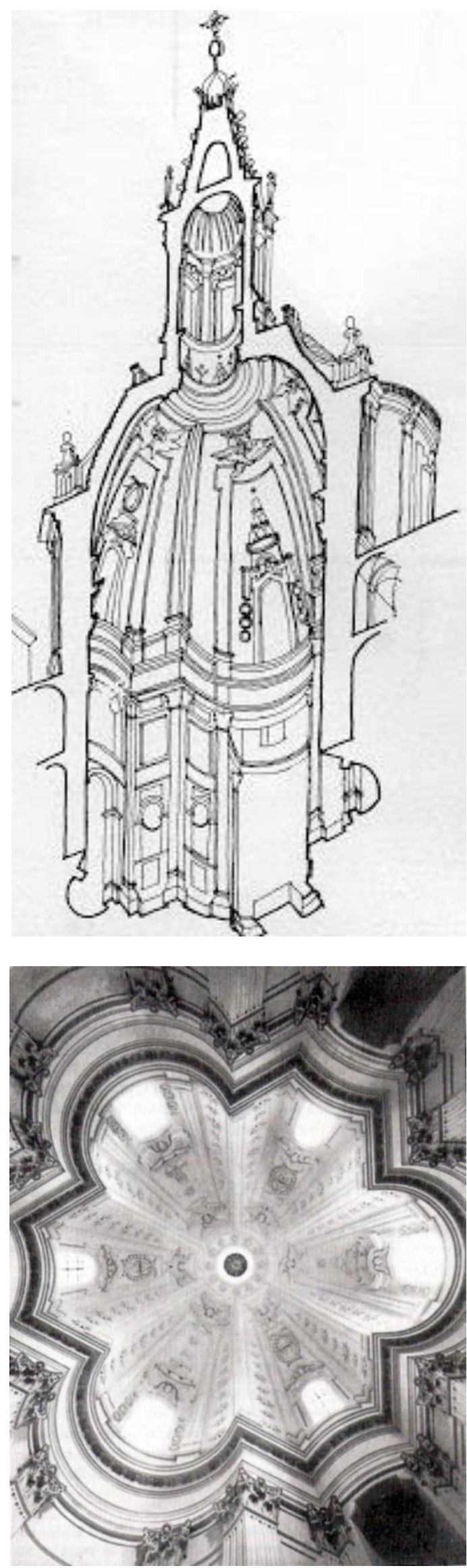

En la Capilla de San Ivo a la Sapienza, Francesco Borromini realiza una de sus obras más enigmáticas, donde las paredes parecen plegarse, el espacio interior se remata con una cúpula formada por gajos esféricos que efectúan una reducción paulatina hacia el centro de los elementos de la planta hexagonal y con ello, de la totalidad del espacio inferior. Sutilmente se dispone un entablamento y unas ventanas superiores que ignoran la forma cóncava de los arcos de circunferencia volcados hacia el interior de la planta.

El efecto expansivo del conjunto genera un dinamismo altamente expresivo, con ello, Borromini logra su ideal de espacio unitario, estableciendo una continuidad total desde el suelo hasta la linterna que remata la cúpula. Efecto que se construye sobre la base de elementos geométricos totalmente simples, planos verticales, sectores cilíndricos y gajos esféricos que, junto a la luz establecen un recinto interior de una grandeza luminosa sin par.

198. Sant'Ivo alla Sapienza.

Sección axonométrica

Representativa del espacio interior.

Christian Norberg Schulz,

Arquitectura Barroca. 1980

Un arquitecto con personalidad propia que, apoyándose en la construcción de los antiguos, articula con formas originales elementos canónicos de la arquitectura histórica. Se trata de un arquitecto que desarrolla de forma consciente la capacidad manipuladora y creativa ejercida también por Miguel Ángel, buscando aspectos distorsionadores propios de la arquitectura manierista. Su composición va de lo sencillo a lo complicado y su arquitectura esta basada en la naturaleza, la proporción, la exactitud matemática y la geometría, constantes que se repiten a lo largo de una vida marcada por la sombra de su gran rival, Bernini.

199.

$$
\text { Interior de la cúpula de S. Ivo. }{ }^{157}
$$

${ }^{157}$ Instituto Nazionale di Studi Romani (1989) Sant'Ivo alla Sapienza e lo -Studium UrbisEditorial Fratelli Palombi, Roma, Italia. 
En el "Éxtasis de Santa Teresa", Bernini genera una variada riqueza de texturas por medio del pliegue: la textura angulosa y variada de la toga de monja, la mórbida del cuerpo del ángel, la esponjosa de las nubes..., buscando así recrear sensaciones pictóricas. Los pliegues son usados aquí para destacar determinadas partes, ocultando y encorsetando la anatomía. Crea así un pliegue exterior que parte de una fuerza interior. Los dos tipos de pliegues todavía siguen unidos, pero ya no de una manera orgánica sino ideológica, impulsiva, casi doctrinal, el pliegue ya no habla de estructurar, de explicar el movimiento del cuerpo; se desestructura del cuerpo confiándose a otras intenciones, ya que el pliegue se concentra en expresar el momento del éxtasis: habla ya de ingravidez, de levedad.

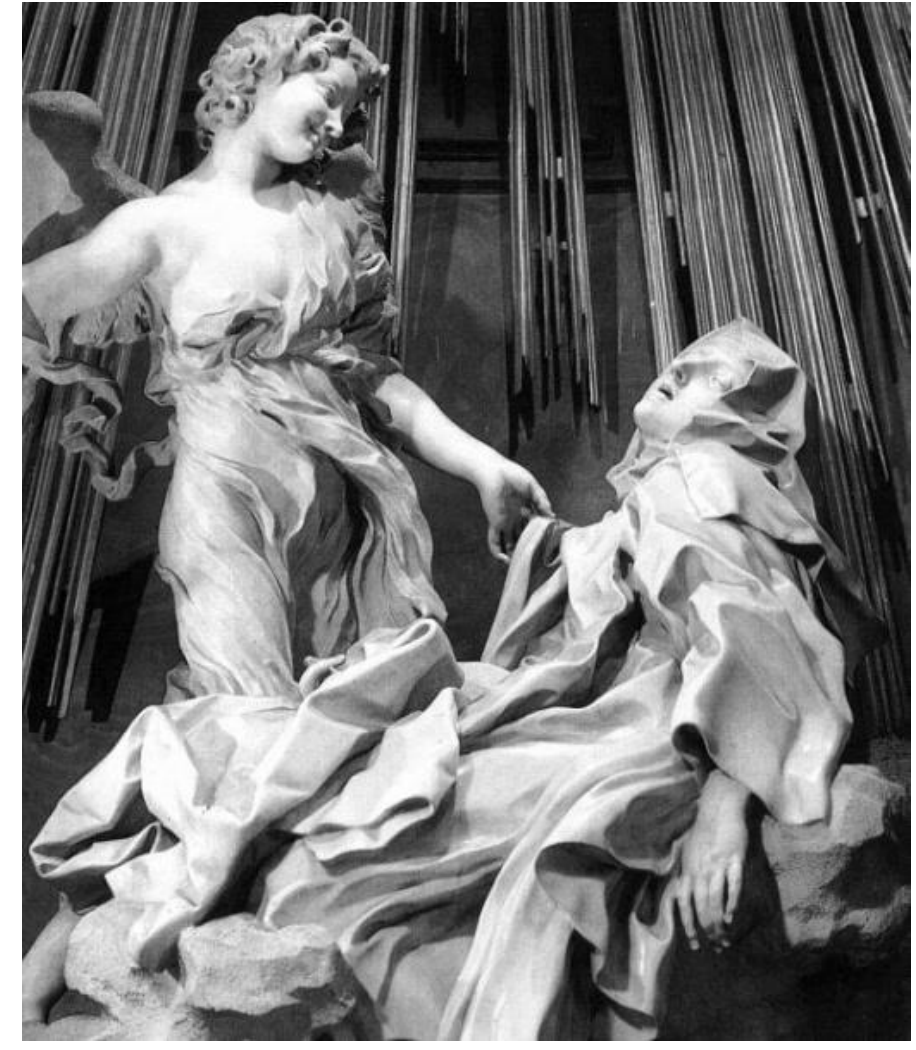

200. Éxtasis de Santa Teresa.

La obra del escultor y pintor Gian Lorenzo Bernini. Fue realizada entre 1647 y 1651, por encargo del cardenal Cornaro, para ser colocada donde iría su tumba, en la iglesia de Santa María de la Victoria (Santa Maria della Vittoria), en Roma, donde actualmente se encuentra, en la Ilamada Capilla Cornaro.

Esta primera independencia del pliegue, que en el Barroco alcanza uno de sus momentos ideológicos álgidos en la acepción pliegue exterior - despliegue interior, volverá a aparecer, aunque ya con otro carácter, durante el siglo XX. Con el pliegue inorgánico, surgido de la presencia posterior de fuerzas basadas en intenciones externas a la materia, con todos sus aliados conceptuales, llegamos a acontecimientos estables en sus características finales particulares (forma, lugar, tamaño...), pero inestables en su concepción; en las leyes que lo generan y que no responden ya a criterios de lo natural. Dependen de la mirada cultural o del momento histórico, siendo por ello externos, variables, cambiantes, diversos, parciales, pero más ricos y más sencillos en su acción. Este tipo de actuación nos aleja de manera radical y crítica del plegado interno, orgánico, envuelta en el contexto histórico y cultural de cada momento. Con esta relación entre el objeto y el espacio en base a operaciones de plegado, se consigue un nuevo status, el de su independencia, el pliegue en si mismo, como generador de espacios. 


\subsubsection{La levedad del pliegue, estructuras difusas.}

"La división del continuo no debe ser considerada como la de la arena en granos, sino como la de una hoja de papel o la de una túnica en pliegues, de tal manera que puede haber en ella una infinidad de pliegues, unos más pequeños que otros, sin que el cuerpo se disocie nunca en puntos o mínimos."

Gottfried Wilhelm Leibniz, pasaje del Pacidius Philalethi citado por Guilles Deleuze ${ }^{158}$

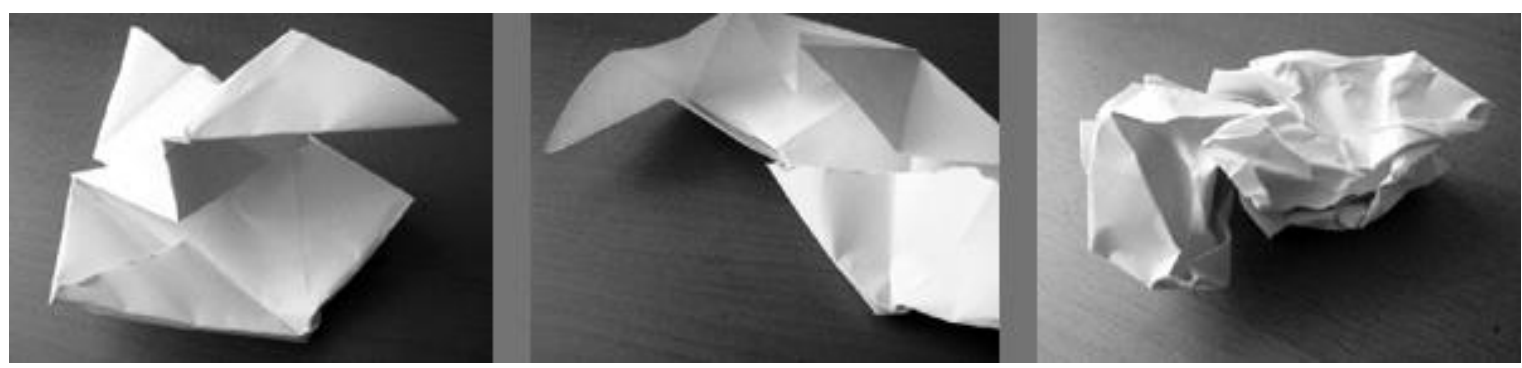

201. Plegado infructuoso de una pajarita de papel.

Cuando se pliega una cosa lo que se hace es extenderla y a veces crear una nueva definición de la misma, permite al objeto tener dos caras o una doble personalidad, por así decirlo. Tal como dijo el matemático y filósofo René Thom, "es un salto que se produce en un sistema dinámico: físico, biológico, conceptual...". Por lo tanto, un pliegue es una variable influenciada no sólo por cambios conceptuales sino también por cambios físicos.

"La manera de plegarse una materia constituye su textura: ésta se define no tanto por sus partes heterogéneas y realmente distintas, como por la manera en que éstas devienen inseparables en virtud de pliegues particulares. Todo se pliega a su manera, los colores, que se distribuyen según la concavidad y la convexidad del rayo luminoso, y los sonidos, tanto más agudos cuanto que las partes temblorosas son más cortas y más tensas. Así, la textura no depende de las partes, sino de los estratos que determinan su "cohesión". El pliegue de materia o textura deviene materia de expresión gracias a la luz, al claroscuro, a la manera en que el pliegue atrae a la luz según la hora y la luminosidad." 159

La suspensión, la levitación y la flotación dependen de relaciones complejas establecidas entre un cuerpo y el medio en el que está inmerso. Principios estructurales dinámicos, como andar, volar, flotar, rozar y nadar, no están basados únicamente en el medio en que se producen, sino que son relaciones estructurales establecidas entre los cuerpos y el medio. ${ }^{160}$

\footnotetext{
${ }_{159}^{158}$ Deleuze, Gilles. (1989) El pliegue. Leibniz y el Barroco. Editorial Paidós Básica, España. pp 14.

${ }^{159}$ Ibídem pp 53.

${ }^{160}$ Lynn, Greg. (1996) Levedad. La cadena de cristal. Editorial Circo, Madrid.
} 
La levedad nos sugiere formas de estabilidad más dinámicas, múltiples y complejas, cargas diferenciales que son cualitativamente diferentes del estancamiento implícito en el apoyo simple y perpendicular al suelo. Y, sin apelar al movimiento literal, se pueden concebir composiciones más leves donde el peso se transmite a través de múltiples vectores, generados por los bordes de superficies plegadas, los cuales no parecen estar sujetos a la fuerza perpendicular de la gravedad terrestre.
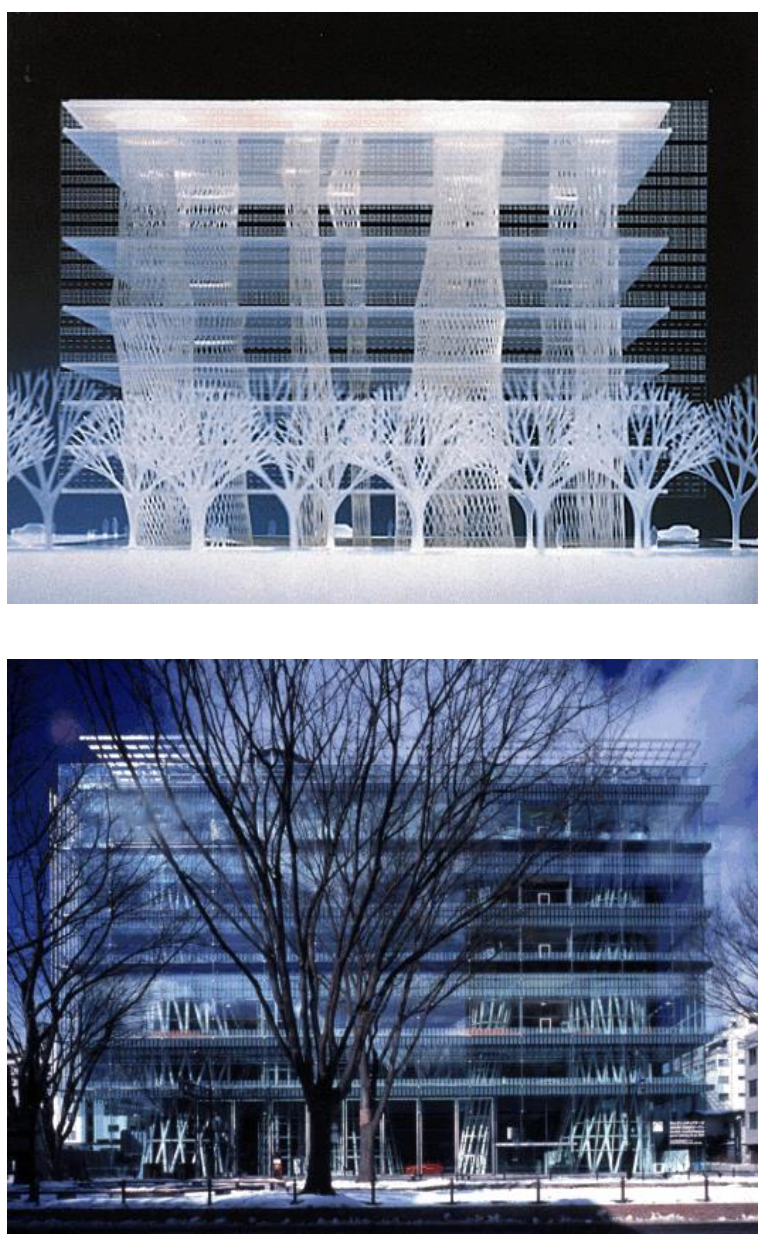

Las posibilidades del movimiento y de la estructura se desplazan y se multiplican, produciéndose tantas gravedades como cuerpos existan. Este principio de suspensión -rodear un objeto con un campo de estructura difuso, aproxima-damente equivalente a su masa y densidad- nos sugiere que, para alcanzar la ligereza, las estructuras no deben desmateriali-zarse, aparentar menor peso, deben hacerse más difusas.

202. Mediateca de Sendai, 1995-2001 Maqueta y obra final, Arquitecto Toyo Ito.

Como nos expone Greg Lynn, en la arquitectura las estructuras difusas son posibles empleando un campo denso de elementos micro-estructurales que minimice los puntos de apoyo al multiplicar el número de ellos. Con estructuras más difusas el aire se volvería, literalmente, más denso, y los objetos masivos flotarían en un medio de fluidez estructural en equilibrio.

Si aceptamos que el aire pudiera ser lo suficientemente denso como para soportar el peso de los objetos, y que la tierra se conciba como una masa porosa capaz de soportar objetos no solo sobre su superficie sino también minando y flotando en el interior de su masa, entonces habremos logrado un entendimiento nuevo del terreno, así como una nueva movilidad. ${ }^{161}$

El pliegue es un gesto leve que, sin modificar la naturaleza del objeto, influye claramente en su relación con el medio, con la repetición y sucesión de pliegues de consigue una nueva entidad dinámica, difusa, incierta, cargada del peso de la levedad.

\footnotetext{
${ }^{161}$ Lynn, Greg (1996) Levedad. La cadena de cristal. Editorial Circo, Madrid.
} 

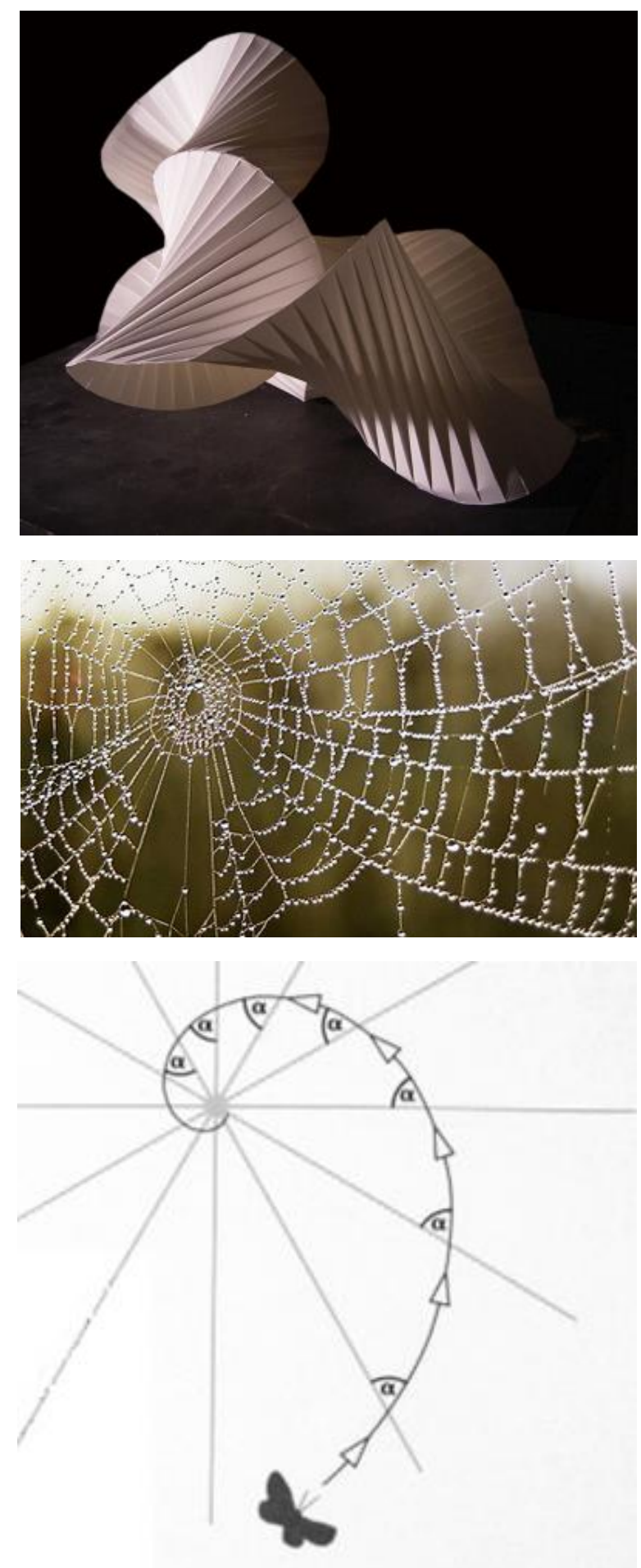

La levedad hace del lenguaje artístico un elemento sin peso que flota sobre las cosas como una nube, polvillo sutil, campo de impulsos magnéticos, partículas de polvo que se arremolinan en un rayo de sol dentro de un aposento a oscuras, las minúsculas conchas, todas iguales, todas diferentes, que la ola empuja indolente sobre la arena embebida, las telarañas que, cuando andamos, nos envuelven sin que nos demos cuenta.

203. Origami de Yuko Nishimura, 2004

Las telarañas, la tupida red de constricciones públicas que termina por envolver toda existencia con nudos cada vez más apretados. Milan Kundera, con su novela "La insoportable levedad del ser", nos narra cómo en la vida todo lo que elegimos y apreciamos por su levedad no tarda en revelar su propio peso insostenible, es en realidad una amarga constatación de la "ineluctable pesadez del vivir" 21, quizás sólo la vivacidad y la movilidad de la inteligancia escapan a esta condena. Hoy todas las ramas de la ciencia parecen querer demostrarnos que el mundo se apoya en entidades sutilísimas, como los mensajes del ADN, los impulsos de las neuronas, los quarks, los neutrinos errantes en el espacio desde el comienzo de los tiempos..

204. Vuelo de una polilla hacia la luz

"ve, leve y silenciosa, sin desviarte, a mi señora" 162

Los dramatis personae de los poemas de Cavalcanti, más que personajes humanos son suspiros, rayos luminosos, imágenes ópticas, y sobre todo, esos impulsos o mensajes inmateriales que él llama "espíritus". Los padecimientos del amor, los descompone Cavalcanti en entidades impalpables que se desplazan entre alma sensitiva y alma intelectiva, entre corazón y mente, entre ojos y voz. Entidades que se distinguen por tres características: es levísimo; está en movimiento; es un vector de información.

${ }^{162}$ Calvino, Italo (2000) Seis propuestas para el próximo milenio. Editorial Siruela, Madrid. España. 